\title{
Modeling Unsteady-State VOC Transport in Simulated Waste Drums
}

\author{
Kevin J. Liekhus \\ Garold L. Gresham \\ Eric S. Peterson \\ Cathy Rae \\ Norman J. Hotz \\ Mike J. Connolly
}

Published January 1994

\section{Idaho National Engineering Laboratory \\ EG\&G Idaho, Inc. Idaho Falls, Idaho 83415}

Prepared for the

U.S. Department of Energy

Assistant Secretary for Environmental

Restoration and Waste Management

Under DOE Idaho Field Office

Contract DE-AC07-761D01570 


\section{DISCLAIMER}

This report was prepared as an account of work sponsored by an agency of the United States Government. Neither the United States Government nor any agency thereof, nor any of their employees, make any warranty, express or implied, or assumes any legal biability or responsibitity for the accuracy, completeness, or usefulness of any information, apparatus, product, or process disclosed, or represents that its use would not infringe privately owned rights. Reference herein to any specific commercial product, process, or service by trade name, trademark, manufacturer, or otherwise does not necescarily constitute or imply its endorsement, recommendation, or favoring by the United States Government or any agency thereof. The views and opinions of authors expressed herein do not necessarily state or reflect those of the United States Government or any agency thereof. 


\section{DISCLAIMER}

Portions of this document may be illegible electronic image products. Images are produced from the best available original document. 


\begin{abstract}
This report is a revision of an EG\&G Idaho informal report originally titled Modeling VOC Transport in Simulated Waste Dnums. A volatile organic compound (VOC) transport model has been developed to describe unsteadystate VOC permeation and diffusion within a waste drum. Model equations account for three primary mechanisms for VOC transport from a void volume within the drum. These mechanisms are VOC permeation across a polymer boundary, VOC diffusion across an opening in a volume boundary, and VOC solubilization in a polymer boundary. A series of lab-scale experiments was performed in which the VOC concentration was measured in simulated waste drums under different conditions. A lab-scale simulated waste drum consisted of a sized-down 55-gal metal drum containing a modified rigid polyethylene drum liner. Four polyethylene bags were sealed inside a large polyethylene bag, supported by a wire cage, and placed inside the drum liner. The small bags were filled with VOC-air gas mixture and the VOC concentration was measured throughout the drum over a period of time. Test variables included the type of VOC-air gas mixtures introduced into the small bags, the small bag closure type, and the presence or absence of a variable external heat source.

Model results were calculated for those trials where the VOC permeability had been measured. Permeabilities for five VOCs [methylene chloride, 1,1,1-trichloroethane, carbon tetrachloride, trichloroethylene, and 1,1,2-trichloro-1,2,2-trifluoroethane (Freon-113)] were measured across a polyethylene bag. Comparison of model and experimental results of VOC concentration as a function of time indicate that model accurately accounts for significant VOC transport mechanisms in a lab-scale waste drum.
\end{abstract}




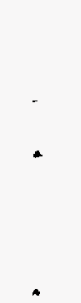




\section{EXECUTIVE SUMMARY}

Pretest waste characterization of waste drums for the bin-scale tests at the Waste Isolation Pilot Plant (WIPP) includes sampling for volatile organic compounds (VOCs) from three areas within drums (drum headspace, the 55-gal poly bag headspace, and the innermost layers of confinement headspace) of transuranic waste. A test program has been initiated at the Idaho National Engineering Laboratory to demonstrate that a VOC concentration in the void space of each layer of confinement can be estimated without extensive sampling of the waste by using a model incorporating theoretical diffusive and permeative transport principles and limited waste drum sampling data. A model incorporating these fundamental transport principles was used to describe unsteady-state VOC transport from lab-scale simulated waste drums. An accurate model of VOC transport in a lab-scale simulated waste drum will serve as the foundation for model development for VOC transport in an actual waste drum. A model capable of characterizing the VOC concentration in a real waste drum will be used to assist in defining drum headspace representativeness and may more quickly eliminate the need for sampling of inner layers of confinement resulting in lower worker radiation exposure, decreased bin loading times, and significant cost savings over the life of the WIPP test phase and operational phase.

The VOC transport model consisted of a series of material balance equations describing unsteady-state VOC transport between each void volume. Model equations accounted for three primary mechanisms for VOC transport from a void volume. These mechanisms were VOC permeation across a polymer boundary, VOC diffusion across an opening in volume boundary, and VOC accumulation in a polymer due to VOC solubility. In order to test the model, experiments were performed to measure VOC concentration throughout a lab-scale simulated waste drum. Each waste drum consisted of a sized-down 55-gal metal drum containing a modified 90-mil high-density rigid polyethylene drum liner. Four small polyethylene bags were sealed inside a large polyethylene bag, supported by a wire cage and placed inside the drum liner. The small bags were each filled with four liters of a VOC-air mixture and the concentration within the waste drum was measured over the 3-week test period. Measurements of the VOC concentrations were taken from six locations inside a simulated waste drum: each small bag headspace, large bag headspace, and drum headspace. Sixteen trials were performed based on a two-level three-variable experimental design with two replications. Test variables included the initial VOC gas mixtures placed in the small bags, the type of small bag closure, and the presence or absence of a variable external heat source.

In addition, permeability measurements were made for VOCs in a gas mixture across the polyethylene bags. Permeabilities for five VOCs (methylene chloride, 1,1,1-trichloroethane, 1,1,2-trichloro-1,2,2-trifluoroethane (Freon-113), carbon tetrachloride, and trichloroethylene) in one gas mixture were measured. Permeability measurements for the VOCs in the other gas mixture (methanol, cyclohexane, 1,1,1-trichloroethane, toluene, p-xylene) used in the lab-scale waste drums experiments were not completed due to system limitations in handling high boiling-point VOCs (toluene and p-xylene).

Most model parameters were measured or estimated from available process information. Other parameters not measured directly were estimated using the VOC transport model and lab-scale waste drum data from a single trial. Model parameters determined in this fashion were used in all other model calculations. Model results were calculated for those trials where the 
VOC permeability had been measured. The mean absolute relative deviation (MARD) defining the mean absolute difference between model predictions and experimental values for a given trial were calculated for small bag, large bag, and drum headspace void volumes. In most trials, the small-bag MARD for each high-permeability VOC was less than $2 \%$ of the initial VOC concentration introduced in the small bags. The average MARD value for the low-permeability VOC (Freon-113) was greater than for the high-permeability VOCs as the result of less accurate model estimates. The model assumption of well-mixed volumes may be inappropriate where large: concentrations of low-permeability VOCs are present. The large bag MARD followed the same trends as observed for the small bags. The MARD for the drum headspace void volume in drums maintained at room temperature was less than $2 \%$ for a majority of the trials. The MARD for the drum headspace void volume in waste drums maintained under a variable-temperature environment were between $2 \%$ and $4 \%$. The increase in the deviation between the model and experimental results in the heated drums was attributed to the failure of the model to account for increased VOC solubility in the polyethylene drum liner at higher temperatures.

Experimental results demonstrated that VOC transport from waste drums exposed to a variable external heat source was greater than drums maintained at a constant temperature. The difference was attributed to an increase of VOC solubility in the polyethylene liner at higher temperatures and an increased rate of aspiration due to fluctuating drum temperature. The model does predict lower drum headspace VOC concentrations in a waste drum exposed to thermal cycling instead of being maintained at room temperature but currently does not account for the temperature dependence of VOC solubility in the polymer drum liner. The effect of the small bag closure type on VOC transport in the lab-scale drum could not be determined from a direct comparison of measured VOC concentration in small bags. Since the model had been demonstrated to accurately follow the small bag VOC concentration over the course of the test period, the model was used to estimate the relative importance of VOC transport through a small bag horsetail compared to VOC permeation across the bag wall in the lab-scale experiments. For the case of a low-permeability VOC, the rate of VOC transport via permeation was estimated to be over $\mathbf{5 0 0}$ times greater than the VOC transport rate across the horsetail.

Future work includes obtaining VOC permeability and solubility data for VOCs in the other gas mixture used in the lab experiments and further examining the capability of the VOC transport model of predicting the VOC concentration throughout the lab-scale waste drum. In addition, the rate of VOC transport out of polymer bottles will be analyzed. Measurement of VOC permeabilities as a function of temperature and over a wider range of VOC concentrations will be made. A major feature of these VOC transport experiments was the transient nature of the VOC gas phase concentration as the result of having no VOC source in the waste drum. The presence of VOC-containing waste, such as a waste sludge, would replenish VOC molecules that had permeated and diffused out of the void volume. The presence of a VOC source in the lab-scale waste drums should more closely simulate real waste. Future simulated waste drum experiments will place VOC-contaminated simulated waste in waste drums and measure VOC concentration over a relatively long period of time. The applicability of the current model to predict the VOC concentration throughout a simulated waste drum containing VOC-contaminated waste will be investigated. Finally, a model that predicts VOC concentration throughout an actual waste drum based on process knowledge and the measured VOC concentration in the drum headspace will be developed and tested. 


\section{FOREWORD}

This report is a revision of an EG\&G Idaho informal report originally titled Modeling VOC Transport in Simulated Waste Drums. The new title more accurately reflects the content of the report. In addition, experimental data and model results incorrectly attributed to methylene chloride and 1,1,2-trichloro-1,2,2-trifluoroethane (Freon-113) were placed in their proper tables or replaced. The conclusions of the original report remain the same in this revised report. 



\section{CONTENTS}

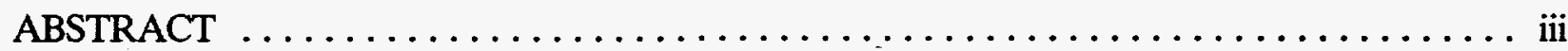

EXECUTIVE SUMMARY $\ldots \ldots \ldots \ldots \ldots \ldots \ldots \ldots \ldots \ldots \ldots \ldots \ldots \ldots \ldots \ldots$

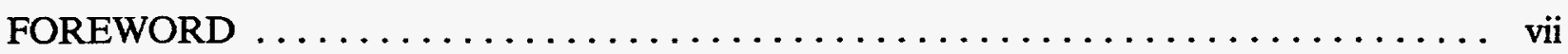

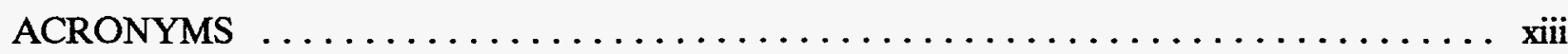

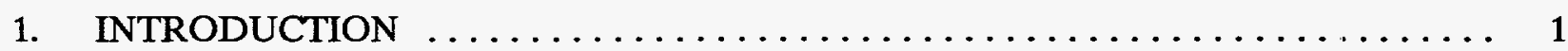

2. VOC TRANSPORT MODEL $\ldots \ldots \ldots \ldots \ldots \ldots \ldots \ldots \ldots \ldots \ldots \ldots \ldots \ldots \ldots \ldots \ldots$

2.1 Model Equations $\ldots \ldots \ldots \ldots \ldots \ldots \ldots \ldots \ldots \ldots \ldots \ldots \ldots \ldots \ldots \ldots \ldots \ldots \ldots \ldots$

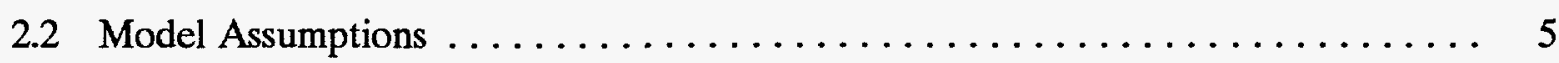

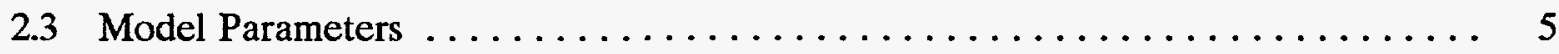

2.3.1 VOC-Polymer Permeability $\ldots \ldots \ldots \ldots \ldots \ldots \ldots \ldots \ldots \ldots \ldots$

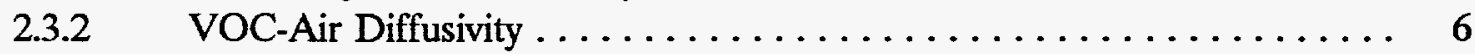

2.3.3 VOC Solubility in Polymer $\ldots \ldots \ldots \ldots \ldots \ldots \ldots \ldots \ldots \ldots \ldots \ldots \ldots \ldots \ldots$

3. EXPERIMENTAL $\ldots \ldots \ldots \ldots \ldots \ldots \ldots \ldots \ldots \ldots \ldots \ldots \ldots \ldots \ldots \ldots \ldots \ldots$

3.1 VOC Transport Experiments $\ldots \ldots \ldots \ldots \ldots \ldots \ldots \ldots \ldots \ldots \ldots \ldots \ldots$

3.1.1 Experimental Design $\ldots \ldots \ldots \ldots \ldots \ldots \ldots \ldots \ldots \ldots \ldots .8$

3.1.2 Automated VOC Transport Experimental Configuration $\ldots \ldots \ldots \ldots 8$

3.1.3 Experimental Procedures ......................... 22

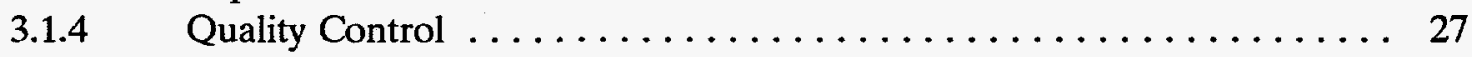

3.2 VOC-Polymer Permeability Measurements $\ldots \ldots \ldots \ldots \ldots \ldots \ldots \ldots \ldots . \ldots \ldots$

3.2.1 Single-Component Pressure Change Method $\ldots \ldots \ldots \ldots \ldots \ldots . \ldots 31$

3.2.2 Mixed-Component Chromatographic Detection Method .......... 33

4. EXPERIMENTAL RESULTS AND DISCUSSION $\ldots \ldots \ldots \ldots \ldots \ldots \ldots \ldots \ldots$

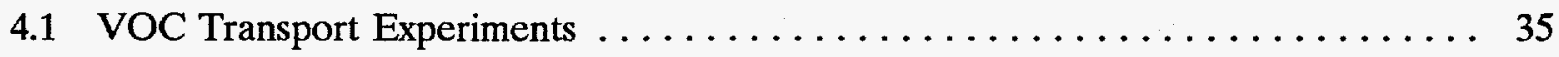

4.2 VOC-Polymer Permeability Measurements $\ldots \ldots \ldots \ldots \ldots \ldots \ldots \ldots \ldots$

4.2.1 Single-Component Pressure Change Method ............. 36

4.2.2 Mixed-Component Chromatographic Detection Method .......... 38 
5. MODEL RESULTS AND DISCUSSION $\ldots \ldots \ldots \ldots \ldots \ldots \ldots \ldots \ldots \ldots \ldots$

5.1 Model Parameter Determination $\ldots \ldots \ldots \ldots \ldots \ldots \ldots \ldots \ldots \ldots \ldots \ldots$

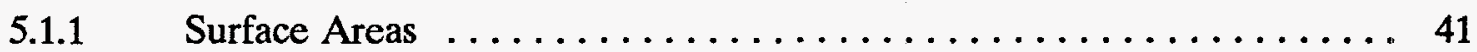

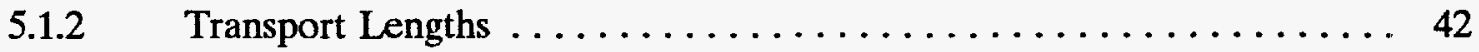

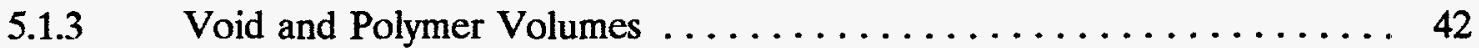

$5.1 .4 \quad$ VOC Transport Properties . . . . . . . . . . . . . . . . 42

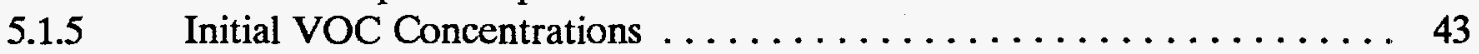

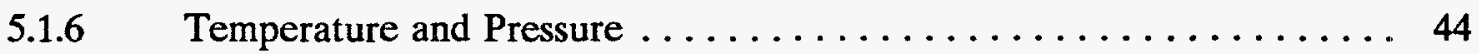

5.2 Model Results $\ldots \ldots \ldots \ldots \ldots \ldots \ldots \ldots \ldots \ldots \ldots \ldots \ldots \ldots \ldots \ldots \ldots$

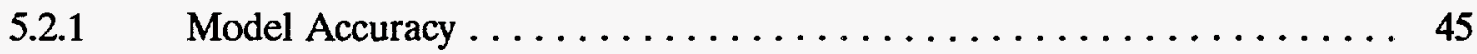

$5.2 .2 \quad$ Effect of Drum Temperature $\ldots \ldots \ldots \ldots \ldots \ldots \ldots \ldots \ldots \ldots \ldots$

$5.2 .3 \quad$ Effect of Small Bag Closure $\ldots \ldots \ldots \ldots \ldots \ldots \ldots \ldots \ldots$

5.3 Effect of Parameter Values on Model Results $\ldots \ldots \ldots \ldots \ldots \ldots \ldots$

$5.3 .1 \quad$ Permeable Surface Area $\ldots \ldots \ldots \ldots \ldots \ldots \ldots \ldots \ldots \ldots$

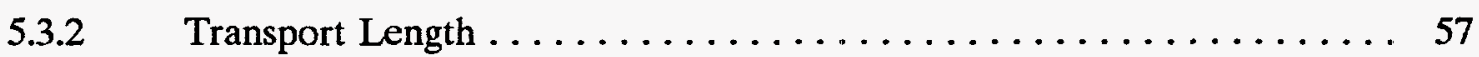

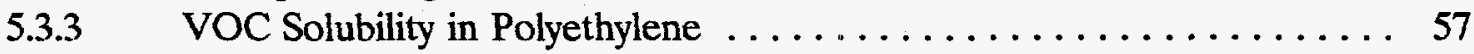

$5.3 .4 \quad$ Other Model Parameters $\ldots \ldots \ldots \ldots \ldots \ldots \ldots \ldots \ldots \ldots \ldots \ldots$

5.4 Experimental and Model Refinements $\ldots \ldots \ldots \ldots \ldots \ldots \ldots \ldots \ldots$

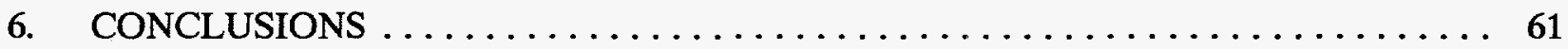

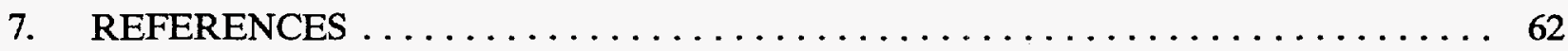

Appendix A-Measured VOC Concentrations in Lab-Scale Simulated Waste Drums . . . . . A-1

Appendix B-VOC Measured Concentrations in Polyethylene Bottles . . . . . . . . . B-1

Appendix C-Statistics Characterizing Initial Calibration Curves, Continuing Calibration

Curves, and Sample Duplicates $\ldots \ldots \ldots \ldots \ldots \ldots \ldots \ldots \ldots \ldots \ldots \ldots \ldots$

Appendix D-Computer Program of VOC Transport Model for Lab-Scale Simulated Waste

Drums . . . . . . . . . . . . . . . . . . . . . . .

Appendix E-Computer Program Output for Lab-Scale Simulated Waste Drum VOC

Transport Experiments . . . . . . . . . . . . . . . . . . . 


\section{FIGURES}

1. Automated VOC transport experimental configuration $\ldots \ldots \ldots \ldots \ldots \ldots \ldots \ldots$

2. Simulated lab-scale waste drum $\ldots \ldots \ldots \ldots \ldots \ldots \ldots \ldots \ldots \ldots \ldots \ldots \ldots \ldots$

3. NFT-020 carbon-composite filter $\ldots \ldots \ldots \ldots \ldots \ldots \ldots \ldots \ldots \ldots \ldots \ldots \ldots \ldots$

4. Feedthrough for small polyethylene bags $\ldots \ldots \ldots \ldots \ldots \ldots \ldots \ldots \ldots \ldots$

5. Feedthroughs for large polyethylene bags $\ldots \ldots \ldots \ldots \ldots \ldots \ldots \ldots \ldots \ldots$

6. Feedthroughs for drum lid $\ldots \ldots \ldots \ldots \ldots \ldots \ldots \ldots \ldots \ldots \ldots \ldots \ldots \ldots \ldots$

7. Large-mouth polyethylene bottle configuration $\ldots \ldots \ldots \ldots \ldots \ldots \ldots \ldots$

8. Environmental chamber . . . . . . . . . . . . . . . . . . . 19

9. Automated gas sampling system $\ldots \ldots \ldots \ldots \ldots \ldots \ldots \ldots \ldots \ldots \ldots \ldots \ldots$

10. Configuration of 10 -port gas sampling valve $\ldots \ldots \ldots \ldots \ldots \ldots \ldots \ldots \ldots \ldots$

11. Automated calibration sequence $\ldots \ldots \ldots \ldots \ldots \ldots \ldots \ldots \ldots \ldots \ldots \ldots \ldots$

12. Automated sampling sequence $\ldots \ldots \ldots \ldots \ldots \ldots \ldots \ldots \ldots \ldots \ldots \ldots \ldots$

13. Single-component pressure change experimental configuration $\ldots \ldots \ldots \ldots \ldots$

14. Mixed-component chromatographic detection method experimental configuration .... 34

15. Model predictions and experimental data of average Freon-113, TCA, and TCE concentration in small bag void volumes of waste drum in variable-temperature environment

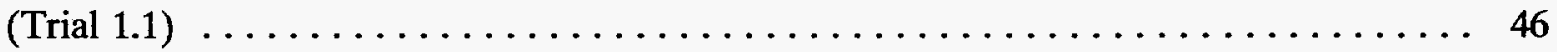

16. Model predictions and experimental data of average Freon-113, TCA, and TCE concentration in small bag void volumes of waste drum in constant-temperature

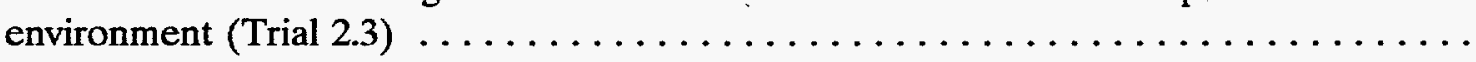

17. Model predictions and experimental data of Freon-113, methylene chloride (MC), and carbon tetrachloride $\left(\mathrm{CCl}_{4}\right)$ concentration in large bag void volume of waste drum in variable-temperature environment (Trial 2.1$) \ldots \ldots \ldots \ldots \ldots \ldots \ldots \ldots \ldots \ldots$

18. Model predictions and experimental data of Freon-113, methylene chloride (MC) and carbon tetrachloride $\left(\mathrm{CCl}_{4}\right)$, concentration in the large bag void volume of waste drum in constant-temperature environment (Trial 3.4) $\ldots \ldots \ldots \ldots \ldots \ldots \ldots \ldots \ldots$

19. Mean absolute relative deviation of VOC concentration in small bags 
20. Mean absolute relative deviation of VOC concentration in large bags $\ldots \ldots \ldots \ldots$

21. Mean absolute relative deviation of VOC concentration in drum headspace ....... 53

22. Average Freon-113 and 1,1,1-trichloroethane (TCA) concentration in drum headspace for constant-temperature $(O, \square)$ and variable-temperature $(\boldsymbol{O}, \mathbf{0})$ experiments $\ldots \ldots \ldots 54$

23. Predicted Freon-113 concentration in small bags as a function of available permeable small and large bag surface area $\ldots \ldots \ldots \ldots \ldots \ldots \ldots \ldots \ldots \ldots \ldots \ldots$

24. Predicted average TCA concentration difference between large bag and drum headspace void volumes in waste drums maintained at a constant temperature (Trial 2.3) as a function of diffusion lengths $\left(\mathrm{x}_{\mathrm{d}}\right)$ across drum liner lid $\ldots \ldots \ldots \ldots$

25. Comparison of experimental data (Trial 2.3) and model predictions of TCA concentration in large bags (LB) and drum headspace $(\mathrm{DH})$ void volumes with and without $(\eta=0)$ VOC accumulation in polyethylene drum liner $\ldots \ldots \ldots \ldots \ldots$

\section{TABLES}

1. Experimental design for simulated waste drum VOC transport experiments . . . ... 9

2. Experimental design for polyethylene bottles VOC transport experiments $\ldots \ldots \ldots$

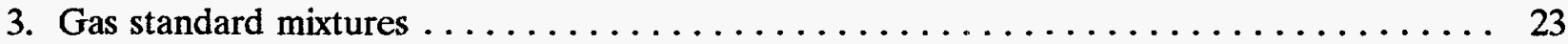

4. Sampling scheme for simulated waste drums $\ldots \ldots \ldots \ldots \ldots \ldots \ldots \ldots \ldots \ldots$

5. Permeability, diffusivity and solubility of VOC-air mixtures in yellow polyethylene bag . . . 38

6. Measured VOC permeability from mixed-component chromatographic detection method . 39

7. VOC transfer coefficients used in Equation $(3) \ldots \ldots \ldots \ldots \ldots \ldots \ldots \ldots$ 


\section{ACRONYMS}

CCS continuing calibration standards

DOE U.S. Department of Energy

EPA U.S. Environmental Protection Agency

FID flame ionization detector

GC gas chromatograph

INEL Idaho National Engineering Laboratory

MARD mean absolute relative deviation

MC methylene chloride

STP standard temperature and pressure

TCA 1,1,1-trichloroethane

TCD thermal conductivity detectors

TCE trichloroethylene

VOC volatile organic compound

WIPP Waste Isolation Pilot Plant 


\section{Modeling Unsteady-State VOC Transport in Simulated Waste Drums}

\section{INTRODUCTION}

Pretest waste characterization of waste drums for the bin-scale tests at the Waste Isolation Pilot Plant (WIPP) includes sampling for volatile organic compounds (VOCs) from three areas within drums (drum headspace, the 55-gal poly bag headspace, and the innermost layers of confinement headspace) of transuranic waste. ${ }^{1}$ The Department of Energy (DOE) must demonstrate to the Environmental Protection Agency (EPA) that a drum headspace sample is representative of the VOCs within the entire void space of the waste container in order to demonstrate compliance in the future when drums could be directly emplaced in the WIPP. It is specified in the WIPP No-Migration Determination (55 FR 44700) that the EPA expects all layers of confinement in a container will have to be sampled until DOE can demonstrate, based on data collected, that sampling of all layers is either unnecessary or can be safely reduced.

A test program has been initiated at the Idaho National Engineering Laboratory to demonstrate that the VOC concentration in the void space of each layer of confinement can be estimated using a model incorporating theoretical diffusive and permeative transport principles and limited waste drum sampling data. This approach will be used to model unsteady state and quasi-steady state VOC transport from simulated waste drums. An accurate model of VOC transport in a simulated waste drum will serve as the foundation for model development for VOC transport in an actual waste drum. Finally, the accuracy of a VOC transport model to estimate VOC concentration within actual waste drums will be investigated. A model capable of characterizing the VOC concentration in an actual waste drum will be used to assist in defining drum headspace representativeness and may more quickly eliminate the need for sampling of inner layers of confinement, resulting in lower worker radiation exposure, decreased bin loading times, and significant cost savings over the life of the WIPP test phase and operational phase.

In this report, the development and application of a VOC transport model to predict the VOC concentration within simulated waste drums under unsteady-state conditions is described. Development of the VOC transport model for a simulated waste drum is presented in Section 2. Section 3 contains a description of the experimental for the VOC transport experiments and permeability measurements. The results of these experiments are presented and discussed in Section 4. Model results are presented and discussed in Section 5. Conclusions of VOC transport model applicability to other waste drum configurations are summarized in Section 6. 


\section{VOC TRANSPORT MODEL}

A VOC transport model is developed to estimate the transient VOC gas-phase concentration throughout a simulated waste drum. A simulated waste drum is a scaled-down vented metal drum containing a rigid polymer drum liner that holds a large polyethylene bag with four smaller bags initially filled with a VOC-containing gas mixture. A small hole is punctured in the drum liner lid. The small bags, large bag, drum liner and drum headspace are distinct and separate void volumes. The model consists of a series of material balance equations describing unsteady-state VOC transport between each void volume. The small bags are referred to as the first, or innermost, void volume. The large poly bag, drum liner and drum are the second, third, and fourth void volumes, respectively.

\subsection{Model Equations}

The rate of VOC permeation across a polymer film is defined by

$$
Q_{P, i}=P A_{P, i} \frac{\Delta P}{\Delta x_{P, i}}
$$

where

$$
\begin{aligned}
& \mathrm{Q}_{\mathrm{P}, \mathrm{i}}=\text { rate of } \mathrm{VOC} \text { permeation from } \mathrm{i}^{\text {th }} \text { void volume at standard temperature and } \\
& \text { pressure, } \mathrm{cm}^{3} \text { (STP) } \mathrm{s}^{-1} \\
& \rho=\text { VOC permeability coefficient, } \mathrm{cm}^{3}(\mathrm{STP}) \mathrm{cm} \mathrm{cm}^{-2}\left(\mathrm{~cm} \mathrm{Hg}^{-1} \mathrm{~s}^{-1}\right. \\
& A_{P, i}=\text { surface area across which VOC permeates from } i^{\text {th }} \text { void volume, } \mathrm{cm}^{2} \\
& \Delta \mathrm{p} \quad=\quad \text { VOC partial pressure difference across polymer boundary, } \mathrm{cm} \mathrm{Hg} \\
& \Delta \mathrm{X}_{\mathrm{P}, \mathrm{i}}=\text { thickness of polymer boundary surrounding } \mathrm{i}^{\text {th }} \text { void volume, } \mathrm{cm} \text {. }
\end{aligned}
$$

The rate of VOC diffusion in air across an opening, such as a punctured hole or bag horsetail is defined by

$$
Q_{D, i}=D A_{D, i} \frac{\Delta y}{\Delta x_{D, i}}
$$

where

$Q_{D, i}=$ rate of VOC diffusion from $i^{\text {th }}$ void volume, $\mathrm{cm}^{3} \mathrm{~s}^{-1}$

$\mathrm{D}=\mathrm{VOC}$ diffusivity in air, $\mathrm{cm}^{2} \mathrm{~s}^{-1}$

$A_{D, i}=$ cross-sectional area of diffusional path across $i^{\text {th }}$ void volume, $\mathrm{cm}^{2}$ 
$\Delta y=$ VOC mole fraction difference across opening, $\left(\mathrm{cm}^{3} \mathrm{VOC}\right) \mathrm{cm}^{-3}$

$\Delta \mathrm{x}_{\mathrm{D}, \mathrm{i}}=$ diffusional path length between void volumes, $\mathrm{cm}$.

Soluble VOCs will accumulate within a polymer film until an equilibrium concentration is reached. The rate of accumulation is estimated to be

$$
\mathrm{P} \frac{d s_{i}}{d t}=\eta \mathrm{P}\left[s_{\infty, i}-s_{i}\right]
$$

where

$$
\begin{aligned}
& s_{\mathrm{i}}=\begin{array}{l}
\text { average VOC solubility in } \mathrm{i}^{\text {th }} \text { polymer volume, }\left[\mathrm{cm}^{3}(\mathrm{STP}) \mathrm{VOC}\right]\left(\mathrm{cm}^{-3} \text { polymer }\right) \\
\left(\mathrm{cm} \mathrm{Hg}^{-1}\right)
\end{array} \\
& \mathrm{s}_{\infty, i}=\begin{array}{l}
\text { VOC equilibrium solubility in } \mathrm{i}^{\text {th }} \text { polymer volume, }\left[\mathrm{cm}^{3}(\mathrm{STP}) \mathrm{VOC}\right]\left(\mathrm{cm}^{-3}\right. \\
\text { polymer })\left(\mathrm{cm} \mathrm{Hg}^{-1}\right)
\end{array} \\
& \mathrm{dt}=\text { differential time interval, } \mathrm{s} \\
& \mathrm{\eta}=\text { transfer coefficient, } \mathrm{sec}^{-1}
\end{aligned}
$$

The total rate of VOC transport from each small polymer bag is defined by summing the contribution of each transport mechanism defined by Equations (1)-(3)

$$
V_{1, j} \frac{d y_{1, j}}{d t}=(\alpha \phi+\beta)_{1, j}\left[y_{2}-y_{1, j}\right]-\gamma_{1, j} \phi \frac{d s_{1, j}}{d t}
$$

where

$$
\begin{aligned}
& \mathrm{V}_{1, \mathrm{j}}=\text { void volume within } \mathrm{j}^{\text {th }} \text { small bag, } \mathrm{cm}^{3} \\
& y_{1, j}=\text { VOC mole fraction in } V_{1, j}, \mathrm{~mol} \mathrm{~cm}^{-3} \\
& \Delta y=y_{2}-y_{1, j},\left(\mathrm{~cm}^{3} \text { VOC }\right) \mathrm{cm}^{-3} \\
& f_{1, j}=y_{1, j} v_{1, j} /\left[y_{1, j} v_{1, j}+y_{2} v_{2}\right] \\
& \mathrm{V}_{\mathrm{p}, 1, \mathrm{j}}=\text { polymer volume of } \mathrm{j}^{\mathrm{th}} \text { small bag, } \mathrm{cm}^{3} \text { polymer. } \\
& \alpha_{1, j}=\left(P A_{P} P / \Delta x_{p}\right)_{1, j} \\
& \beta_{1, j}=\left(D A_{D} / \Delta x_{D}\right)_{1, j} \\
& \boldsymbol{\gamma}_{1, \mathrm{j}}=\left(\mathrm{f} \mathrm{V}_{\mathrm{p}} \mathrm{P}\right)_{1, \mathrm{j}}
\end{aligned}
$$




$$
\begin{aligned}
& \phi_{1, j}=76 T_{1} /(273.15 \mathrm{P}) \\
& T_{i}=\text { temperature in } i^{\text {th }} \text { void volume, } K
\end{aligned}
$$

In defining the coefficient $f$, it was assumed that the number of moles sorbed on a polymer film from a void volume is proportional to the total number of moles available in all void volumes adjacent to the film.

The VOCs exiting the small bags enter the void space within the large bag. The equation for the rate of change in the large bag is defined as

$$
V_{2} \frac{d y_{2}}{d t}=\left[\sum_{j=1}^{4}-(\alpha \phi+\beta)_{1, j}\left[y_{2}-y_{1, j}\right]\right]+(\alpha \phi+\beta)_{2}\left[y_{3}-y_{2}\right]-\phi g\left(s_{1}, s_{2}\right)
$$

where, in general

$$
g\left(s_{k}, s_{m}\right)=\left(1-\gamma_{k}\right) \frac{d s_{k}}{d t}+\gamma_{m} \frac{d s_{m}}{d t}
$$

In the liner and drum lids there are relatively large openings through which VOCs exit by diffusion and convective flow resulting from changes in temperature. In the case of increasing temperature, the rate of change in the liner headspace is defined as

$$
V_{3} \frac{d y_{3}}{d t}=\left[\sum_{i=2}^{3}(-1)^{3-i}(\alpha \phi+\beta)_{i}\left[y_{i+1}-y_{i}\right]\right]-\phi g\left(s_{2}, s_{3}\right)-\frac{V_{3} y_{3}}{T_{3}} \frac{d T_{3}}{d t}
$$

and in the drum headspace the rate of change is defined as

$$
V_{4} \frac{d y_{4}}{d t}=-(\alpha \phi+\beta)_{3}\left[y_{4}-y_{3}\right]-\frac{D^{*}}{C_{o}} y_{4} \frac{T_{4}}{T_{o}}-\phi g\left(s_{3}, s_{4}\right)+V_{4} y_{4}\left[\frac{T_{4}}{T_{3}^{2}} \frac{d T_{3}}{d t}+\frac{1}{T_{4}} \frac{d T_{4}}{d t}\right]
$$

where

$$
\begin{aligned}
& D^{*}=\text { VOC-filter diffusion characteristic, } \mathrm{mol} \mathrm{s}^{-1}(\mathrm{~mol} \mathrm{fraction})^{-1} \\
& C_{0}=\text { total gas concentration in drum }=\mathbf{P} / \mathrm{RT}_{0}, \mathrm{~mol} \mathrm{~cm}^{-3} \\
& T_{0}=\text { gas temperature during filling of small bags, } \mathrm{K}
\end{aligned}
$$

In the case of decreasing temperature, the rate of change in the liner headspace is defined as 


$$
V_{3} \frac{d y_{3}}{d t}=\left[\sum_{i=2}^{3}(-1)^{3-i}(\alpha \phi+\beta)_{i}\left[y_{i+1}-y_{i}\right]\right]-\phi g\left(s_{2}, s_{3}\right)-\frac{V_{3} y_{4}}{T_{3}} \frac{d T_{3}}{d t}
$$

and in the drum headspace is defined as

$$
V_{4} \frac{d y_{4}}{d t}=-(\alpha \phi+\beta)_{3}\left[y_{4}-y_{3}\right]-\frac{D^{*}}{C_{o}} y_{4} \frac{T_{4}}{T_{o}}-\phi g\left(s_{3}, s_{4}\right)+\frac{V_{4} y_{4}}{T_{3}} \frac{d T_{3}}{d t}
$$

\subsection{Model Assumptions}

The following assumptions were made in deriving model equations:

- All void volumes are well-mixed and the VOC concentration is identical throughout.

- The diffusion pathway length between two void volumes is:

- Across a horsetail, the length of the horsetail.

- Across a puncture or hole, the sum of the polymer boundary thickness and the mean hole diameter.

- Pressure differential across puncture hole in the liner lid and drum filter is negligible.

- VOC molecules that exit the drum through the filter are not drawn back into the drum.

- All surface areas, void volumes, and diffusion path lengths specified for a given system remain constant during the entire test period.

\subsection{Model Parameters}

\subsubsection{VOC-Polymer Permeability}

The sorption, diffusion, and permeation of several organic vapors in polyethylenes of different densities over a wide range of vapor activity and concentrations has been investigated ${ }^{2}$. In general, VOC permeability is an exponential function of vapor activity (VOC partial pressure/VOC vapor pressure). As the vapor activity approaches zero, VOC permeability approaches a constant nonzero value.

The transmission rate of a number of organic liquids through low-density polyethylene at different temperatures has been reported. ${ }^{3,4} \mathrm{~A}$ semi-empirical equation has been used to estimate the VOC transmission rate, $\mathrm{Q}$, in polyethylene and related polymers: ${ }^{3}$ 
where

$$
\begin{aligned}
\log _{10} Q=K-c \pi \\
\text { c } \quad=\text { constant } \\
\pi \quad=\text { function of VOC molecular structure. }^{3}
\end{aligned}
$$

For low-density polyethylene ${ }^{3}$

$$
K=16.55-\frac{3700}{T} \text {. }
$$

The transmission rate is often used to estimate VOC permeability when the saturated vapor: pressure of the permeant at a specified temperature is applied across a film. ${ }^{4}$ Thus,

$$
P \propto \frac{Q}{P_{\text {vap }}}
$$

where $P_{\text {vap }}$ is the saturated vapor pressure at temperature $T$. Temperature dependence of the VOC vapor pressure is estimated using the Antoine Equation: ${ }^{5}$

$$
\log _{10} P_{\text {vap }}=A-\frac{B}{C+T}
$$

where $A, B$, and $C$ are equation constants. The effect of temperature on VOC vapor permeability in low-density polyethylene is estimated by combining Equations (11)-(14):

$$
\log _{10}\left[\frac{P\left(T_{1}\right)}{P\left(T_{2}\right)}\right]=B\left[\frac{1}{C+T_{1}}-\frac{1}{C+T_{2}}\right]-3700\left[\frac{1}{T_{1}}-\frac{1}{T_{2}}\right] \text {. }
$$

\subsubsection{VOC-Air Diffusivity}

The VOC-air diffusivity can be estimated at low pressures using an equation developed frorn a combination of kinetic theory and corresponding-states arguments: ${ }^{6}$

$$
D_{A B}=2.745 \times 10^{-4} \frac{T^{1.823}}{P}\left[p_{c A} p_{c B}\right]^{1 / 3}\left[T_{C A} T_{c B}\right]^{-0.495}\left[\frac{1}{M_{A}}+\frac{1}{M_{B}}\right]^{1 / 2}
$$

where

$$
\begin{aligned}
& D_{A B}=\text { mass diffusivity for } \operatorname{VOC}(A) \text {-air(B) system, } \mathrm{cm}^{2} \mathrm{~s}^{-1} \\
& \mathrm{P}_{\mathrm{ci}}=\text { critical pressure of species } \mathrm{i}, \text { atm }
\end{aligned}
$$




$$
\begin{aligned}
& \mathbf{T}_{\mathrm{ci}}=\text { critical temperature of species } \mathrm{i}, \mathrm{K} \\
& \mathbf{M}_{\mathrm{i}}=\text { molecular weight of species } \mathrm{i} .
\end{aligned}
$$

The VOC diffusion characteristic across a carbon-composite filter is estimated from the knowledge of the hydrogen $\left(\mathrm{H}_{2}\right)$ diffusion characteristic across the same filter and the ratio of VOC-to- $\mathrm{H}_{2}$ diffusivity

$$
D_{v o c}^{*}=\left[\frac{D_{\text {voc-air }}}{D_{H_{2} \text {-air }}}\right] D_{H_{2}}^{*} .
$$

The diffusivity ratio has been estimated by the square root of the inverse ratio of molecular weights of the VOC and $\mathrm{H}_{2}{ }^{7}$

\subsubsection{VOC Solubility in Polymer}

Henry's law provides a good approximation of VOC vapor solubility in a polymer at very low vapor concentrations: ${ }^{8}$

$$
x=y / H
$$

where

$$
\begin{aligned}
& \mathbf{x} \quad=\text { VOC mole fraction in polymer }(<1) \\
& \mathbf{y} \quad=\text { VOC mole fraction in gas phase } \\
& \mathbf{H} \quad=\text { Henry's constant. }
\end{aligned}
$$




\section{EXPERIMENTAL}

\subsection{VOC Transport Experiments}

\subsubsection{Experimental Design}

A two-level, three-variable, four-block experimental design with two replications was constructed to investigate VOC transport within lab-scale simulated waste drums. Test variables were the initial VOC gas mixtures placed in the small inner bags, the presence or absence of horsetail ties on the small bags, and the presence or absence of a variable external heat source. The experimental design is summarized in Table 1.

A two-level two-variable experiment was designed to investigate VOC transport from polyethylene bottles. Test variables were the size of the bottle lid and the presence or absence of seal across the bottle lid. The experimental design is summarized in Table 2.

\subsubsection{Automated VOC Transport Experimental Configuration}

The automated VOC transport experimental configuration, shown in Figure 1, consisted of four simulated waste drums, four polyethylene bottles, a heated environmental chamber, an automated gas sampling system which included a high and low level gas sampling manifold, a gas chromatograph (GC) with flame ionization detector (FID), a GC data station, a 10-port gas sampling valve, a mechanical vacuum pump, a Pirani micro controller, and a process controller.

3.1.2.1 Gas Chromatograph and GC Data System. A Hewlett Packard (HP) 5890 series II GC with FID configured with a Restek RT-35 analytical column (30 meters $\times$ $1.0 \mu \mathrm{m}$ df $\times 0.32 \mathrm{ID}$ ) was used to analyze the headspace samples. The column head pressure was set to 5 psi with a split flow of $35.5 \mathrm{~cm}^{3} / \mathrm{min}$. Splitless injections were made with a purge time of 1.0 min using a straight $2.0 \mathrm{~mm}$ ID inlet sleeve. An initial oven temperature of $50^{\circ} \mathrm{C}$ was held for $4.5 \mathrm{~min}$ and then ramped at $20^{\circ} \mathrm{C} / \mathrm{min}$ to $150^{\circ} \mathrm{C}$, with a final hold time of $1.25 \mathrm{~min}$. Total $\mathrm{GC}$ run time was 10.75 min. An HP Vectra QS/20 personal computer with HP 3365 series II Chemstation (DOS) software, Version B.01.02 was used to control the GC and store all GC data files. The daily sampling sequences were loaded on to the GC data system to configure the 10-port sampling valve and select the correct sample loop for each sample run.

3.1.2.2 Simulated Lab-Scale Waste Drums. Each simulated waste drum consisted of a modified 55-gal metal drum containing a modified 90-mil, high-density, rigid polyethylene drum liner. Four small 4-liter polyethylene bags were sealed inside a large polyethylene bag, supported by a wire cage and placed inside the drum liner. A schematic of a lab-scale simulated waste drum is shown in Figure 2.

Each simulated waste drum was a scaled-down version of a DOT 17C 55-gal drum. A 21.75 in. center section of the drum was removed and the two end pieces welded together. The internal weld was smoothed so that no gross burrs were present and then spray painted. The modified drum had an internal diameter of $22.4 \mathrm{in}$. and an outside drum height of $14.25 \mathrm{in}$. A 
Table 1. Experimental design for simulated waste drum VOC transport experiments.

\begin{tabular}{|c|c|c|c|c|c|}
\hline $\begin{array}{l}\text { Test } \\
\text { period }\end{array}$ & $\begin{array}{c}\text { Drum } \\
\text { number }\end{array}$ & $\begin{array}{c}\text { Trial } \\
\text { number }\end{array}$ & $\begin{array}{c}\text { Standard } \\
\text { gas mixture }^{\mathrm{a}}\end{array}$ & $\begin{array}{l}\text { Small bag } \\
\text { closure }\end{array}$ & $\begin{array}{c}\text { Variable } \\
\text { heat source }\end{array}$ \\
\hline \multirow[t]{4}{*}{ I } & 1 & 1.1 & A & Horsetail & Yes \\
\hline & 2 & 1.2 & B & Heat sealed & Yes \\
\hline & 3 & 1.3 & A & Heat sealed & No \\
\hline & 4 & 1.4 & B & Horse tail & No \\
\hline \multirow[t]{4}{*}{ II } & 1 & 2.1 & A & Heat sealed & Yes \\
\hline & 2 & 2.2 & B & Horse tail & Yes \\
\hline & 3 & 2.3 & A & Horse tail & No \\
\hline & 4 & 2.4 & B & Heat sealed & No \\
\hline \multirow[t]{4}{*}{ III } & 1 & 3.1 & A & Horse tail & Yes \\
\hline & 2 & 3.2 & B & Heat sealed & Yes \\
\hline & 3 & 3.3 & $\mathbf{B}$ & Horse tail & No \\
\hline & 4 & 3.4 & $\mathbf{A}$ & Heat sealed & No \\
\hline \multirow[t]{4}{*}{ IV } & 1 & 4.1 & A & Heat sealed & Yes \\
\hline & 2 & 4.2 & $\mathbf{B}$ & Horse tail & Yes \\
\hline & 3 & 4.3 & A & Horse tail & No \\
\hline & 4 & 4.4 & B & Heat sealed & No \\
\hline
\end{tabular}

a. Standard gas mixture $\mathbf{A}$ (high-level) contains approximately 1,000 parts per million by volume (ppmv) 1,1,1-trichloroethane, 1,000 ppmv methylene chloride, 1,000 ppmv 1,1,2-trichloro-1,2,2trifluoroethane (Freon-113), $300 \mathrm{ppmv}$ carbon tetrachloride, and $300 \mathrm{ppmv}$ trichloroethylene.

Standard gas mixture B (high-level) contains approximately 1,000 ppmv trichloroethane, 1,000 ppmv methanol, $750 \mathrm{ppmv}$ cyclohexane, $400 \mathrm{ppmv}$ toluene, and 100 ppmv para-xylene.

Table 2. Experimental design for polyethylene bottles VOC transport experiments.

Bottle number Type of bottle lid $\quad$ Lid seal

\begin{tabular}{lll}
\hline & & \\
1 & Large mouth & Yes \\
2 & Large mouth & No \\
3 & Small mouth & Yes \\
4 & Small mouth & No \\
\hline
\end{tabular}




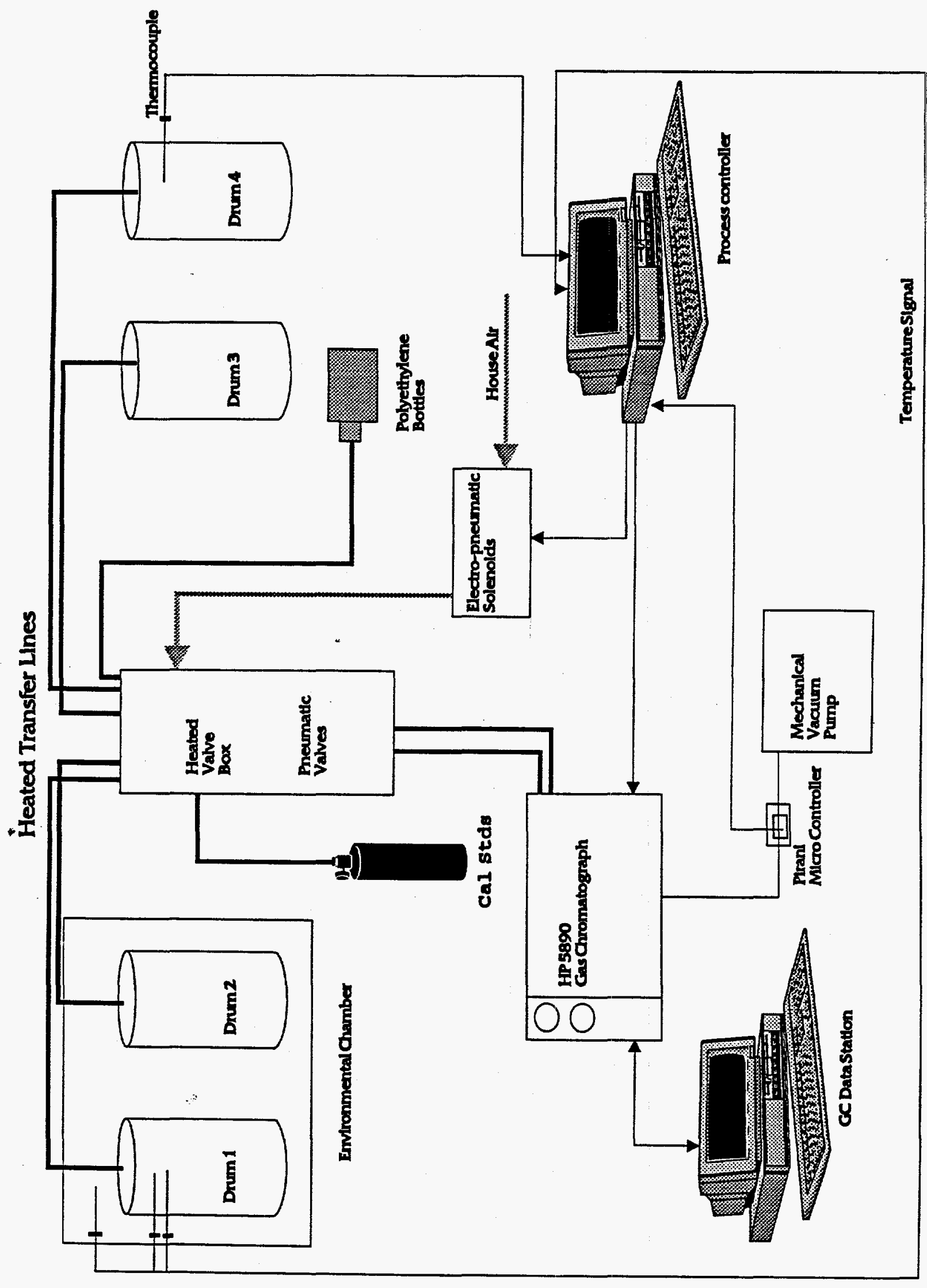

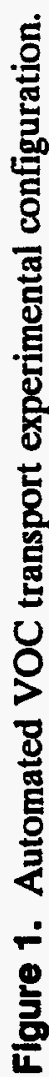




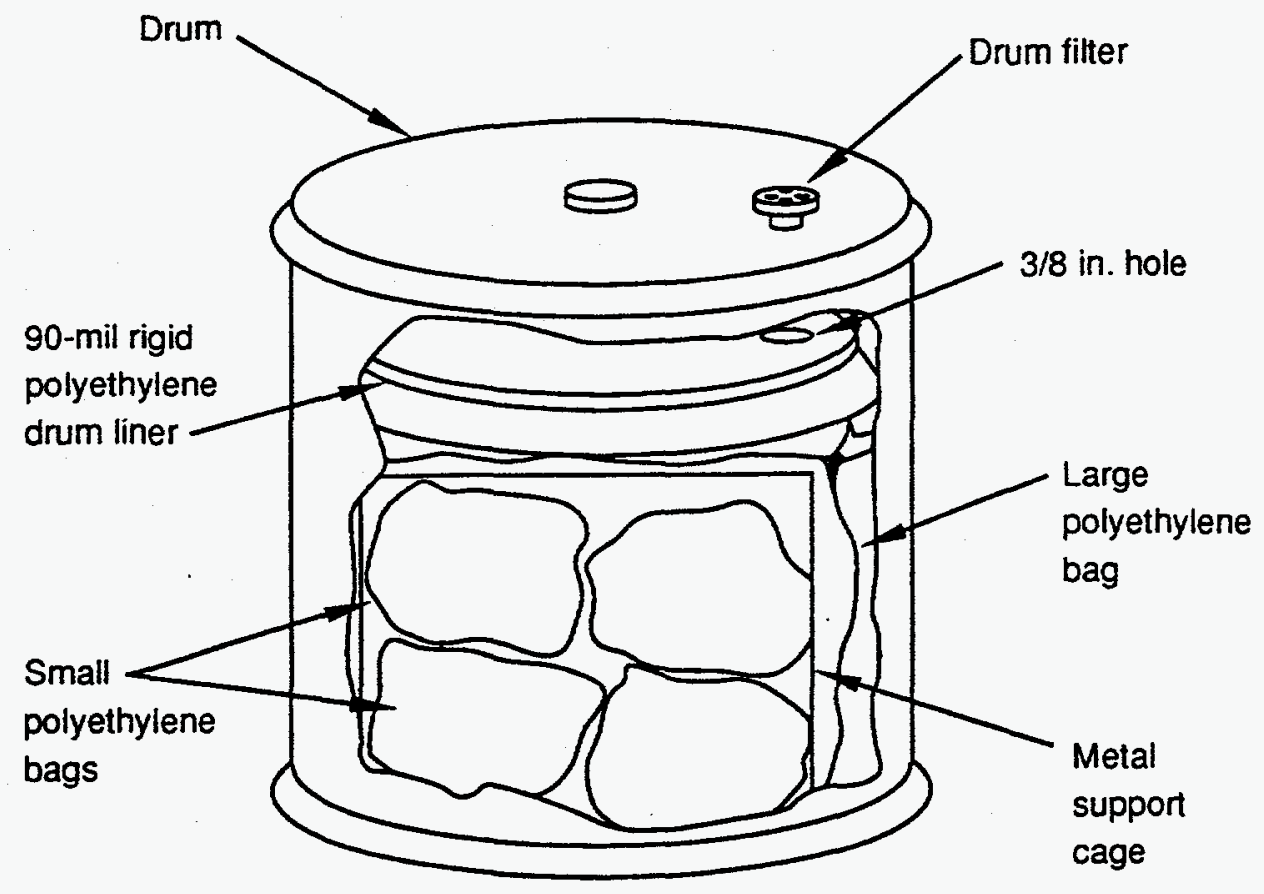

R93 0871

Figure 2. Simulated lab-scale waste drum. 
0.375-in. hole was drilled in the drum lid approximate 4.3 in. from the outside edge and a NFT-020 (Nuclear Filter Technology Corp.) carbon-composite filter, shown in Figure 3, was screwed securely in the hole.

The drum liner was a scaled-down version of a Type III liner. The rigid 90-mil liner had a removable lid with a metal closure ring with bolt and gasket. A 21 in. center section of the liner was removed and the two end sections heat welded together. The modified Type III liner had an outside base diameter of 22.0 in., an inside lid diameter of $22.5 \mathrm{in}$., and outside height (with lid) of 11.5 in. The nominal wall thickness of the liner was 0.090 in. A 0.375 in. hole was drilled in the lid below the carbon composite filter in the drum lid.

Two sizes of yellow polyethylene bags were used in the experiment. Both sizes are used by the INEL for the disposal of radiologically contaminated waste. The original dimensions of the large bag were $33.0 \mathrm{in}$. in width and $40.0 \mathrm{in}$. in length and a wall thickness of $0.004 \mathrm{in}$. The original dimensions of the small bags were $18.0 \mathrm{in}$. in width and $24.0 \mathrm{in}$. in length and a wall thickness of 0.004 in. The length of the small bags were reduced to $18.5 \mathrm{in}$. before being sealed with a horsetail and reduced to 12.0 in. before being heat sealed.

Modified bulkhead feedthroughs were constructed to isolate each layer of confinement. The feedthroughs for the small bags, shown in Figure 4, were fabricated from modified 0.0625 -in. brass Swagelock bulkhead unions with two backing washer, two teflon sealing washers, and an n-butyl O-ring. The outer sealing washer was machined to allow the O-ring to seat between the sealing washer and the polyethylene bag. The outer backing washer and outer teflon sealing washer were epoxied, using MasterMend E-POX-E epoxy (Loctite Corp.), to the body of the bulkhead union. The 0.0625 -in. teflon ferrules were used to seal the 0.0625 -in. sample transfer lines. The feedthroughs for the large bags, shown in Figure 5, were fabricated from 0.375 -in. brass Swagelock bulkhead unions with a backing washer and two teflon sealing washers. Teflon coated silica septa (Supelco, Inc., 2-244) were pre-drilled to allow feedthrough of the five sample transfer lines. Feedthroughs for the drum, shown in Figure 6, were fabricated from 0.625 -in. stainless steel. Swagelock SAE/MS male connectors with two teflon sealing washers and backing nuts. Teflon coated silica septa were pre-drilled to allow feedthrough of the six sample transfer lines. Five holes of 0.060 -in. diameter were drilled in the 90 -mil liner lid to allow feedthrough of the sample transfer lines. Swagelock thermocouple connectors were place in the sides of drum \#1 and drum \#4 with 0.125 -in. teflon ferrules to seal the thermocouple probes.

3.1.2.3 Polyethylene Bottles. Both large and small mouth polyethylene bottles were used. to investigate the VOC transport from sealed bottles. The nominal volume of each bottle was $4,000 \mathrm{~cm}^{3}$. The large-mouth bottles were made of high-density polyethylene with lids made of polypropylene (Nalge Labware, 2120-0010). The inside diameter of the bottle mouth was 3.5 in. and the nominal wall thickness of the bottle was 0.080 in. The small-mouth bottles were made of low-density polyethylene with lids made of polypropylene (Nalge Labware, 2202-0010). The inside diameter of the bottle mouth was $1.0 \mathrm{in}$. and the nominal wall thickness of the bottle was $0.100 \mathrm{in}$. Modified 0.0625-in. brass Swagelock bulkhead unions were tapped and epoxied into the caps of the bottles to allow feedthrough of the sample transfer lines. Teflon ferrules were used to seal 0.0625 -in. sample transfer lines. The 0.125 -in. brass Swagelock toggle valves were tapped and epoxied in the bottom center of the bottles to allow purging of the bottles during the initial filling: 

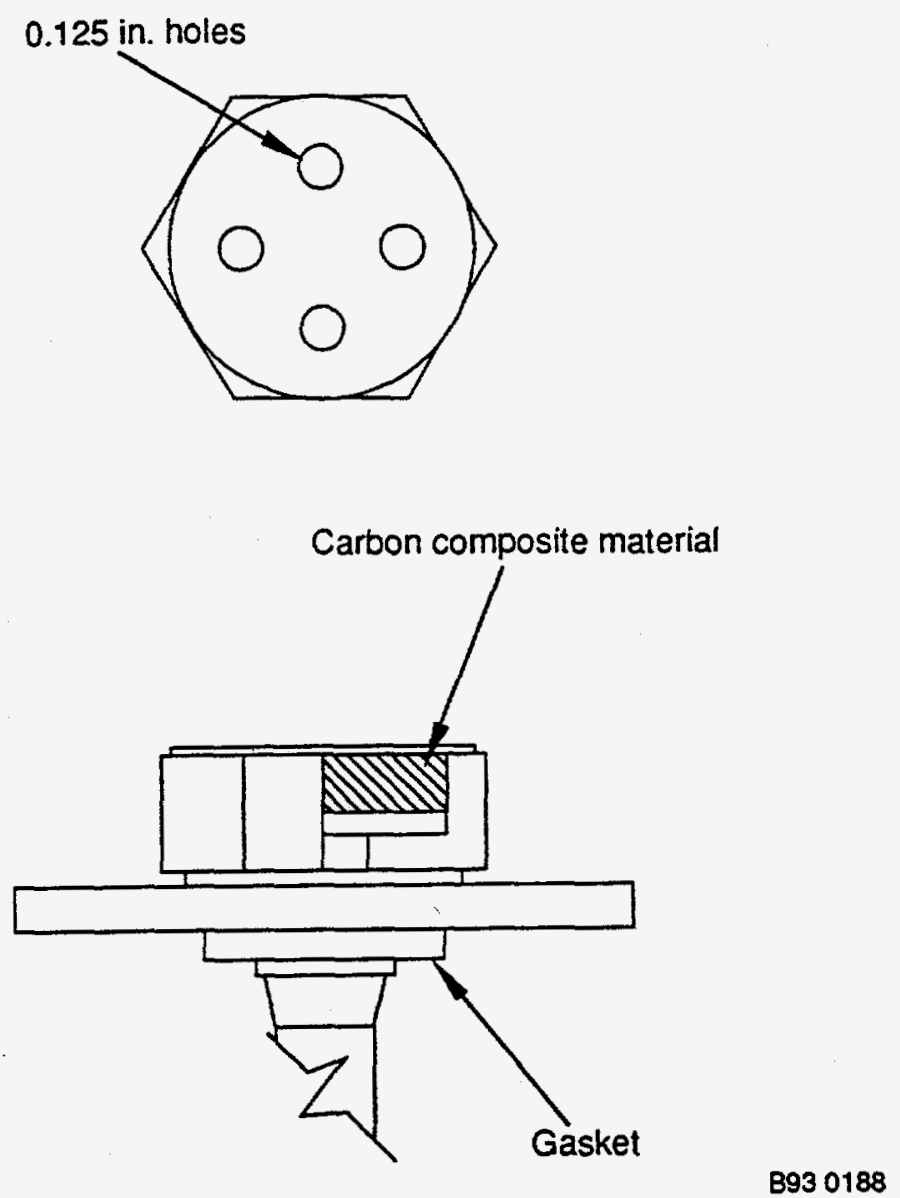

Figure 3. NFT-020 carbon-composite filter. 


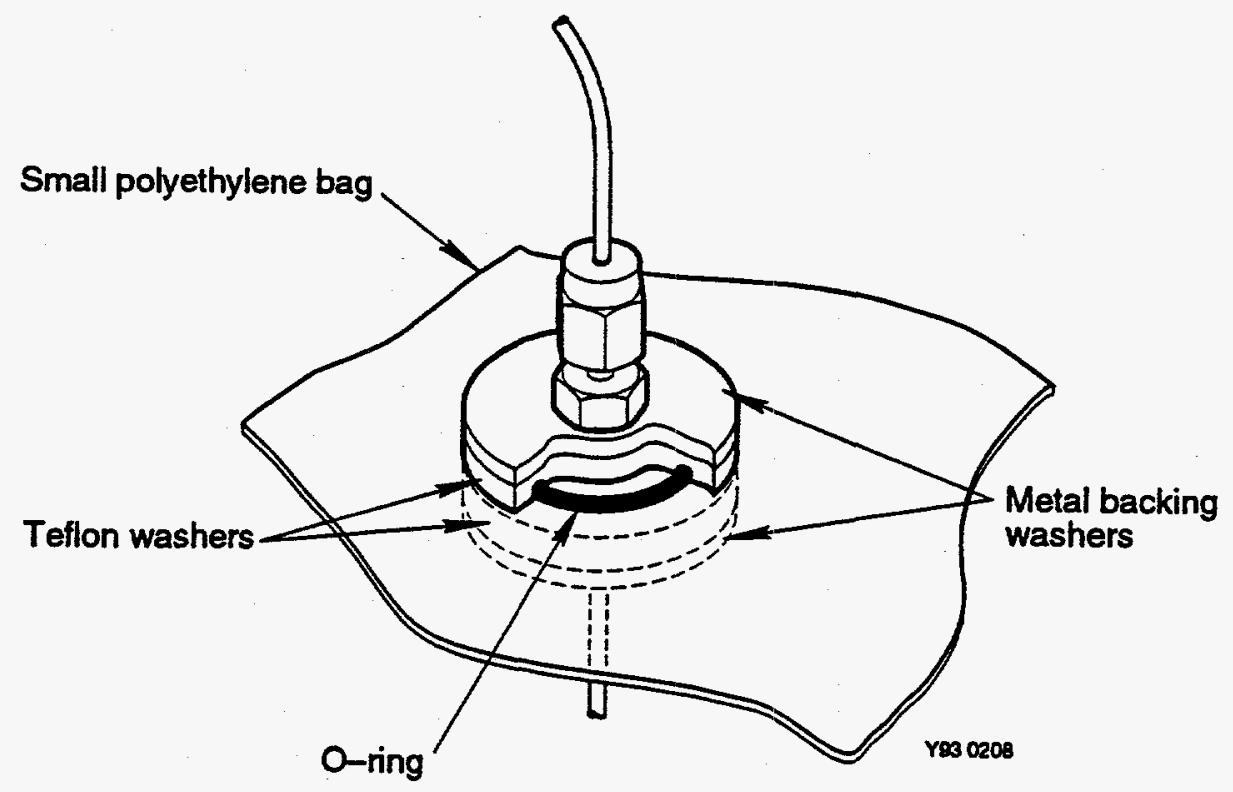

Figure 4. Feedthrough for small polyethylene bags. 


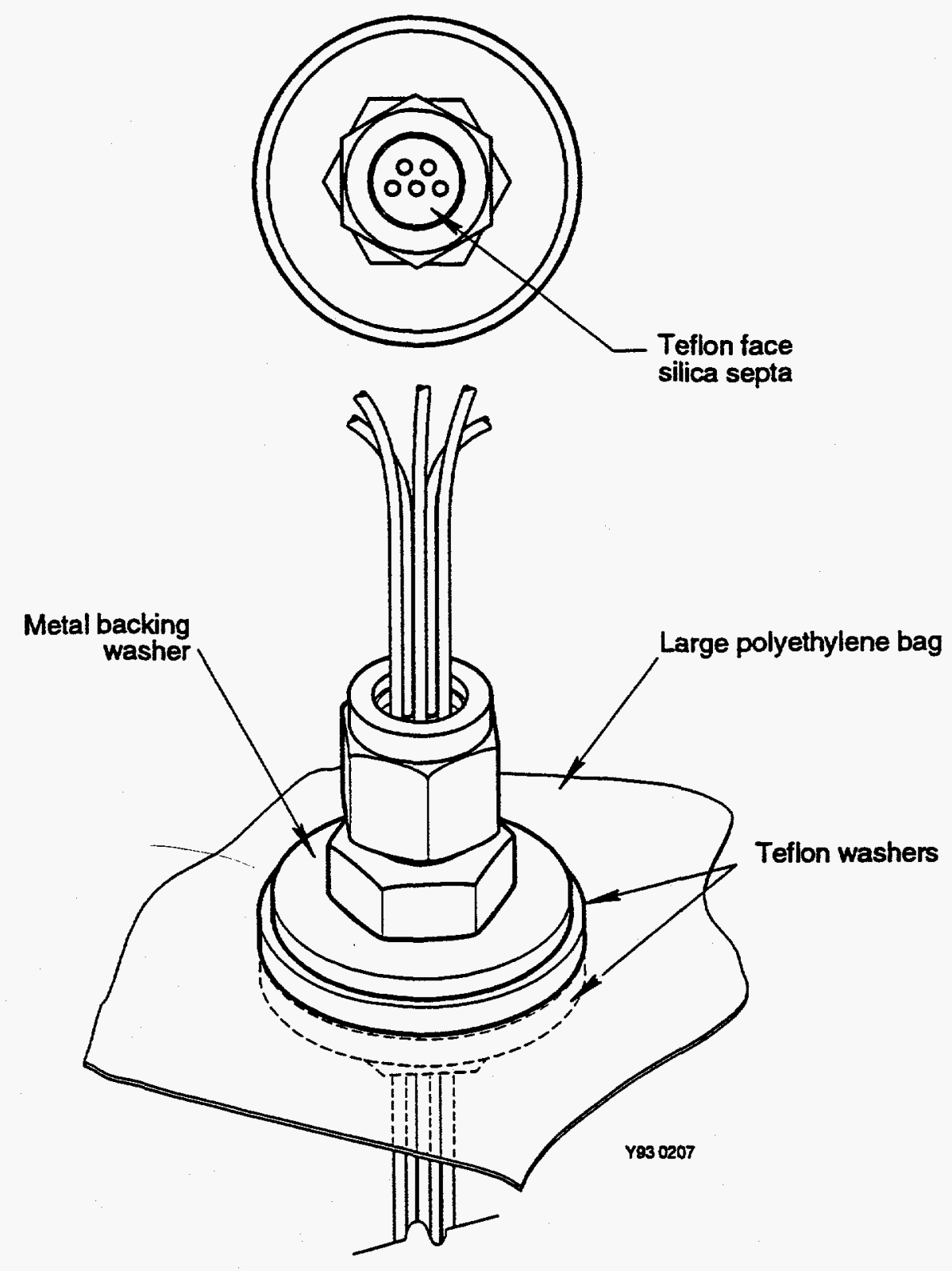

Figure 5. Feedthroughs for large polyethylene bags. 


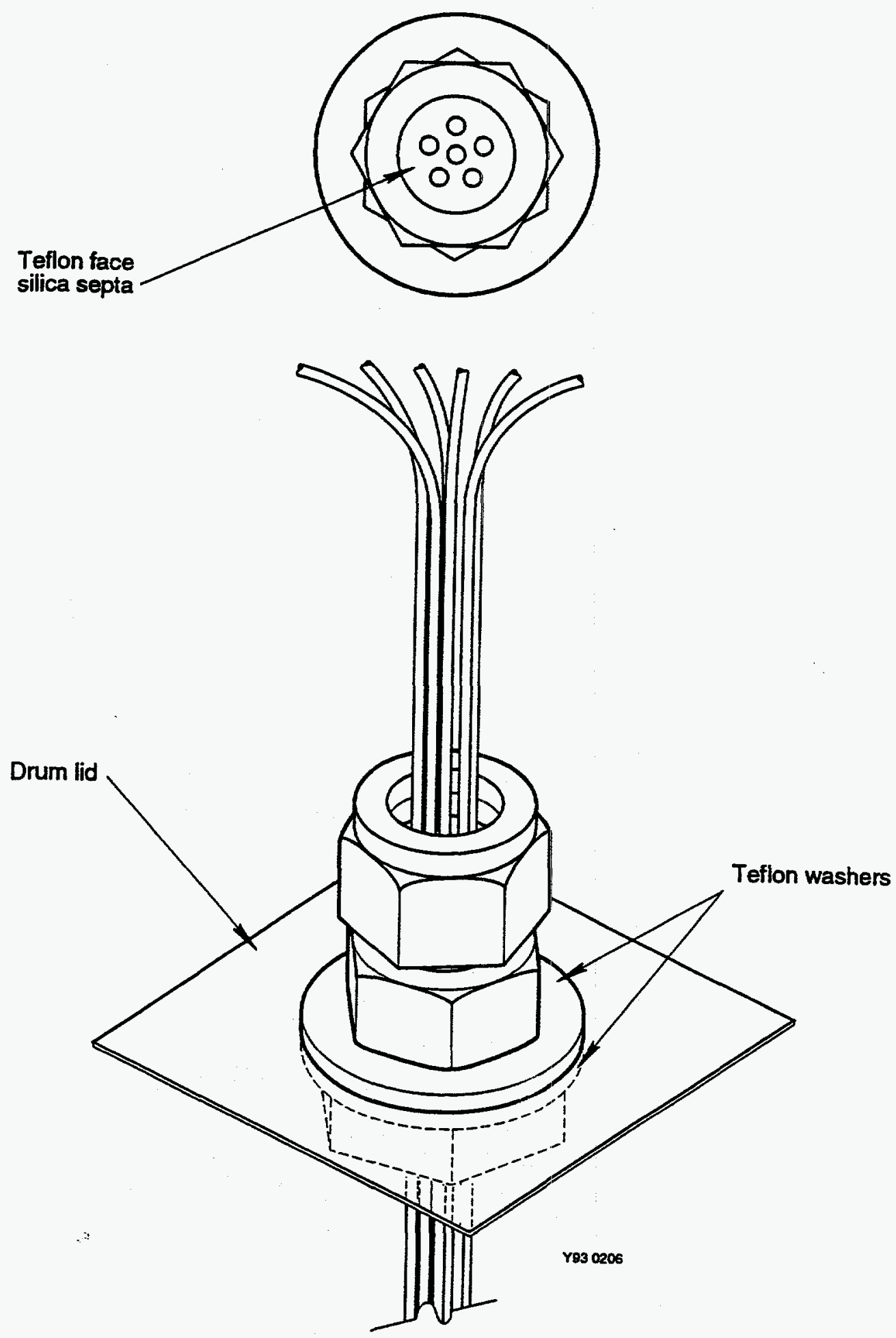

Figure 6. Feedthroughs for drum lid. 
process. One large-mouth and one small-mouth bottle were sealed using an aluminum foil gasket place at the mouth of the bottle. A large-mouth polyethylene bottle adapted for these experiments is shown in Figure 7.

3.1.2.4 Environmental Chamber. An environmental chamber was constructed to expose two of the four simulated lab-scale waste drums to a variable heat source to determine the effect of temperature variation on VOC transport from the waste drum. The environmental chamber, shown in Figure 8, was constructed of 0.0625 -in. aluminum sheet metal with overall dimensions of 58.0 in. in length, 32.0 in. in height, and 28.0 in. in depth. The lid and four walls of the chamber were insulated with 0.5 -in. rigid Firestone polyiso insulation. Two simulated waste drums were set on a raised platform $9.0 \mathrm{in}$. above the chamber floor and centered in the environmental chamber to allow air to circulate around the drums. A 4.0-in. fan circulated air inside the sealed chamber. Six 100-watt light bulbs controlled by an Omega temperature controller (6102-J-0/300) coupled to a J-type thermocouple were used as a heat source. A Micronto programmable timer was used to turn the temperature controller on for 4 hours each day during each test period. The upper working temperature of the environmental chamber was set to $40^{\circ} \mathrm{C}$. Temperature measurements were taken every 15 minutes throughout each test period. J-type Omega stainless steel 12-in. thermocouples (JQSS-18G-12) were used for all temperature measurements.

3.1.2.5 Automated Gas Sampling System. A schematic of the automatic gas sampling system is shown in Figure 9. Headspace samples were collected by evacuating the manifold system to a vacuum of 10 millitorr then back-filling the gas sampling loops. The gas sample flowed into the selected sampling loop until the pressure equilibrated to ambient pressure. Between samples, the automated gas sampling system evacuated both high and low sampling manifolds and both gas sampling loops. Pressurized standard gas mixtures were used to establish the initial calibration curves for the nine analytes of interest and also used on a daily basis as the continuing calibration standards (CCS). Initial calibration samples and CCS samples were collected by purging the manifold system and then allowing the standard gas mixture to equilibrate to ambient pressure. Between samples, the automated gas sampling system evacuated the high and low sampling manifolds and gas sampling loops. The system automatically monitored the pressure of the manifolds and 10-port gas sampling valve and sequenced the pneumatic valves in response to the sequence files downloaded to the process controller. Samples were transferred from the gas sampling loop to the GC injector and analyzed by GC-FID. A two-level (high and low level) sampling system was developed to quantitate VOC headspace samples with sample concentrations varying from less than $1.0 \mathrm{ppmv}$ to greater than $1,000 \mathrm{ppmv}$.

The gas sampling system utilized a low- and a high-level sampling manifold configured to a 10-port gas sampling valve with 5.0 and $2.0 \mathrm{~cm}^{3}$ sampling loops. The configuration of the 10-port gas sampling valve is shown in Figure 10. The 24.0 in. manifold headers were fabricated by Scientific Instrument Services from 0.25-in. OD stainless steel tubing (0.095-in. wall thickness) with 0.0625-in. stainless steel sampling ports. Pneumatic needle valves (Scientific Glass Engineering, \#MOVP-1-100) were used for the manifold isolation valves, vacuum valve, purge valve, and sample isolation valves. Silcosteel 0.0625 -in. silica lined stainless steel tubing (0.020 in. ID) was used for the gas sampling lines and manifold transfer lines. The valve box, all transfer lines, and 10-port gas sampling valve were heated to $145^{\circ} \mathrm{C}$ to prevent cold trapping of VOCs. For drums 1 and 2, 9-in. sections of the sample transfer lines were unheated inside the 


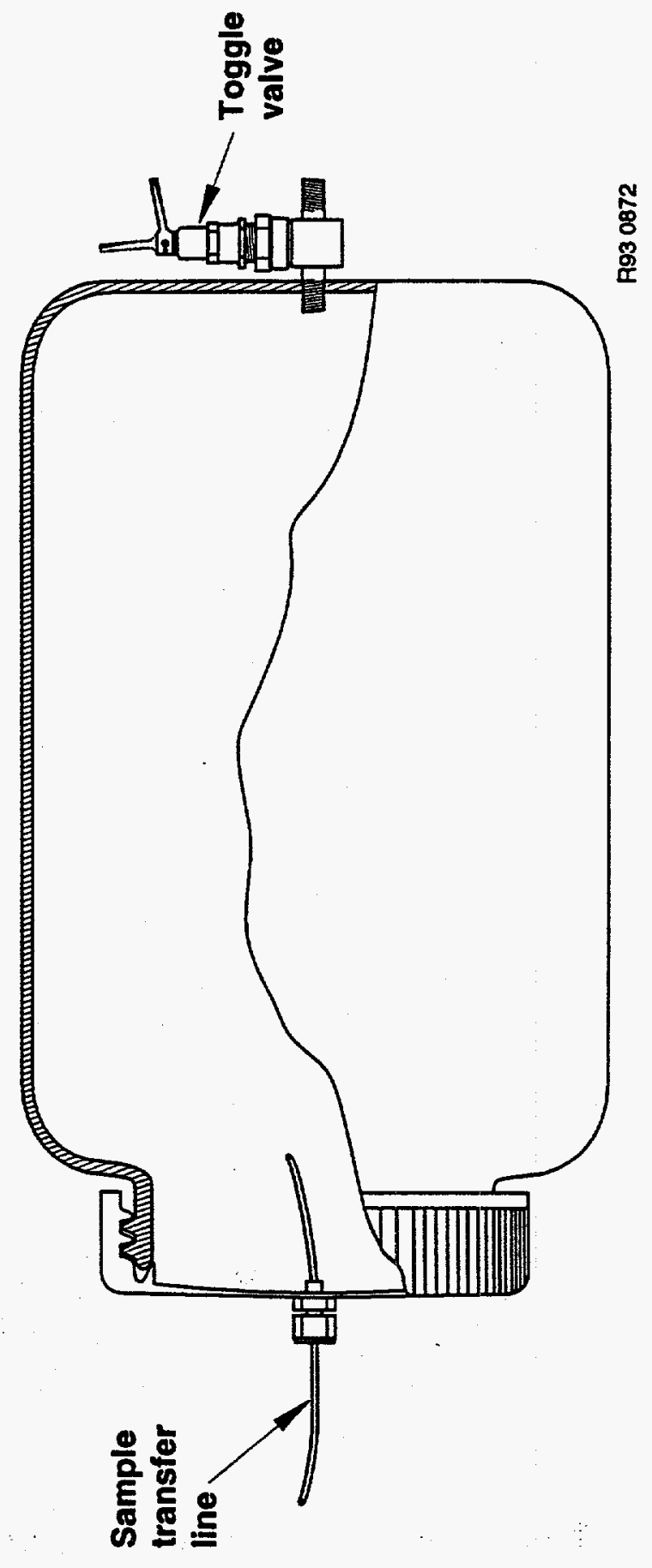

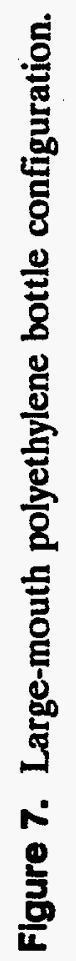




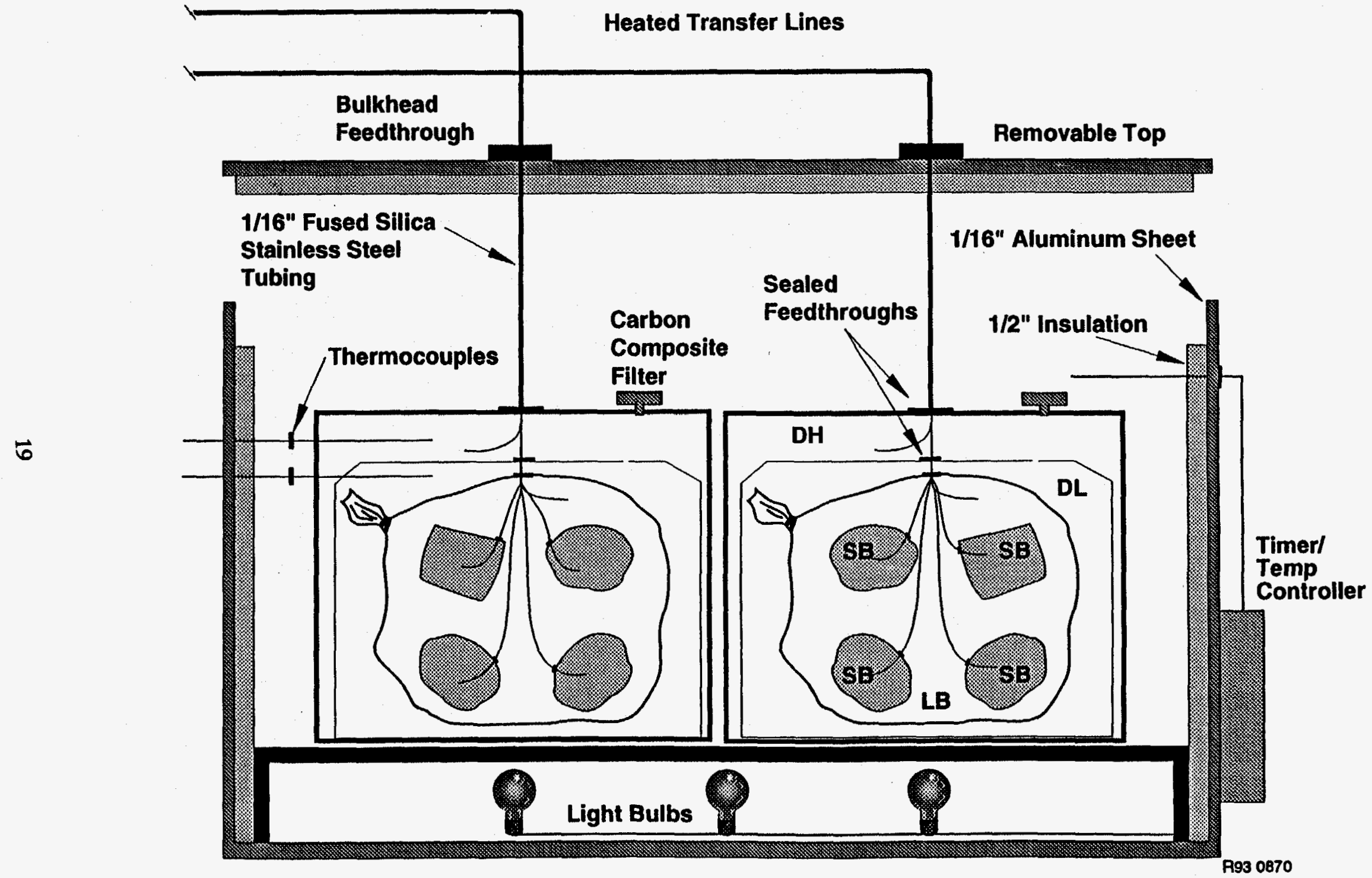

Figure 8. Environmental chamber. 


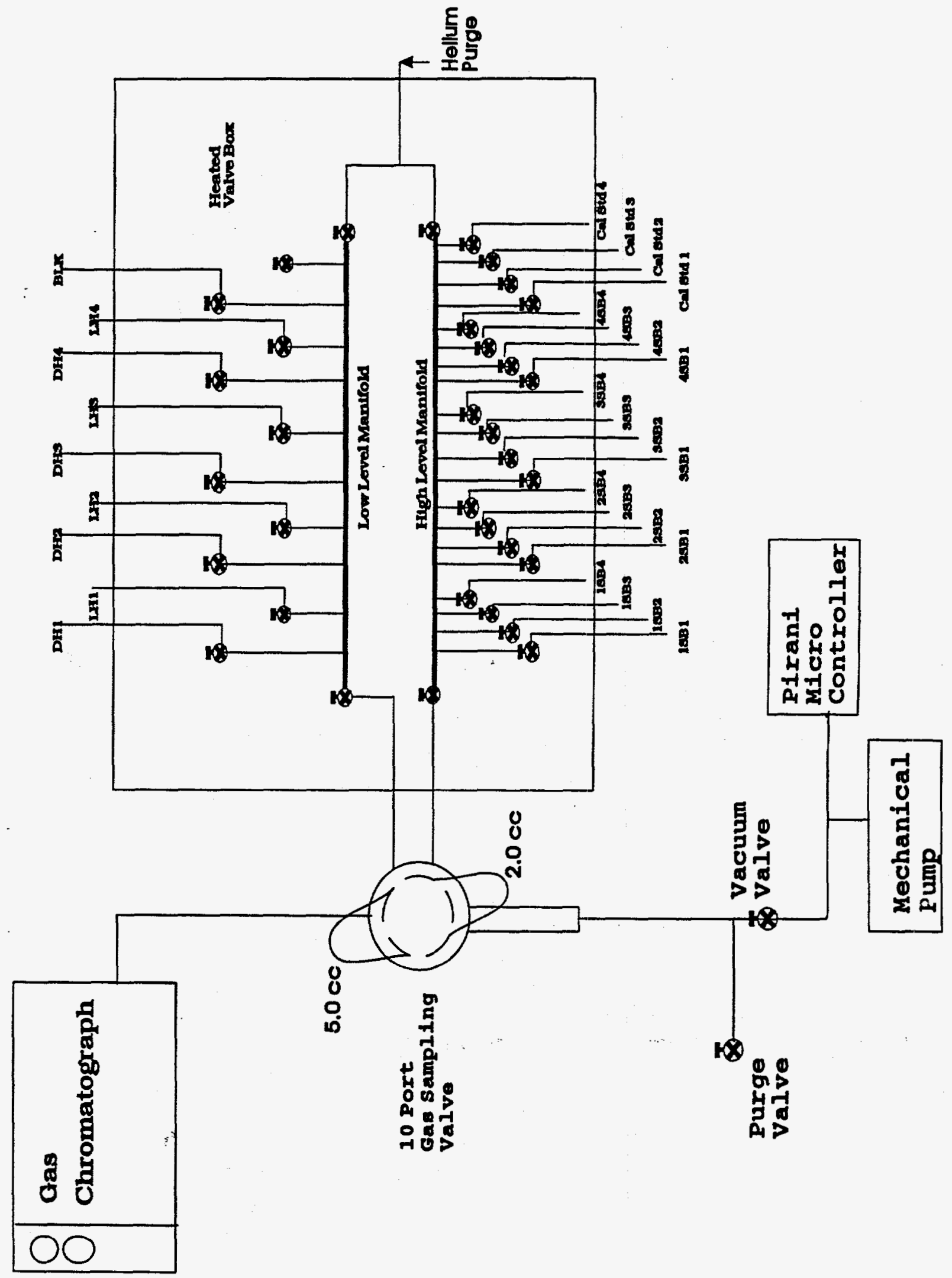

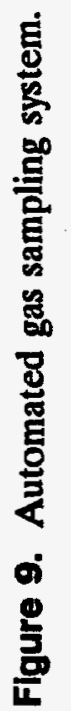




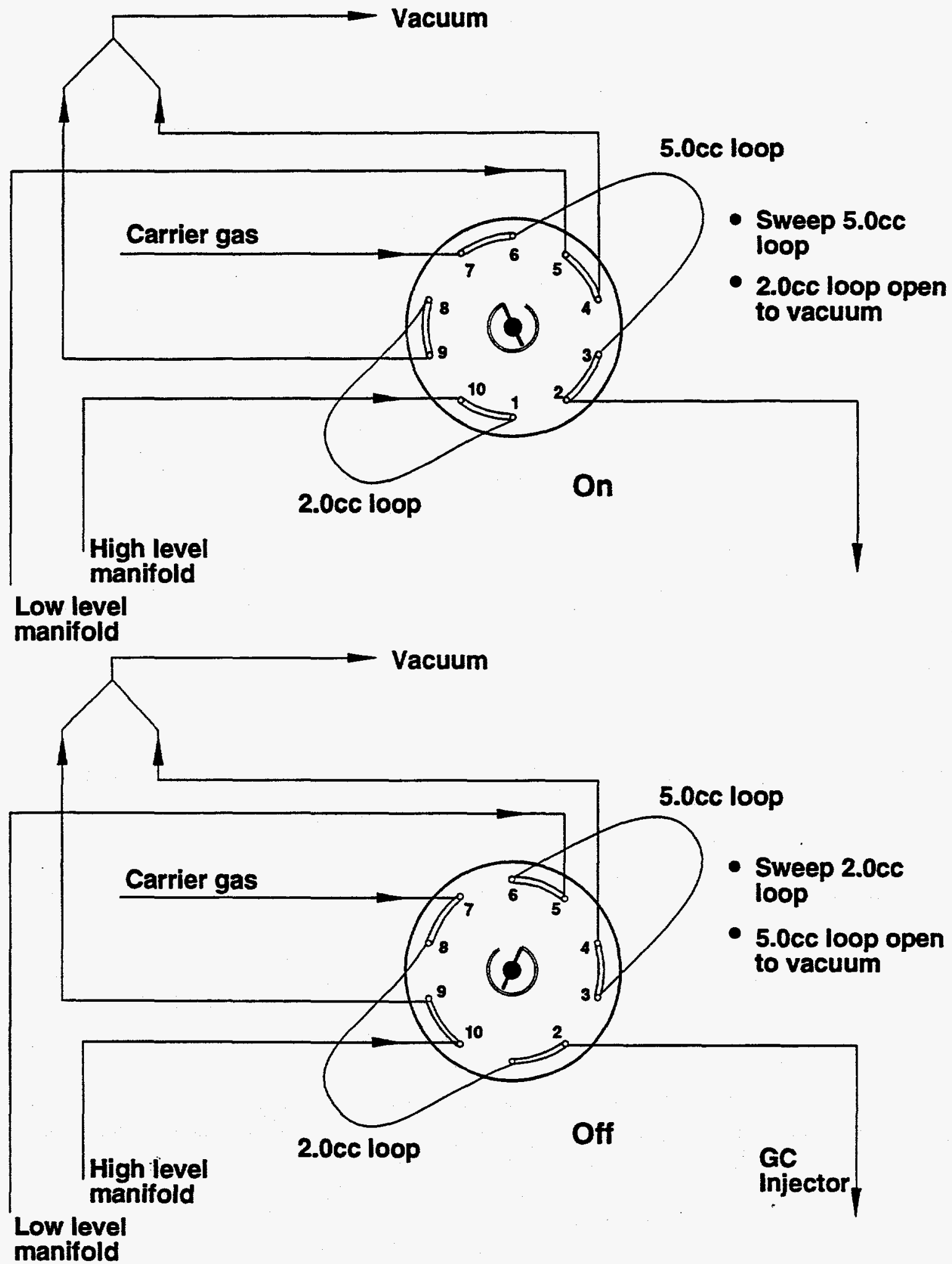

Figure 10. Configuration of 10-port gas sampling valve. 
environmental chamber between the drum lid and top to the chamber. The pneumatic needle valves were actuated by electro-pneumatic Clippard solenoids (\#ETO-3-24) controlled by the process control unit. The process control unit utilized a dedicated IBM AT personal computer operating with LabTech Notebook software, Version 7.0.0. The 16-channel multiplex temperature board (LabTech, \#CIO-EXP16) was used to provide temperature data. A 48-channel system control module (LabTech, \#CIO-DIO96) provided selection of the electro-pneumatic solenoids controlling the pneumatic needle valves. Remote start signals from the Pirani micro controller (MKS Instruments, Model 315) initiated the sampling sequence of the process control unit and began the GC run.

3.1.2.6 Standard Gas Mixtures. The gas standard mixtures used in this experiment were prepared by Alphagaz, Division of Liquid Air Corporation and Scott Specialty Gas, Incorporated with a specified analytical accuracy of $\pm 2.0 \%$. Three concentration levels of standard mixture $A$ and B were prepared by Alphagaz, as shown in Table 3. Because of the limitations of analytes condensing out of the vapor phase at higher pressures, two low pressure cylinders of standard gas mix B-I were obtained from Alphagaz. Additional standard gas be prepared to meet experimental needs and were obtained from Scott Specialty Gas. During test period I, II, III standard gas mixtures $A-I_{a}$ and $B-I_{a 1}$ were used to fill the small bags. Standard gas mixtures $A-I_{a}, A-I_{a}$, and A-III $a$ and standard gas mixtures $\mathrm{B}-\mathrm{I}_{\mathrm{a} 1}, \mathrm{~B}-\mathrm{II}_{\mathrm{a}}$, and $\mathrm{B}-\mathrm{III}_{\mathrm{a}}$ were used to establish the initial calibration curves. During test period IV standard gas mixtures $A-I_{s}$ and $B-I_{s}$ were used to fill the small poly bags. Standard gas mixtures $\mathrm{A}-\mathrm{I}_{\mathrm{s}}, \mathrm{A}-\mathrm{II}_{\mathrm{a}}$, and $\mathrm{A}-\mathrm{II}_{\mathrm{a}}$ and standard gas mixtures $\mathrm{B}-\mathrm{I}_{\mathrm{s}}$, $\mathrm{B}-\mathrm{II}_{\mathrm{a}}$, and $\mathrm{B}-\mathrm{III}_{\mathrm{a}}$ were used to establish the initial calibration curves. Standard gas mixture B-I $\mathrm{I}_{\mathrm{a}}$ was used to purge and fill the polyethylene bottles.

\subsubsection{Experimental Procedures}

3.1.3.1 Bag Preparation and Filling Procedures. The small polyethylene bags configured with 0.0625 -in. bulkhead feedthroughs were prepared and leak-tested before being placed into the simulated waste drums at the beginning of each test period. The heat-sealed polyethylene bags were cut to size (12 in. in height and 18 in. in width, with the bulkhead feedthrough $3 \mathrm{in.} \mathrm{from} \mathrm{the} \mathrm{bottom} \mathrm{of} \mathrm{the} \mathrm{bag)} \mathrm{and} \mathrm{heat-sealed.} \mathrm{The} \mathrm{horsetail} \mathrm{polyethylene} \mathrm{bags}$ were heat-sealed before being cut down to their final size (18.5 in. in height and 18 in. in width, with the bulkhead feedthrough 3 in. from the bottom of the bag). The feedthroughs were sealed with an appropriate sized septa and each bag was filled with one to two liters of air. The entire bag and feedthrough were submerged under water and firm pressure placed on the bag. If any bubbles were observed indicating a leak, the feedthroughs were removed and the bag discarded.

Each small bag sealed by the horsetail method was cut to size and sealed before being placed in the waste drum. The horsetail was formed by bunching the bag together in one hand with 6-in. of the open end of the bag protruding. The 6-in. section of bag was twisted $360^{\circ}$ once and an 8-in. piece of tape was wrapped over the entire length of the twist. The end of the horsetail was folded over and a 3-in. piece of tape was placed over the fold. As much air as possible was expelled from the small bags before being connected to gas sampling lines. After the small bags were placed inside the large poly bag along with the metal support cage, the same horsetail sealing procedure was used to seal the large bags. 
Table 3. Gas standard mixtures. ${ }^{\mathrm{a}}$

\begin{tabular}{|c|c|c|c|c|c|c|c|c|c|}
\hline Analyte & $\mathrm{A}-\mathrm{I}_{\mathrm{a}}$ & $\mathrm{A}-\mathrm{II}_{\mathrm{a}}$ & A-III & $A-I_{s}$ & $\mathrm{~B}-\mathrm{I}_{\mathrm{a} 1}$ & $\mathrm{~B}-\mathrm{I}_{\mathrm{a} 2}$ & B-II & B-III & B-I \\
\hline Methylene chloride & 1,012 & 475 & 95.2 & 1,010 & - & - & - & - & - \\
\hline Freon-113 & 903 & 451 & 91.0 & 1,010 & - & - & - & - & - \\
\hline Carbon tetrachloride & 305 & 149 & 33.9 & 301 & - & - & - & - & - \\
\hline Trichloroethylene & 310 & 153 & 35.3 & 297 & - & - & - & - & - \\
\hline 1,1,1-trichloroethane & 977 & 496 & 101 & 1,020 & 1,054 & 1,020 & 508 & 94.6 & 980 \\
\hline Methanol & - & - & - & - & 987 & 1,002 & 499 & 103 & 764 \\
\hline Cyclohexane & - & - & - & - & 787 & 777 & 377 & 71.4 & 746 \\
\hline Toluene & - & - & - & - & 425 & 421 & 211 & 39.3 & 398 \\
\hline P-xylene & - & - & - & - & 99.2 & 120 & 69 & 12.7 & 99 \\
\hline
\end{tabular}

a. A-I $\quad$ - Alphagaz high-level standard

A-II ${ }_{\mathrm{a}}$ - Alphagaz mid-level standard

A-III ${ }_{a}$ - Alphagaz low-level standard

A-Is - Scott Specialty high-level standard

B-I $\mathrm{I}_{\mathrm{a} 1}$ - Alphagaz high-level standard bottle \#1

B-I $I_{\text {a2 }}$ - Alphagaz high-level standard bottle \#2

B-II - Alphagaz mid-level standard

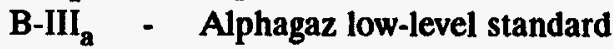

B-I s $_{\text {a }}$ - Scott Specialty Gas high level standard

Analytical accuracy $\pm 2 \%$

Balance hydrocarbon free air

All gas concentrations in ppmv. 
3.1.3.2 Introduction of Gas Mixture into Bags and Bottles. After each small bag was placed inside the drum; and the liner, and drum lids clamped into place, $4,000 \mathrm{~cm}^{3}$ of a standard gas mixture were introduced into the small bags by back-filling through the sampling manifold using a MKS mass flow controller. The capacity of the small bags was slightly larger than $4,000 \mathrm{~cm}^{3}$ so as not to generate a pressure differential across the bags. Each small bag was filled separately and all bags using the same standard gas mixture were filled sequentially.

The polyethylene bottles, which lay on their sides during the experiment, were purged and filled with standard gas mixture $B-I_{a 1}$ using the toggle valve as the purge vent. The bottles were sequentially purged with $4,000 \mathrm{~cm}^{3}$ of the standard gas mixture at a rate of $1,000 \mathrm{~cm}^{3} / \mathrm{min}$ for $4 \mathrm{~min}$. The toggle valves were closed after flow was stopped so as not to generate a pressure differential across the bottles. The bottles were allowed to equilibrate for 1 hour and then purged with an additional $15,000 \mathrm{~cm}^{3}$ liters of the standard gas mixture before being sealed off for the duration of the experiment.

3.1.3.3 Automated Sampling Sequence. The sequence for the initial calibration standards and CCS, summarized in the flow diagram in Figure 11, was initiated with the GC ready signal. The GC sequence specified the $O N$ position for the 10-port gas sampling valve with the $2.0 \mathrm{~cm}^{3}$ loop open to the high level manifold. This was coordinated with the sampling sequence file loaded onto the process controller. At the beginning of each sequence all valves were closed. At time 0 min the vacuum valve and the high manifold valve were opened to evacuate the manifold system. When pressure set point \#1 was reached $\left(1.1 \times 10^{-2}\right.$ torr $)$ and $1.5 \mathrm{~min}$ had elapsed, the vacuum valve closed and the calibration gas and vent valves were opened simultaneously. After the vacuum valve closed, pressure set point \#2 (5.2 - $5.6 \times 10^{-3}$ torr) was reached within 2 seconds starting the GC. The calibration gas valve was opened for approximately 16 seconds, while the vent valve remained open to atmosphere for an additional 20 seconds to allow the system pressure to equalize. The 10-port gas sampling valve was switched to the OFF position 30 seconds into the GC run and the $2.0 \mathrm{~cm}^{3}$ sample loop was swept to the injector. At 45 seconds all valves were closed. At $3.75 \mathrm{~min}$, the vacuum valve and the high and low manifold valves were opened to evacuate the manifold system and eliminate any sample carryover. At 10.5 min into the GC run, the 10-port gas sampling valve switched to the ON position to prepare for the next calibration sample. Total cycle time was approximately $15 \mathrm{~min}$.

The sequence for headspace sampling, summarized in the flow diagram in Figure 12, was initiated with a GC ready signal. The GC sequence specified the position of the 10-port gas sampling valve and which loop was opened to the manifold. This was coordinated with the sampling sequence file loaded in the process controller. At the beginning of each sequence all valves were closed. At time $0 \mathrm{~min}$, the vacuum valve and the selected manifold valve were opened to evacuate the manifold system. When pressure set point \#1 was reached $(1.1 \times$ $10^{-2}$ torr) and $1.5 \mathrm{~min}$ had elapsed, the vacuum valve closed and the selected sample valve was opened. After the vacuum valve closed, pressure set point \#2 (5.2-5.6 $\times 10^{-3}$ torr) was reached within 2 seconds starting the GC. The 10-port gas sampling valve was switched 30 seconds into the GC run and the sample loop was swept to the injector. At 45 seconds all valves were closed. At $2.75 \mathrm{~min}$, the vacuum valve and the high and low manifold valves were opened to evacuate the system and eliminate any sample carryover. At 10.5 min into the GC run, the 10-port gas 


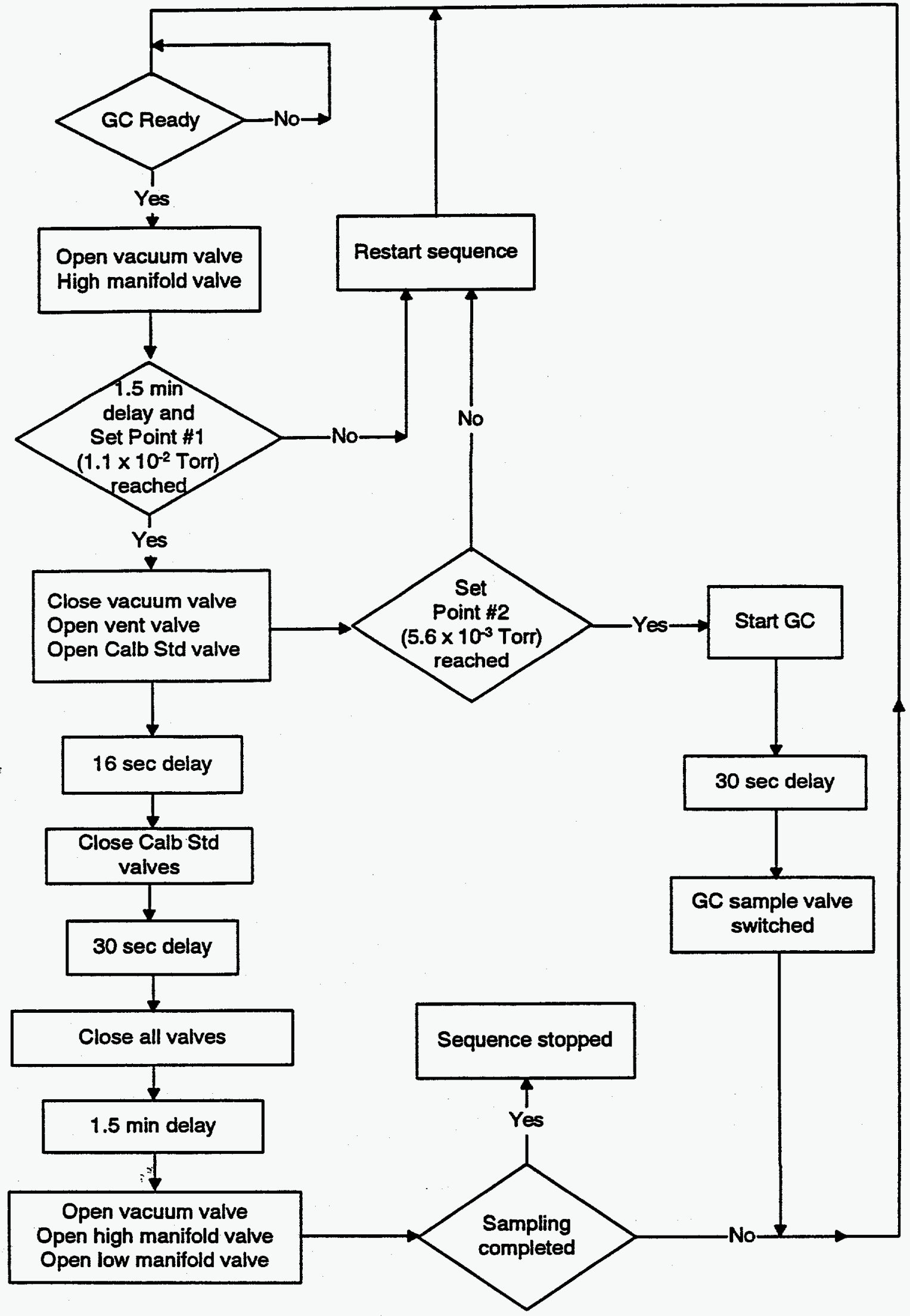

Figure 11. Automated calibration sequence. 


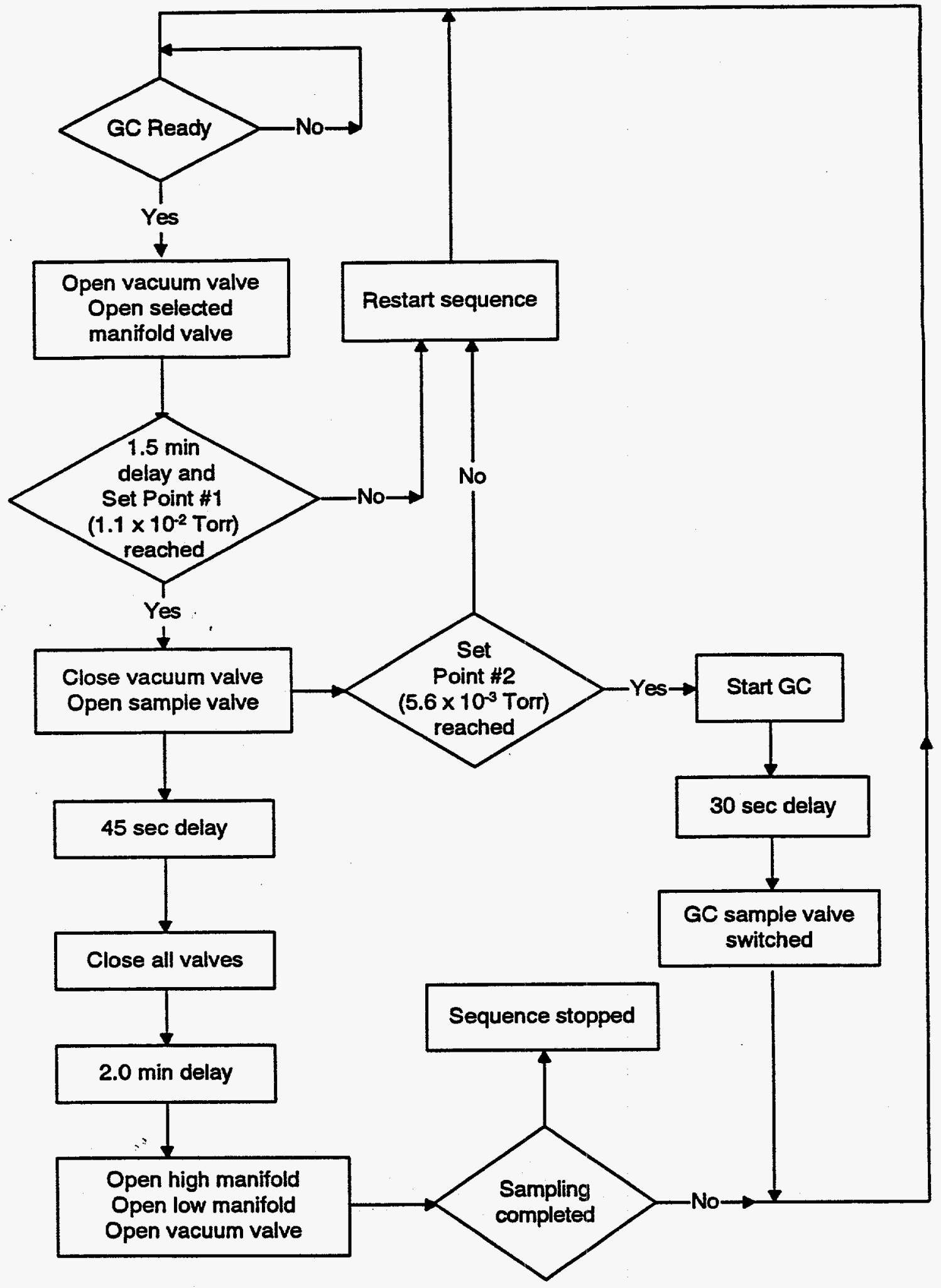

Figure 12. Automated sampling sequence. 
sampling valve switched to the sequence selected position to prepare for the next headspace sample. Total cycle time was approximately $15 \mathrm{~min}$.

3.1.3.4 Analytical Sampling Scheme. Measurements of the VOC concentrations were taken from six locations inside each simulated waste drum: the four small poly bags, the large bag headspace, and the drum headspace. Measurements of the drum headspace and liner headspace temperature in drum \#1 and the drum headspace temperature in drum \#4 were made during the entire duration of each test period. Ambient laboratory temperature was also measured. Barometric pressure measurements were made on each sampling day.

Samples were first collected from all small bags approximately 24 hrs after the bags were filled. During a 3-week period, gas samples were collected from two small bags, the large bag headspace, and drum headspace. Samples were collected every two to four days. At the end of the 3-week period, all four small bags were sampled again. The sampling scheme for the simulated waste drums is listed in Table 4. The sample identification numbers were defined by the following nomenclature. The identification number (i.e. 312-2SB1D) included the test period number (3), the sampling day (12), the drum number (2), the sampling location (DH = drum headspace, LB = large bag headspace, SB1 = small bag \#1), and the duplicate (D). A 3-point initial standard calibration was established prior to each test period. Continuing calibration standards were analyzed and evaluated against the initial calibration curve prior to samples analysis. A sample blank from the low level manifold was analyzed at the beginning of the sample sequence to determine if there were any interference or residual VOCs in the sampling system. One sample duplicate of a small poly bag was randomly selected and analyzed on each sampling day. The polyethylene bottles were filled at the beginning of test period I and sampled immediately after the final filling to establish the time zero concentrations. Each bottle was sampled on day 1 , day 21 , day 50 , day 81 and day 124 of the experiment.

\subsubsection{Quality Control}

This section defines the quality control procedures and components that were used in the performance of the VOC transfer experiments.

3.1.4.1 Quality Control Samples. Initial calibration curves, continuing calibration standards, system blanks, and sample duplicates were part of the quality control procedures used to ensure the quality of the experimental data. An initial calibration curve is defined as a curve which plots concentration of known analyte standards versus the instrument response (area counts) to the analyte. Three-point five-replicate external calibration curves were prepared for every target compound prior to the start of each test period. Continuing calibration standards are defined as analyte standards used to validate the initial calibration curve and verify system performance (retention time shifts, peak shape, etc.). The CCS analyses were performed at the beginning of each sampling day prior to sample analysis using the mid-level standard gas mixtures 
Table 4. Sampling scheme for simulated waste drums.

\begin{tabular}{|c|c|c|c|}
\hline \multicolumn{2}{|c|}{ Sample days } & \multirow[b]{2}{*}{ Drum number } & \multirow[b]{2}{*}{ Headspace sample identification number ${ }^{2}$} \\
\hline $\begin{array}{c}\text { Test periods } \\
\text { I, I, IV }\end{array}$ & $\begin{array}{c}\text { Test period } \\
\text { III }\end{array}$ & & \\
\hline \multirow[t]{4}{*}{2} & 2 & 1 & $\mathrm{X02-1SB1,} \mathrm{X02-1SB2,} \mathrm{X02-1SB3,} \mathrm{X02-1SB4}$ \\
\hline & & 2 & $\mathrm{X} 02-2 \mathrm{SB} 1, \mathrm{X} 02-2 \mathrm{SB} 2, \mathrm{X} 02-2 \mathrm{SB} 3, \mathrm{X} 02-2 \mathrm{SB} 4$ \\
\hline & & 3 & X02-3SB1, X02-3SB2, X02-3SB3, X02-3SB4 \\
\hline & & 4 & $\mathrm{X02-4SB1,} \mathrm{X02-4SB2,} \mathrm{X02-4SB3,} \mathrm{X02-4SB4}$ \\
\hline \multirow[t]{4}{*}{3} & 5 & 1 & X05-1DH, X05-1LB, X05-1SB1, X05-1SB3 \\
\hline & & 2 & X05-2DH, X05-2LB, X05-2SB1, X05-2SB2 \\
\hline & & 3 & X05-3DH, X05-3LB, X05-3SB2, X05-3SB4 \\
\hline & & 4 & X05-4DH, X05-4LB, X05-4SB2, X05-4SB3 \\
\hline \multirow[t]{4}{*}{5} & 7 & 1 & X07-1DH, X07-1LB, X07-1SB2, X07-1SB4 \\
\hline & & 2 & X07-2DH, X07-2LB, X07-2SB2, X07-2SB4 \\
\hline & & 3 & X07-3DH, X07-3LB, X07-3SB3, X07-3SB4 \\
\hline & & 4 & X07-4DH, X07-4LB, X07-4SB1, X07-4SB4 \\
\hline \multirow[t]{4}{*}{8} & 9 & 1 & X09-1DH, X09-1LB, X09-1SB2, X09-1SB4 \\
\hline & & 2 & X09-2DH, X09-2LB, X09-2SB1, X09-2SB2 \\
\hline & & 3 & X09-3DH, X09-3LB, X09-3SB1, X09-3SB3 \\
\hline & & 4 & X09-4DH, X09-4LB, X09-4SB1, X09-4SB4 \\
\hline \multirow[t]{4}{*}{10} & 12 & 1 & X12-1DH, X12-1LB, X12-1SB1, X12-1SB2 \\
\hline & & 2 & $\mathrm{X} 12-2 \mathrm{DH}, \mathrm{X} 12-2 \mathrm{LB}, \mathrm{X12-2SB} 1, \mathrm{X} 12-2 \mathrm{SB} 4$ \\
\hline & & 3 & X12-3DH, X12-3LB, X12-3SB1, X12-3SB4 \\
\hline & & 4 & X12-4DH, X12-4LB, X12-4SB1, X12-4SB2 \\
\hline \multirow[t]{4}{*}{12} & 14 & 1 & X14-1DH, X14-1LB, X14-1SB2, X14-1SB4 \\
\hline & & 2 & X14-2DH, X14-2LB, X14-2SB2, X14-2SB3 \\
\hline & & 3 & X14-3DH, X14-3LB, X14-3SB2, X14-3SB3 \\
\hline & & 4 & X14-4DH, X14-4LB, X14-4SB1, X14-4SB4 \\
\hline
\end{tabular}

a. Sample identification number (example 105-3SB2)

1-Test period number; 05-Sample day; 3-Drum number

SB2-Small bag \#2 (DH-Drum head space; LB-Large bag). 
Table 4. (continued).

\begin{tabular}{|c|c|c|c|}
\hline \multicolumn{2}{|c|}{ Sample days } & \multirow[b]{2}{*}{ Drum number } & \multirow[b]{2}{*}{ Headspace sample identification number ${ }^{\mathrm{a}}$} \\
\hline $\begin{array}{l}\text { Test periods } \\
\text { I, II, IV }\end{array}$ & $\begin{array}{c}\text { Test period } \\
\text { III }\end{array}$ & & \\
\hline \multirow[t]{4}{*}{16} & 16 & 1 & X16-1DH, X16-1LB, X16-1SB3, X16-1SB4 \\
\hline & & 2 & X16-2DH, X16-2LB, X16-2SB3, X16-2SB4 \\
\hline & & 3 & X16-3DH, X16-3LB, X16-3SB1, X16-3SB3 \\
\hline & & 4 & X16-4DH, X16-4LB, X16-4SB3, X16-4SB4 \\
\hline \multirow[t]{4}{*}{19} & 19 & 1 & X19-1DH, X19-1LB, X19-1SB1, X19-1SB3 \\
\hline & & 2 & X19-2DH, X19-2LB, X19-2SB1, X19-2SB3 \\
\hline & & 3 & X19-3DH, X19-3LB, X19-3SB1, X19-3SB2 \\
\hline & & 4 & X19-4DH, X19-4LB, X19-4SB2, X19-4SB3 \\
\hline \multirow[t]{4}{*}{22} & 22 & 1 & X22-1SB1, X22-1SB2, X22-1SB3, X22-1SB4 \\
\hline & & 2 & $\mathrm{X} 22-2 \mathrm{SB} 1, \mathrm{X} 22-2 \mathrm{SB} 2, \mathrm{X} 22-2 \mathrm{SB} 3, \mathrm{X} 22-2 \mathrm{SB} 4$ \\
\hline & & 3 & X22-3SB1, X22-3SB2, X22-3SB3, X22-3SB4 \\
\hline & & 4 & X22-4SB1, X22-4SB2, X22-4SB3, X22-4SB4 \\
\hline
\end{tabular}

a. Sample identification number (example 105-3SB2)

1-Test period number; 05-Sample day; 3-Drum number

SB2-Small bag \#2 (DH-Drum head space; LB-Large bag). 
(A- $\mathrm{II}_{\mathrm{a}}$ and $\mathrm{B}-\mathrm{II}_{\mathrm{a}}$ ). The validity of the initial calibration curve was checked by calculating the percent recovery and the relative percent error for each target analyte

$$
\begin{aligned}
& \% \operatorname{Rec}=\frac{C_{c}}{C_{k}} \times 100 \\
& \% R E=\left(\frac{C_{c}}{C_{k}}-1\right) \times 100
\end{aligned}
$$

where

$$
\begin{array}{ll}
\% \mathrm{Rec} & =\text { percent recovery } \\
\% \mathrm{RE} & =\text { relative percent error } \\
\mathrm{C}_{\mathrm{C}} & =\text { calculated concentration } \\
\mathrm{C}_{\mathrm{K}} & =\text { known concentration. }
\end{array}
$$

The data were corrected for bias based on the relative percent error.

For the VOC transport experiments, a clean small polyethylene bag filled with filtered house air was attached to the low level manifold and used as a system blank. One sample duplicate of a small bag was performed each sampling day. Relative percent differences for the sample duplicate were calculated to evaluate the precision of the automated sampling and analytical system.

The relative percent difference is defined as

$$
R P D=\frac{C_{s}-C_{D}}{C_{s}+C_{D}} \times 200
$$

where

$$
\begin{array}{lll}
\mathrm{RPD} & =\text { relative percent difference } \\
\mathrm{C}_{\mathrm{s}} & = & \text { sample concentration } \\
\mathrm{C}_{\mathrm{D}} & = & \text { duplicate concentration. }
\end{array}
$$


3.1.4.2 Other Quality Control Components. Additional baseline checks were performed to ensure that the system performed as designed.

- The process controller block configuration controlling the Clippard pneumatic solenoids was checked to verify that when a valve was actuated the valve did open and close as specified.

- Sequential timing was verified to allow quantitative sample transfer prior to any sample analysis.

- The maximum attainable vacuum for the vacuums and open manifold system were determined. Pressure set points \#1 and \#2 were based on those determinations and were modified slightly as needed to ensure the correct sequencing.

- The leak rate of the manifold system was determined and found to be within experimental parameters.

- The temperature thermocouples were standardized using a calibrated thermocouple and Fluke $52 \mathrm{~K} / \mathrm{J}$ thermometer. At the beginning of each test period and randomly throughout the experiments the temperatures of the heated transfer lines and manifold valve box were checked.

- Before filling the bottles and small poly bags, the mass flow controller was calibrated using digital and bubbles flow meters.

- The small bag and bulkhead feedthroughs were prepared and leak-tested prior to being placed in the simulated waste drum. The same procedures were used for testing the large bag feedthroughs.

\subsection{VOC-Polymer Permeability Measurements}

Two methods were used for the measuring gas permeabilities. The single-component pressure change method was used to determine VOC solubility in the polyethylene bag. The mixed-component chromatography detection method was used to determine individual VOC permeability across polyethylene bag.

\subsubsection{Single-Component Pressure Change Method}

A schematic of the single-component pressure change experimental configuration is shown in Figure 13. A fully automated membrane cell and gas valving system with pressure transducers was used to pressurize a gas mixture on one side of a polymer film while measuring the resultant pressure increase (at constant volume) on the evacuated side of the film. ${ }^{11}$ The experimental sequence of events during data acquisition was as follows:

- Both sides of the film were evacuated to less than $10 \mathrm{um}-\mathrm{Hg}$ to de-gas the system and the polymer film. 


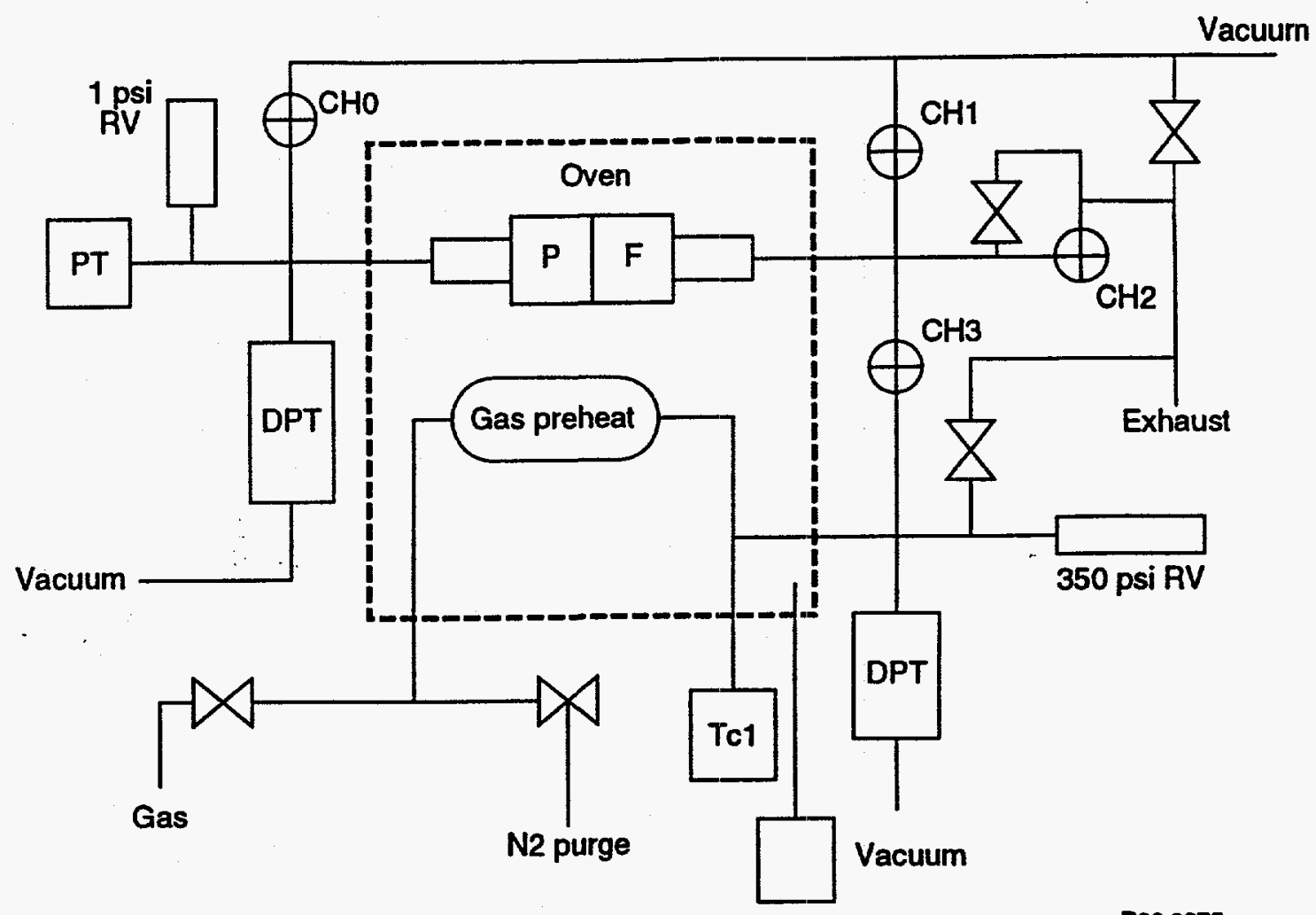

R93 0875

Figure 13. Single-component pressure change experimental configuration. 
- Baseline pressure measurements on both sides of the membrane were taken to account for potential atmospheric diffusion (via small leaks) into the system.

- The feed gas side of the film was pressurized while the other side was still essentially evacuated. Data collection occurred as the permeate transducer detected the increasing pressure due to gas permeation. Another transducer monitored the feed pressure.

- Repeat sequence 1 through 3 for the next test.

The transducers for data collection and operational valving were facilitated via an in-house PASCAL program run from an IBM AT computer. Raw data and determined values for permeability, diffusivity, and solubility were stored on a hard disk at the end of each test. A number of standard test gases (oxygen, nitrogen, argon, helium, carbon dioxide, and propane) were used on polyethylene for comparison to literature values and calibration of the instrument.

\subsubsection{Mixed-Component Chromatographic Detection Method}

A schematic of the experimental configuration used for the mixed-component chromatographic detection method is shown in Figure 14. The system consisted of two subsystems. The first subsystem involved the metered delivery of an inert sweep gas and a feed gas to opposite sides of a cell containing the membrane material. The purpose of the sweep gas was to carry permeating vapors from the permeate side of the cell to the detection system. The feed gas was operated at a differential pressure of 17 to 18 psi above the sweep side and at twice the sweep flow to provide ample permeate potential. Typical flow rates were $1.5 \mathrm{~cm} / \mathrm{min}$ for the sweep gas and $3.0 \mathrm{~cm}^{3} / \mathrm{min}$ for the feed gas. The detection system consisted of two Hewlett Packard 5800 series gas chromatographs. The first chromatograph in the series, an HP 5890 series II, contained two Restek 10454, (30 meter, $0.32 \mathrm{~mm}$ id., $1.0 \mathrm{um}$ df) columns with flame ionization detectors (FID) to determine the concentrations of the feed and permeating gases. The second chromatograph in the series, an HP 5890a, contained two CHROMPACK 007551, 25 meter, $0.32 \mathrm{~mm}$ id., Poraplot $\mathrm{Q}$ coated columns with thermal conductivity detectors (TCD) to monitor the components of the compressed air.

The following single VOC-air mixtures were tested on 0.004 -in. $(0.01-\mathrm{cm})$ polyethylene membranes: Methylene chloride at 1,006 ppmv, Freon-113 at 1,010 ppmv, 1,1,1-trichloroethane at 994 ppmv, and trichloroethylene at 300 ppmv. In addition, gas standards $\mathrm{A}-\mathrm{I}_{\mathrm{a}}, \mathrm{A}-\mathrm{III}_{\mathrm{a}}$, and B-I were used to determine VOC permeability across the polyethylene bags in VOC mixture. 


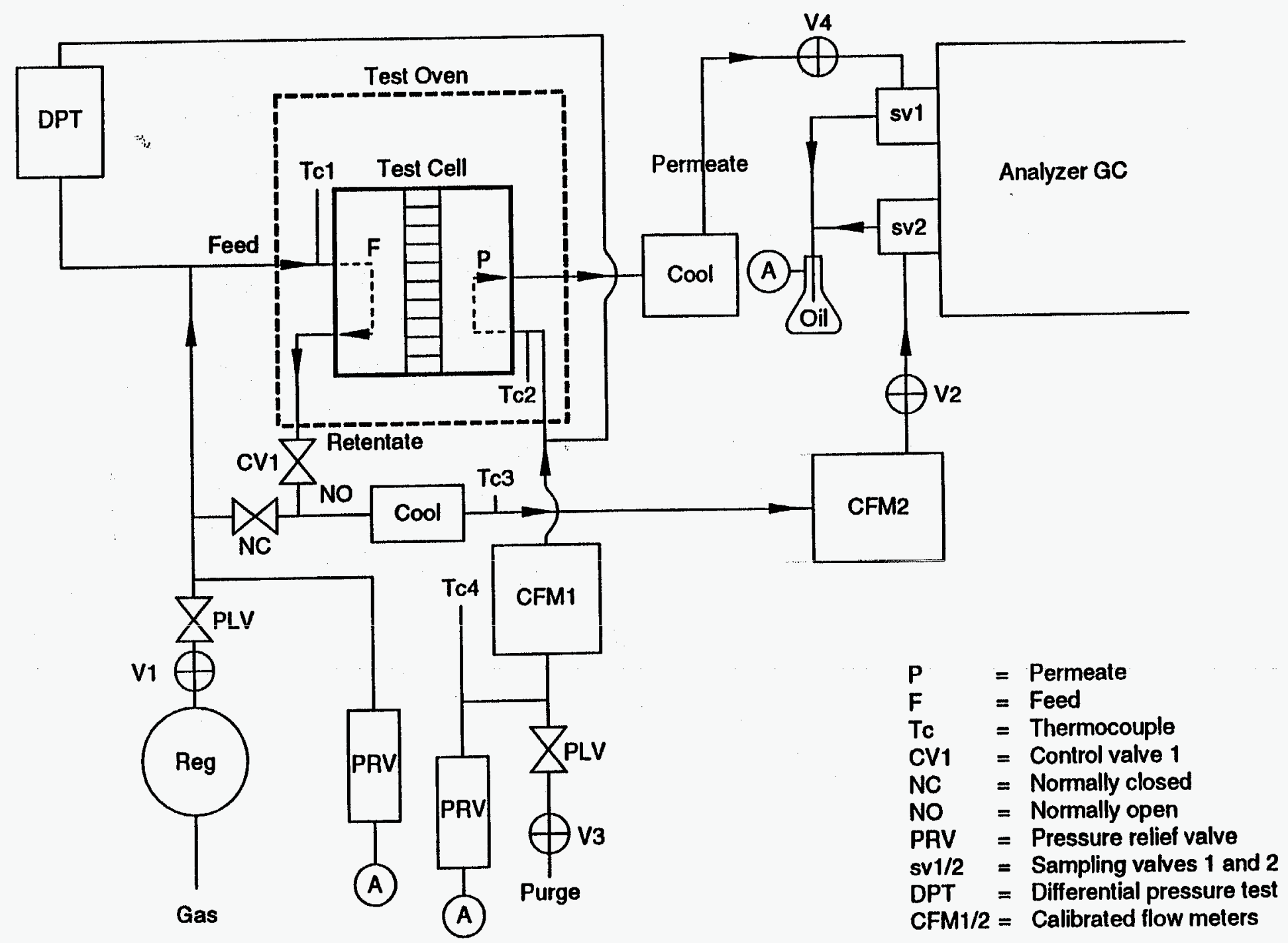

Figure 14. Mixed-component chromatographic detection method experimental configuration. 


\section{EXPERIMENTAL RESULTS AND DISCUSSION}

\subsection{VOC Transport Experiments}

The measured VOC concentrations from each laboratory-scale waste drum trial are listed in Appendix A. The measured VOC concentrations in the polyethylene bottles are listed in Appendix B. Data characterizing the initial calibration curves, continuing calibration standards, and sample duplicates are summarized in Appendix C.

The percent relative standard deviations for the initial calibration standards were typically less than $2.5 \%$ with only five exceptions. The coefficient of determination, $r^{2}$, is a measure of linearity and for most calibration curves was greater than 0.995 . The greatest difficulty was encountered with $p$-xylene. The values of $r^{2}$ for $p$-xylene ranged from 0.979 to 0.994 . The difficulty encountered with p-xylene is possibly due to its high boiling point and the possibility of cold trapping. The percent relative standard deviations and $r^{2}$ values are listed in Table C.1 in Appendix C.

The validity of the initial calibration curves were checked using continuing calibration standards. The relative percent error for the CCS analytes were within $\pm 20 \%$, with most being within $\pm 10 \%$. Mean percent errors were all within $10 \%$ with only one exception. Tables listing the relative percent error for the CCS are found in Tables C.2-C.5 in Appendix C.

Precision was assessed through the analysis of sample duplicates and expressed as the relative percent difference. The relative percent differences were generally less than $25 \%$. In test period IV, the relative percent difference for $p$-xylene on days 8 and 12 were greater than $100 \%$. This is attributed to very low sample concentrations which were significantly below the linear dynamic range established by the initial calibration curves. Outside the linear dynamic range the precision and accuracy of the data is suspect, varying as much as $\pm 30-100 \%$ from the reported value. The relative percent differences for the duplicate samples are listed in Tables C.6-C.9 in Appendix C.

The drum and large bag headspace VOC concentrations were calculated from the calibration curve extrapolated using a loop ratio of 2.5 (low level manifold uses a 5.0- $\mathrm{cm}^{3}$ sample loop and the high level manifold uses a $2.0-\mathrm{cm}^{3}$ sample loop). Upon review of the drum headspace and large bag headspace samples a possible systematic error was found in the system loop ratios. The error was apparently due to the efficiency of the sample being swept from the loop, the efficiency of the split ratio, and integration of broadened peaks. The data indicated that there was a variance in the loop ratio which varied with the analyte of interest. Low level standards A-III and B-III were randomly analyzed on each loop 5 times and their area counts were then compared. If the true loop ratio was exactly 2.5 , the area counts for the standards sampled on the $5.0 \mathrm{~cm}^{3}$ loop would be 2.5 times larger than the standards sample on the $2.0 \mathrm{~cm}^{3}$ loop. The loop ratio for standard gas mixture A-III analytes methylene chloride, Freon-113, TCA, carbon tetrachloride, and TCE were established at $2.55 \pm 0.04,2.61 \pm 0.03,2.70 \pm 0.04,2.89 \pm 0.13$, and $2.95 \pm 0.05$, respectively. The loop for standard gas mixture B-III analytes cyclohexane and TCA were established at $2.6 \pm 0.04$ and $2.6 \pm 0.02$, respectively. The methanol, toluene, and p-xylene in the 
standard gas mixture overloaded the column on the $5.0 \mathrm{~cm}^{3}$ loop, therefore an average system correction factor of 2.7 was used.

During the test periods I, II, and III samples were missed due to sample sequence errors. Samples 108-2SB2, 108-4SB4, and 108-2SB2D were missed during test period I and sample 212-3SB3 was mixed during test period II. Samples 314-3SB3, 314-4SB4, 314-2SB3D, 316-1SB4, 316-2SB4, and 319-3DH were missed during test period III.

Drums were disassembled to determined if there were any failures in the layers of confinement. The drum lid seals, drum feedthrough septa, large bag feedthrough septa, large bags, and small bags were all intact throughout all four test periods with the following exceptions. In test period I, two $1.0 \mathrm{~mm}$ holes were detected in small bag 3SB3 near the bulkhead feedthrough. A $2.0 \mathrm{~mm}$ hole was found in small bag 4SB4. The tape came undone on 4SB3 at the base of the horsetail; however, the bag was still sealed. Sample analyte concentrations from drum \#2 headspace were significantly lower than the concentration from the matching replicate sample in drum \#4 headspace. No determination could be made at the time for the discrepancy.

In test period II, two $3.0 \mathrm{~mm}$ slits were found in small bag 1SB4. The tape on the large bag horsetail drum \#3 came undone and the horsetail unraveled, but the small piece of tape folded over the end of the horsetail did stay in place. Sample concentrations from drum \#2 headspace again were significantly lower than the sample concentration from the matching replicate drum \#.4 headspace. It was determined that the sample transfer line was partially blocked and was replaced.

In test period III, the horsetail on 3 SB1 and the large poly bags from drums \#3 and \#4 were open at the top but were still sealed at the base. Small poly bag 4SB3 was flat and appeared not have been filled with the standard gas mixture. In test period IV, the horsetail on 2SB1 was open at the top but still sealed at the base. The thermocouple probe for drum \#4 was not placed in the drum; thus, there was an 0.125 -in. hole in the side of the drum.

\subsection{VOC-Polymer Permeability Measurements}

\subsubsection{Single-Component Pressure Change Method}

The gas mixture solubility in the polyethylene bag was determined using the single-component pressure change method. The gas mixture solubility is defined as:

$$
\begin{aligned}
S_{m} & =\frac{P_{m}}{D_{m}} \\
\mathrm{~S}_{\mathrm{m}} & =\text { gas solubility in polymer, } \mathrm{cm}^{3}(\mathrm{STP})\left(\mathrm{cm}^{-3} \text { polymer }\right)(\mathrm{cm} \mathrm{Hg})^{-1} \\
P_{\mathrm{m}} & =\text { gas permeability in polymer, } \mathrm{cm}^{3}(\mathrm{STP}) \mathrm{cm} \mathrm{cm}^{-2} \mathrm{~s}^{-1}(\mathrm{~cm} \mathrm{Hg})^{-1}
\end{aligned}
$$




$$
D_{m}=\text { gas diffusivity in polymer, } \mathrm{cm}^{-2} \mathrm{~s}^{-1}
$$

The values of $P_{m}$ and $D_{m}$ were experimentally determined. Gas permeability in a polymer was calculated using experimental data.

$$
P_{m}=\frac{P_{2}^{\prime} V_{2} L T_{s}}{T P_{1} A P_{s}}
$$

where

$$
\begin{aligned}
& P_{2}^{\prime}=\text { experimental rate of change in pressure on permeate side of test cell }(\mathrm{cm} H g) \mathrm{s}^{-1} \\
& V_{2}=\text { permeate volume, } \mathrm{cm}^{3} \\
& T=\text { experimental temperature, } \mathrm{K} \\
& P_{1}=\text { feed gas pressure, } \mathrm{cm} \mathrm{Hg} \\
& \mathrm{A}=\text { membrane surface area, } \mathrm{cm}^{2} \\
& \mathrm{~L}=\text { membrane thickness, } \mathrm{cm} \\
& T_{S}=\text { standard temperature, } \mathrm{K} \\
& \mathrm{P}_{\mathrm{S}}=\text { standard pressure, } \mathrm{cm} \mathrm{Hg} .
\end{aligned}
$$

and gas diffusivity in the polymer was calculated as

$$
D_{m}=\frac{L^{2}}{6 T_{l}}
$$

where

$$
\mathrm{T}_{1} \quad=\quad \text { time lag, } \mathrm{s}
$$

Permeabilities, diffusivities, and solubilities for the VOC-air mixtures on the polyethylene bag are listed in Table 5. The permeabilities of the single component mixtures in air were indistinguishable from compressed air alone as a result of the low sensitivity of the pressure swing method. The detection limit of this method was approximately $1 \%$ by volume. Permeabilities determined by the pure gas methods were composite permeabilities for the gas mixture. The 
Table 5. Permeability, diffusivity and solubility of VOC-air mixtures in yellow polyethylene bag.

\begin{tabular}{lccc}
\hline \multicolumn{1}{c}{ Test gas } & $\begin{array}{c}\text { Permeability } \\
(\mathrm{Ba})\end{array}$ & $\begin{array}{c}\text { Diffusivity } \\
\left(\mathrm{cm}^{2} \mathrm{~s}^{-1} \times 10^{7}\right)\end{array}$ & $\begin{array}{c}\text { Solubility } \\
{\left[\mathrm{cm}^{3}\left(\mathrm{~cm}^{-3}\right.\right.} \\
\text { polymer }) \\
\left(\mathrm{cm} \mathrm{Hg}^{-1} \times 10^{4}\right]\end{array}$ \\
\hline $\begin{array}{l}\text { 300 ppmv trichloroethylene in } \\
\text { air }\end{array}$ & $1.62 \pm 0.15$ & $9.39 \pm 1.37$ & $1.7 \pm 0.3$ \\
$\begin{array}{l}1,006 \text { ppmv methylene chloride } \\
\text { in air }\end{array}$ & $1.74 \pm 0.04$ & $5.94 \pm 0.58$ & $3.0 \pm 0.3$ \\
994 ppmv trichloroethane in air & $1.64 \pm 0.04$ & $6.81 \pm 0.92$ & $2.2 \pm 0.3$ \\
1,010 ppmv Freon-113 in air & $1.64 \pm 0.06$ & $7.86 \pm 0.84$ & $2.1 \pm 0.3$ \\
\hline
\end{tabular}

permeability is a function of all gases in the mixture and should not be expected to represent any single component of the mixture.

\subsubsection{Mixed-Component Chromatographic Detection Method}

The permeability of specific VOC in a VOC-air mixture were determined via the mixed-component chromatographic detection method. The VOC permeability was calculated from Equation 23.

$$
\rho=\frac{\Delta V_{g} T_{s} P_{2} L}{\Delta t_{\exp } T P_{s} A \Delta P_{g}}
$$

where

$$
\begin{aligned}
& \Delta V_{g}=\text { partial volume of the permeating species in the flow, } \mathrm{cm}^{3} \\
& \Delta P_{g} \quad=\text { partial pressure differential of the permeating species across the membrane, } \mathrm{cm} \mathrm{Hg} \\
& \Delta \mathrm{t}_{\text {exp }}=\text { time for partial volume flow under experimental condition, s } \\
& P_{2} \quad=\text { pressure on permeate side of the membrane, } \mathrm{cm} \mathrm{Hg}
\end{aligned}
$$

The partial volume of a particular gas was determined by multiplying the total volume of the bulk permeate by percent volume gas concentration in the bulk flow.

The calculated permeabilities assumed an ideal case of noninteracting-noncompeting gases. Actual interactions of various gases (i.e., the competition or co-solubility) in a mixture are difficult: to assess. Calculated VOC permeabilities for different VOC-air mixtures are listed in Table 6. 
Table 6. Measured VOC permeability from mixed-component chromatographic detection method.

\begin{tabular}{|c|c|c|c|}
\hline \multirow[b]{2}{*}{ VOC } & \multicolumn{2}{|c|}{ Multiple VOC-air mixtures } & \multirow{2}{*}{$\begin{array}{c}\text { Single VOC-air mixture } \\
\text { (Ba) }\end{array}$} \\
\hline & $\begin{array}{l}A-I_{a} \\
(B a)^{a}\end{array}$ & $\begin{array}{c}\mathrm{A}-\mathrm{III}_{\mathrm{a}} \\
(\mathrm{Ba})\end{array}$ & \\
\hline Methylene chloride & $244 \pm 37$ & $313 \pm 21$ & $232 \pm 15^{b}$ \\
\hline Freon-113 & $27.4 \pm 2.6$ & $54 \pm 8.0$ & $34.3 \pm 1.3^{c}$ \\
\hline 1,1,1-trichloroethane & $138 \pm 15$ & $209 \pm 14$ & $83.1 \pm 3.4^{d}$ \\
\hline Carbon tetrachloride & $224 \pm 16$ & $161 \pm 49$ & $-\mathbf{e}$ \\
\hline Trichloroethylene & $779 \pm 40$ & $311 \pm 22$ & $660 \pm 15^{f}$ \\
\hline \multicolumn{4}{|c|}{ a. $\mathrm{Ba}=10^{-10} \mathrm{~cm}^{3}(\mathrm{STP}) \mathrm{cm} \mathrm{cm}^{-2} \mathrm{~s}^{-1}(\mathrm{~cm} \mathrm{Hg})^{-1}$. } \\
\hline \multicolumn{4}{|c|}{ b. $1,006 \mathrm{ppmv}$ methylene chloride in air. } \\
\hline \multicolumn{4}{|c|}{ c. 1,010 ppmv Freon-113 in air. } \\
\hline \multicolumn{4}{|c|}{ d. 994 ppmv 1,1,1-trichloroethane in air. } \\
\hline \multicolumn{4}{|l|}{ e. Not measured. } \\
\hline f. 300 ppmv trichloroet & & & \\
\hline
\end{tabular}

The permeabilities varied depending upon whether the test gas contained a single VOC or a mixture of VOCs. Examination of the measured permeabilities for the gases at high and low VOC concentration showed some differences in the values. The difference may be the result that one or more of the VOCs may act as a plasticizer. This phenomenon needs to be investigated further.

During the experiment, the time required for the permeate to reach a steady state increased with the increased boiling point of the gaseous component of interest. A system limitation was identified to be the plumbing external to the permeation cell. Transfer lines and valving for the current system provided excessive dead-space and were operated at ambient temperature ( 23 to $28^{\circ} \mathrm{C}$ ). Thus, it was difficult to obtain an equilibrium measurement for gases with boiling points above the 75 to $80^{\circ} \mathrm{C}$ range. Gases such as toluene (b.p. $111^{\circ} \mathrm{C}$ ) and p-xylene (b.p. $135^{\circ} \mathrm{C}$ ) in gas standard B-I $\mathrm{I}_{1 \mathrm{a}}$ were generally not equilibrated within a 24 -hour period. Permeabilities for VOC constituents in gas standard $\mathrm{B}-\mathrm{I}_{1 \mathrm{a}}$ were not determined because it was not possible to obtain a steady-state measurement in the current system. These data will have to be measured when the system is redesigned to eliminate or reduce the deadspace. 
Deviations presented in the tables are a measure of reproducibility and not of accuracy.

Reasons for the observed variance lie in the difficulty of comparing chromatographic peaks, which differed by as much as an order of magnitude. Additional studies involving concentration and temperature profiles of single and multi-component mixtures should yield a better understanding of the conditions affecting the gas permeabilities. Slow equilibration can be overcome by redesigning the system to incorporate most of the plumbing and valving in a temperature-controlled oven. External lines that cannot be placed in the oven must be wrapped in heat tape and held above ambient temperature to inhibit surface binding of low-volatility components. 


\section{MODEL RESULTS AND DISCUSSION}

The model equations presented in Section 2 were solved to estimate the VOC concentration as a function of time for those experiments where the VOC permeability was measured. Thus, model calculations of the waste drum and polyethylene bottle VOC transport experiments that used gas standard B-I are not presented in this report.

\subsection{Model Parameter Determination}

Many model parameters were measured or estimated from available process information. Other parameters that were not measured directly were estimated using the VOC transport model and lab-scale waste drum data from Trial 2.3. This trial was used because the drum temperature was constant and no leaks were identified in the small bags. Model parameters determined in this fashion were used in all other model calculations.

Model input included specifying the total surface area, diffusional area, void volume, bag thickness, and diffusional pathway length for small and large bags. Although every effort was made to prepare four small bags that were identical, occasionally one small bag was different from the other bags. In several experiments one small bag had a puncture in it, and in another experiment a small bag was unintentionally not filled with a gas mixture. Thus, the program was written to require model input for two small bags. One set of parameters specified bag parameters for three small bags assumed to be identical. The other set of parameters pertained to the fourth small bag. If all four small bags were identical, then the model parameters for the two small bags were identical.

\subsubsection{Surface Areas}

5.1.1.1 Permeable Area. The dimensions of the heat-sealed bags were 11 in. $(27.9 \mathrm{~cm})$ by 18 in. $(45.7 \mathrm{~cm})$. The total bag surface area was $400.0 \mathrm{in}^{2}\left(2,550 \mathrm{~cm}^{2}\right)$. In the case of the small bags sealed with horsetails, the horsetail base was between generally 11 and 12 in. (27.9 and $30.5 \mathrm{~cm}$ ) from the bottom of the bag. In addition, approximately $1 \mathrm{in}$. $(2.5 \mathrm{~cm})$ of bag material was bunched together very closely below the horsetail. The total surface area of a small bag was estimated to be $400.0 \mathrm{in}^{2}\left(2,550 \mathrm{~cm}^{2}\right)$. The large-bag dimensions before closure by horsetail were 33 in. $(83.8 \mathrm{~cm})$ wide and 36 in. $(91.4 \mathrm{~cm})$ long. Allowing for approximately 6 in. $(15.2 \mathrm{~cm})$ in length, the maximum surface area of the large bag was estimated to be 1,980 in. $^{2}\left(12,800 \mathrm{~cm}^{2}\right)$.

The actual bag surface area available for permeation is less than the total bag surface area. Small bags in intimate contact with each other, contact between small bags and the large bag, the large bag resting on the drum liner floor, and the overlapping and folding of the bags near the horsetail all decrease the total available surface area. The actual surface area of each bag in each drum could not be measured. For the lab-scale waste drums, the total permeable bag surface area was estimated to be $50 \%$ of the total bag surface area. The percentage of total bag surface area available to VOC permeation was estimated to the nearest $25 \%$.

5.1.1.2 Diffusional Area. The cross-sectional diffusional area of a horsetail was estimated to be 0.002 in. $^{2}\left(0.01 \mathrm{~cm}^{2}\right)$. Holes and slits observed in small bags upon removal from the drum 
were measured between 0.04 and $0.12 \mathrm{in} .(0.1$ and $0.3 \mathrm{~cm})$ in length. The diffusional area of a hole in a small bag was estimated in the model to be $0.005 \mathrm{in}^{2}\left(0.03 \mathrm{~cm}^{2}\right)$. The cross-sectional area of the hole punched in the lid of the drum liner is 0.11 in. $^{2}\left(0.71 \mathrm{~cm}^{2}\right)$.

\subsubsection{Transport Lengths}

All bags have a thickness of 0.004 in. $(0.01 \mathrm{~cm})$. The drum liner has a thickness of 0.090 in. $(0.23 \mathrm{~cm})$. Horsetail lengths of $6 \mathrm{in} .(15.2 \mathrm{~cm})$ were assumed. Model input for the diffusional length between drum liner and drum headspace void volumes was $0.47 \mathrm{in}$. $(1.18 \mathrm{~cm})$. Diffusion lengths across small bag punctures was estimated to be 0.17 in. $(0.43 \mathrm{~cm})$.

\subsubsection{Void and Polymer Volumes}

The small bags have an approximate internal volume of 240 in. $^{3}\left(4,000 \mathrm{~cm}^{3}\right)$. Small bags with small holes were observed to be partially filled at the end of the test period. The bag volume could not be estimated due to extensive handling upon removal from the drum. Small bags with a visible puncture or tear were assumed to have a bag volume of approximately 120 in. $^{3}$ $\left(2,000 \mathrm{~cm}^{3}\right)$. A metal cage was placed inside the large bag before drum closure to assure that the shape of the bag was similar in each drum. The cage has a diameter of 18.6 in. $(47.3 \mathrm{~cm})$ and a height of $8.1 \mathrm{in} .(20.6 \mathrm{~cm})$. The final shape of the large bag was assumed to be a cylinder with a height $1 \mathrm{in} .(2.5 \mathrm{~cm})$ and a diameter $2 \mathrm{in.}(5.1 \mathrm{~cm})$ greater than that of the support cage. The internal volume of the large bag is estimated to be $3,050 \mathrm{in}^{3}\left(50,000 \mathrm{~cm}^{3}\right)$. Large bag void volume was the difference between the total estimated internal volume of the large bag and the total volume of the small bags.

The total volume of the lab-scale drum liner and drum were determined by weighing the mass of water that each container could hold. The total volume of the drum liner was determined to be approximately $3,800 \mathrm{in}^{3}\left(62,000 \mathrm{~cm}^{3}\right)$. Thus, the void volume inside the drum liner containing the large and small bags was estimated to be 730 in. $^{3}\left(12,000 \mathrm{~cm}^{3}\right)$. The total void volume of the drum headspace outside the drum liner was determined to be approximately 980 in. ${ }^{3}\left(16,000 \mathrm{~cm}^{3}\right)$. The polyethylene bottles have a norninal void volume of $240 \mathrm{in}^{3}$ $\left(4,000 \mathrm{~cm}^{3}\right)$.

The total polymer volume was calculated as the product of the total surface area of the polymer and the polymer thickness. The volume of any horsetail or bag edges was neglected.

\subsubsection{VOC Transport Properties}

5.1.4.1 VOC Permeability. The smaller value of the permeability coefficients for each VOC in gas mixture A listed in Table 6 was used in model calculations. 
5.1.4.2 VOC Solubility in Polymers. The gas solubility for each VOC in gas mixture A are summarized in Table 7. Gas solubility in the polymer during the experiment was estimated using Henry's law

$$
s=\frac{c_{v o c}}{H_{s}}
$$

where

$$
\begin{aligned}
& \mathrm{s}=\text { gas solubility, } \mathrm{cm}^{3}(\mathrm{STP})\left(\mathrm{cm}^{-3} \text { polymer }\right)(\mathrm{cm} \mathrm{Hg})^{-1} \\
& \mathrm{c}=\text { VOC concentration in gas phase, mol cm}{ }^{-3} \\
& \mathrm{H}_{\mathrm{s}}=\text { Henry's constant }=\mathrm{c}_{\mathrm{o}} / \mathrm{s}_{\mathrm{o}} \\
& \mathrm{s}_{\mathrm{o}}=\text { gas solubility at VOC concentration } \mathrm{c}_{\mathrm{o}}, \mathrm{cm}^{3}(\mathrm{STP})\left(\mathrm{cm}^{-3} \text { polymer }\right)(\mathrm{cm} \mathrm{Hg})^{-1} .
\end{aligned}
$$

Permeability experiments to determine the gas solubility in the drum liner could not be performed because the drum liner wall thickness was too great. Gas solubility in the polyethylene drum liner was estimated using the values in Table 5. In the case of carbon tetrachloride, an approximation of the VOC solubility in polyethylene was estimated using lab-scale results from Trial 2.3 and the VOC transport model. The solubility of 1,000 ppmv carbon tetrachloride in air at $77^{\circ} \mathrm{F}\left(25^{\circ} \mathrm{C}\right)$ in the polyethylene drum liner was estimated to be $3.3 \times 10^{-4} \mathrm{~cm}^{3}(\mathrm{STP})\left(\mathrm{cm}^{-3}\right.$ polymer) $\left(\mathrm{cm} \mathrm{Hg}^{-1}\right.$.

5.1.4.3 Transfer Coefficient $\eta$. The transfer coefficient in Equation (3) defines the rate of VOC uptake in a polymer film. The values for each VOC were determined using the experimental data from Trial 2.3 and are summarized in Table 7.

5.1.4.4 VOC-Air Diffusivity. The diffusivity of most VOCs in air at a given temperature and pressure were identified in the literature. ${ }^{10}$ In the case where diffusivity data could not be identified, the VOC diffusivity in air was estimated using Equation (16). Equation (16) was also used to correct for any difference in temperature and pressure observed in the experiments.

5.1.4.5 $\mathrm{H}_{2}$ Diffusion Characteristic across Carbon Composite Filter. The $\mathrm{H}_{2}$ diffusion characteristic across a NFT-020 carbon composite filter was reported to be $44 \times 10^{-7} \mathrm{~mol} \mathrm{~s}^{-1}$ (mol fraction) ${ }^{-1}$ at $77^{\circ} \mathrm{F}\left(25^{\circ} \mathrm{C}\right) .^{7}$

\subsubsection{Initial VOC Concentrations}

Initial VOC concentration in the small bags was assumed to be equal to the concentration of the feed gas mixture and zero in all other void volumes unless a small bag was punctured. In that case, the small bag was assumed to contain only $120 \mathrm{in}^{3}\left(2,000 \mathrm{~cm}^{3}\right)$ of the 240 in. $^{3}\left(4,000 \mathrm{~cm}^{3}\right)$ of the gas mixture introduced in the bag. The initial large bag VOC concentration was calculated as the number of VOC moles introduced into the large bag divided by the large bag void volume. 
Table 7. VOC transfer coefficients used in Equation (3).

\begin{tabular}{ll}
\hline VOC & $\eta, \sec ^{-1}$ \\
\hline Methylene chloride & $1 \times 10^{-6}$ \\
Freon-113 & $8 \times 10^{-7}$ \\
Trichloroethane & $4 \times 10^{-6}$ \\
Carbon tetrachloride & $8 \times 10^{-6}$ \\
Trichloroethylene & $4 \times 10^{-6}$ \\
\hline
\end{tabular}

\subsubsection{Temperature and Pressure}

Two waste drums were placed in an environmental chamber to simulate the heating and cooling of waste drums that occur as the result of changes in environmental conditions. The daily temperature in the drum and drum liner headspace of these drums varied as a function of time. In order to simplify model calculations, equations defining, the measured temperature as a function of time was determined for each void volume by performing a nonlinear regression. analysis of the recorded temperature data. The equations estimating actual temperatures at a given time were accurate within $0.9^{\circ} \mathrm{F}\left(0.5^{\circ} \mathrm{C}\right)$. The first day of each test period began at $\mathbf{t}=\mathbf{0} \mathrm{sec}$ after all small bags were filled. All waste drums were at room temperature when the small bags were filled. The heating cycle began and ended at $t_{1}$ and $t_{2}$ seconds, respectively. The heating cycle lasted approximately four hours, or 14,400 seconds. In the case of $t_{1}<t<t_{2}$, the time-dependent nature of the measured temperature in the drum headspace was described by the equation

$$
T_{d h}\left({ }^{o} C\right)=25.3899+20.345\left(1-e^{-1.22 \times 10^{-4}\left[t-t_{1}+797.7\right]}\right)
$$

and the measured drum liner headspace temperature was described by the equation

$$
T_{d l}\left({ }^{\circ} C\right)=24.4287+22.2311\left(1-e^{-1.014 \times 10^{-4}\left[t-t_{1}+723.29\right]}\right) \text {. }
$$

During the cooldown period $\left(t>t_{2}\right)$, the temperature in the drum headspace was described by the equation

$$
T_{d h}\left({ }^{\circ} C\right)=27.4542+41.456 e^{-8.451 \times 10^{-5}\left[t-t_{2}+11583.4\right]},
$$

and the drum liner headspace temperature was described by the equation 


$$
T_{d l}\left({ }^{o} C\right)=26.5389+31.320 e^{-8.174 \times 10^{-5}\left[t-t_{2}+8370.18\right]} .
$$

After each 24-hour period, $t$ was reset to zero. The temperature in the waste drum continued to cool until the heat cycle was reinitiated. In the case of $t<t_{1}$ (for all days except the first), the temperature in the drum headspace was described by the equation

$$
T_{d h}\left({ }^{o} C\right)=27.4542+41.456 e^{-8.451 \times 10^{-5}\left[t-t_{2}+97983.4\right]},
$$

and the drum liner headspace temperature was described by the equation

$$
T_{d l}\left({ }^{\circ} C\right)=26.5389+31.320 e^{-8.174 \times 10^{-5}\left[t-t_{2}+94,770.2\right]} .
$$

The temperatures inside the large and small bags were not measured and were assumed to be the same as the drum liner headspace temperature.

The temperature in the drum headspace of a lab-scale waste drum maintained at ambient room temperature varied between 75.2 and $77.9^{\circ} \mathrm{F}\left(24\right.$ and $\left.25.5^{\circ} \mathrm{C}\right)$ during all trials. A constant temperature of $76.5^{\circ} \mathrm{F}\left(24.7^{\circ} \mathrm{C}\right)$ was used in model calculations for the waste drums maintained at room temperature. The ambient pressure varied between 638.0 and 651.5 torr during the experiments. A constant pressure of 644.8 torr was used in all model calculations.

\subsection{Model Results}

The VOC transport model was used to estimate the VOC concentration within lab-scale waste drums as a function of time. Model calculations were performed using a computer program listed in Appendix D. The program used IMSL subroutines to solve a series of first-order differential equations. The program was run on a CRAY X-MP 216 supercomputer. Model predictions of the first measured small bag concentration were made at the approximate hour the samples were collected. All other model results are calculated at 24-hour intervals. Model input and output listing the predicted VOC concentration in the small bags, large bag, and drum headspace void volumes for all trial using gas mixture $A$ are tabulated in Appendix $E$.

\subsubsection{Model Accuracy}

Some examples of model predictions of VOC concentrations in small bag void volumes in lab-scale waste drums maintained under different thermal environments are shown in Figures 15 and 16. Examples of model predictions of VOC concentrations in the large bag void volumes maintained under different thermal environments are shown in Figures 17 and 18. In each figure, a continuous function was defined that estimated the time dependence of predicted VOC concentrations during the experiment. Model values are also shown. 


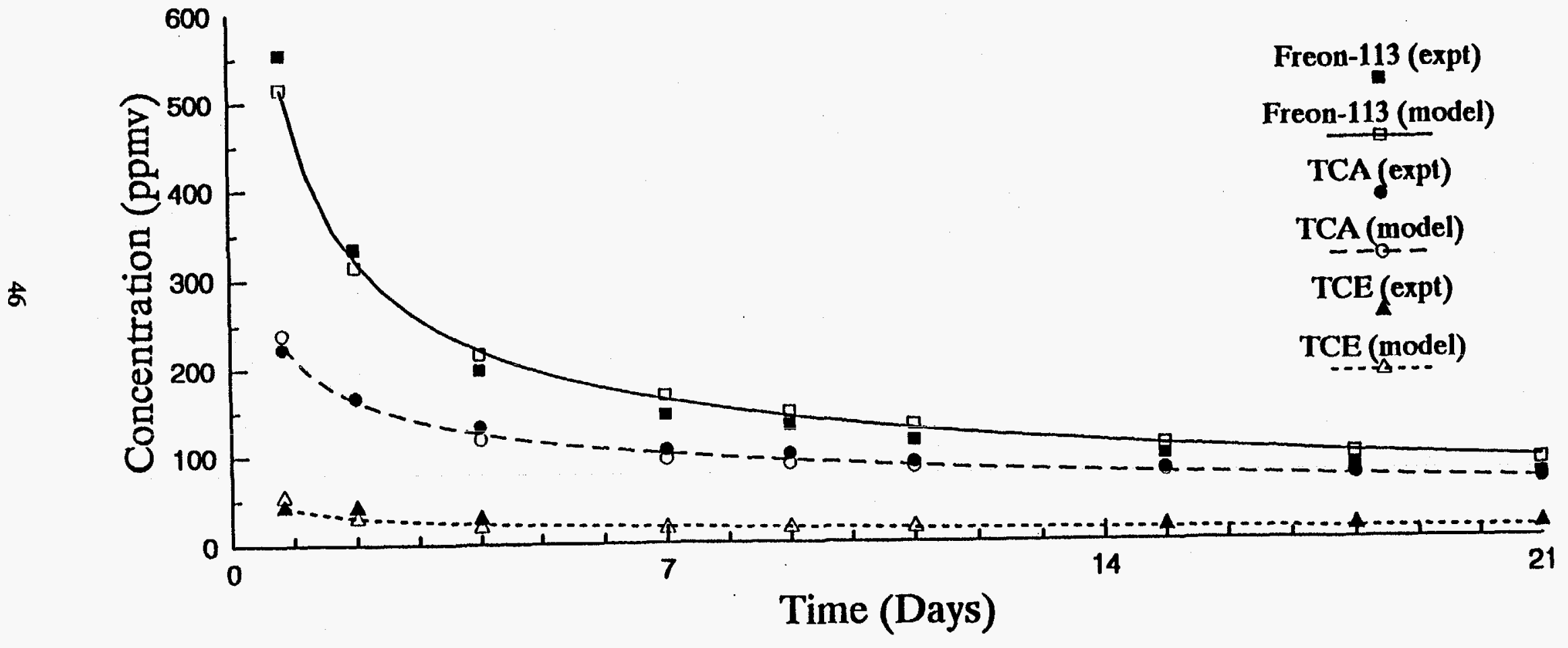

Figure 15. Model predictions and experimental data of average Freon-113, TCA, and TCE concentration in small bag void volumes of . waste drum in variable-temperature environment (Trial 1.1). 


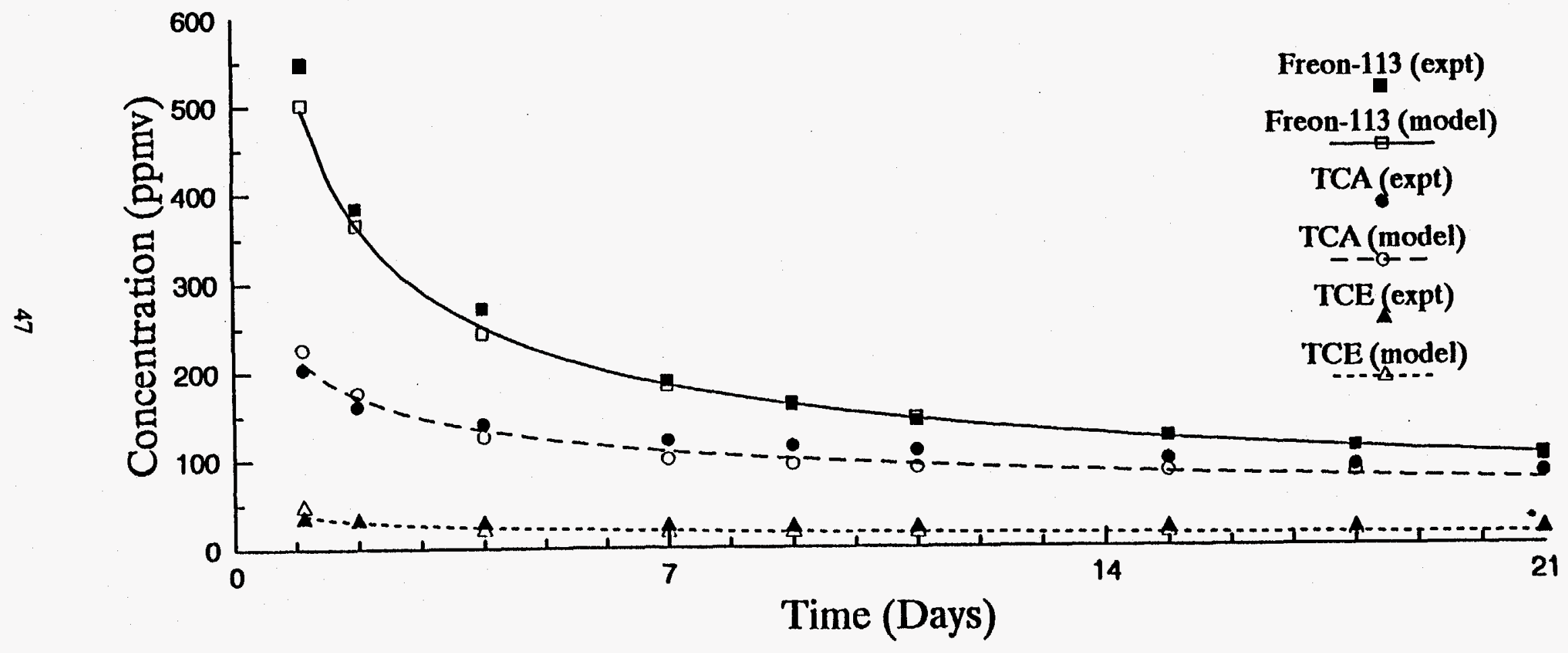

Figure 16. Model predictions and experimental data of average Freon-113, TCA, and TCE concentration in small bag void volumes of waste drum in constant-temperature environment (Trial 2.3). 


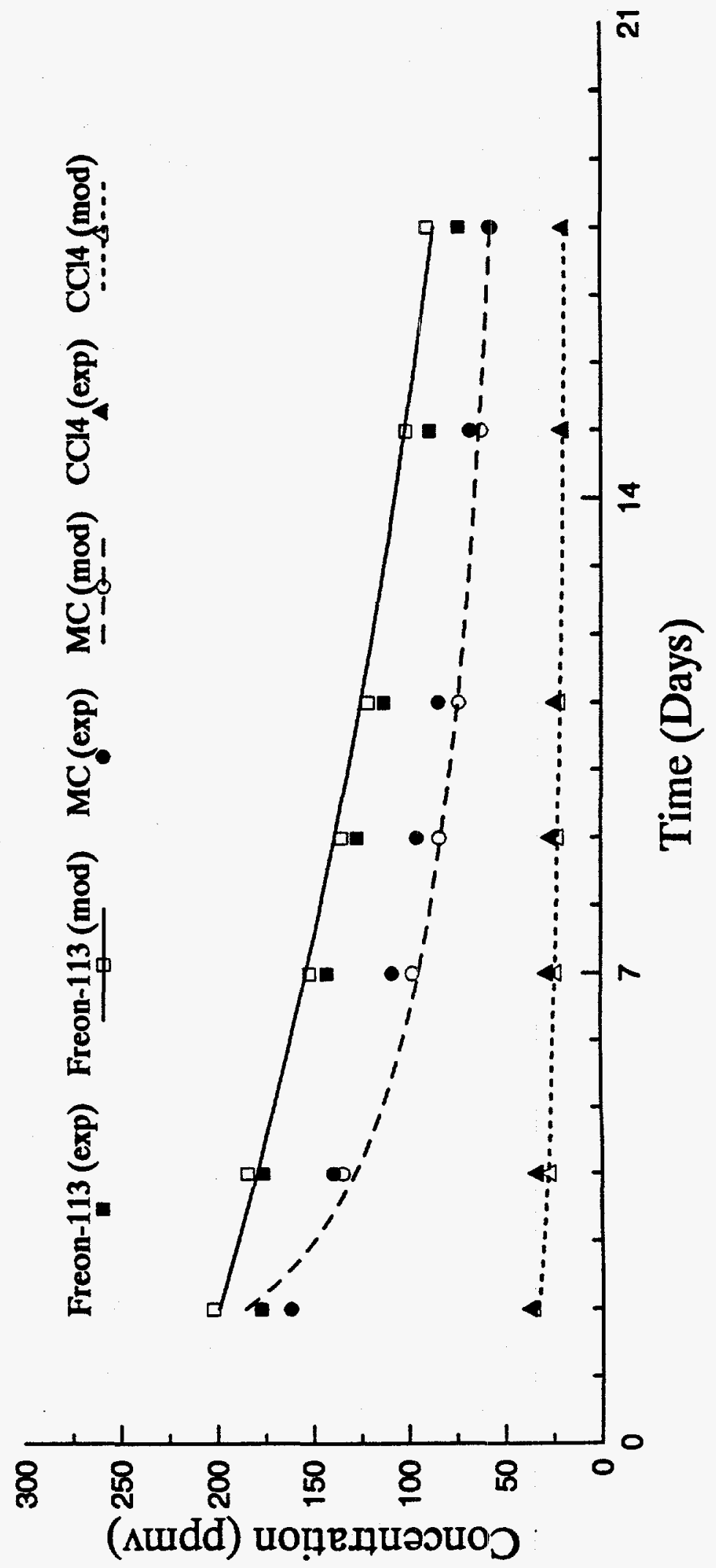

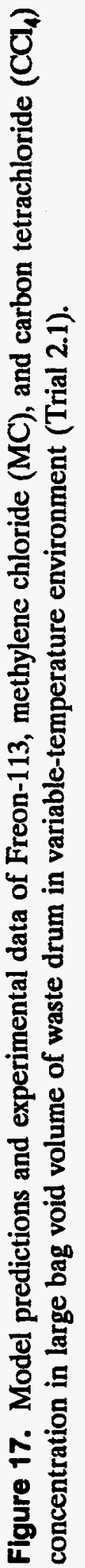




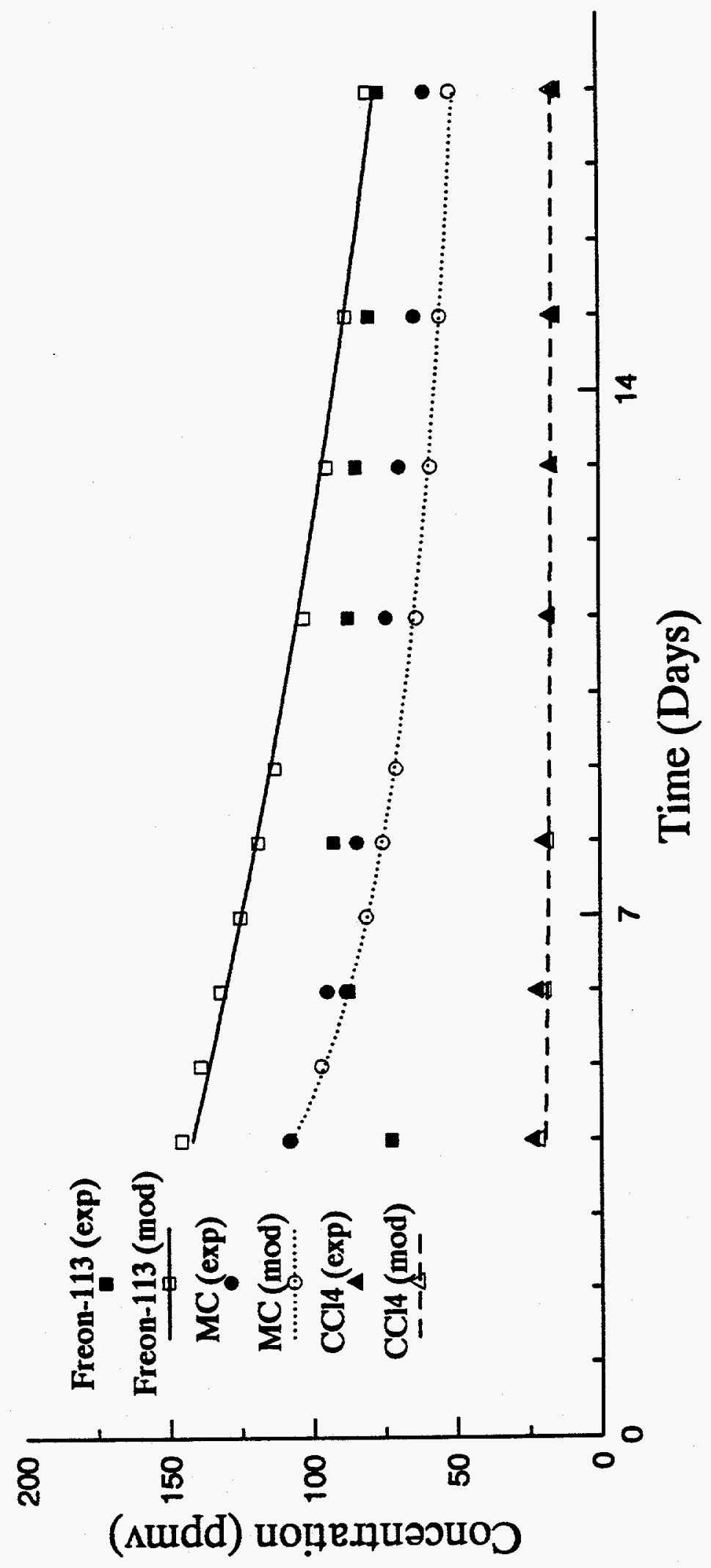

웜

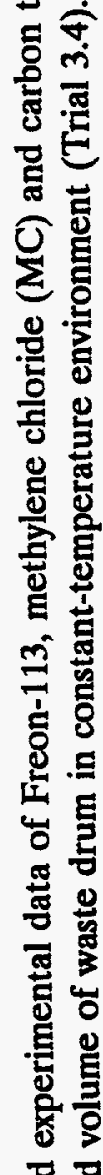

믕 믕

.

을 뽄

흥

온.

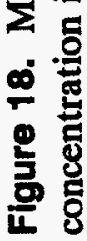


The accuracy of model predictions of VOC concentration in each void volume in each trial was characterized by the mean absolute relative deviation defined as

$$
|\vec{a}|=\sum_{i=1}^{N} \frac{\left|\left(c_{\bmod }-c_{\exp }\right)_{i}\right|}{N c_{o}}
$$

where

$$
\begin{aligned}
& |\overline{\mathrm{d}}|=\text { mean absolute relation deviation } \\
& c_{\text {mod }}=\text { model prediction of VOC concentration at time } t \\
& c_{\exp }=\text { measured VOC concentration at time } t \\
& c_{0} \quad=\text { initial VOC concentration introduced into small bags } \\
& N \quad=\text { number of comparisons made during trial for a given void volume. }
\end{aligned}
$$

The mean absolute relative deviation for small bag, large bag, and drum headspace void volumes in each trial involving gas mixture A are summarized in Figures 19 through 21.

In most trials, the small bag mean absolute relative deviation for each VOC was less than 2\%. The calculated deviation was much greater for Freon-113 in Trial 4 than for any other VOC in any trial. Trial 4 experiments were performed using a different gas mixture than was used in other trials. The gas was reanalyzed to check the Freon-113 concentration, but the analysis did not indicate any significant deviation from the value reported. No other possible explanation for the significantly higher measured Freon-113 concentration in Trial 4 could be determined. The large bag mean absolute relative deviation followed the same trends as observed for the small bags.

The mean absolute relative deviation for the drum headspace void volume in waste drums maintained at room temperature was less than $2 \%$ for a majority of the trials. Most mean absolute relative deviations for the drum headspace void volume in waste drums maintained under a variable-temperature environment were between $2 \%$ and $4 \%$. The increase in the deviation between the model and experimental results in the heated drums was attributed to the failure of the model to account for increased VOC solubility in the polyethylene drum liner at higher temperatures.

\subsubsection{Effect of Drum Temperature}

The average concentrations of Freon-113 and TCA in the drum headspace of waste drums maintained in constant-temperature and variable-temperature environments are plotted as a function of time in Figure 22. The VOC concentration in the drum headspace of waste drums maintained at room temperature was consistently greater during the course of the 3-week 


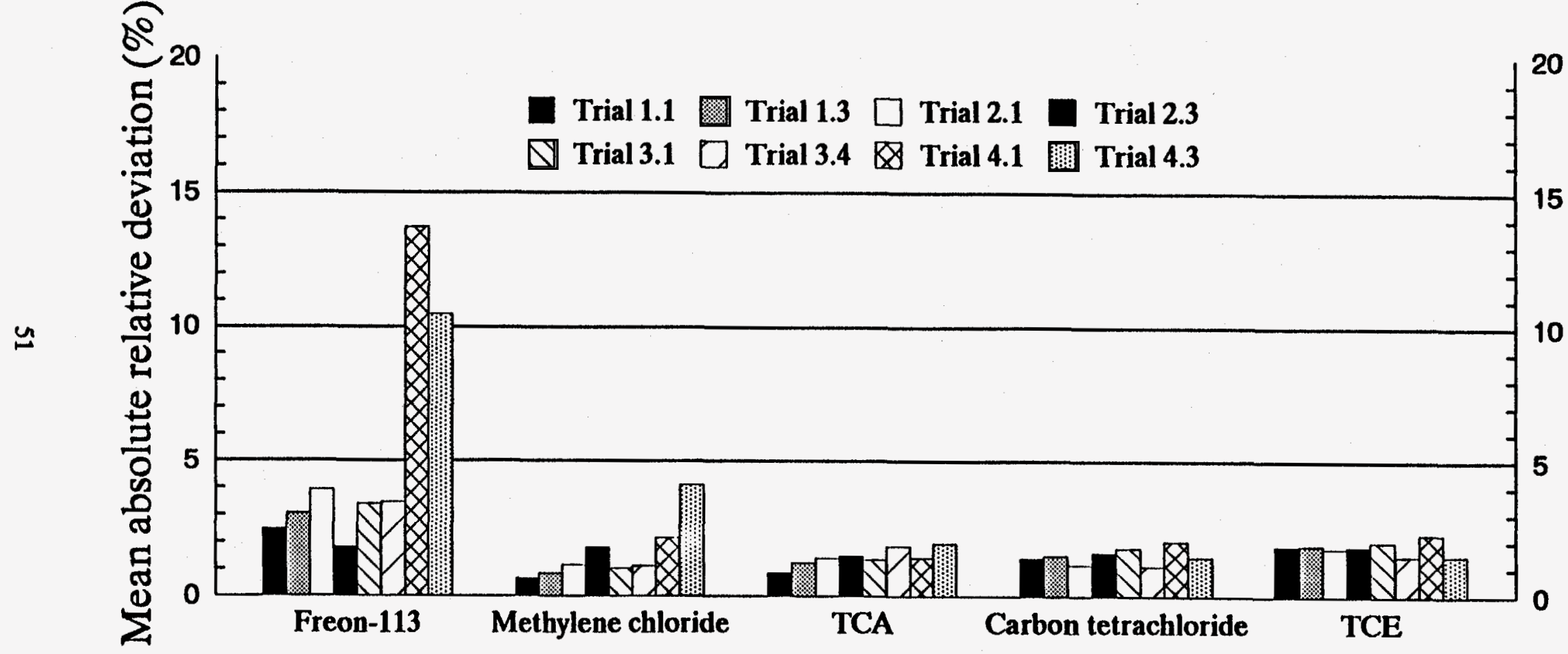

Figure 19. Mean absolute relative deviation of VOC concentration in small bags. 


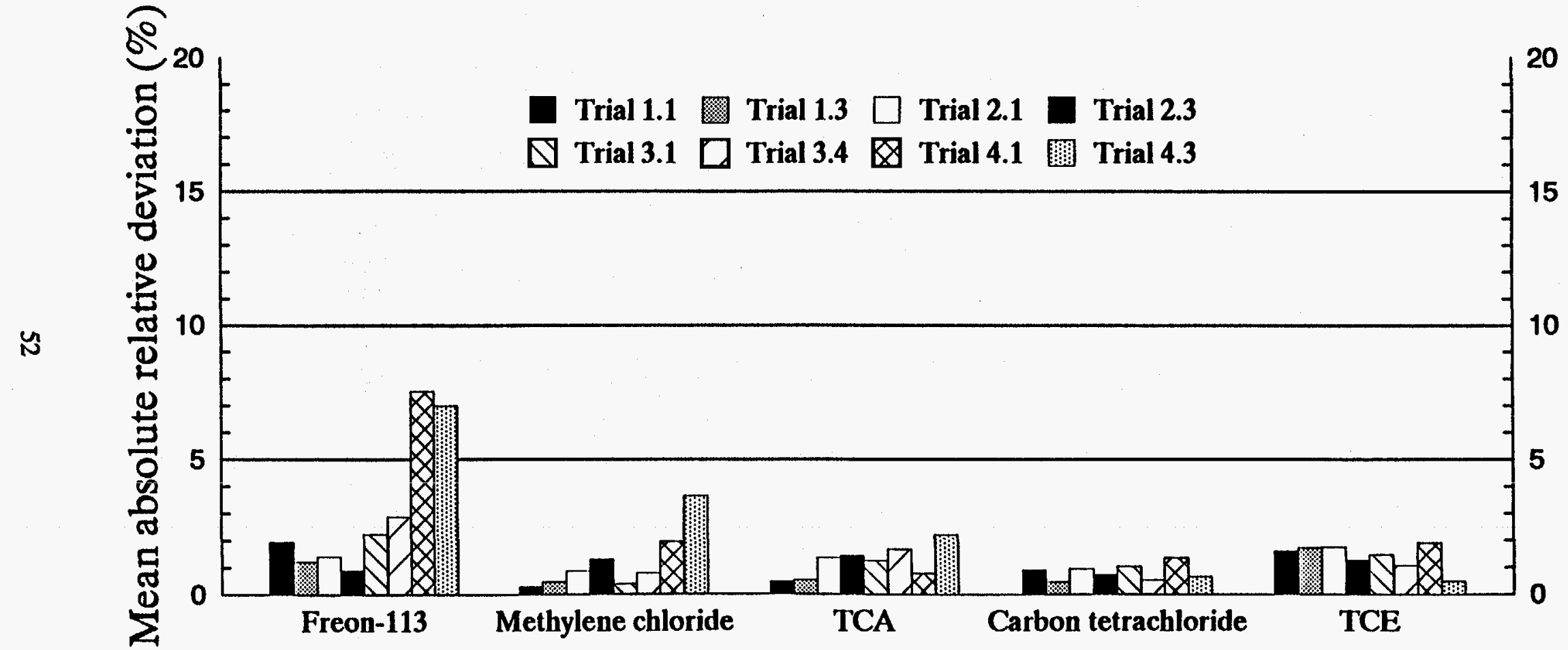

Figure 20. Mean absolute relative deviation of VOC concentration in large bags. 


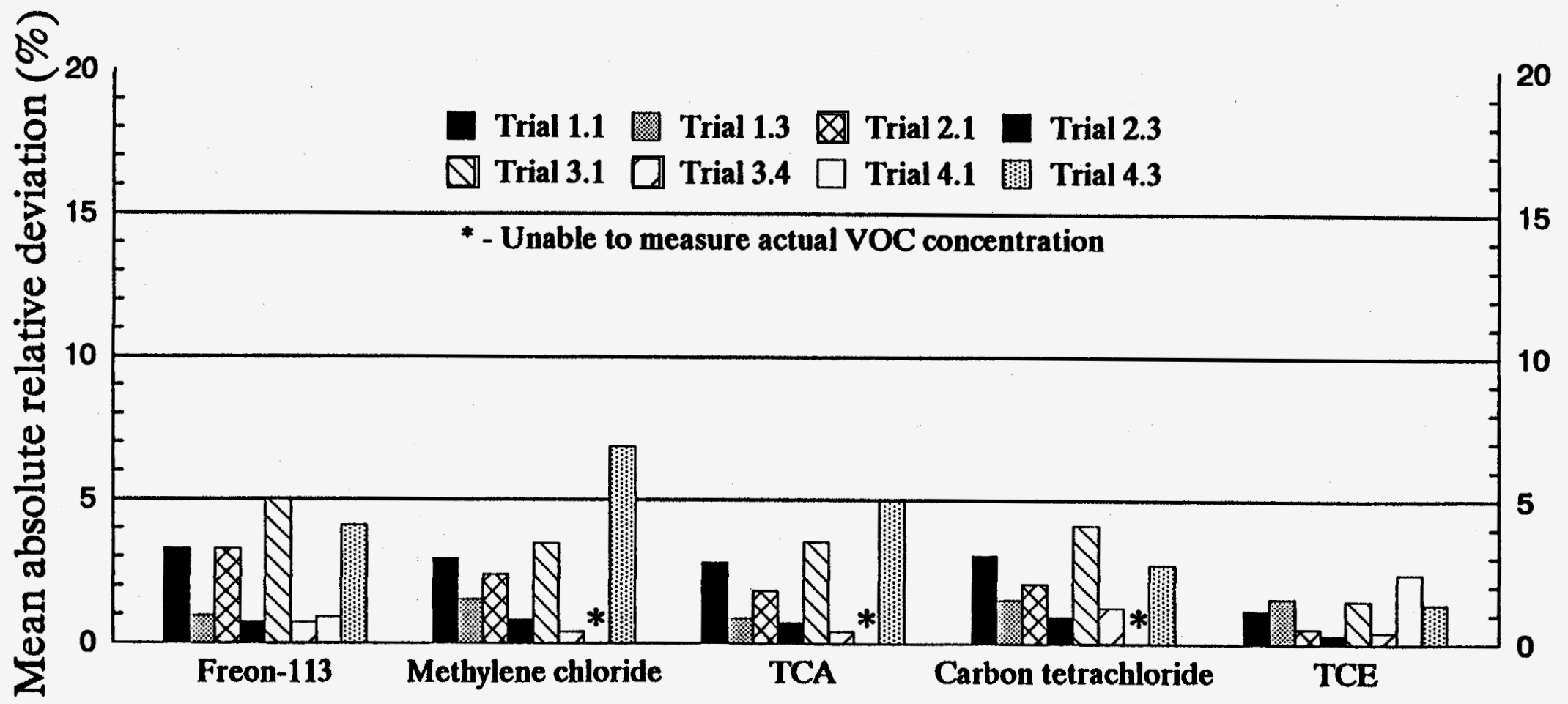

Figure 21. Mean absolute relative deviation of VOC concentration in drum headspace. 
$\downarrow S$

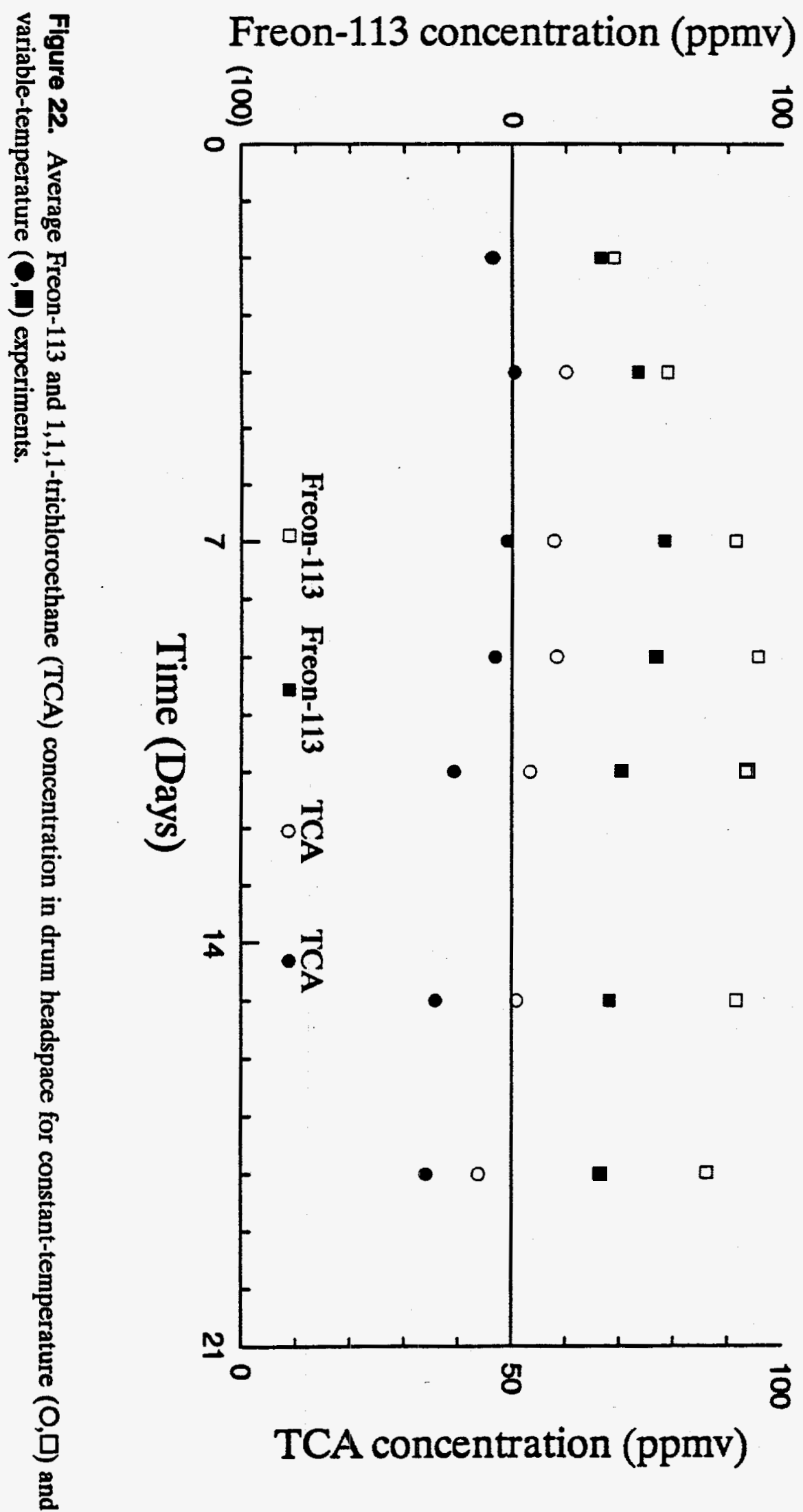


experiment than that in the waste drums exposed to a variable heat source. The difference was attributed to an increase of VOC solubility in the polyethylene liner at higher temperatures and an increased rate of aspiration due to fluctuating drum temperature. Although the current model does not account for the temperature dependence of VOC solubility in the polymer drum liner, the model does predict lower drum headspace VOC concentrations in a waste drum exposed to thermal cycling than in a drum maintained at room temperature.

\subsubsection{Effect of Small Bag Closure}

The effect of the small bag closure type on VOC transport in the lab-scale drum cannot be determined from a direct comparison of measured VOC concentration in small bags. In several trials, a small bag was damaged. In addition, the time between the filling of the small bags and the first gas samples was not the same in each trial.

The model was used to estimate the relative importance of the VOC transport through a small bag horsetail compared to VOC permeation across the bag wall. Recall Equation (4)

$$
V_{1, j} \frac{d y_{1, j}}{d t}=(\alpha \phi+\beta)_{1, j}\left[y_{2}-y_{1}\right]-\gamma_{1, j} \phi \frac{d s_{1, j}}{d t}
$$

where

$$
\begin{aligned}
& \alpha_{1, j}=\left(P A_{P} P / \Delta x_{P}\right)_{1, j} \\
& \beta_{1, j}=\left(D A_{D} / \Delta x_{D}\right)_{1, j} \\
& \phi_{1, j}=\text { temperature and pressure correction, } 76 T_{1} /(273.15 P)
\end{aligned}
$$

The value of $\alpha_{1, j}$ reflects the importance of VOC transport via permeation. The value of $\beta_{1, j}$ reflect the importance of VOC transport via diffusion. The ratio of $\alpha \phi / \beta$ provides a measure of which term is most important. A ratio value much greater than unity would indicate that VOC transport primarily occurs via permeation across the bag. A ratio value much less than unity would indicate that VOC transport via diffusion predominates. The ratio was calculated for the low-permeability Freon-113 using model parameters from Trial 2.3 and was greater than 500 . This indicates that for lab-scale waste drums with no gas generation, VOC permeation out of the small polyethylene bags is much greater than diffusion through the horsetail. In the case of a punctured small bag with a hole similar in size as observed in the trials, the $\alpha \phi / \beta$ ratio was approximately six.

\subsection{Effect of Parameter Values on Model Results}

\subsubsection{Permeable Surface Area}

The effect of available permeable small bag surface area on VOC transport from small bags is shown in Figure 23. Model results demonstrate that the total bag surface area is not as important as knowledge of available permeable surface area. Use of the total bag surface area may result in an overestimation of the rate of VOC transport from a bag. 


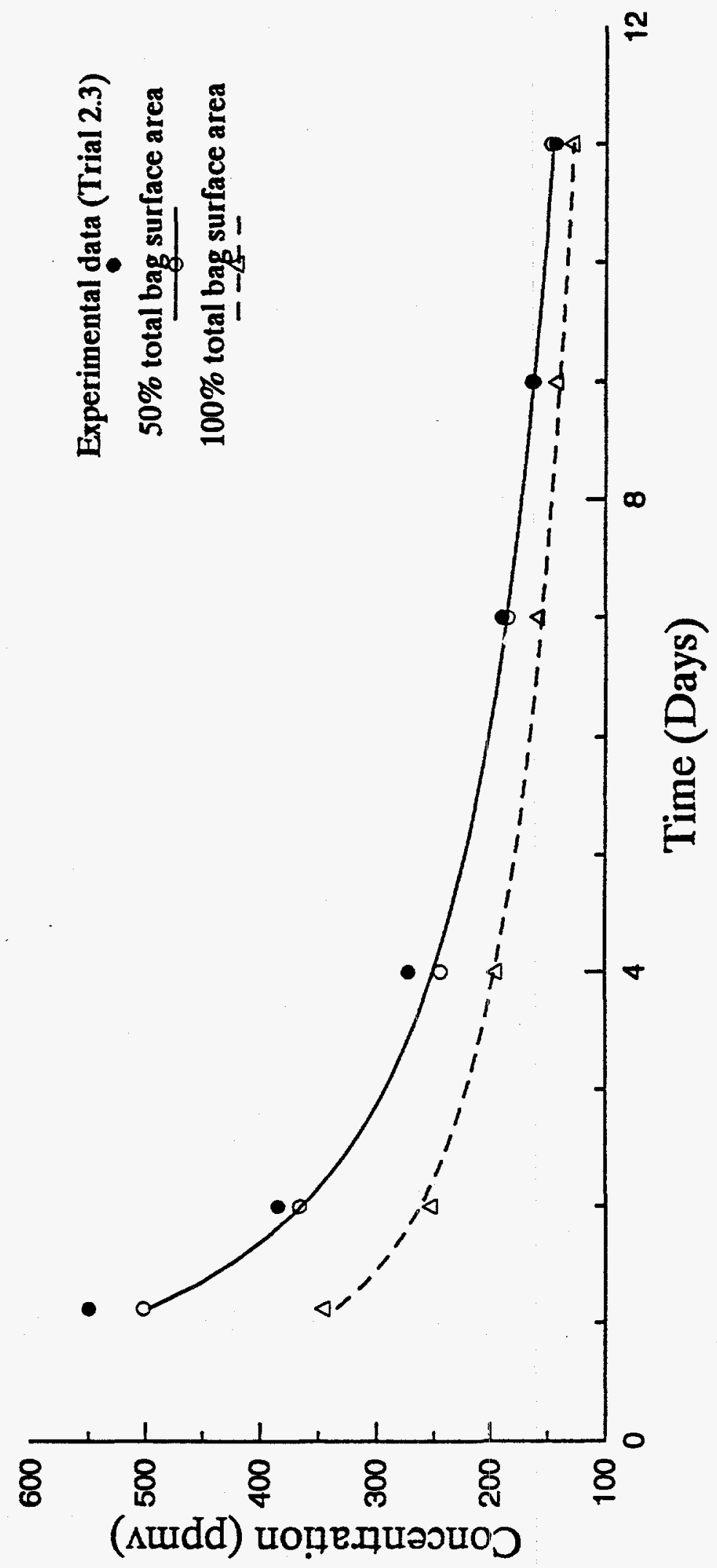

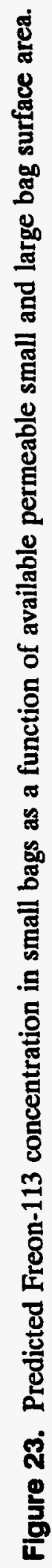




\subsubsection{Transport Length}

The assumption that each void volume is a well-mixed region in which the VOC concentration is the same throughout the volume at any time is made for computational simplicity. The assumption is less appropriate when the area across which VOCs enter or exit a volume is relatively small as compared to the total void volume. This is the case for the drum liner and drum headspace void volumes. The specification of a diffusion length between two well-mixed volumes greater than actual thickness of the boundary separating the volumes is a simple means to better model VOC transport between the two volumes. The effect on the model diffusional length on the predicted VOC concentration difference between the drum liner and drum headspace void volumes is shown in Figure 24.

\subsubsection{VOC Solubility in Polyethylene}

The effect of neglecting VOC solubility in polyethylene on model predictions of the VOC concentration in the large bag and drum headspace void volumes is shown in Figure 25 . Failure to account for any VOC solubility in polyethylene is equivalent to letting $\eta=0$ in Equation (3). Model assumptions of VOC solubility in the polyethylene drum liner and the empirical determination of the transfer coefficient $\eta$ used in Equation (3) results in a model that only approximates the general effect of VOC solubility in the drum liner on VOC concentration in the drum headspace. The nature of the experiments aggravated the significance of VOC solubility in the drum liner on experimental results. The VOC capacity of a drum liner represented a significant fraction of the total VOCs introduced initially into the waste drum.

\subsubsection{Other Model Parameters}

The effect of varying other model parameters was also investigated and shown to have little effect on model results. Model results did not vary significantly when the large bag void volume was decreased by 1,240 in. $^{2}\left(8,000 \mathrm{~cm}^{2}\right)$ and the drum liner void volume increased by the same amount.

Tests were performed on drum filters identical in design to those used on the lab-scale waste drums to determine if the lower VOC drum headspace concentration was the result of a higher VOC diffusion characteristic than would be predicted by Equation (17). The test cell was similar in size to a previous test apparatus. ${ }^{7}$ Test results indicated that Equation (17) is an appropriate means of estimating the VOC diffusion characteristic across the drum filter.

\subsection{Experimental and Model Refinements}

A major feature of these VOC transport experiments was the transient nature of the VOC gas phase concentration as a result of having no VOC source in the waste drums. The presence of VOC-containing waste, such as a waste sludge, would replenish VOC molecules that had 


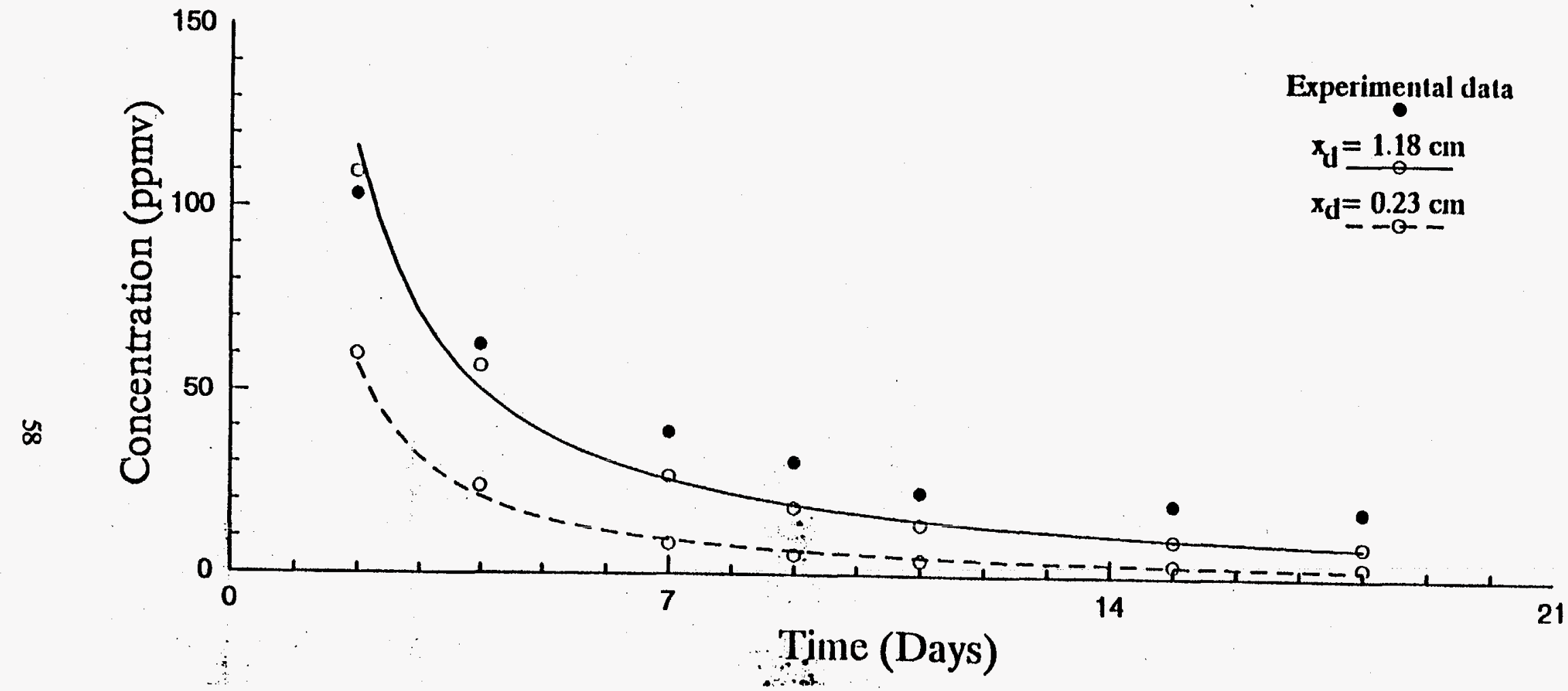

Figure 24. Predicted average TCA concentration difference between large bag and drum headspace void volumes in waste drums maintained at a constant temperature (Trial 2.3 ) as a function of diffusion lengths $\left(x_{d}\right)$ across drum linei lid. 


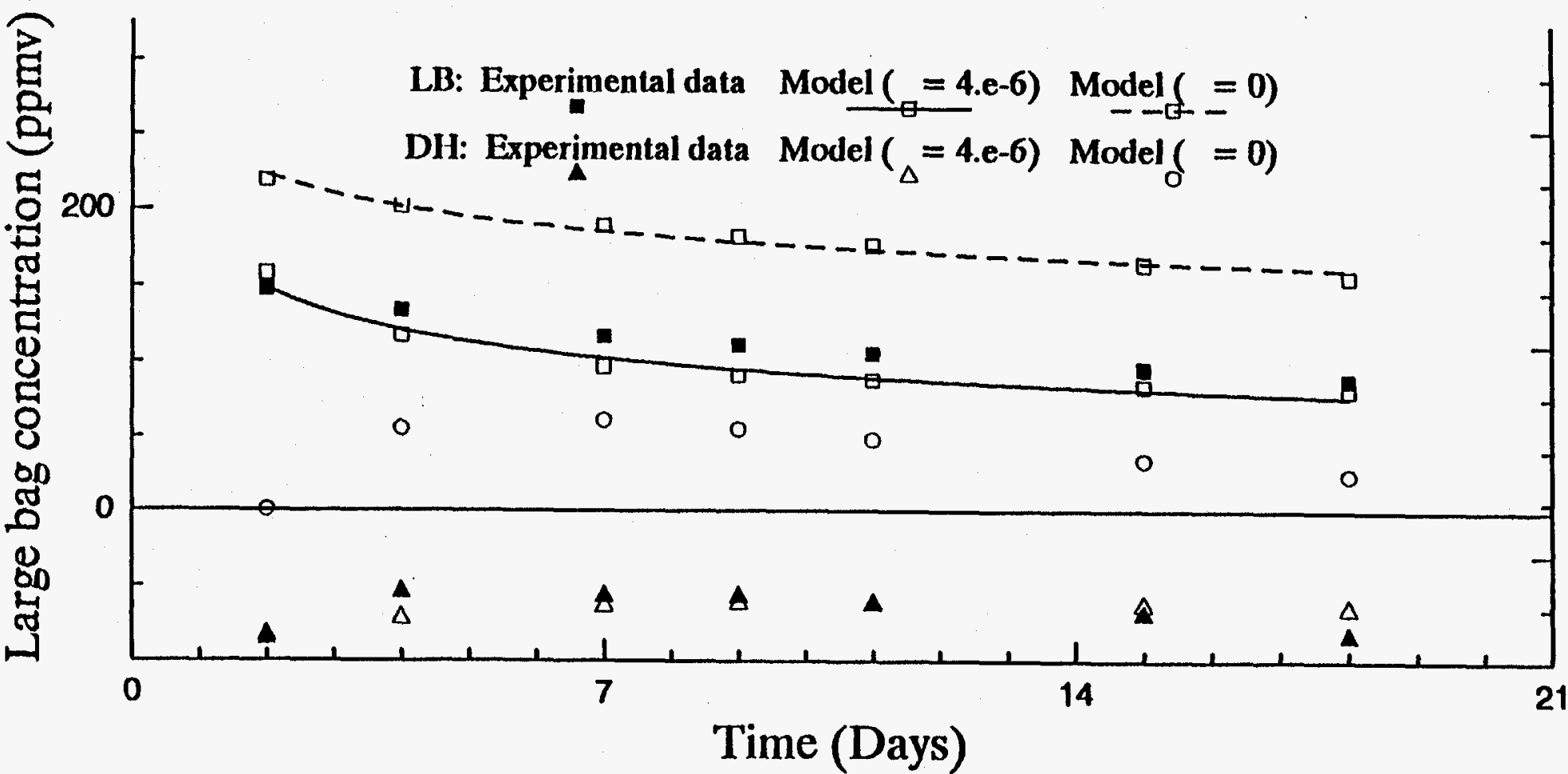

Figure 25. Comparison of experimental data (Trial 2.3) and model predictions of TCA concentration in large bags (LB) and drum headspace $(\mathrm{DH})$ void volumes with and without $(\eta=0)$ VOC accumulation in polyethylene drum liner. 
permeated and diffused out of the void volume. A drum containing such waste and kept in a constant-temperature environment should reach a quasi-steady state. A system at quasi-steady state appears to be at steady state over a short time period but is slowly changing with time. The transient behavior reflects the fact that as the VOC concentration in the waste slowly decreases, the VOC equilibria between the waste and surrounding gas phase also changes. The presence of a VOC source in the lab-scale waste drums would more closely simulate real waste. The effect of VOC solubility in the drum liner on the drum headspace VOC concentration should be diminished under quasi-steady state conditions.

Future work includes obtaining VOC permeability and solubility data for the components in gas mixture B and examining the capability of the VOC transport model of predicting the VOC concentration throughout the lab-scale waste drum. In addition, the rate of VOC transport out of the polymer bottles will be analyzed. Measurements of VOC permeabilities as a function of temperature and over a wider range of VOC concentrations will be made. Future simulated waste drum experiments will place VOC-contaminated simulated waste in waste drums and measure VOC concentration over a relatively long period of time. The applicability of the current model to predict the VOC concentration throughout a simulated waste drum containing VOC-contaminated waste will be investigated. Finally, a model that predicts VOC concentration throughout an actual waste drum based on process knowledge and the measured VOC concentration in the drum headspace will be developed and tested. 


\section{CONCLUSIONS}

A VOC transport model has been developed that accurately predicts the VOC concentration in the void volumes within a simulated waste drum. The success of the model over a variety of operating conditions indicated that the model accounted for the important transport mechanisms within the waste drum and the accuracy of model parameters. Model and experimental results have demonstrated that the primary mechanisms of VOC transport from void volumes inside a waste drum were permeation and diffusion to an adjacent void volume with lower VOC concentration and solubilization into a polymer. The model estimated the effect of temperature on VOC permeability and diffusivity but did not account for increased VOC solubility at higher temperatures. Model results demonstrated the importance of knowing the available permeable surface area. Vapor permeabilities of five VOCs across polyethylene waste bags were experimentally measured. These model and experimental data will be useful in developing and testing a VOC transport model to predict VOC concentrations within actual waste drums. 


\section{REFERENCES}

1. Quality Assurance Program Plan for the Waste Isolation Pilot Plant Experimental-Waste Characterization Program, Rev. 1, July 1991.

2. C. E. Rogers, V. Stannett, and M. Szwarc, "The Sorption, Diffusion, and Permeation of Organic Vapors in Polyethylene," Joumal of Polymer Science, 45, 1960, pp. 61-82.

3. M. Salame, "The Prediction of Liquid Permeation in Polyethylene and Related Polymers," SPE Trans., 1, 4, 1961, pp. 153-166.

4. H. Yasuda and V. Stannett, in Polymer Handbook, 2ed., J. Brandup and E.H. Immergut, eds., New York: John Wiley, 1975.

5. R. M. Felder and R. W. Rousseau, Elementary Principles of Chemical Processes, 2nd edition, New York: John Wiley, 1986.

6. R. B. Bird, W. E. Stewart, and E. N. Lightfoot, Transport Phenomena, New York, John Wiley, 1960.

7. S. H. Peterson and G. R. Marshall, Determination of Diffusion Characteristics of Organic Vapors through Carbon Composite Filters, Westinghouse STC, Pittsburgh; P.O. No. 9594-75WRS36917, October 19, 1990.

8. R. C. Reid, J. M. Prausnitz, and T. K. Sherwood, The Properties of Gases and Liquids, 3rd edition, New York: McGraw-Hill, 1977.

9. Department of Energy No-Migration Petition, 89-003, DOE/WIPP, Appendices A-B, 1989.

10. G. A. Lugg, Diffusion coefficients of some organic and other vapors in air. Anal Chem. 40, 1073 (1968).

11. R. R. McCaffrey, and D. G. Cummings, Sep. Sci. and Tech., 23(12\&13), 1627-1643 (1988).

12. Vapor Pressure, Critical Temperature and Critical Pressures of Organic Compounds, G. G. Schlessinger, Handbook of Chemistry and Physics, CRC Press, 53 ${ }^{\text {rd }}$ ed., R. C. Weast, ed., (1972-73). 
Appendix A

Measured VOC Concentrations in Lab-Scale Simulated Waste Drums 
A-2 
DRUM: 1.1 GAS: A TEMP: Variable SMALL BAG CLOSURE: horsetail

\begin{tabular}{|c|c|c|c|c|c|c|c|}
\hline Voc: & DAY & SB1 & $\mathrm{SB2}$ & SB3 & SB4 & L. $B A G$ & DRUM \\
\hline \multirow{3}{*}{$\begin{array}{l}\text { 1,1,2-Trichloro-1,2,2- } \\
\operatorname{trif} \text { luoroethane (Freon-113) }\end{array}$} & $1^{a}$ & 599.6 & 509.2 & 560.0 & 549.5 & - & - \\
\hline & 2 & 357.6 & - & 309.8 & - & 198.8 & 13.1 \\
\hline & 4 & - & 199.4 & - & 197.1 & 169.6 & 39.4 \\
\hline Initial concentration: & 7 & - & 145.3 & - & 144.2 & 128.4 & 40.9 \\
\hline \multirow[t]{5}{*}{903 ppmv } & 9 & 133.6 & 130.8 & - & - & 114.2 & 37.7 \\
\hline & 11 & - & 113.5 & - & 113.5 & 100.8 & 32.2 \\
\hline & 15 & - & - & 96.2 & 96.1 & 86.2 & 28.9 \\
\hline & 18 & 83.5 & - & 81.7 & - & 72.4 & 25.0 \\
\hline & 21 & 71.1 & 69.5 & 69.2 & 68.9 & - & - \\
\hline \multirow[t]{2}{*}{ voc: } & $1^{a}$ & 207.6 & 204.2 & 203.7 & 202.1 & - & - \\
\hline & 2 & 175.5 & - & 174.9 & - & 175.6 & 71.6 \\
\hline \multirow{3}{*}{ Methylene chloride } & 4 & - & 138.4 & - & 137.6 & 132.1 & 63.1 \\
\hline & 7 & - & 97.1 & - & 96.7 & 92.2 & 45.1 \\
\hline & 9 & 88.2 & 87.7 & - & - & 83.2 & 40.8 \\
\hline \multirow[t]{4}{*}{ Initial concentration: } & 11 & - & 76.7 & - & 76.4 & 73.1 & 36.9 \\
\hline & 15 & - & - & 65.8 & 66.0 & 62.8 & 35.3 \\
\hline & 18 & 57.4 & - & 57.0 & - & 54.2 & 32.4 \\
\hline & 21 & 51.6 & 51.3 & 51.1 & 50.9 & - & - \\
\hline \multirow[t]{2}{*}{ voc: } & $1^{a}$ & 243.1 & 216.3 & 220.4 & 213.4 & - & - \\
\hline & 2 & 168.1 & - & 166.0 & - & 151.9 & 43.7 \\
\hline \multirow[t]{2}{*}{ 1.1.1-Trich loroethane } & 4 & - & 133.1 & - & 132.5 & 122.6 & 45.5 \\
\hline & 7 & - & 105.1 & - & 104.6 & 95.4 & 42.1 \\
\hline \multirow[t]{2}{*}{ Initial concentration: } & 9 & 99.3 & 98.3 & - & - & 89.1 & 40.4 \\
\hline & 11 & - & 88.8 & - & 88.6 & 80.4 & 37.7 \\
\hline \multirow[t]{3}{*}{977 ppmv } & 15 & - & - & 79.8 & 79.5 & 73.3 & 37.6 \\
\hline & 18 & 71.9 & - & 71.5 & - & 65.2 & 35.6 \\
\hline & 21 & 65.6 & 65.1 & 64.7 & 64.5 & - & - \\
\hline voc: & $1^{a}$ & 53.5 & 50.3 & 50.1 & 48.8 & - & - \\
\hline \multirow[t]{2}{*}{ Carbon tetrachloride } & 2 & 41.2 & - & 41.2 & - & 36.5 & 9.0 \\
\hline & 4 & - & 32.3 & - & 32.1 & 28.5 & 9.3 \\
\hline \multirow[t]{2}{*}{ Initial concentration: } & 7 & - & 24.4 & - & 24.0 & 21.1 & 7.7 \\
\hline & 9 & 23.0 & 23.0 & - & - & 19.6 & 7.3 \\
\hline \multirow[t]{4}{*}{305 ppmv } & 11 & - & 21.7 & - & 21.6 & 18.4 & 7.1 \\
\hline & 15 & - & - & 18.8 & 18.8 & 16.5 & 7.1 \\
\hline & 18 & 17.2 & - & 17.9 & - & 13.6 & 6.7 \\
\hline & 21 & 14.4 & 14.5 & 15.9 & 14.2 & - & - \\
\hline \multirow[t]{2}{*}{ voc: } & $1^{a}$ & 42.3 & 42.2 & 41.9 & 41.7 & - & - \\
\hline & 2 & 41.0 & - & 40.9 & - & 37.5 & 15.0 \\
\hline \multirow{2}{*}{ Trich loroethy lene } & 4 & - & 28.1 & - & 27.8 & 25.6 & 12.2 \\
\hline & $7^{b}$ & - & 13.9 & - & 13.8 & 11.6 & 2.0 \\
\hline \multirow[t]{2}{*}{ Initial concentration: } & $9^{b}$ & 12.8 & 12.7 & - & - & 10.5 & 1.8 \\
\hline & $11^{b}$ & - & 11.4 & - & 11.4 & 9.1 & 1.5 \\
\hline \multirow{3}{*}{$310 \mathrm{ppmv}$} & 15 & - & - & 14.0 & 14.1 & 12.6 & 6.9 \\
\hline & 18 & 13.0 & - & 13.0 & - & 12.7 & 8.7 \\
\hline & 21 & 12.9 & 12.7 & 12.7 & 12.7 & - & - \\
\hline
\end{tabular}

Notes:
a. Sampled approximately 19 hours after filling small bags at $t=0$.

b. Suspect data. 
ORUM: 1.2 GAS: B TEMP: Variable SMALL BAG CLOSURE: heat sea

VOC:

Methanol

Initial concentration:

$1002 \mathrm{ppmv}$

VOC:

Cyc lohexane

Initial concentration:

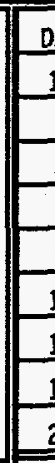

\begin{tabular}{|c|c|}
\hline DAY & SB1 \\
\hline $1^{b}$ & 309.3 \\
\hline 2 & 217.8 \\
\hline 4 & - \\
\hline
\end{tabular}

\begin{tabular}{c|c|c|c|c|} 
SB2 & SB3 & SB4 & L. BAG & DRUM $^{a}$ \\
\hline 336.6 & 316.6 & 341.7 & - & \\
\hline
\end{tabular}

\begin{tabular}{l|l|l}
\hline 221.6 & - & 341.7 \\
\hline
\end{tabular}

$\frac{165.7}{d}$

\begin{tabular}{|c|c|}
\hline 7 & $98.1^{c}$ \\
\hline 9 & 101.6 \\
\hline 11 & \\
\hline
\end{tabular}

$-$

\begin{tabular}{c|c}
- & - \\
\hline- & 166. \\
\hline & -
\end{tabular}

181.1

20.5

\begin{tabular}{|c|c|c|c|c|c|c|}
\hline 7 & & & & & 98.0 & 13.1 \\
\hline 11 & - & 81.8 & 81.6 & - & 74.1 & 15.0 \\
\hline 15 & - & - & 66.1 & 66.9 & 62.6 & 4.9 \\
\hline 18 & 48.9 & - & 49.2 & - & 47.0 & 3.4 \\
\hline 21 & 37.2 & 38.3 & 37.1 & 37.4 & - & \\
\hline
\end{tabular}

VOC:

1,1,1-Trichloroethane

Initial concentration:

1020 ppmv

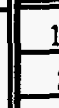

777 ppmv

\begin{tabular}{|c|c|c|c|c|c|c|}
\hline $1^{b}$ & 132.0 & 141.5 & 137.9 & 149.7 & - & - \\
\hline 2 & 99.3 & 100.3 & - & - & 92.3 & 2.5 \\
\hline 4 & - & 812.1 & - & 82.4 & 76.6 & 4.6 \\
\hline 7 & $73.7^{c}$ & $-d$ & - & - & 74.0 & 7.3 \\
\hline
\end{tabular}

Toluene

Initial concentration:

$421 \mathrm{ppmv}$

VOC:

P-xylene

Initial concentration:

$120 \mathrm{ppmv}$

Notes:
a. Suspect data.
b. Sampled approximately $24 \mathrm{hrs}$ after filling sma 11 bags at $t=0$.
c. 5-cc sample loop.
d. No data detected. 
DRUM: 1.3

GAS: A TEMP: Constant SMALL BAG CLOSURE: heat seal

VOC:

1,1,2-Trichloro-1,2,2trifluoroethane (Freon-113)

Initial concentration:

903 pprnv

VOC:

Methylene chloride

Initial concentration:

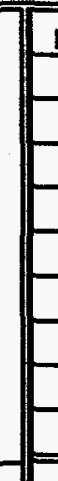

\begin{tabular}{|c|c|c|c|c|c|c|}
\hline $\mathrm{DAY}$ & $\mathrm{SB} 1$ & $\mathrm{SB} 2$ & $\mathrm{SB3}^{\mathrm{a}}$ & $\mathrm{SB4}$ & L. BAG & DRUM \\
\hline $1^{\mathrm{b}}$ & 643.6 & 681.7 & 321.0 & 640.2 & - & - \\
\hline 2 & - & 519.3 & - & 468.9 & 179.2 & 11.8 \\
\hline 4 & - & - & 186.4 & 282.2 & 174.1 & 43.0 \\
\hline 7 & 197.1 & - & 175.6 & - & 144.4 & 63.6 \\
\hline 9 & 171.3 & - & - & 163.1 & 138.7 & 64.1 \\
\hline 11 & - & 156.6 & 135.8 & - & 123.9 & 63.2 \\
\hline 15 & 131.9 & - & 123.8 & - & 115.2 & 68.5 \\
\hline 18 & 119.8 & 121.9 & - & - & 104.9 & 62.7 \\
\hline 21 & 109.5 & 111.7 & 104.0 & 108.2 & - & - \\
\hline \hline
\end{tabular}

1012 ppmv

VOC:

1,1,1-Trichloroethane

Initial concentration:

977 ppmv

VOC:

Carbon tetrachloride

Initial concentration:

305 ppmv

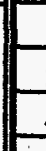

\begin{tabular}{|c|c|c|c|c|c|c|}
\hline $1^{b}$ & 207.9 & 200.0 & 207.7 & 204.4 & - & - \\
\hline 2 & - & 186.2 & - & 185.6 & 176.7 & 84.9 \\
\hline 4 & - & - & 139.2 & 140.4 & 134.3 & 83.2 \\
\hline 7 & 102.5 & - & 107.0 & - & 97.8 & 70.3 \\
\hline 9 & 97.2 & & & 97.6 & 92.7 & 62.0 \\
\hline
\end{tabular}

$$
\frac{9}{11}
$$

\begin{tabular}{|c|c|c|c|c|c|c|}
\hline 9 & 97.2 & - & - & 97.6 & 92.7 & 62.0 \\
\hline 11 & - & 88.0 & 87.6 & - & 83.2 & 57.9 \\
\hline 15 & 79.2 & - & 78.7 & - & 75.8 & 57.0 \\
\hline 18 & 71.3 & 71.6 & - & - & 68.2 & 51.6 \\
\hline 21 & 66.9 & 67.1 & 66.7 & 66.8 & - & - \\
\hline \hline
\end{tabular}

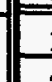

\begin{tabular}{|c|c|c|c|c|}
\hline \hline $1^{\mathrm{b}}$ & 275.4 & 269.3 & 189.3 & 25 \\
\hline 2 & - & 189.7 & - & 18 \\
\hline 4 & - & - & 142.1 & 143 \\
\hline
\end{tabular}

4

\begin{tabular}{|c|c|c|c|}
\hline 4 & - & - & 142 \\
\hline 7 & 116.1 & - & 1 \\
\hline 9 & 111.4 & - & \\
\hline
\end{tabular}

\begin{tabular}{|c|c|c|c|c|c|c|}
\hline 9 & 111.4 & - & - & 113.0 & 102.4 & 63.9 \\
\hline 11 & - & 103.7 & 102.7 & - & 91.2 & 60.6 \\
\hline 15 & 98.5 & - & 95.2 & - & 88.3 & 63.0 \\
\hline 18 & 88.6 & 89.1 & - & - & 81.8 & 58.6 \\
\hline 21 & 84.0 & 84.4 & 83.8 & 84.2 & - & - \\
\hline \hline
\end{tabular}

\begin{tabular}{l|l}
142.1 & 143.8 \\
\hline 119.8 & -
\end{tabular}

\begin{tabular}{l|l}
161.5 \\
\hline
\end{tabular}

\begin{tabular}{l|l}
- & 113.0 \\
\hline
\end{tabular}

$\frac{131.2}{105.8}$

53.6

Trich loroethylene

Initial concentration:

$310 \mathrm{ppmv}$

\begin{tabular}{|c|c|c|c|c|c|c|}
\hline $1^{\mathrm{b}}$ & 56.5 & 59.9 & 48.1 & 58.8 & - & - \\
\hline 2 & - & 45.4 & - & 45.3 & 39.2 & 12.1 \\
\hline 4 & - & - & 34.7 & 34.5 & 30.9 & 14.5 \\
\hline 7 & 27.2 & - & 30.9 & - & 24.0 & 15.2 \\
\hline 9 & 27.1 & - & - & 27.6 & 23.3 & 13.3 \\
\hline 11 & - & 25.3 & 24.9 & - & 21.5 & 12.6 \\
\hline 15 & 22.7 & - & 22.8 & - & 20.1 & 13.2 \\
\hline 18 & 21.0 & 21.7 & - & - & 18.4 & 12.1 \\
\hline 21 & 19.1 & 19.5 & 19.4 & 19.3 & - & - \\
\hline $1^{\mathrm{b}}$ & 43.7 & 43.9 & 43.4 & 43.7 & - & - \\
\hline $2^{2}$ & - & 43.2 & - & 43.1 & 39.2 & 16.4 \\
\hline 4 & - & - & 29.5 & 29.6 & 27.0 & 17.2 \\
\hline $7^{c}$ & 15.1 & - & 17.4 & - & 12.9 & 4.9 \\
\hline $9^{\mathrm{c}}$ & 14.1 & - & - & 14.2 & 11.8 & 3.9 \\
\hline $11^{\mathrm{c}}$ & - & 12.8 & 12.9 & - & 10.4 & 3.5 \\
\hline 15 & 15.3 & - & 15.4 & - & 13.7 & 9.0 \\
\hline 18 & 14.1 & 14.2 & - & - & 12.7 & 8.7 \\
\hline 21 & 14.1 & 14.1 & 14.0 & 14.0 & - & - \\
\hline
\end{tabular}

Notes:
a. Small hole in bag.
b. Sampled approximately $20 \mathrm{hrs}$ after filling small bags at $t=0$.
c. Suspect data. 
DRUM: 1.4

GAS: B TEMP: Constant SMALL BAG CLOSURE: horsetail

$$
\text { VOC: }
$$

Methano 1

Initial concentration:

$1002 \mathrm{ppmv}$

VOC:

Cyclohexane

Initial concentration:

777 ppmy

VOC:

1,1,1-Trich Toroethane

Initial concentration:

$1020 \mathrm{ppmv}$

\begin{tabular}{|c|c|c|c|c|c|c|}
\hline DAY & SB1 & SB2 & SB3 & SB4 $^{a}$ & L. BAG & DRUM \\
\hline $1^{b}$ & 254.2 & 220.5 & 250.5 & 205.7 & - & - \\
\hline 2 & - & 169.8 & 176.0 & - & 149.1 & 115.6 \\
\hline 4 & 140.8 & - & - & 138.0 & 124.8 & 110.1 \\
\hline 7 & 102.2 & - & - & - & 102.7 & 89.7 \\
\hline 9 & 110.7 & 107.6 & - & - & 97.4 & 87.8 \\
\hline 11 & 93.4 & - & - & 92.8 & 85.0 & 79.2 \\
\hline 15 & - & - & 87.3 & 86.5 & 82.0 & 75.8 \\
\hline 18 & - & 72.7 & 73.4 & - & 68.6 & 63.4 \\
\hline 21 & 61.7 & 62.2 & 62.5 & 62.0 & - & - \\
\hline
\end{tabular}

$$
1
$$

\begin{tabular}{l|l}
$1^{b}$ & 111 \\
\hline 2 & \\
\hline
\end{tabular}

\begin{tabular}{l|l|l|}
\hline 111.8 & 97.9 & 106.8 \\
\hline
\end{tabular}

\begin{tabular}{l|r|r|r}
- & 76.1 & 77.8 & 89.9 \\
\hline
\end{tabular}

\begin{tabular}{|l|l}
\hline 2 & \\
\hline 4 & \\
\hline 7 & \\
\hline
\end{tabular}

65.9

\begin{tabular}{|l|l|l|l|l}
\hline & 69.4 & - & - & - \\
\hline 9 & 63.7 & 62.4 & - & - \\
\hline
\end{tabular}

\begin{tabular}{|c|c|c|c}
\hline 11 & 56.4 & - & - \\
\hline 15 & - & - & 61.9 \\
\hline
\end{tabular}

\begin{tabular}{|l|l}
\hline 15 & - \\
\hline 18 & -
\end{tabular}

\begin{tabular}{|c|c|c|}
\hline 21 & \\
\hline $1^{b}$ & 2017 \\
\hline
\end{tabular}

- 524

- $\quad 56.3$

61.7

61.9

\begin{tabular}{l}
- \\
\hline
\end{tabular}

52.4

-

\begin{tabular}{l|l}
- & 50.9 \\
\hline
\end{tabular}

\begin{tabular}{|c|c|c|c|c|c|c|}
\hline 1 & 201.5 & 116.9 & 190.7 & 147.4 & - & - \\
\hline 2 & - & 128.4 & 133.3 & - & 119.2 & 91.5 \\
\hline 4 & 111.5 & - & - & 110.5 & 104.9 & 92.2 \\
\hline 7 & 106.9 & - & - & $-\mathrm{c}$ & 104.9 & 92.9 \\
\hline
\end{tabular}

\begin{tabular}{|c|c|c|c}
\hline 7 & 106.9 & - & - \\
\hline 9 & 100.8 & 98.7 & - \\
\hline 11 & 89.7 & - & - \\
\hline
\end{tabular}

\begin{tabular}{|c|c|c|}
\hline 11 & 89.7 & \\
\hline 15 & - & \\
\hline
\end{tabular}

\begin{tabular}{c|c|c|c}
\hline 18 & - & 79.7 & 79.7 \\
\hline & 72.6 & 72.6 & 72.7 \\
\hline
\end{tabular}

VOC:

Toluene

Initial concentration:

421 ppinv

\begin{tabular}{|c|c|c|c|c|c|c|}
\hline 21 & 72.6 & 72.6 & 72.7 & 72.5 & - & - \\
\hline $1^{\mathrm{b}}$ & 27.1 & 27.0 & 27.0 & 26.9 & - & - \\
\hline 2 & - & 18.1 & 18.1 & - & 24.4 & 16.5 \\
\hline 4 & 14.5 & - & - & 14.5 & 19.4 & 15.6 \\
\hline 7 & 21.2 & - & - & $-\mathrm{b}$ & 21.0 & 23.1 \\
\hline 9 & 19.9 & 19.6 & - & - & 22.9 & 21.1 \\
\hline 11 & $43.8^{\mathrm{c}}$ & - & - & $-\mathrm{c}$ & 21.4 & 19.9 \\
\hline 15 & - & - & 19.9 & 19.9 & 23.7 & 22.4 \\
\hline 18 & - & 17.6 & 17.6 & - & 20.9 & 20.0 \\
\hline 21 & 15.7 & 15.7 & 15.7 & 15.6 & - & - \\
\hline \hline
\end{tabular}

VOC:

P-xylene

Initial concentration:

$120 \mathrm{ppmv}$

\begin{tabular}{|c|c|c|c|c|c|c|}
\hline $\mathrm{I}^{\mathrm{b}}$ & 5.4 & 5.4 & 6.1 & 6.2 & - & - \\
\hline 2 & - & 3.9 & 3.8 & - & 4.6 & 2.8 \\
\hline 4 & 3.9 & - & - & 3.8 & 4.5 & 3.4 \\
\hline 7 & 6.5 & - & - & $-\mathrm{b}$ & 7.3 & 6.9 \\
\hline 9 & 7.2 & 7.2 & - & - & 7.7 & 7.2 \\
\hline 11 & 7.6 & - & - & 7.5 & 11.1 & 10.5 \\
\hline 15 & - & - & 6.7 & 6.6 & 6.8 & 6.8 \\
\hline 18 & - & 7.5 & 7.4 & - & 7.6 & 7.7 \\
\hline 21 & 6.2 & 6.2 & 6.2 & 6.1 & - & - \\
\hline
\end{tabular}

Notes:
a. Small hole in bag.
b. Sampled approximately 26 hrs after filling small bags at $t=0$.
c. No data detected.
d. Suspect data. 
DRUM: 2.1

GAS: A TEMP: Variable SMALL BAG CLOSURE: heat seal

Voc:

1,1,2-Trichloro-1,2,2trif luoroethane (Freon-113)

Initial concentration:

903 ppmv

\begin{tabular}{|c|c|c|c|c|c|c|}
\hline DAY & SB1 & SB2 & SB3 & SB4 & L. BAG & DRUM \\
\hline $1^{\mathrm{b}}$ & 596.6 & 582.7 & 596.8 & 371.6 & - & - \\
\hline 2 & 408.3 & - & 417.7 & - & 177.1 & 7.5 \\
\hline 4 & - & 230.8 & - & 182.0 & 176.1 & 43.5 \\
\hline 7 & - & 160.5 & - & 148.9 & 142.8 & 46.0 \\
\hline 9 & 140.4 & 139.3 & - & - & 126.8 & 42.6 \\
\hline 11 & - & 123.7 & - & 116.8 & 112.9 & 35.5 \\
\hline 15 & - & - & 98.2 & 91.0 & 88.7 & 26.1 \\
\hline 18 & 81.0 & - & 81.3 & - & 73.9 & 24.3 \\
\hline 21 & 65.7 & 65.7 & 66.2 & 61.4 & - & - \\
\hline \hline
\end{tabular}

VOC:

Methy lene chloride

Initial concentration:

\begin{tabular}{|c|c|c|c|c|c|c|}
\hline $1^{b}$ & 188.5 & 187.3 & 189.1 & 185.9 & - & - \\
\hline 2 & 165.7 & - & 165.8 & - & 161.8 & 63.5 \\
\hline 4 & - & 140.8 & - & 140.1 & 139.4 & 71.2 \\
\hline 7 & - & 110.4 & - & 109.6 & 108.7 & 56.8 \\
\hline 9 & 95.6 & 95.3 & - & - & 95.4 & 51.4 \\
\hline 11 & - & 85.5 & - & 85.3 & 84.4 & 44.8 \\
\hline 15 & - & - & 68.8 & 68.7 & 67.8 & 37.3 \\
\hline 18 & 58.5 & - & 58.5 & - & 57.8 & 35.8 \\
\hline 21 & 49.8 & 49.7 & 49.5 & 49.5 & - & - \\
\hline \hline
\end{tabular}

VOC:

1,1,1-Trichloroethane

Initial concentration:

977 ppmv

VOC:

Carbon tetrachloride

Initial concentration:

305 ppmy

Voc:

Trichloroethylene

Initial concentration:

$310 \mathrm{ppmv}$

\begin{tabular}{|c|c|c|c|c|c|c|}
\hline $1^{b}$ & 234.3 & 227.0 & 246.4 & 200.5 & - & - \\
\hline 2 & 168.8 & - & 170.4 & - & 153.6 & 48.4 \\
\hline 4 & - & 147.8 & - & 146.0 & 139.4 & 63.5 \\
\hline 7 & - & 121.9 & - & 120.4 & 115.3 & 55.7 \\
\hline 9 & 108.6 & 108.3 & - & - & 104.9 & 52.9 \\
\hline 11 & - & 99.7 & - & 98.8 & 95.9 & 47.0 \\
\hline 15 & - & - & 84.2 & 83.4 & 80.6 & 40.6 \\
\hline 18 & 77.4 & - & 77.8 & - & 75.8 & 41.0 \\
\hline 21 & 64.3 & 63.9 & 63.9 & 63.3 & - & - \\
\hline \hline
\end{tabular}

\begin{tabular}{|c|c|c|c|c|}
\hline $1^{\mathrm{b}}$ & 53.7 & 53.5 & 56.9 & \\
\hline 2 & 40.4 & - & 40.4 & \\
\hline 4 & - & 36.3 & - & \\
\hline 7 & - & 29.8 & - & \\
\hline
\end{tabular}

\begin{tabular}{|c|c|c|c|c|}
\hline 7 & - & 29.8 & - & \\
\hline 9 & 27.1 & 27.2 & - & \\
\hline 11 & & 25.5 & &
\end{tabular}

- 36.6

\begin{tabular}{l|l} 
& 36.6 \\
\hline 35.7 & 33.0
\end{tabular}

$-$

\begin{tabular}{|c|c|c|c|c|c|c|}
\hline 11 & - & 25.5 & - & 25.5 & 23.4 & 10.1 \\
\hline 15 & - & - & 20.5 & 20.0 & 18.9 & 8.5 \\
\hline 18 & 19.3 & - & 20.1 & - & 18.9 & 8.8 \\
\hline 21 & 15.6 & 15.1 & 15.4 & 15.5 & - & - \\
\hline $1^{b}$ & 39.7 & 41.2 & 42.1 & 43.3 & - & - \\
\hline 2 & 32.2 & - & 32.2 & - & 29.6 & 10.9 \\
\hline 4 & - & 29.6 & - & 29.6 & 27.5 & 12.5 \\
\hline 7 & - & 24.4 & - & 24.2 & 22.5 & 11.9 \\
\hline 9 & 22.1 & 21.9 & - & - & 21.2 & 11.9 \\
\hline 11 & - & 20.7 & - & 20.6 & 19.8 & 11.2 \\
\hline 15 & - & - & 18.5 & 18.6 & 17.6 & 10.7 \\
\hline 18 & 18.8 & - & 18.8 & - & 18.0 & 11.4 \\
\hline 21 & 15.7 & 15.5 & 15.6 & 15.5 & - & - \\
\hline
\end{tabular}

Notes:

a. Small hole in bag.

b. Sampled approximately $24 \mathrm{hrs}$ after filling small bags at $t=0$. 
DRUM: 2.2 GAS: B TEMP: Variable SMALL BAG CLOSURE: horsetail

\begin{tabular}{|c|c|c|c|c|c|c|c|}
\hline VOC: & DAY & SB1 & SB2 & SB3 & SB4 & L. $B A G$ & DRUM $^{2}$ \\
\hline & $1^{b}$ & 271.9 & 267.8 & 269.2 & 292.6 & - & - \\
\hline Methanol & 2 & 204.1 & 202.9 & - & - & 171.1 & 24.1 \\
\hline Initiol concentrating. & 4 & - & 150.8 & - & 152.1 & 137.2 & 33.6 \\
\hline Imilid concentration: & 7 & 101.0 & 100.9 & - & - & 92.6 & 9.2 \\
\hline \multirow[t]{5}{*}{$1002 \mathrm{ppmv}$} & 9 & 85.0 & - & - & 85.1 & 79.8 & 17.8 \\
\hline & 11 & - & 73.8 & 71.3 & - & 69.9 & 8.1 \\
\hline & 15 & - & - & 53.6 & 54.0 & 52.5 & 9.9 \\
\hline & 18 & 42.8 & - & 42.7 & - & 42.7 & 19.4 \\
\hline & 21 & 33.4 & 33.2 & 33.3 & 33.4 & - & - \\
\hline \multirow[t]{2}{*}{ VOC: } & $1^{b}$ & 129.6 & 132.1 & 136.3 & 143.7 & - & - \\
\hline & 2 & 94.4 & 92.9 & $=$ & - & 85.5 & 1.8 \\
\hline \multirow[t]{3}{*}{ Cyc lohexane } & 4 & - & 80.7 & $=$ & 81.4 & 79.0 & 8.9 \\
\hline & 7 & 68.6 & 68.6 & - & - & 67.3 & -4.2 \\
\hline & 9 & 56.7 & - & - & 57.0 & 56.9 & 3.3 \\
\hline Initial concentration: & 11 & - & 50.0 & 49.4 & - & 48.3 & -3.6 \\
\hline \multirow{3}{*}{777 ppmv } & 15 & - & - & 41.0 & 42.3 & 40.1 & -1.1 \\
\hline & 18 & 39.0 & $=$ & 40.4 & - & 39.7 & 10.3 \\
\hline & 21 & 27.8 & 27.7 & 27.7 & 27.7 & - & - \\
\hline \multirow[t]{2}{*}{ VOC: } & $1^{6}$ & 222.9 & 222.5 & 228.4 & 247.7 & - & $=$ \\
\hline & 2 & 155.7 & 154.5 & - & - & 139.8 & 8.7 \\
\hline \multirow{2}{*}{ 1,1,1-Trichloroethane } & 4 & - & 131.4 & - & 132.8 & 128.2 & 20.8 \\
\hline & 7 & 112.3 & 11.1 .9 & - & - & 109.3 & 1.6 \\
\hline \multirow[t]{2}{*}{ Initial concentration: } & 9 & 94.2 & - & - & 94.6 & 93.5 & 12.2 \\
\hline & 11 & - & 82.2 & 80.8 & - & 80.9 & 1.2 \\
\hline \multirow{3}{*}{$1020 \mathrm{ppmv}$} & 15 & - & - & 67.4 & 68.9 & 66.1 & 5.0 \\
\hline & 18 & 61.4 & $=$ & 62.8 & - & 61.9 & 19.5 \\
\hline & 21 & 47.2 & 47.1 & 47.0 & 47.2 & - & - \\
\hline \multirow[t]{2}{*}{ voc: } & $1^{b}$ & 40.3 & 41.9 & 42.6 & 41.7 & - & $=$ \\
\hline & 2 & 27.9 & 26.4 & - & - & 33.0 & 5.0 \\
\hline \multirow[t]{2}{*}{ Toluene } & 4 & - & 23.6 & $=$ & 23.7 & 31.1 & 6.7 \\
\hline & 7 & 18.6 & 18.6 & - & - & 24.8 & 4.5 \\
\hline Initial concentration: & 9 & 15.3 & - & - & 15.3 & 20.9 & 5.3 \\
\hline \multirow[t]{4}{*}{421 ppmv } & 11 & - & 15.8 & 16.3 & - & 20.5 & 4.2 \\
\hline & 15 & - & - & 13.8 & 14.6 & 17.8 & 4.9 \\
\hline & 18 & 15.4 & - & 15.7 & - & 21.0 & 10.3 \\
\hline & 21 & 10.0 & 9.9 & 10.0 & 9.9 & - & - \\
\hline \multirow[t]{2}{*}{ VOC: } & $1^{b}$ & 9.3 & 9.8 & 9.9 & 9.7 & - & - \\
\hline & 2 & 6.2 & 5.9 & $=$ & - & 6.5 & 3.2 \\
\hline \multirow{2}{*}{ P-xylene } & 4 & - & 6.0 & - & 5.9 & 6.8 & 3.8 \\
\hline & 7 & 5.2 & 5.1 & - & - & 6.0 & 3.6 \\
\hline \multirow[t]{2}{*}{ Initial concentration: } & 9 & 4.6 & - & - & 4.4 & 5.0 & 3.1 \\
\hline & 11 & 5.0 & - & - & 5.1 & 5.5 & 4.3 \\
\hline \multirow[t]{3}{*}{120 ppmv } & 15 & - & - & 4.9 & 4.9 & 4.7 & 3.3 \\
\hline & 18 & 5.8 & - & 5.7 & - & 6.2 & 4.2 \\
\hline & 21 & 3.9 & 3.9 & 4.0 & 4.0 & - & - \\
\hline
\end{tabular}

Notes: a. Suspect data (faulty sample line).

b. Sampled 25 hrs after filling small bags at $t=0$. 
DRUM: 2.3

GAS: A TEMP: Constant SMALL BAG CLOSURE: horsetail

VOC:

1,1,2-Trichloro-1,2,2trifluoroethane (Freon-113)

Initial concentration:

903 ppmv

\begin{tabular}{|c|c|c|c|c|c|c|}
\hline DAY & SB1 & SB2 & SB3 & SB4 & L. BAG & DRUM \\
\hline $1^{\mathrm{a}}$ & 582.0 & 506.8 & 570.0 & 537.3 & - & - \\
\hline 2 & - & 365.3 & - & 403.0 & 171.7 & 10.3 \\
\hline 4 & - & - & 287.6 & 256.0 & 176.7 & 51.1 \\
\hline 7 & 189.7 & - & 190.0 & - & 152.4 & 73.2 \\
\hline 9 & 164.8 & - & - & 158.1 & 143.2 & 79.0 \\
\hline 11 & - & 143.5 & - & - & 133.7 & 78.3 \\
\hline 15 & 125.7 & - & $90.9^{c}$ & - & 117.0 & 73.0 \\
\hline 18 & 112.8 & 111.2 & - & - & 104.6 & 57.0 \\
\hline 21 & 100.0 & 98.7 & 101.2 & 99.9 & - & - \\
\hline
\end{tabular}

VOC:

Methylene chloride

Initial concentration:

\begin{tabular}{|c|c|c|c|c|c|c|}
\hline $1^{\mathrm{a}}$ & 176.7 & 174.8 & 176.7 & 175.5 & - & - \\
\hline 2 & - & 159.1 & - & 160.0 & 157.5 & 85.5 \\
\hline 4 & - & - & 138.9 & 139.0 & 138.0 & 96.9 \\
\hline 7 & 115.8 & - & 116.1 & - & 114.9 & 86.1 \\
\hline 9 & 106.8 & - & - & 107.2 & 106.9 & 82.2 \\
\hline 11 & & 110.0 & $b$ & & 99.6 & 76.9 \\
\hline
\end{tabular}

1.1.1-Trichloroethane

1012 ppmv

Initial concentration:

977 ppmv

VOC:

Carbon tetrachloride

Initial concentration:

305 ppmv

\begin{tabular}{|c|c|c|}
\hline 11 & - & 110 \\
\hline 15 & 87.7 & \\
\hline 18 & 78.0 & \\
\hline 21 & 69.4 & \\
\hline
\end{tabular}

110.6

$-\quad 674^{c}$

$-$

\begin{tabular}{c|c|c}
- & $67.4^{\mathrm{c}}$ & - \\
\hline 77.9 & - & -
\end{tabular}

\begin{tabular}{l|l}
\hline 77 \\
\hline
\end{tabular}

\begin{tabular}{l|l|l}
69.8 & 70.0 & 69.8 \\
\hline
\end{tabular}

\begin{tabular}{|c|c|c|c|c|c|c|}
\hline $1^{\mathrm{a}}$ & 213.5 & 191.6 & 208.9 & 200.3 & - & - \\
\hline 2 & - & 160.0 & - & 162.2 & 147.8 & 59.7 \\
\hline 4 & - & - & 141.3 & 141.3 & 133.8 & 81.9 \\
\hline 7 & 121.6 & - & 121.9 & - & 116.6 & 80.0 \\
\hline
\end{tabular}

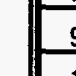

\begin{tabular}{|c|c|c|c|c|c|c|}
\hline 9 & 114.6 & - & - & 114.7 & 111.1 & 79.9 \\
\hline 11 & - & 109.3 & $-b$ & - & 105.8 & 76.7 \\
\hline 15 & 98.8 & & 75.8 & & 95.9 & 71.6 \\
\hline
\end{tabular}<smiles>C1CC2CC1C1CC2C1</smiles>

\begin{tabular}{|l|l|l|l|}
\hline 15 & 98.8 & \\
\hline 18 & 90.3 & \\
\hline 21 & 82.2 & \\
\hline
\end{tabular}

\begin{tabular}{|c|c|c|}
\hline \multicolumn{1}{|c|}{} & 82.2 & \\
\hline $1^{\mathrm{a}}$ & 47.2 & \\
\hline 2 & - & \\
\hline 4 & - & \\
\hline 7 & 28.9 & \\
\hline
\end{tabular}

\begin{tabular}{l|c|l} 
& $75.8^{\mathrm{C}}$ & \\
90.2 & - & -
\end{tabular}

82.3

82.4

$-$

3

88.7

\begin{tabular}{l|l|l|}
45.1 & 46.9 & 45.8 \\
\hline
\end{tabular}

$-$

\begin{tabular}{l|l}
\hline .7 & 61.7 \\
\hline &
\end{tabular}

\begin{tabular}{|c|c|c|c|c|c|c|c|}
\hline \multirow{4}{*}{305 ppmv } & 11 & - & 27.0 & - & - & 25.0 & 17.6 \\
\hline & 15 & 23.4 & - & $17.6^{\mathrm{C}}$ & - & 22.1 & 15.7 \\
\hline & 18 & 22.0 & 21.8 & - & - & 20.8 & 13.7 \\
\hline & 21 & 19.3 & 19.6 & 19.5 & 19.6 & - & - \\
\hline \multirow[t]{2}{*}{ VOC: } & $1^{a}$ & 33.7 & 33.7 & 34.0 & 33.7 & - & - \\
\hline & 2 & - & 30.9 & - & 30.8 & 28.7 & 13.1 \\
\hline \multirow[t]{2}{*}{ Trichloroethylene } & 4 & - & - & 27.2 & 27.3 & 25.6 & 14.0 \\
\hline & 7 & 23.2 & - & 23.2 & - & 21.8 & 14.0 \\
\hline \multirow[t]{2}{*}{ Initial concentration: } & 9 & 21.7 & - & - & 21.8 & 20.9 & 14.4 \\
\hline & 11 & - & 20.8 & $-b$ & - & 19.9 & 14.1 \\
\hline \multirow[t]{3}{*}{$310 \mathrm{ppmv}$} & 15 & 19.2 & - & $15.6^{\mathrm{C}}$ & - & 18.1 & 13.4 \\
\hline & 18 & 17.4 & 17.4 & - & - & 16.7 & 12.6 \\
\hline & 21 & 16.1 & 16.1 & 16.1 & 16.1 & - & - \\
\hline
\end{tabular}

Notes:

a. Sampled approximately $27 \mathrm{hrs}$ after filling small bags at $t=0$.

b. No data detected.

c. Suspect data. 
DRUN: 2.4

GAS: B TEMP: Constant SMALL BAG CLOSURE: heat seal

VOC:

Methano 1

Initial concentration:

$1002 \mathrm{ppmv}$

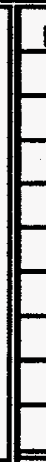

\begin{tabular}{|c|c|}
\hline DAY & SB1 \\
\hline $1^{\mathrm{a}}$ & 281.9 \\
\hline 2 & - \\
\hline 4 & 139.8 \\
\hline
\end{tabular}

$S B 2$

VOC:

Cyclohexane

Initial concentration:

777 ppmv

\begin{tabular}{|c|c|c|c|c|c|c|}
\hline 4 & 139.8 & - & - & 140.9 & 125.2 & 92.8 \\
\hline 7 & 111.1 & - & - & 111.5 & 104.3 & 86.5 \\
\hline 9 & 103.7 & 104 & - & & 98.0 & 85.6 \\
\hline
\end{tabular}

\begin{tabular}{|l|c|c|c}
\hline 9 & 103.7 & 104.1 & \\
\hline 11 & 96.7 & - & \\
\hline
\end{tabular}

\begin{tabular}{l|l|l}
\hline 15 & - & - \\
\hline
\end{tabular}

\begin{tabular}{|c|c|c|c|c|}
\hline 18 & - & 74.2 & 74.9 & \\
\hline 21 & 65.7 & 66.0 & 66.3 & \\
\hline $1^{\mathrm{a}}$ & 130.7 & 129.1 & 131.3 & 122 \\
\hline 2 & - & 105.2 & 106.2 & \\
\hline 4 & 78.0 & - & - & \\
\hline 7 & 76.9 & & & \\
\hline
\end{tabular}

$-\quad 74.2$

\begin{tabular}{l|l}
- & 82. \\
\hline & \\
\hline
\end{tabular}

$-$

96.6

98.0

85.6

\begin{tabular}{|l|l|}
$59.5^{b}$ & 80.5 \\
\hline
\end{tabular}

83.7

VOC:

1,1,1-Trichloroethane

Initial concentration:

$1020 \mathrm{ppmv}$

\begin{tabular}{|c|c|c|c|c|c|c|}
\hline 9 & 68.1 & 68.0 & - & - & 68.8 & 57.2 \\
\hline 11 & 61.5 & - & - & 60.9 & 60.5 & 51.2 \\
\hline
\end{tabular}

\begin{tabular}{|c|c|c|c|c|c|c|}
\hline 11 & 61.5 & - & - & 60.9 & 60.5 & 51.2 \\
\hline 15 & - & - & 55.0 & $37.0^{b}$ & 55.2 & 47.0 \\
\hline 18 & - & 48.8 & 48.9 & - & 49.8 & 42.1 \\
\hline
\end{tabular}

\begin{tabular}{|l|l|l|l|l|l}
\hline 21 & 44.6 & 44.6 & 44.8 & 44.7 \\
\hline
\end{tabular}

\begin{tabular}{|c|c|c|c|c|c|c|}
\hline $1^{\mathrm{a}}$ & 234.7 & 235.6 & 236.9 & 220.7 & - & - \\
\hline 2 & - & 175.8 & 177.0 & - & 155.6 & 71.9 \\
\hline 4 & 126.8 & - & - & 126.4 & 122.1 & 84.4 \\
\hline 7 & 124.5 & - & - & 124.6 & 122.6 & 100.3 \\
\hline 9 & 112.1 & 112.1 & - & - & 112.4 & 95.4 \\
\hline
\end{tabular}

Notes: a. Sampled approximately $27 \mathrm{hrs}$ after filling small bag at $\mathbf{t}=0$.

b. Suspect data. 
ORUM: 3.1

GAS: A TEMP: Variable SMALL BAG CLOSURE: horsetail

voc:

1,1,2-Trichloro-1,2,2-

trifluoroethane (Freon-113)

Initial concentration:

903 ppmv

\begin{tabular}{|c|c|c|c|c|c|c|}
\hline DAY & SB1 & SB2 & SB3 & SB4 & L. BAG & ORUM \\
\hline $1^{\mathrm{a}}$ & 481.2 & 540.3 & 562.1 & 567.0 & - & - \\
\hline 2 & 178.2 & - & 181.6 & - & 172.0 & 26.5 \\
\hline 6 & - & 155.9 & - & 154.9 & 144.3 & 28.4 \\
\hline 8 & - & 134.5 & - & 133.8 & 125.4 & 27.4 \\
\hline 11 & 110.4 & 112.0 & - & - & 104.0 & 18.2 \\
\hline 13 & - & 96.7 & - & 96.6 & 91.4 & 18.7 \\
\hline 15 & - & - & 85.9 & $-b$ & 79.5 & 13.0 \\
\hline 18 & 69.6 & - & 70.7 & - & 65.7 & 8.3 \\
\hline 21 & 56.7 & 57.4 & 58.8 & 57.5 & - & - \\
\hline
\end{tabular}

VOC:

Methylene chloride

Initial concentration:

\begin{tabular}{|c|c|c|c|c|c|c|}
\hline $1^{a}$ & 188.8 & 188.1 & 188.5 & 188.3 & - & - \\
\hline 4 & 145.1 & - & 144.8 & - & 145.0 & 47.3 \\
\hline
\end{tabular}

$1012 \mathrm{ppmv}$

VOC:

1,1,1-Trichloroethane

Initial concentration:

977 ppmv

Voc:

Carbon tetrachloride

Initial concentration:

305 ppmv

\begin{tabular}{|c|c|c|c|c|c|c|}
\hline 4 & 143.1 & - & 144.8 & $=$ & 145.0 & 47.3 \\
\hline 6 & - & 112.2 & $=$ & 112.3 & 111.2 & 41.2 \\
\hline 8 & $=$ & 94.8 & $=$ & 94.7 & 93.6 & 37.4 \\
\hline 11 & 77.8 & 78.2 & - & - & 77.0 & 31.7 \\
\hline 13 & - & 70.4 & - & 70 & 703 & 31 \\
\hline
\end{tabular}

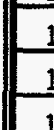

\begin{tabular}{|c|c|c|c|}
\hline 13 & - & 70.4 & \\
\hline 15 & - & - & 6 \\
\hline 18 & 53.4 & - & 53. \\
\hline
\end{tabular}

\begin{tabular}{|l|l|}
\hline 18 & 53 \\
\hline 21 & 46 \\
\hline
\end{tabular}

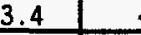

53.0

\begin{tabular}{c|c}
- & 70.6 \\
\hline
\end{tabular}

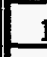

\begin{tabular}{l|l|l}
\hline $1^{a}$ & 206.4 & 212.4 \\
\hline 4 & 154.3 & \\
\hline
\end{tabular}

\begin{tabular}{|l|l|l|}
\hline .4 & 46.5 & 46.5 \\
\hline
\end{tabular}

\begin{tabular}{|c|c|c|}
\hline 4 & 154.3 & - \\
\hline 6 & - & 117.8 \\
\hline 8 & - & 104 \\
\hline
\end{tabular}

\begin{tabular}{l|l}
4 & $22 i$ \\
\hline
\end{tabular}

\begin{tabular}{c|c|c}
\hline $11^{\mathrm{C}}$ & 90.5 & 91.7 \\
\hline 13 & - & 90.1 \\
\hline
\end{tabular}

\begin{tabular}{l|l}
.8 & -
\end{tabular}

\begin{tabular}{c|c}
153.2 & - \\
\hline- & 117. \\
\hline
\end{tabular} $-$

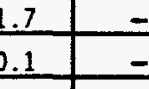

\begin{tabular}{|c|c|c|}
\hline 13 & - & 90 \\
\hline 15 & - & - \\
\hline 18 & 66.7 & - \\
\hline 21 & 59.1 & 59 \\
\hline
\end{tabular}

\begin{tabular}{l|l}
- & 78 \\
\hline
\end{tabular}

\begin{tabular}{|l|l|}
\hline 104.2 & 17.3 \\
\hline
\end{tabular}

\begin{tabular}{|c|c|c|c|c|c|c|}
\hline 18 & 66.7 & - & 67.1 & - & 65.0 & 25.4 \\
\hline 21 & 59.1 & 59.2 & 58.8 & 70.7 & - & - \\
\hline $1^{\mathrm{a}}$ & 48.9 & 46.2 & 47.2 & 47.9 & - & - \\
\hline 4 & 36.7 & - & 35.5 & - & 34.3 & 7.1 \\
\hline 6 & - & 26.5 & - & 26.3 & 25.5 & 6.5 \\
\hline 8 & - & 23.0 & - & 23.4 & 21.9 & 6.3 \\
\hline
\end{tabular}

\begin{tabular}{|l|}
\hline 60.3 \\
\hline 52.7 \\
\hline
\end{tabular}

26.4

\begin{tabular}{|c|c|c|c|c|c|c|}
\hline $11^{\mathrm{c}}$ & 20.7 & 20.8 & - & - & 19.6 & 5.2 \\
\hline 13 & - & 20.1 & - & 20.9 & 19.6 & 5.4 \\
\hline 15 & - & - & 17.2 & $-\mathrm{b}$ & 16.6 & 4.2 \\
\hline 18 & 16.1 & - & 13.9 & - & 13.4 & 3.3 \\
\hline 21 & 12.5 & 13.2 & 12.5 & 12.5 & - & - \\
\hline
\end{tabular}

VOC:

Trichloroethylene

Initial concentration:

$310 \mathrm{ppmiv}$

\begin{tabular}{|c|c|c|c|c|c|c|}
\hline 21 & 12.5 & 13.2 & 12.5 & 12.5 & - & - \\
\hline $1^{\mathrm{a}}$ & 37.2 & 36.0 & 37.0 & 37.1 & - & - \\
\hline 4 & 33.7 & - & 33.6 & - & 32.1 & 10.4 \\
\hline 6 & - & 21.7 & - & 21.7 & 20.8 & 8.3 \\
\hline 8 & - & 19.5 & - & 19.6 & 18.7 & 8.2 \\
\hline $1^{\mathrm{c}}$ & 17.6 & 18.1 & - & - & 16.8 & 8.1 \\
\hline 13 & - & 20.2 & - & 20.3 & 19.7 & 9.9 \\
\hline 15 & - & - & 17.0 & $-b$ & 16.3 & 8.0 \\
\hline 18 & 14.6 & - & 14.8 & - & 14.1 & 7.4 \\
\hline 21 & 13.9 & 13.8 & 13.8 & 13.7 & - & - \\
\hline
\end{tabular}

Notes:
a. Sampled approximately 21 hrs after filling small bags at $t=0$.
b. No data detected.
c. Suspect data. 
DRUM: 3.2

GAS: B TEMP: Variable SMALL BAG CLOSURE: heat seal

VOC:
Methanol
Initial concentration:

987 ppmv

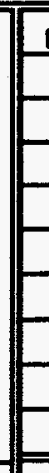

VOC:

Cyc lohexane

Initial concentration:

787 ppmy

VOC:

1,1,1-Trich loroethane

Initial concentration:

$1054 \mathrm{ppmv}$

\begin{tabular}{|c|c|}
\hline DAY & SB \\
\hline $1^{a}$ & 31 \\
\hline 4 & 15 \\
\hline 6 & \\
\hline 8 & 107 \\
\hline 11 & 89 \\
\hline 13 & \\
\hline 15 & \\
\hline 18 & 59 \\
\hline 21 & 5 \\
\hline
\end{tabular}

SB2

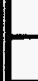

$\frac{1}{4}$

51.1

286.0

274.5

\begin{tabular}{c|c}
\hline 283 & SB \\
\hline- & 303. \\
\hline
\end{tabular}

303.3

L. $B A G$

\begin{tabular}{c|c}
- & - \\
\hline- & 127. \\
\hline- & -
\end{tabular}

148.6

$-$

\begin{tabular}{|l|}
144.3 \\
\hline 119.6
\end{tabular}

\begin{tabular}{c|c}
- & - \\
73.4 & $55.6^{b}$
\end{tabular}

\begin{tabular}{l}
$-\quad 100.7$ \\
\hline
\end{tabular}

87.5

85.4

\begin{tabular}{l|r}
- & 63.9 \\
\hline- & 58.9 \\
\hline
\end{tabular}

\begin{tabular}{c|c}
- & 72.7 \\
\hline$c$ & 65.9
\end{tabular}

\begin{tabular}{l|l}
- & 65.9 \\
\hline- & 58.1
\end{tabular}

\begin{tabular}{l|l|l}
51.0 & 50.9 & 51.0 \\
\hline
\end{tabular}

\begin{tabular}{l|l}
151.4 & 125.1
\end{tabular}

96.4

\begin{tabular}{l|l}
25.1 & 125.0 \\
\hline
\end{tabular}

\begin{tabular}{l|l}
125.0 & 137. \\
\hline
\end{tabular}

\begin{tabular}{|c|c|c|c|c|c|c|}
\hline 4 & 96.4 & 94.2 & - & - & 96.4 & 43.6 \\
\hline 6 & - & 76.0 & - & 75.9 & 75.3 & 36.7 \\
\hline 8 & 68.4 & 68.1 & - & - & 67.9 & 35.7 \\
\hline 11 & 62.5 & - & - & 62.8 & 63.0 & 32.3 \\
\hline
\end{tabular}

\begin{tabular}{|c|c|c}
\hline 11 & 62.5 & - \\
\hline 13 & - & 55 \\
\hline
\end{tabular}

\begin{tabular}{|c|c|}
\hline- & \\
\hline $38.1^{b}$ & \\
\hline 48.3 &
\end{tabular}

\begin{tabular}{|l|r}
\hline 15 & - \\
\hline 18 & 40.7 \\
\hline
\end{tabular}

40.7

\begin{tabular}{l|l}
$-\quad 48$ \\
\hline
\end{tabular}

$-$

63.0

32.3

21

1

voC:

Toluene

Initial concentration:

425 ppmv

\begin{tabular}{|c|c|c|c|c|c|c|c|}
\hline \multirow{4}{*}{425 ppmv } & 13 & - & 17.1 & 12.1 & $=$ & 25.2 & 15.4 \\
\hline & 15 & - & - & 15.3 & $-{ }^{c}$ & 22.6 & 13.2 \\
\hline & 18 & 11.4 & - & 11.7 & - & 16.4 & 4.2 \\
\hline & 21 & 11.1 & 11.0 & 11.0 & 11.1 & - & - \\
\hline \multirow[t]{2}{*}{ VOC: } & $1^{a}$ & 12.3 & 12.2 & 12.2 & 12.3 & - & - \\
\hline & 4 & 10.4 & 10.5 & - & - & 11.6 & 8.7 \\
\hline \multirow{2}{*}{$p$-xy lene } & 6 & - & 10.8 & - & 9.6 & 10.6 & 8.9 \\
\hline & 8 & 8.7 & $B .6$ & - & - & 9.3 & 7.8 \\
\hline \multirow[t]{2}{*}{ Initial concentration: } & 11 & 10.9 & - & - & 11.0 & 11.9 & 9.7 \\
\hline & 13 & - & $16.1^{b}$ & $10.2^{b}$ & - & 9.2 & 9.0 \\
\hline \multirow[t]{3}{*}{99.2 ppmv } & 15 & - & - & 10.0 & $-c$ & 10.5 & 9.1 \\
\hline & 18 & 9.6 & - & 9.5 & - & 9.9 & 8.5 \\
\hline & 21 & 9.9 & 9.9 & 9.9 & 9.9 & - & - \\
\hline
\end{tabular}

Notes: a. Sampled approximately $2 I$ hrs after small bags filled at $t=0$.

b. Suspect data.

c. No data detected. 
DRUM: 3.3

GAS: B TEMP: Constant SMALL BAG CLOSURE: horsetail

\begin{tabular}{|c|c|c|c|c|c|c|c|}
\hline \multirow[t]{2}{*}{ VOC: } & DAY & SB1 & SB2 & SB3 & SB4 & L. $B A G$ & DRUM \\
\hline & $1^{a}$ & 220.0 & 261.7 & 281.2 & 285.3 & - & - \\
\hline \multirow[t]{2}{*}{ Methanol } & 4 & - & 143.8 & - & 125.0 & 131.2 & 45.2 \\
\hline & 6 & - & - & 121.8 & 121.6 & 112.7 & 44.5 \\
\hline Initial concentration: & 8 & 102.4 & - & 104.2 & - & 96.3 & 50.3 \\
\hline \multirow{5}{*}{987 ppmi } & 11 & 88.6 & - & - & 88.7 & 82.9 & $36.5^{b}$ \\
\hline & 13 & - & 80.4 & $-c$ & - & 74.2 & $37.1^{b}$ \\
\hline & 15 & 72.1 & - & 73.9 & - & 68.7 & 37.5 \\
\hline & 18 & 68.4 & 67.6 & - & - & 62.8 & $-c$ \\
\hline & 21 & 61.9 & 62.2 & 63.4 & 61.3 & - & - \\
\hline \multirow[t]{2}{*}{ VOC: } & $1^{a}$ & 99.6 & 118.2 & 120.2 & 122.1 & - & - \\
\hline & 4 & - & 79.1 & - & 66.5 & 78.9 & 16.0 \\
\hline \multirow[t]{3}{*}{ Cyclohexane } & 6 & $=$ & - & 72.7 & 71.5 & 73.1 & 16.9 \\
\hline & 8 & 66.9 & - & 67.0 & - & 67.8 & 23.7 \\
\hline & 11 & 56.0 & - & - & 56.0 & 56.7 & $9.7^{b}$ \\
\hline \multirow[t]{2}{*}{ Initial concentration: } & 13 & - & 52.0 & $-c$ & - & 53.3 & $12.2^{b}$ \\
\hline & 15 & 47.9 & - & 49.3 & - & 48.6 & 13.3 \\
\hline \multirow{2}{*}{787 ppinv } & 18 & 46.0 & 46.0 & - & - & 46.9 & $-^{c}$ \\
\hline & 21 & 43.5 & 43.8 & 43.6 & 43.6 & - & - \\
\hline VOC: & $1^{2}$ & 158.5 & 204.8 & 213.5 & 216.9 & - & $=$ \\
\hline \multirow{3}{*}{ 1,1,1-Trichloroethane } & 4 & - & 126.7 & - & 106.6 & 126.1 & 25.0 \\
\hline & 6 & - & - & 115.9 & 114.0 & 115.3 & 26.6 \\
\hline & 8 & 106.6 & - & 107.0 & $=$ & 107.2 & 38.3 \\
\hline \multirow[t]{2}{*}{ Initial concentration: } & 11 & 90.1 & - & - & 90.2 & 90.4 & $14.8^{b}$ \\
\hline & 13 & - & 83.7 & $-c$ & - & 84.6 & $19.0^{b}$ \\
\hline \multirow{3}{*}{$1054 \mathrm{ppmv}$} & 15 & 77.3 & - & 79.7 & $=$ & 77.6 & 21.0 \\
\hline & 18 & 74.4 & 74.7 & - & - & 75.2 & $-^{\mathrm{C}}$ \\
\hline & 21 & 70.8 & 70.6 & 70.7 & 70.4 & - & - \\
\hline \multirow[t]{2}{*}{ VOC: } & $1^{a}$ & 26.9 & 27.0 & 26.8 & 26.7 & - & - \\
\hline & 4 & - & 17.8 & - & 15.2 & 25.0 & 3.4 \\
\hline \multirow[t]{2}{*}{ Toluene } & 6 & - & - & 16.2 & 16.0 & 22.9 & 3.9 \\
\hline & 8 & 14.3 & - & 14.3 & - & 20.4 & 4.9 \\
\hline Initial concentration: & 11 & 11.9 & - & - & 11.9 & 16.8 & $3.4^{b}$ \\
\hline \multirow[t]{4}{*}{425 ppmv } & 13 & - & 10.5 & $\mathbf{-}^{\mathrm{c}}$ & - & 15.0 & $3.4^{b}$ \\
\hline & 15 & 9.7 & - & 10.0 & $=$ & 14.2 & 3.8 \\
\hline & 18 & 9.3 & 9.3 & - & - & 13.5 & $-^{c}$ \\
\hline & 21 & 8.9 & 9.0 & 8.9 & 9.0 & - & - \\
\hline \multirow[t]{2}{*}{ VOC: } & $1^{a}$ & 11.3 & 11.4 & 11.3 & 11.3 & - & - \\
\hline & 4 & - & 9.2 & - & 8.9 & 9.9 & 7.5 \\
\hline \multirow{2}{*}{ P-xylene } & 6 & - & - & 9.5 & 9.4 & 10.0 & 7.9 \\
\hline & 8 & 8.4 & - & 8.4 & - & 8.9 & 7.3 \\
\hline \multirow[t]{2}{*}{ Initial concentration: } & 11 & 9.9 & - & - & 9.8 & 10.3 & $8.7^{b}$ \\
\hline & 13 & - & 12.3 & $-^{c}$ & - & 8.0 & $8.4^{\mathrm{b}}$ \\
\hline \multirow[t]{3}{*}{$99.2 \mathrm{ppmv}$} & 15 & 8.9 & - & 8.8 & - & 9.2 & 7.9 \\
\hline & 18 & 9.4 & 9.3 & - & - & 9.7 & $-{ }^{c}$ \\
\hline & 21 & 9.6 & 9.7 & 9.7 & 9.6 & - & - \\
\hline
\end{tabular}

Notes: a. Sampled approximately 21 hrs after filling sma 11 bags at $t=0$.

b. Suspect data.

c. No data detected. 
DRUM: 3.4

GAS: A TEMP: Constant SMALL BAG CLOSURE: heat seal

VOC:

1,1,2-Trichloro-1,2,2-

trif luoroethane (Freon-113)

Initial concentration:

903 ppmv

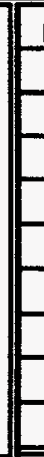

\begin{tabular}{|c|c|c|c|c|c|c|}
\hline DAY & SB1 & SB2 & SB3 $^{\mathrm{a}}$ & SB4 & L. BAG & DRUM \\
\hline $1^{\mathrm{b}}$ & 610.0 & 637.3 & 57.1 & 619.9 & - & - \\
\hline 4 & - & 281.1 & 129.5 & - & 72.3 & 16.9 \\
\hline 6 & 189.8 & - & 152.5 & - & 87.3 & 36.6 \\
\hline 8 & 150.4 & - & - & 152.5 & 92.1 & 52.8 \\
\hline 11 & 121.7 & 124.3 & - & - & 87.0 & 54.1 \\
\hline 13 & 107.9 & - & - & - & 89.0 & 56.6 \\
\hline 15 & - & - & 84.0 & 100.1 & 79.4 & 53.4 \\
\hline 18 & - & 93.7 & 74.7 & - & 76.0 & 55.1 \\
\hline 21 & 85.1 & 85.6 & 57.3 & 85.3 & - & - \\
\hline
\end{tabular}

VOC:

Methylene chloride

Initial concentration:

$1012 \mathrm{ppmv}$

\begin{tabular}{|c|c|c|c|c|c|c|}
\hline $1^{b}$ & 150.1 & 153.1 & 144.5 & 149.6 & - & - \\
\hline 4 & - & 111.7 & 100.9 & - & 108.0 & 66.6 \\
\hline 6 & 63.8 & - & 78.3 & - & 94.6 & 64.6 \\
\hline 8 & 85.5 & - & - & 85.3 & 84.1 & 62.9 \\
\hline 11 & 75.5 & 75.4 & - & - & 73.7 & 55.5 \\
\hline 13 & 70.2 & - & - & $-c$ & 68.9 & 53.7 \\
\hline 15 & - & - & 61.0 & 64.7 & 63.5 & 49.5 \\
\hline 18 & - & 61.1 & 54.2 & - & 59.7 & 48.2 \\
\hline 21 & 56.2 & 56.4 & 44.2 & 56.2 & - & - \\
\hline \hline
\end{tabular}

VOC:

1.1.1-Trichloroethane

Initial concentration:

977 ppmv

VOC:

Carbon tetrachloride

Initial concentration:

305 ppmv

VOC:

Trich loroethylene

Initial concentration:

310 ppmv

\begin{tabular}{|c|c|c|c|c|c|c|}
\hline $1^{b}$ & 205.1 & 231.1 & 141.1 & 209.4 & - & $=$ \\
\hline 4 & - & 120.2 & 117.4 & - & 108.9 & 57.2 \\
\hline 6 & 106.1 & - & 85.8 & - & 98.6 & 60.7 \\
\hline 8 & 97.1 & - & - & 97.2 & 91.7 & 63.7 \\
\hline 11 & 88.7 & 88.9 & $=$ & - & 83.9 & 59.9 \\
\hline 13 & 84.1 & - & - & $-^{c}$ & 80.5 & 60.1 \\
\hline 15 & - & - & 73.7 & 78.9 & 75.0 & 55.8 \\
\hline 18 & - & 75.6 & 67.3 & - & 72.3 & 55.9 \\
\hline 21 & 70.7 & 70.6 & 55.4 & 70.7 & - & - \\
\hline $1^{b}$ & 39.9 & 44.7 & 33.5 & 40.9 & - & $=$ \\
\hline 4 & - & 25.9 & 25.5 & - & 23.1 & 9.9 \\
\hline 6 & 23.1 & - & 18.7 & - & 21.4 & 11.2 \\
\hline 8 & 20.8 & $=$ & - & 21.0 & 18.9 & 11.4 \\
\hline 11 & 18.7 & 18.9 & - & - & 17.1 & 10.4 \\
\hline 13 & 17.3 & - & - & $-c$ & 15.1 & 10.1 \\
\hline 15 & - & $=$ & 15.2 & 16.3 & 14.1 & 9.6 \\
\hline 18 & - & 14.7 & 13.2 & - & 13.9 & 9.3 \\
\hline 21 & 13.8 & 13.6 & 10.3 & 13.9 & - & - \\
\hline $1^{b}$ & 29.3 & 29.4 & 28.9 & 29.3 & - & $=$ \\
\hline 4 & - & 22.3 & 22.2 & - & 21.1 & 9.0 \\
\hline 6 & 18.5 & - & 15.4 & - & 17.5 & 8.7 \\
\hline 8 & 16.7 & $=$ & - & 16.7 & 16.1 & 9.0 \\
\hline 11 & 14.9 & 14.9 & - & - & 14.3 & 9.3 \\
\hline 13 & 14.4 & - & - & $=^{c}$ & 13.8 & 9.4 \\
\hline 15 & - & - & 12.5 & 13.0 & 12.4 & 8.7 \\
\hline 18 & $=$ & 12.7 & 11.6 & - & 12.1 & 8.9 \\
\hline 21 & 11.8 & 11.8 & 10.0 & 11.8 & - & - \\
\hline
\end{tabular}

Notes: $\quad$ a. Bag not initially filled with gas mixture.

b. Sampled approximately 23 hrs after filling small bags at $t=0$.

c. No data detected. 
DRUM: 4.1

GAS: A TEMP: Variable SMALL BAG CLOSURE: heat seal

Voc:

1,1,2-Trichloro-1,2,2trif luoroethane (Freon-113)

Initial concentration:

$1010 \mathrm{ppmv}$

\begin{tabular}{|c|c|c|c|c|c|c|}
\hline DAY & SB1 & SB2 & SB3 & SB4 & L. BAG & DRUM \\
\hline $1^{\mathrm{a}}$ & 863.4 & 863.5 & 827.3 & 744.7 & - & - \\
\hline 2 & 596.0 & - & 552.4 & - & 275.4 & 77.3 \\
\hline 4 & - & 383.6 & - & 314.7 & 281.3 & 76.0 \\
\hline 7 & - & 291.3 & - & 272.4 & 253.3 & 81.9 \\
\hline 9 & 263.2 & 264.3 & - & - & 240.0 & 78.4 \\
\hline 11 & - & 244.1 & - & 236.2 & 220.7 & 74.4 \\
\hline 15 & - & - & 209.2 & 205.2 & 191.7 & 76.0 \\
\hline 18 & 192.7 & - & 189.3 & - & 178.5 & 71.5 \\
\hline 21 & 176.9 & 176.9 & 175.8 & 173.7 & - & - \\
\hline
\end{tabular}

VOC:

Methylene chloride

Initial concentration:

$1010 \mathrm{ppmv}$

VoC:

1,1,1-Trichloroethane

Initial concentration:

$1020 \mathrm{ppmv}$

Voc:

Carbon tetrachloride

Initial concentration:

301 ppmy

VOC:

Trich loroethylene

Initial concentration:

$297 \mathrm{ppmv}$

\begin{tabular}{|c|c|c|c|c|c|c|}
\hline \hline $1^{\mathrm{a}}$ & 181.1 & 179.4 & 173.6 & 172.7 & - & - \\
\hline 2 & 150.3 & - & 149.0 & - & 139.2 & $12.5^{\mathrm{b}}$ \\
\hline 4 & - & 121.4 & - & 121.8 & 112.4 & $19.5^{\mathrm{b}}$ \\
\hline 7 & - & 91.9 & - & 91.9 & 84.9 & $3.7^{\mathrm{b}}$ \\
\hline 9 & 78.1 & 77.5 & - & - & 73.5 & $-^{\mathrm{c}}$ \\
\hline 11 & - & 66.1 & - & 65.7 & 60.7 & $-^{\mathrm{c}}$ \\
\hline 15 & - & - & 49.1 & 48.7 & 44.7 & $-^{\mathrm{c}}$ \\
\hline 18 & 40.0 & - & 38.8 & - & 37.1 & $-^{\mathrm{c}}$ \\
\hline 21 & 29.8 & 29.6 & 29.5 & 29.8 & - & - \\
\hline
\end{tabular}

\begin{tabular}{|c|c|c|c|c|c|c|}
\hline 21 & 29.8 & 29.6 & 29.5 & 29.8 & - & - \\
\hline $1^{\mathrm{a}}$ & 292.2 & 288.6 & 254.2 & 230.8 & - & - \\
\hline 2 & 169.5 & - & 164.1 & - & 142.0 & $-\mathrm{c}$ \\
\hline 4 & - & 138.4 & - & 139.9 & 121.5 & $-^{\mathrm{c}}$ \\
\hline 7 & - & 114.3 & - & 111.9 & 100.4 & $-^{\mathrm{c}}$ \\
\hline
\end{tabular}

\begin{tabular}{|c|c|c|c|c|c|c|}
\hline 7 & - & 114.3 & - & 111.9 & 100.4 & - \\
\hline 9 & 101.9 & 101.2 & - & - & 93.1 & $-\mathrm{c}$ \\
\hline 11 & - & 9.8 & - & 90.8 & 82.3 & $-^{c}$ \\
\hline 15 & - & - & 75.2 & 74.7 & 67.5 & $\mathbf{S}^{\mathrm{c}}$ \\
\hline
\end{tabular}

\begin{tabular}{|c|c|c|c|c|c|c|}
\hline 15 & - & - & 75.2 & 74.7 & 67.5 & $-^{c}$ \\
\hline 18 & 71.2 & - & 70.3 & - & 66.2 & $-^{c}$ \\
\hline 21 & 58.7 & 58.9 & 59.5 & 61.4 & - & - \\
\hline
\end{tabular}

\begin{tabular}{|c|c|c|c|c|c|c|}
\hline 21 & 58.7 & 58.9 & 59.5 & 61.4 & - & - \\
\hline $1^{a}$ & 64.3 & 64.7 & 58.7 & 58.7 & - & - \\
\hline & 45.8 & & 45.8 & & 38.4 & $\mathrm{c}$ \\
\hline
\end{tabular}

\begin{tabular}{|c|c|c|c|c|c|c|}
\hline 1 & 64.3 & 64.7 & 58.7 & 58.7 & - & - \\
\hline 2 & 45.8 & - & 45.8 & - & 38.4 & $-c$ \\
\hline 4 & - & 38.7 & - & 39.8 & 32.9 & $-^{c}$ \\
\hline 7 & & 33.7 & & 33.5 & 28.5 & ${ }^{c}$ \\
\hline
\end{tabular}

\begin{tabular}{|c|c|c|c|c|c|c|}
\hline 7 & - & 33.7 & - & 33.5 & 28.5 & $-^{c}$ \\
\hline 9 & 30.3 & 29.4 & - & - & 27.5 & $-^{c}$ \\
\hline
\end{tabular}

\begin{tabular}{|c|c|c|c|c|c|c|}
\hline & 30.0 & 20.4 & - & & 21.0 & - \\
\hline 11 & - & 28.1 & - & 28.4 & 24.9 & $-^{c}$ \\
\hline 15 & - & - & 23.4 & 24.0 & 21.1 & $-c$ \\
\hline
\end{tabular}

\begin{tabular}{l|l|l|l|l|}
\hline 18 & 21.5 & - & 21.8 & \\
\hline
\end{tabular}

\begin{tabular}{|c|c|c|c|c|c|c|}
\hline 21 & 20.4 & 20.6 & 20.5 & 21.2 & - & - \\
\hline $1^{2}$ & 39.1 & 40.2 & 41.6 & 44.2 & - & - \\
\hline 2 & 34.8 & - & 34.7 & - & 30.9 & 6.0 \\
\hline 4 & - & 29.4 & - & 31.1 & 25.8 & 5.1 \\
\hline 7 & - & 24.6 & - & 24.7 & 22.1 & 5.5 \\
\hline 9 & 22.1 & 22.0 & - & - & 20.5 & 5.1 \\
\hline 11 & - & 20.7 & - & 20.7 & 18.8 & 4.7 \\
\hline 15 & - & - & 18.5 & 18.5 & 17.0 & 5.3 \\
\hline 18 & 20.2 & - & 20.2 & - & 18.9 & 5.2 \\
\hline 21 & 17.0 & 17.3 & 17.7 & 18.2 & - & - \\
\hline
\end{tabular}

Notes:

a. Sampled approximately $23 \mathrm{hrs}$ after filling small bags at $\mathbf{t}=0$.

b. Suspect data.

c. No data detected. 
DRUM: 4.2 GAS: B TEMP: Variable SMALL BAG CLOSURE: horsetai]

\begin{tabular}{|c|c|c|c|c|c|c|c|}
\hline \multirow[t]{2}{*}{ voc: } & DAY & $\mathrm{SB1}$ & SB2 & SB3 & SB4 & L. $B A G$ & DRUM \\
\hline & $1^{a}$ & 159.8 & 166.0 & 170.7 & 165.6 & - & - \\
\hline \multirow[t]{2}{*}{ Methanol } & 2 & 135.8 & 137.7 & - & - & 117.0 & 67.6 \\
\hline & 4 & - & 110.2 & - & 109.8 & 98.3 & 74.0 \\
\hline Initial concentration: & 6 & 87.3 & 89.5 & - & - & 82.7 & - \\
\hline \multirow[t]{5}{*}{$764 \mathrm{ppmv}$} & 9 & 76.8 & - & - & 75.8 & 71.9 & 58.6 \\
\hline & 11 & - & 68.5 & 68.8 & - & 66.5 & 53.4 \\
\hline & 15 & - & - & 57.0 & 57.2 & 54.5 & 45.0 \\
\hline & 18 & 51.4 & - & 51.3 & - & 49.9 & - \\
\hline & 21 & 46.2 & 46.2 & 46.2 & 45.8 & - & - \\
\hline \multirow[t]{2}{*}{ voc: } & $1^{a}$ & 149.8 & 154.7 & 161.5 & 155.5 & - & - \\
\hline & 2 & 87.8 & 88.2 & - & - & 79.0 & 22.0 \\
\hline \multirow[t]{3}{*}{ Cyclohexane } & 4 & - & 83.4 & - & 84.0 & 77.4 & 36.5 \\
\hline & 7 & 63.5 & 63.9 & - & - & 59.3 & - \\
\hline & 9 & 64.2 & - & - & 64.4 & 61.2 & 32.7 \\
\hline Initial concentration: & 11 & - & 52.4 & 52.6 & - & 49.4 & 28.0 \\
\hline \multirow{3}{*}{746 ppmv } & 15 & - & - & 41.9 & 41.7 & 39.3 & 22.4 \\
\hline & 18 & 45.1 & - & 45.2 & - & 43.6 & - \\
\hline & 21 & 37.9 & 38.1 & 37.6 & 37.9 & $\underline{-}$ & - \\
\hline \multirow[t]{2}{*}{ VOC: } & $1^{a}$ & 308.9 & 305.2 & 269.1 & 244.7 & - & - \\
\hline & 2 & 147.8 & 148.5 & - & - & 132.4 & 39.5 \\
\hline \multirow[t]{2}{*}{ 1,1,1-Trichloroethane } & 4 & - & 134.2 & - & 134.8 & 124.6 & 64.3 \\
\hline & 7 & 106.0 & 106.4 & - & - & 98.8 & $\#$ \\
\hline \multirow[t]{2}{*}{ Initial concentration: } & 9 & 102.8 & - & - & 102.9 & 98.4 & 57.4 \\
\hline & 11 & $=$ & 87.8 & 88.2 & - & 82.4 & 49.3 \\
\hline \multirow[t]{3}{*}{980 ppmv } & 15 & - & - & 70.9 & 70.6 & 66.4 & 39.6 \\
\hline & 18 & 70.9 & - & 71.1 & - & 68.4 & $\#$ \\
\hline & 21 & 60.4 & 60.7 & 60.3 & 60.5 & - & - \\
\hline \multirow[t]{2}{*}{ voc: } & $1^{a}$ & 28.6 & 29.5 & 30.0 & 30.7 & - & - \\
\hline & 2 & $9.1^{b}$ & $9.2^{b}$ & - & - & $15.0^{b}$ & $--^{c}$ \\
\hline \multirow[t]{2}{*}{ Toluene } & 4 & - & 12.2 & - & 12.8 & 19.2 & $-\mathrm{c}$ \\
\hline & 7 & 3.2 & 3.2 & - & - & 9.0 & $-\mathrm{c}$ \\
\hline Initial concentration: & 9 & 6.2 & - & - & 6.5 & 12.6 & $-^{c}$ \\
\hline \multirow{4}{*}{$398 \mathrm{ppmv}$} & 11 & - & 0.7 & 0.7 & - & 6.2 & $-c$ \\
\hline & 15 & - & - & $<0^{b}$ & $<0^{b}$ & 3.7 & $-c$ \\
\hline & 18 & 3.7 & - & 7.0 & - & 9.5 & - \\
\hline & 21 & $-c$ & $-c$ & $-c$ & $-^{c}$ & - & - \\
\hline \multirow[t]{2}{*}{ voc: } & $1^{a}$ & $-\mathrm{c}$ & $-\bar{c}$ & $-c$ & $-c$ & - & - \\
\hline & 2 & $-\mathrm{c}$ & $=\mathrm{c}$ & - & - & $-c$ & $-c$ \\
\hline \multirow[t]{2}{*}{$P-x y$ lene } & 4 & - & $-\mathrm{c}$ & - & $-c$ & $-\mathrm{c}$ & $-\mathrm{c}$ \\
\hline & 7 & $-^{c}$ & $\mathrm{C}^{\mathrm{c}}$ & - & - & $\mathrm{-}^{\mathrm{c}}$ & $-^{c}$ \\
\hline \multirow[t]{2}{*}{ Initial concentration: } & 9 & $-c$ & - & - & $-^{c}$ & $-^{c}$ & $\Omega^{c}$ \\
\hline & 11 & - & $-c$ & $-\mathrm{c}$ & - & $-\mathrm{c}$ & $-c$ \\
\hline \multirow[t]{3}{*}{99 ppmv } & 15 & - & - & $-^{c}$ & $-c$ & $\mathrm{C}^{\mathrm{C}}$ & $-c$ \\
\hline & 18 & $-c$ & $=$ & $-c$ & - & $-c$ & $=c$ \\
\hline & 21 & $-^{c}$ & $-^{c}$ & $-^{c}$ & $-c$ & - & - \\
\hline
\end{tabular}

Notes: a. Sampled approximately $23 \mathrm{hrs}$ after filling small bags at $t=0$.

b. Suspect data.

c. No data detected. 
DRUM: 4.3

GAS: A TEMP: Constant SMALL BAG CLOSURE: horseta il

\begin{tabular}{|c|c|c|c|c|c|c|c|}
\hline VOC: & DAY & SB1 & SB2 & SB3 & SB4 & L. $B A G$ & DRUM \\
\hline \multirow{3}{*}{$\begin{array}{l}\text { 1,1,2-Trichloro-1,2,2- } \\
\text { trif luoroethane (Freon-113) }\end{array}$} & $1^{a}$ & 705.6 & 705.4 & 747.7 & 738.5 & - & - \\
\hline & 2 & - & 547.1 & - & 581.3 & 264.6 & 91.0 \\
\hline & 4 & - & - & 392.1 & 370.8 & 274.8 & 108.1 \\
\hline Initial concentration: & 7 & 303.2 & - & 315.5 & - & 254.6 & 111.8 \\
\hline \multirow[t]{5}{*}{$1010 \mathrm{ppmv}$} & 9 & 272.9 & - & - & 271.3 & 241.1 & 130.5 \\
\hline & 11 & - & 252.8 & 258.9 & - & 230.5 & 118.5 \\
\hline & 15 & 228.8 & - & 230.8 & - & 209.5 & 107.6 \\
\hline & 18 & 212.9 & 211.9 & - & - & 197.8 & 96.8 \\
\hline & 21 & 202.2 & 201.7 & 203.6 & 201.8 & - & - \\
\hline \multirow[t]{2}{*}{ voc: } & $1^{a}$ & 144.2 & 143.6 & 146.9 & 143.9 & - & - \\
\hline & 2 & - & 121.5 & - & 122.0 & 114.2 & 25.9 \\
\hline \multirow[t]{3}{*}{ Methylene chloride } & 4 & - & - & 101.0 & 100.9 & 95.1 & 21.4 \\
\hline & 7 & 82.0 & - & 82.4 & - & 76.3 & $10.0^{b}$ \\
\hline & 9 & 71.6 & - & - & 71.6 & 66.4 & 17.5 \\
\hline Initial concentration: & 11 & - & 63.7 & 63.9 & - & 59.1 & $8.2^{b}$ \\
\hline \multirow{3}{*}{$1010 \mathrm{pprnv}$} & 15 & 51.4 & - & 51.6 & $=$ & 48.0 & $3.1^{b}$ \\
\hline & 18 & 43.5 & 43.2 & - & - & 40.0 & $-^{c}$ \\
\hline & 21 & 36.0 & 36.2 & 36.0 & 36.0 & - & $\underline{-}$ \\
\hline \multirow[t]{2}{*}{ VOC: } & $1^{a}$ & 207.2 & 195.5 & 227.7 & 211.8 & - & - \\
\hline & 2 & - & 144.1 & - & 148.5 & 121.0 & 26.0 \\
\hline \multirow{2}{*}{ 1,1,1-Trichloroethane } & 4 & - & - & 117.1 & 116.1 & 103.3 & 30.3 \\
\hline & 7 & 102.7 & - & 103.1 & - & 92.8 & $22.8^{b}$ \\
\hline \multirow[t]{2}{*}{ Initial concentration: } & 9 & 92.4 & - & - & 92.5 & 83.7 & 30.9 \\
\hline & 11 & - & 87.2 & 87.1 & - & 78.9 & 22.7 \\
\hline \multirow{3}{*}{$1020 \mathrm{ppmv}$} & 15 & 76.5 & - & 77.0 & - & 69.4 & 17.7 \\
\hline & 18 & 70.6 & 70.5 & - & - & 64.6 & 11.2 \\
\hline & 21 & 63.0 & 63.1 & 62.9 & 63.4 & - & $=$ \\
\hline \multirow[t]{2}{*}{ VOC: } & $1^{a}$ & 48.0 & 46.7 & 51.9 & 49.8 & - & - \\
\hline & 2 & - & 39.2 & - & 39.0 & 32.5 & 11.0 \\
\hline \multirow{2}{*}{ Carbon tetrachloride } & 4 & - & - & 31.9 & 32.0 & 27.4 & 10.7 \\
\hline & 7 & 30.4 & - & 29.4 & - & 26.3 & 9.2 \\
\hline Initial concentration: & 9 & 26.2 & - & - & 26.0 & 22.8 & 11.1 \\
\hline \multirow[t]{4}{*}{301 ppmv } & 11 & - & 25.9 & 24.3 & - & 22.0 & 8.9 \\
\hline & 15 & 22.2 & - & 21.1 & - & 19.5 & 7.7 \\
\hline & 18 & 19.4 & 19.7 & - & - & 17.7 & 5.7 \\
\hline & 21 & 18.6 & 18.6 & 18.7 & 18.6 & - & - \\
\hline \multirow[t]{2}{*}{ VOC: } & $1^{a}$ & 31.1 & 31.1 & 31.1 & 31.0 & - & - \\
\hline & 2 & - & 27.2 & - & 27.2 & 24.4 & 10.4 \\
\hline \multirow{2}{*}{ Trichloroethylene } & 4 & - & - & 21.9 & 21.9 & 19.8 & 10.1 \\
\hline & 7 & 19.0 & - & 19.1 & - & 17.4 & 8.7 \\
\hline Initial concentration: & 9 & 16.9 & - & - & 16.8 & 15.4 & 9.3 \\
\hline \multirow{4}{*}{$297 \mathrm{ppmv}$} & 11 & - & 15.9 & 15.9 & - & 14.6 & 8.1 \\
\hline & 15 & 14.3 & - & 14.4 & $=$ & 13.3 & 7.3 \\
\hline & 18 & 13.6 & 13.6 & - & - & 12.6 & 6.8 \\
\hline & 21 & 12.5 & 12.6 & 12.5 & 12.6 & - & - \\
\hline
\end{tabular}

Notes:

a. Sampled approximately $25 \mathrm{hrs}$ after $f i l l i n g$ small bags at $t=0$.

b. Suspect data.

c. No data detected. 
DRUM: 4.4

GAS: B TEMP: Constant SMALL BAG CLOSURE: heat sea ]

voc:

Methanol

Initial concentration:

764 ppmv

VOC:

Cyc lohexane

Initial concentration:

746 ppmv

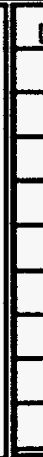

\begin{tabular}{|c|c|c|c|c|c|c|}
\hline DAY & SB1 & SB2 & SB3 & SB4 & L. BAG & DRUM \\
\hline $1^{\mathrm{a}}$ & 161.5 & 169.5 & 162.7 & 170.5 & - & - \\
\hline 2 & - & 142.6 & 141.0 & - & 103.6 & 56.3 \\
\hline 4 & 113.1 & - & - & 113.7 & 89.8 & 58.8 \\
\hline 7 & 89.2 & - & - & 93.9 & 78.1 & 59.2 \\
\hline 9 & 75.5 & 76.2 & - & - & 65.7 & 51.0 \\
\hline 11 & 67.5 & - & - & 68.8 & 61.9 & 49.3 \\
\hline 15 & - & - & 54.9 & 55.4 & 49.7 & 40.8 \\
\hline 18 & - & 49.2 & 49.3 & - & 44.8 & 36.6 \\
\hline 21 & 43.7 & 43.7 & 43.6 & 44.0 & - & - \\
\hline
\end{tabular}

VOC:

1,1,1-Trichloroethane

Initial concentration:

$980 \mathrm{ppmv}$

VOC:

Toluene

Initial concentration:

$398 \mathrm{ppmv}$

\begin{tabular}{|c|c|c|c|c|c|c|c|}
\hline $1^{2}$ & 138.9 & 126.6 & 136.2 & 124.7 & - & - \\
\hline 2 & - & 102.6 & 99.4 & - & 81.5 & 16.7 \\
\hline 4 & 85.5 & - & - & 85.7 & 73.5 & 25.8 \\
\hline 7 & 72.6 & - & - & 75.0 & 64.8 & 29.3 \\
\hline 9 & 65.6 & 65.7 & - & - & 58.6 & 27.5 \\
\hline
\end{tabular}

\begin{tabular}{|c|c|c|c|}
\hline 11 & 59.4 & - & \\
\hline 15 & - & - & 45. \\
\hline 18 & - & 41.1 & 41 \\
\hline
\end{tabular}

\begin{tabular}{|c|c|c|c|}
\hline 18 & - & 41.1 & 41.1 \\
\hline 21 & 33.5 & 34.0 & 33.8 \\
\hline
\end{tabular}

$-\quad 59.5$

$\begin{array}{ll}45.6 & 45.7\end{array}$

\begin{tabular}{||c|c|c|c|c|c|c|}
\hline $1^{a}$ & 234.6 & 242.9 & 254.3 & 243.9 & - & - \\
\hline 2 & - & 175.4 & 167.8 & - & 130.2 & 31.6 \\
\hline 4 & 142.1 & - & - & 142.7 & 119.5 & 47.3 \\
\hline 7 & 120.2 & - & - & 124.6 & 105.6 & 52.9 \\
\hline 9 & 108.3 & 108.4 & - & - & 98.2 & 49.5 \\
\hline 11 & 98.9 & - & - & 99.1 & 88.3 & 45.5 \\
\hline 15 & - & - & 77.5 & 77.6 & 68.9 & 34.5 \\
\hline 18 & - & 69.5 & 69.3 & - & 61.2 & 27.7 \\
\hline
\end{tabular}

\begin{tabular}{|c|c|c|c|c|c|c|}
\hline 21 & 58.2 & 58.5 & 58.3 & 58.6 & - & - \\
\hline $1^{\mathrm{a}}$ & 21.4 & 21.5 & 21.1 & 21.1 & - & - \\
\hline 2 & - & 11.8 & 12.0 & - & 17.9 & $-^{\mathrm{c}}$ \\
\hline
\end{tabular}

Voc:

P-xylene

Initial concentration:

99 ppmv

\begin{tabular}{|c|c|c|c|c|c|c|}
\hline & & & & & & \\
\hline 4 & 8.7 & - & - & 8.8 & 15.5 & $-c$ \\
\hline 7 & 5.1 & - & - & 5.8 & 10.4 & $-c$ \\
\hline 9 & 3.3 & 3.4 & - & - & 9.5 & $-c$ \\
\hline 11 & 1.9 & $=$ & $=$ & 1.9 & 7.6 & $\Omega^{c}$ \\
\hline 15 & - & - & $-c$ & $-c$ & 4.4 & $-c$ \\
\hline 18 & - & $-c$ & $-^{c}$ & - & 2.9 & $-c$ \\
\hline 21 & 1.5 & 1.7 & 1.6 & 1.9 & - & - \\
\hline 1 & $-c$ & $-c$ & $-c$ & $-c$ & - & - \\
\hline 2 & - & $-c$ & $-c$ & - & $-c$ & $-\mathrm{c}$ \\
\hline 4 & -c & - & - & $-c$ & $-c$ & $-_{-c}^{c}$ \\
\hline 7 & $-_{-}^{c}$ & - & - & $-c$ & $-c$ & $-c$ \\
\hline 9 & $-^{c}$ & $-c$ & - & - & $\mathrm{C}^{\mathrm{C}}$ & $-\mathbf{C}$ \\
\hline 11 & $-c$ & - & - & $-c$ & $-^{c}$ & $-^{c}$ \\
\hline 15 & - & - & $-c$ & $-c$ & $-c$ & $\Omega_{-c}^{c}$ \\
\hline 18 & $=$ & $-c$ & $-^{c}$ & - & $\Omega^{c}$ & $-c$ \\
\hline 21 & $-^{c}$ & $-c$ & $-^{c}$ & $-c$ & - & - \\
\hline
\end{tabular}

Notes: a. Sampled approximately $26 \mathrm{hrs}$ after filling bags at $t=0$.

b. Suspect data.

c. No data detected. 
Appendix B

VOC Concentrations in Polyethylene Bottles

B-1 
B-2 
Table B-1 . VOC concentration (ppmv) in polyethylene bottles during transport experiment.

\begin{tabular}{|c|c|c|c|c|c|c|}
\hline Sample day & $\begin{array}{c}\text { Bottle } \\
\text { number }\end{array}$ & Methanol & $\begin{array}{l}\text { Cyclo- } \\
\text { hexane }\end{array}$ & TCA & Toluene & p-xylene \\
\hline \multirow[t]{4}{*}{ Time 0} & 1 & $1,036.3$ & 837.5 & $1,102.2$ & 411.1 & 101.1 \\
\hline & 2 & $1,096.0$ & 875.7 & $1,151.2$ & 437.5 & 112.4 \\
\hline & 3 & $1,098.7$ & 865.0 & $1,145.8$ & 396.9 & 86.7 \\
\hline & 4 & $1,095.4$ & 862.2 & $1,142.4$ & 392.7 & 84.9 \\
\hline \multirow[t]{4}{*}{ Day 21} & 1 & 654.1 & 404.2 & 603.6 & 55.0 & 11.2 \\
\hline & 2 & 823.3 & 449.9 & 674.3 & 57.2 & 11.3 \\
\hline & 3 & 637.3 & 189.5 & 331.5 & 32.8 & 8.8 \\
\hline & 4 & 641.1 & 201.2 & 351.9 & 32.2 & 8.7 \\
\hline \multirow[t]{4}{*}{ Day 50} & 1 & 214.1 & 194.1 & 292.8 & 20.7 & 5.6 \\
\hline & 2 & 396.3 & 250.0 & 384.4 & 22.5 & 5.7 \\
\hline & 3 & 207.9 & 79.6 & 150.6 & 9.5 & 4.4 \\
\hline & 4 & 213.3 & 87.5 & 166.2 & 7.4 & 4.3 \\
\hline \multirow[t]{4}{*}{ Day 81} & 1 & 94.7 & 149.5 & 218.0 & 12.1 & 8.3 \\
\hline & 2 & 235.5 & 210.7 & 323.8 & 13.7 & 8.4 \\
\hline & 3 & 91.6 & 60.9 & 111.0 & 3.5 & 7.6 \\
\hline & 4 & 92.8 & 65.3 & 121.0 & 1.5 & 7.4 \\
\hline \multirow[t]{4}{*}{ Day 124} & 1 & -40.2 & 134.0 & 175.1 & -4.4 & -4.2 \\
\hline & 2 & 109.3 & 208.7 & 292.9 & -2.8 & -4.1 \\
\hline & 3 & -41.8 & 52.5 & 92.2 & -12.3 & -5.3 \\
\hline & 4 & -41.8 & 52.9 & 95.6 & -13.9 & -5.5 \\
\hline \multicolumn{7}{|c|}{$\begin{array}{l}\text { 1-Large mouth with seal } \\
\text { 2-Large mouth without seal } \\
\text { 3-Small mouth with seal } \\
\text { 4-Small mouth without seal }\end{array}$} \\
\hline
\end{tabular}




\section{Appendix C}

Statistics Characterizing Initial Calibration Curves, Continuing Calibration Curves, and Sample Duplicates 
C-2 


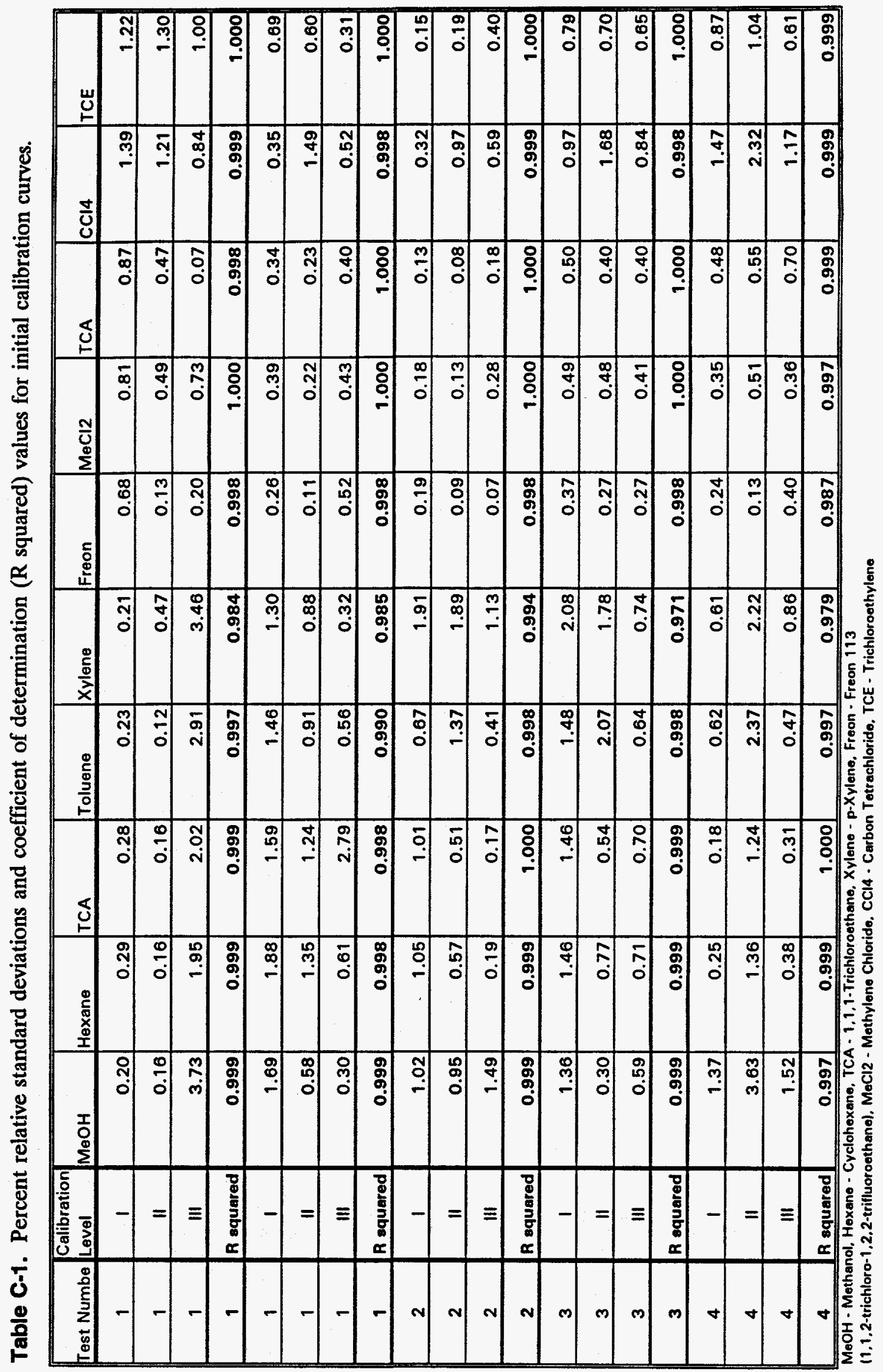

C-3 
Table C-2. Percent relative error for continuing calibration standard analytes for test period $I$.

\begin{tabular}{|c|c|c|c|c|c|c|c|c|c|c|c|}
\hline CCS Day & & $\mathrm{MeOH}$ & Hexane & TCA & Toluene & Xylene & Freon & $\mathrm{MeCl} 2$ & TCA & CCL4 & TCE \\
\hline \multirow[t]{3}{*}{ Day 2} & Conc. & 555.1 & 444.8 & 590.2 & 239.4 & 66.0 & 571.5 & 498.8 & 556.9 & 171.8 & 173.4 \\
\hline & $\% \operatorname{Rec}$ & 111.2 & 118.0 & 116.2 & 113.5 & 113.2 & 120.3 & 110.6 & 112.3 & 115.3 & 113.3 \\
\hline & Rel. \% Error & 11.2 & 18.0 & 16.2 & 13.5 & 13.2 & 20.3 & 10.6 & 12.3 & 15.3 & 13.3 \\
\hline \multirow[t]{3}{*}{ Day 3} & Conc. & 568.6 & 444.1 & 592.4 & 244.5 & 69.7 & 563.1 & 472.3 & 540.0 & 159.5 & 151.0 \\
\hline & $\% \operatorname{Rec}$ & 113.9 & 117.8 & 116.6 & 115.9 & 119.6 & 118.5 & 104.7 & 108.9 & 107.0 & 98.7 \\
\hline & Rel. \% Error & 13.9 & 17.8 & 16.6 & 15.9 & 19.6 & 18.5 & 4.7 & 8.9 & 7.0 & -1.3 \\
\hline \multirow[t]{3}{*}{ Day 5} & Conc. & 576.2 & 446.4 & 593.7 & 242.8 & 61.6 & 592.5 & 530.9 & 584.0 & 181.3 & 187.5 \\
\hline & $\% \operatorname{Rec}$ & 115.5 & 118.4 & 116.9 & 115.1 & 105.7 & 124.7 & 117.7 & 117.7 & 121.7 & 122.5 \\
\hline & Rel. \% Error & 15.5 & 18.4 & 16.9 & 15.1 & 5.7 & 24.7 & 17.7 & 17.7 & 21.7 & 22.5 \\
\hline \multirow[t]{3}{*}{ Day 8} & Conc. & 567.9 & 376.6 & 510.1 & 196.6 & 52.5 & 513.4 & 471.9 & 512.3 & 162.2 & 167.1 \\
\hline & $\% \operatorname{Rec}$ & 113.8 & 99.9 & 100.4 & 93.2 & 90.1 & 108.1 & 104.6 & 103.3 & 108.9 & 109.2 \\
\hline & Rel. \% Error & 13.8 & -0.1 & 0.4 & -6.8 & -9.9 & 8.1 & 4.6 & 3.3 & 8.9 & 9.2 \\
\hline \multirow[t]{3}{*}{ Day 10} & Conc. & 502.5 & 396.7 & 522.4 & 199.9 & 51.9 & 493.6 & 449.3 & 489.7 & 155.7 & 156.2 \\
\hline & $\% \operatorname{Rec}$ & 100.7 & 105.2 & 102.8 & 94.7 & 89.0 & 103.9 & 99.6 & 98.7 & 104.5 & 102.1 \\
\hline & Rel. \% Error & 0.7 & 5.2 & 2.8 & -5.3 & -11.0 & 3.9 & -0.4 & -1.3 & 4.5 & 2.1 \\
\hline \multirow[t]{3}{*}{ Day 12} & Conc. & 511.7 & 401.3 & 525.6 & 192.6 & 48.1 & 497.5 & 438.8 & 486.0 & 149.6 & 150.0 \\
\hline & $\% \operatorname{ReC}$ & 102.5 & 106.4 & 103.5 & 91.3 & 82.5 & 104.7 & 97.3 & 98.0 & 100.4 & 98.0 \\
\hline & Rel. \% Error & 2.5 & 6.4 & 3.5 & -8.7 & -17.5 & 4.7 & -2.7 & -2.0 & 0.4 & -2.0 \\
\hline \multirow[t]{3}{*}{ Day 16} & Conc. & 505.2 & 370.4 & 499.4 & 184.1 & 54.6 & 507.5 & 462.3 & 502.3 & 155.5 & 161.3 \\
\hline & $\% \operatorname{Rec}$ & 101.2 & 98.2 & 98.3 & 87.3 & 93.7 & 106.8 & 102.5 & 101.3 & 104.4 & 105.4 \\
\hline & Rel. \% Error & 1.2 & -1.8 & -1.7 & \begin{tabular}{|c|}
-12.7 \\
\end{tabular} & -6.3 & 6.8 & 2.5 & 1.3 & 4.4 & 5.4 \\
\hline \multirow[t]{3}{*}{ Day 19} & Conc. & 541.2 & 410.2 & 548.2 & 199.5 & 48.0 & 503.9 & 457.2 & 495.0 & 153.2 & 157.5 \\
\hline & $\%$ Rec & 108.5 & 108.8 & 107.9 & 94.5 & 82.3 & 106.1 & 101.4 & 99.8 & 102.8 & 102.9 \\
\hline & Rel. \% Error & 8.5 & 8.8 & 7.9 & -5.5 & -17.7 & 6.1 & 1.4 & -0.2 & 2.8 & 2.9 \\
\hline \multirow[t]{3}{*}{ Day 22} & Conc. & 562.7 & 418.8 & 558.3 & 214.5 & 56.8 & 504.4 & 442.4 & 483.7 & 154.8 & 147.6 \\
\hline & $\% \operatorname{Rec}$ & 112.8 & 111.1 & 109.9 & 101.7 & 97.4 & 106.2 & 98.1 & 97.5 & 103.9 & 96.5 \\
\hline & Rel. \% Error & 12.8 & 11.1 & 9.9 & 1.7 & -2.6 & 6.2 & -1.9 & -2.5 & 3.9 & -3.5 \\
\hline \multicolumn{2}{|c|}{ Mean \% Error } & 8.9 & 9.3 & 8.1 & 0.8 & -3.0 & 11.1 & 4.1 & 4.2 & 7.7 & 5.4 \\
\hline \multicolumn{2}{|c|}{ Standard Deviation } & 5.9 & 7.7 & 7.3 & 11.2 & 13.2 & 7.9 & 6.5 & 7.2 & 6.8 & 8.4 \\
\hline
\end{tabular}

MeOH - Methanol, Hexane - Cyclohexane, TCA - 1,1,1-Trichloroethane, Xylene - para Xylene, Freon - Freon 113

(1,1,2-trichioro-1,2,2-trifluoroethane), CCl4 - Carbon Tetrachloride, TCE - Trichloroethylene

$\%$ Rec - Percent Recovery, Rel. \% Error - Relative Percent Error 
Table C-3. Percent relative error for continuing calibration standard analytes for test period II.

\begin{tabular}{|c|c|c|c|c|c|c|c|c|c|c|c|}
\hline CCS Day & & $\mathrm{MeOH}$ & Hexane & TCA & Toluene & Xylene & Freon & $\mathrm{MeCl} 2$ & TCA & CCL4 4 & TCE \\
\hline \multirow[t]{3}{*}{ Day 2} & Conc. & 500.8 & 396.6 & 536.6 & 209.6 & 49.2 & 497.4 & 439.5 & 480.0 & 158.6 & 149.9 \\
\hline & $\%$ Rec & 100.4 & 105.2 & 105.6 & 99.3 & 84.4 & 104.7 & 97.5 & 96.8 & 106.4 & 98.0 \\
\hline & Rel. \% Error & 0.4 & 5.2 & 5.6 & -0.7 & -15.6 & 4.7 & -2.5 & -3.2 & 6.4 & -2.0 \\
\hline \multirow[t]{3}{*}{ Day 3} & Conc. & 519.5 & 383.9 & 520.2 & 219.9 & 55.4 & 507.6 & 436.0 & 480.9 & 158.7 & 146.5 \\
\hline & $\% \operatorname{Rec}$ & 104.1 & 101.8 & 102.4 & 104.2 & 95.0 & 106.9 & 96.7 & 97.0 & 106.5 & 95.8 \\
\hline & Rel. \% Error & 4.1 & 1.8 & 2.4 & 4.2 & -5.0 & 6.9 & \begin{tabular}{|c|}
-3.3 \\
\end{tabular} & -3.0 & 6.5 & -4.2 \\
\hline \multirow[t]{3}{*}{ Day 5} & Conc. & 515.0 & 382.6 & 520.1 & 211.7 & 52.7 & 513.4 & 451.2 & 497.2 & 162.3 & 158.0 \\
\hline & $\%$ Rec & 103.2 & 101.5 & 102.4 & 100.3 & 90.4 & 108.1 & 100.0 & 100.2 & 108.9 & 103.3 \\
\hline & Rel. \% Error & 3.2 & 1.5 & 2.4 & 0.3 & -9.6 & 8.1 & 0.0 & 0.2 & 8.9 & 3.3 \\
\hline \multirow[t]{3}{*}{ Day 8} & Conc. & 510.1 & 373.5 & 507.5 & 212.0 & 58.0 & 506.4 & 452.5 & 492.6 & 156.4 & 155.8 \\
\hline & \%Rec & 102.2 & 99.1 & 99.9 & 100.5 & 99.5 & 106.6 & 100.3 & 99.3 & 105.0 & 101.8 \\
\hline & Rel. \% Error & 2.2 & -0.9 & -0.1 & 0.5 & -0.5 & 6.6 & 0.3 & -0.7 & 5.0 & 1.8 \\
\hline \multirow[t]{3}{*}{ Day 10} & Conc. & 469.7 & 361.0 & 482.9 & 199.6 & 48.3 & 456.9 & 423.3 & 448.5 & 138.7 & 143.4 \\
\hline & \%Rec & 94.1 & 95.8 & 95.1 & 94.6 & 82.8 & 96.2 & 93.9 & 90.4 & 93.1 & 93.7 \\
\hline & Rel. \% Error & -5.9 & -4.2 & -4.9 & -5.4 & -17.2 & -3.8 & -6.1 & -9.6 & -6.9 & -6.3 \\
\hline \multirow[t]{3}{*}{ Day 12} & Conc. & 465.8 & 347.6 & 470.0 & 199.0 & 51.9 & 468.6 & 421.3 & 434.0 & 116.3 & 136.3 \\
\hline & \%Rec & 93.3 & 92.2 & 92.5 & 94.3 & 89.0 & 98.7 & 93.4 & 87.5 & 78.1 & 89.1 \\
\hline & Rel. \% Error & -6.7 & -7.8 & -7.5 & -5.7 & -11.0 & -1.3 & -6.6 & -12.5 & -21.9 & -10.9 \\
\hline \multirow[t]{3}{*}{ Day 16} & Conc. & 477.0 & 363.0 & 489.3 & 200.9 & 52.5 & 479.3 & 437.1 & 451.7 & 124.4 & 144.1 \\
\hline & $\% \operatorname{Rec}$ & 95.6 & 96.3 & 96.3 & 95.2 & 90.1 & 100.9 & 96.9 & 91.1 & 83.5 & 94.2 \\
\hline & Rel. \% Error & -4.4 & -3.7 & -3.7 & -4.8 & -9.9 & 0.9 & -3.1 & -8.9 & -16.5 & -5.8 \\
\hline \multirow[t]{3}{*}{ Day 19} & Conc. & 472.2 & 363.0 & 491.7 & 198.3 & 49.8 & 486.6 & 436.2 & 460.4 & 129.7 & 144.1 \\
\hline & $\% \operatorname{Rec}$ & 94.6 & 96.3 & 96.8 & 94.0 & 85.4 & 102.4 & 96.7 & 92.8 & 87.0 & 94.2 \\
\hline & Rel. \% Error & -5.4 & -3.7 & -3.2 & -6.0 & -14.6 & 2.4 & -3.3 & -7.2 & -13.0 & -5.8 \\
\hline \multirow[t]{3}{*}{ Day 22} & Conc. & 467.2 & 356.9 & 484.7 & 188.9 & 47.3 & 489.8 & 436.1 & 465.5 & 135.3 & 144.1 \\
\hline & \%Rec & 93.6 & 94.7 & 95.4 & 89.5 & 81.1 & 103.1 & 96.7 & 93.9 & 90.8 & 94.2 \\
\hline & Rel. \% Error & -6.4 & -5.3 & -4.6 & -10.5 & -18.9 & 3.1 & -3.3 & -6.1 & -9.2 & -5.8 \\
\hline \multicolumn{2}{|c|}{ Mean \% Error } & -2.1 & -1.9 & -1.5 & -3.1 & -11.4 & 3.1 & -3.1 & -5.7 & -4.5 & -4.0 \\
\hline \multicolumn{2}{|c|}{ Standard Deviation } & 4.5 & 4.1 & 4.3 & 4.5 & 5.9 & 4.0 & 2.3 & 4.3 & 11.5 & 4.4 \\
\hline
\end{tabular}

MeOH - Methanol, Hexane - Cyclohexane, TCA - 1,1,1-Trichloroethane, Xylene - para Xylene, Freon - Freon 113

(1,1,2-trichloro-1,2,2-trifluoroethane), CCl4 - Carbon Tetrachloride, TCE - Trichloroethylene

\% Rec - Percent Recovery, Rel. \% Error - Relative Percent Error 


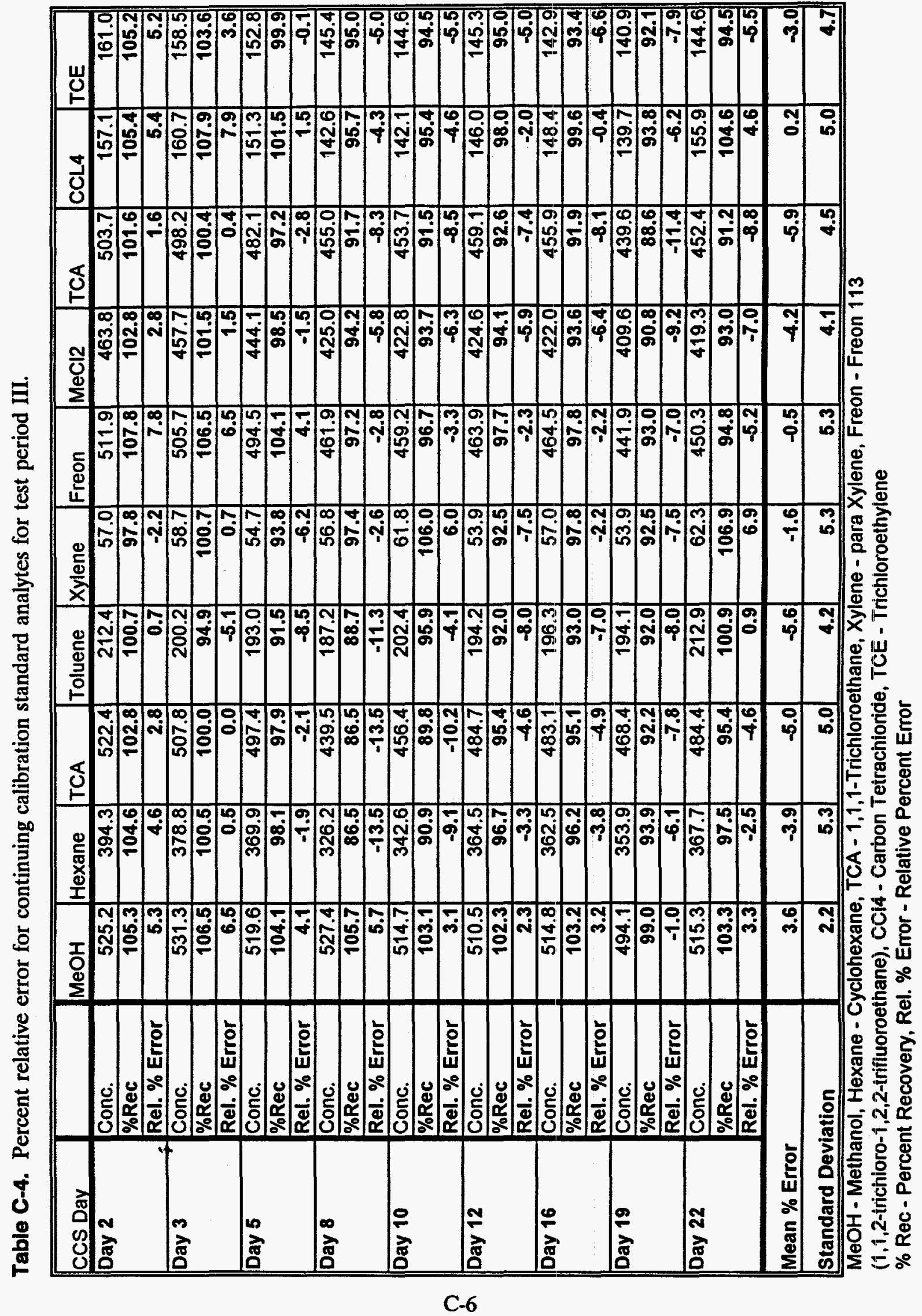


Table C-5. Percent relative error for continuing calibration standard analytes for test period IV.

\begin{tabular}{|c|c|c|c|c|c|c|c|c|c|c|c|}
\hline ccs Day & & $\mathrm{MeOH}$ & Hexane & TCA & Toluene & Xylene & Freon & $\mathrm{MeCl} 2$ & TCA & CCL4 & TCE \\
\hline \multirow[t]{3}{*}{ Day 2} & Conc. & 447.6 & 405.1 & 504.5 & 214.3 & 52.8 & 362.1 & 446.2 & 531.3 & 264.2 & 166.5 \\
\hline & \%Rec & 89.7 & 107.5 & 99.3 & 101.6 & 90.6 & 76.2 & 98.9 & 107.1 & 177.3 & 108.8 \\
\hline & Rel. \% Error & -10.3 & 7.5 & -0.7 & 1.6 & $\mid-9.4$ & -23.8 & -1.1 & 7.1 & 77.3 & 8.8 \\
\hline \multirow[t]{3}{*}{ Day 3} & Conc. & 417.6 & 350.6 & 463.8 & 197.9 & 56.7 & 387.9 & 447.9 & 457.3 & 136.3 & 140.2 \\
\hline & $\% \operatorname{Rec}$ & 83.7 & 93.0 & 91.3 & 93.8 & 97.3 & 81.7 & 99.3 & 92.2 & 91.5 & 91.6 \\
\hline & Rel. \% Error & -16.3 & -7.0 & -8.7 & -6.2 & \begin{tabular}{|c|}
-2.7 \\
\end{tabular} & -18.3 & -0.7 & \begin{tabular}{|c|}
-7.8 \\
\end{tabular} & -8.5 & -8.4 \\
\hline \multirow[t]{3}{*}{ Day 5} & Conc. & 444.1 & 375.9 & 503.0 & 205.5 & 59.1 & 418.6 & 485.8 & 509.6 & 155.1 & 155.4 \\
\hline & $\% \operatorname{Rec}$ & 89.0 & 99.7 & 99.0 & 97.4 & 101.4 & 88.1 & 107.7 & 102.7 & 104.1 & 101.6 \\
\hline & Rel. \% Error & -11.0 & -0.3 & -1.0 & -2.6 & 1.4 & -11.9 & 7.7 & 2.7 & 4.1 & 1.6 \\
\hline \multirow[t]{3}{*}{ Day 8} & Conc. & 451.4 & 379.1 & 504.9 & 214.9 & 63.2 & 416.5 & 484.6 & 508.6 & 152.1 & 155.2 \\
\hline & $\% \operatorname{Rec}$ & 90.5 & 100.6 & 99.4 & 101.8 & 108.4 & 87.7 & 107.5 & 102.5 & 102.1 & 101.4 \\
\hline & Rel. \% Error & -9.5 & 0.6 & -0.6 & 1.8 & 8.4 & -12.3 & 7.5 & 2.5 & 2.1 & 1.4 \\
\hline \multirow[t]{3}{*}{ Day 10} & Conc. & 473.2 & 380.4 & 509.4 & 213.3 & 65.0 & 420.8 & 495.1 & 525.7 & 160.1 & 162.9 \\
\hline & $\% \operatorname{Rec}$ & 94.8 & 100.9 & 100.3 & 101.1 & 111.5 & 88.6 & 109.8 & 106.0 & 107.4 & 106.5 \\
\hline & Rel. \% Error & -5.2 & 0.9 & 0.3 & 1.1 & 11.5 & -11.4 & 9.8 & 6.0 & 7.4 & 6.5 \\
\hline \multirow[t]{3}{*}{ Day 12} & Conc. & 473.8 & 381.4 & 507.3 & 217.7 & 66.8 & 420.1 & 495.2 & 527.9 & 164.3 & 162.4 \\
\hline & $\%$ Rec & 94.9 & 101.2 & 99.9 & 103.2 & 114.6 & 88.4 & 109.8 & 106.4 & 110.3 & 106.1 \\
\hline & Rel. \% Error & -5.1 & 1.2 & -0.1 & 3.2 & 14.6 & -11.6 & 9.8 & 6.4 & 10.3 & 6.1 \\
\hline \multirow[t]{3}{*}{ Day 16} & Conc. & 488.0 & 404.7 & 546.0 & 231.9 & 68.7 & 447.0 & 522.4 & 543.0 & 155.7 & 164.8 \\
\hline & \%Rec & 97.8 & 107.3 & 107.5 & 109.9 & 117.8 & 94.1 & 115.8 & 109.5 & 104.5 & 107.7 \\
\hline & Rel. \% Error & -2.2 & 7.3 & 7.5 & 9.9 & 17.8 & -5.9 & 15.8 & 9.5 & 4.5 & 7.7 \\
\hline \multirow[t]{3}{*}{ Day 19} & Conc. & 473.1 & 388.4 & 527.2 & 226.0 & 67.9 & 445.2 & 516.9 & 536.7 & 162.4 & 164.0 \\
\hline & $\% \operatorname{Rec}$ & 94.8 & 103.0 & 103.8 & 107.1 & 116.5 & 93.7 & 114.6 & 108.2 & 109.0 & 107.2 \\
\hline & Rel. \% Error & -5.2 & 3.0 & 3.8 & 7.1 & 16.5 & -6.3 & 14.6 & 8.2 & 9.0 & 7.2 \\
\hline \multirow[t]{3}{*}{ Day 22} & Conc. & 476.3 & 395.7 & 530.9 & 229.9 & 67.3 & 434.3 & 511.0 & 531.7 & 153.1 & 165.1 \\
\hline & \%Rec & 95.5 & 105.0 & 104.5 & 109.0 & 115.4 & 91.4 & 113.3 & 107.2 & 102.8 & 107.9 \\
\hline & Rel. \% Error & -4.5 & 5.0 & 4.5 & 9.0 & 15.4 & -8.6 & 13.3 & 7.2 & 2.8 & 7.9 \\
\hline \multicolumn{2}{|c|}{ Mean \% Error } & -7.7 & 2.0 & 0.5 & 2.8 & 8.2 & -12.2 & 8.5 & 4.7 & 12.1 & 4.3 \\
\hline \multicolumn{2}{|c|}{ Standard Deviation } & 4.4 & 4.5 & 4.5 & 5.3 & 9.6 & 5.7 & 6.1 & 5.2 & 25.1 & 5.5 \\
\hline
\end{tabular}

MeOH - Methanol, Hexane - Cyclohexane, TCA - 1,1,1-Trichloroethane, Xylene - para Xylene, Freon - Freon 113

(1,1,2-trichloro-1,2,2-trifluoroethane), CCl4 - Carbon Tetrachloride, TCE - Trichloroethylene

$\%$ Rec - Percent Recovery, Rel. \% Error - Relative Percent Error 
Table C-6. Relative percent difference (RPD) for duplicate sample analyses during test period I.

\begin{tabular}{|c|c|c|c|c|c|c|c|c|c|c|}
\hline $\begin{array}{l}\text { Sample } \\
\text { Location }\end{array}$ & $\mathrm{MeOH}$ & Hexane & TCA & Toluene & Xylene & Freon & $\mathrm{MeCl} 2$ & TCA & CCL4 & TCE \\
\hline $102-3 S B 4$ & & & & & & 774.6 & 228.9 & 303.2 & 68.0 & 49.0 \\
\hline $102-35 B 4 D$ & & & & & & 758.7 & 225.2 & 291.7 & 65.1 & 48.4 \\
\hline RPD & & & & & & 2.07 & 1.63 & 3.87 & 4.36 & 1.23 \\
\hline 103. $3 \mathrm{SB} 2$ & & & & & & 615.4 & 195.0 & 206.6 & 48.6 & 42.6 \\
\hline 103-3SB2D & & & & & & 601.7 & 192.2 & 202.9 & 47.9 & 42.1 \\
\hline RPD & & & & & & 2.25 & 1.45 & 1.81 & 1.45 & 1.18 \\
\hline 105-1SB2 & & & & & & 248.7 & 162.9 & 156.7 & 39.3 & 34.4 \\
\hline $105-1 \mathrm{SB} 2 \mathrm{D}$ & & & & & & 247.0 & 162.7 & 163.3 & 41.3 & 37.5 \\
\hline RPD & & & & & & 0.69 & 0.12 & -4.13 & -4.96 & .8 .62 \\
\hline 108-2SB2 & No Data & No Data & No Data & No Data & No Data & & & & & \\
\hline $108-2 \mathrm{SB} 2 \mathrm{D}$ & No Data & No Date & No Data & No Data & No Data & & & & & \\
\hline RPD & & & & & & & & & & \\
\hline $110-4 S B 2$ & 108.3 & 65.7 & 101.5 & 18.6 & 6.4 & & & & & \\
\hline $110-4 S B 2 D$ & 108.4 & 65.5 & 101.1 & 18.5 & 6.4 & & & & & \\
\hline RPD & -0.09 & 0.30 & 0.39 & 0.54 & 0.00 & & & & & \\
\hline 112-2SB3 & 83.7 & 62.1 & 93.5 & 19.8 & 6.7 & & & & & \\
\hline 112-2SB3D & 83.3 & 70.4 & 101.3 & 24.3 & 7.6 & & & & & \\
\hline RPD & 0.48 & -12.53 & -8.01 & -20.41 & -12.59 & & & & & \\
\hline $116-1 \mathrm{SB} 4$ & & & & & & 102.3 & 67.3 & 79.9 - & 19.6 & 14.7 \\
\hline $116.1 \mathrm{SB} 4 \mathrm{D}$ & & & & & & 104.5 & 68.7 & $\left.88.2\right|^{*}$ & 22.7 & 17.6 \\
\hline RPD & & & & & & -2.13 & -2.06 & -9.88 & -15.17 & .17 .96 \\
\hline $119-4 S B 3$ & 79.6 & 57.0 & 86.0 & 16.7 & 6.1 & & & & & \\
\hline 119-4SB3D & 79.5 & 57.1 & 86.1 & 16.6 & 6.1 & & & & & \\
\hline RPD & 0.13 & -0.18 & -0.12 & 0.60 & 0.00 & & & & & \\
\hline 122-3SB3 & & & & & & 110.6 & 65.4 & $82.00^{\circ}$ & 20.2 & 13.6 \\
\hline 122-3SB3D & & & & & & 111.0 & 65.3 & 91.9 |* & 19.4 & 13.6 \\
\hline RPD & & & & & & -0.36 & 0.15 & 0.12 & 4.04 & -0.74 \\
\hline
\end{tabular}

MeOH - Methanol, Hexane - Cyclohexane, TCA - 1,1,1-Trichloroethane, Xylene - para Xylene, Freon - Freon 113

11,1,2-trichloro-1,2,2-trifluoroethane), CCl4 - Carbon Tetrachloride. TCE - Trichloroethylene

RPD - Relative Percent Difference, - Outside Linear Dynamic Range 
Table C-7. Relative percent difference (RPD) for duplicate sample analyses during test period II.

\begin{tabular}{|c|c|c|c|c|c|c|c|c|c|c|}
\hline \begin{tabular}{|l} 
Sample \\
Location
\end{tabular} & $\mathrm{MeOH}$ & Hexane & TCA & Toluene & Xylene & Freon & $\mathrm{MeCl} 2$ & TCA & $\mathrm{CCL} 4$ & TCE \\
\hline 202-3SB4 & & & & & & 579.2 & 180.4 & 203.3 & 48.3 & 35.5 \\
\hline 202-3SB4D & & & & & & 568.0 & 179.0 & 198.8 & 48.2 & 35.2 \\
\hline RPD & & & & & & 1.95 & 0.78 & 2.24 & 0.21 & 0.85 \\
\hline 203-3SB2 & & & & & & 389.0 & 161.5 & 160.6 & $41.1{ }^{*}$ & 32.0 \\
\hline 203-3SB2D & & & & & & 380.3 & 160.1 & 159.0 & 40.3." & 31.7 \\
\hline RPD & & & & & & 2.26 & 0.87 & 1.00 & 1.97 & 0.94 \\
\hline $205-15 B 2$ & & & & & & 240.3 & 138.7 & 143.7 & 36.9 & 29.6 \\
\hline $205-1 S B 2 D$ & & & & & & 213.4 & 127.7 & 135.5 & 36.5 & 29.8 \\
\hline RPD & & & & & & 11.86 & 8.26 & 5.87 & 1.09 & -0.67 \\
\hline $208-2 S B 2$ & 106.7 & 59.3 & 96.8 & 16.5 . & 4.9 & & & & & \\
\hline 2O8-2SB2D & 106.0 & 75.5 & 112.8 & $16.4{ }^{\circ}$ & 7.4 & & & & & \\
\hline $\mathrm{RPD}$ & 0.66 & .24 .04 & -15.27 & 0.61 & .40 .65 & & & & & \\
\hline $210-4 S B 2$ & 107.4 & 61.8 & 100.7 & 14.9 & 4.8 & & & & & \\
\hline $210-4$ SB2D & 107.6 & 61.8 & 100.7 & 14.9 & 4.8 & & & & & \\
\hline RPD & -0.19 & 0.00 & 0.00 & 0.00 & 0.00 & & & & & \\
\hline $212.2 S B 3$ & 73.0 & 47.8 & 77.1 & 15.0 & 5.0 & & & & & \\
\hline $212-2 S B 3 D$ & 74.1 & 56.9 & 86.4 & 19.4 & 5.8 & & & & & \\
\hline RPD & -1.50 & -17.38 & -11.38 & -25.58 & -14.81 & & & & & \\
\hline 216-1SB4 & & & & & & 89.0 . & 64.3 & 76.6 & 19.9 & 17.4 \\
\hline $216.1 S B 4 D$ & & & & & & $78.8^{\circ}$ & 58.2 & 74.3 & 19.7 & 18.6 \\
\hline RPD & & & & & & 12.16 & 9.96 & 3.05 & 1.01 & .6 .13 \\
\hline $219-4 \mathrm{SB} 3$ & 74.2 & 46.0 & 76.6 & 10.9 & 4.3 & & & & & \\
\hline $219.4 S B 3 D$ & 74.2 & 46.0 & 76.6 & 10.9 & 4.3 & & & & & \\
\hline RPO & 0.00 & 0.00 & 0.00 & 0.00 & 0.00 & & & & & \\
\hline $222.3 S B 3$ & & & & & & 95.9 & 65.1 & 75.2 & 20.3 & 15.4 \\
\hline $222-3 S B 3 D$ & & & & & & $\left.95.3\right|^{\circ}$ & 64.6 & $75.1{ }^{\circ}$ & 20.6 & 15.4 \\
\hline RPD & & & & & & 0.63 & 0.77 & 0.13 & -1.47 & 0.00 \\
\hline
\end{tabular}

MeOH - Methanol, Hexane - Cyclohexane, TCA - 1,1,1-Trichloroethane, Xylene - para Xylene, Freon - Freon 113

11,1,2-trichloro-1,2,2-trifluoroethanel, CCl4 - Carbon Totrachloride, TCE - Trichloroethylene

RPD - Relativo Percent Difference. " - Outside Linear Dynamic Rango 
Table C-8. Relative percent difference (RPD) for duplicate sample analyses during test period III.

\begin{tabular}{|c|c|c|c|c|c|c|c|c|c|c|}
\hline $\begin{array}{l}\text { Sample } \\
\text { Location }\end{array}$ & $\mathrm{MeOH}$ & Hexane & TCA & Toluene & Xylene & Freon & $\mathrm{MeCl} 2$ & TCA & CCL4 & TCE \\
\hline $302-3 S B 4$ & 286.5 & 128.5 & 229.0 & 26.6 & 9.6 & & & & & \\
\hline $302-3 S B 4 D$ & 271.1 & 123.6 & 219.5 & 26.2 & 9.5 & & & & & \\
\hline RPD & 5.52 & 3.89 & 4.24 & 1.52 & 1.05 & & & & & \\
\hline 305-3SB2 & 149.7 & 80.5 & 129.8 & 18.6. & 8.7 & & & & & \\
\hline 305-3SB2D & 144.3 & 78.5 & 126.5 & 18.3 & 8.6 & & & & & \\
\hline RPD & 3.67 & 2.52 & 2.58 & 1.63 & 1.16 & & & & & \\
\hline $307-15 B 2$ & & & & & & 168.5 & 112.2 & 118.0 * & 28.9 " & 22.4 \\
\hline $307-1$ SB2D & & & & & & 86.6 & $65.3 *$ & 72.8 & $17.8 *$ & 16.3 \\
\hline RPD & & & & & & 64.21 & 52.85 & 47.38 & 47.54 & 31.52 \\
\hline $309-2 \mathrm{SB} 2$ & 108.9 & 67.5 & 103.3 & 16.2 & 8.5 & & & & & \\
\hline $309-2 \mathrm{SB} 2 \mathrm{D}$ & 104.4 & 74.7 & 109.7 & 21.5 & 9.6 & & & & & \\
\hline RPD & 4.22 & -10.13 & .6 .01 & -28.12 & -12.15 & & & & & \\
\hline $312-4 S B 2$ & & & & & & 119.6 & 70.8 & 80.4 & 17.6. & 14.0 \\
\hline $312-4 S B 2 D$ & & & & & & 119.1 & 71.2 & $80.4{ }^{\circ}$ & 17.7. & 14.0 \\
\hline RPD & & & & & & 0.42 & -0.56 & 0.00 & -0.57 & 0.00 \\
\hline 314-2SB3 & 51.9 & 35.2 & 49.4 & 11.4 & 9.1 & & & & & \\
\hline $314-2 S B 3 D$ & No Data & No Data & No Data & No Data & No Data & & & & & \\
\hline RPD & & & & & & & & & & \\
\hline 316-1SB4 & & & & & & No Data & No Data & No Data & No Data & No Data \\
\hline 316-1SB4D & & & & & & 83.7. & 69.4 & 71.1. & 14.7 & 16.1 \\
\hline RPD & & & & & & & & & & \\
\hline $319.4 \mathrm{SB} 3$ & & & & & & 76.5 & 62.4" & 62.5 & 11.5 & 10.9 \\
\hline $319-4 S B 3 D$ & & & & & & 48.8 & 38.6 & $45.6{ }^{\circ}$ & 7.8 & 8.7 \\
\hline RPD & & & & & & 44.21 & 30.58 & 31.27 & 38.34 & 22.45 \\
\hline $322-3 S B 3$ & 69.3 & 41.3 & 67.3 & 8.0 & 7.9 & & & & & \\
\hline 322-3SB3D & $67.45^{\circ}$ & 41.2 & $\left.67.2\right|^{\circ}$ & 8.0 & 7.6 & & & & & \\
\hline RPD & 3.26 & 0.24 & 0.15 & 0.00 & 3.87| & & & & & \\
\hline
\end{tabular}

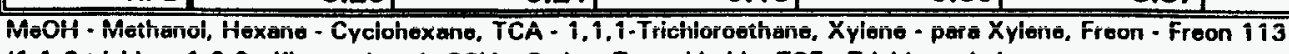

11.1.2-trichloro-1,2,2-triftuoroethano), CC14 - Carbon Tetrachloride, TCE - Trichloroethyleno

APD - Relative Percont Difference. " - Outsido Linear Dynamic Range 
Table C-9. Relative percent difference (RPD) for duplicate sample analyses during test period IV.

\begin{tabular}{|c|c|c|c|c|c|c|c|c|c|c|}
\hline \begin{tabular}{|l|} 
Sample \\
Location
\end{tabular} & $\mathrm{MeOH}$ & Hexane & TCA & Toluene & Xylene & Freon & $\mathrm{MeCl} 2$ & TCA & CCL4 & TCE \\
\hline $402-3 S B 4$ & & & & & & 562.8 & 142.3 & 226.9 & 88.3 & 33.7 \\
\hline 4O2-3SB4D & & & & & & 654.8 & 140.0 & 219.5 & 84.5 . & 33.3 \\
\hline RPD & & & & & & 1.43 & 1.63 & 3.32 & 4.40 & 1.19 \\
\hline $403-3 S B 2$ & & & & & & 447.0 & 120.7 & 132.8 & $35.8{ }^{\circ}$ & 24.9 \\
\hline 403-3SB2D & & & & & & 439.2 & 119.3 & 130.6 & 34.8 & 24.7 \\
\hline RPD & & & & & & 1.76 & 1.17 & 1.67 & 2.83 & 0.81 \\
\hline $405-1$ SB2 & & & & & & 337.9 & 130.8 & 142.1 & 40.2 & 29.9 \\
\hline 405-1SB2D & & & & & & 326.7 & 130.9 & 150.1 & 43.9 & 35.2 \\
\hline RPD & & & & & & 3.37 & .0 .08 & -5.48 & -8.80 & -16.28 \\
\hline $408-2 S B 2$ & 81.0 & 64.2 & 105.8 & 3.3 & ND & & & & & \\
\hline $408-2 S B 2 D$ & 79.9 & 74.8 & 116.9 & 10.6 & $\mathrm{ND}$ & & & & & \\
\hline RPD & 1.37 & .15 .25 & -9.97 & -105.04 & & & & & & \\
\hline $410-4$ SB2 & 72.2 & 66.3 & 108.7 & 3.4 & ND & & & & & \\
\hline 410.4 SB2D & 72,4 & 66.0 & 108.2 & 3.3 & No & & & & & \\
\hline RPD & -0.28 & 0.45 & 0.46 & 2.99 & & & & & & \\
\hline $412.2 S B 3$ & 65.3 & 53.3 & 88.1 & 0.7 & No & & & & & \\
\hline $412-2 S B 3 D$ & 65.0 & 60.8 & 95.6 & 6.1 & NO & & & & & \\
\hline RPD & 0.46 & -13.15 & -8.06 & -158.82 & & & & & & \\
\hline $416-1$ SB4 & & & & & & 193.1 & 56.4 & 81.7 & 25.0 & 20.0 \\
\hline $416-1 \mathrm{SB} 4 \mathrm{D}$ & & & & & & 195.0 & 67.7 & 89.8 & 27.7 & 23.1 \\
\hline RPD & & & & & & .0 .98 & -2.28 & -9.45 & -10.25 & -14.39 \\
\hline 419-4SB3 & 46.7 & 42.3 & 71.9 & ND & No & & & & & \\
\hline 419.4SB3D & 46.8 & 42.2 & 71.9 & ND & $\mathrm{ND}$ & & & & & \\
\hline RPD & -0.21 & 0.24 & 0.00 & & & & & & & \\
\hline $422-3$ SB3 & & & & & & 186.1 & 40.8 & 67.7 & 19.1 & 13.5 \\
\hline $422.3 \mathrm{SB} 3 \mathrm{D}$ & & & & & & 185.7 & 40.8 & 67.9 & 19.1 & 13.6 \\
\hline RPD & & & & & & 0.22 & 0.00 & -0.29 & 0.00 & -0.74 \\
\hline
\end{tabular}

MeOH - Methanol, Hexane - Cyclohexane, TCA - 1,1,1-Trichloroethene, Xylene - para Xylene, Freon - Freon 113

11,1,2-trichloro-1,2,2-trifluoroothano), CC/4 - Carbon Tetrachlorido, TCE - Trichloroethylene

RPD - Relative Percent Difference, ". Outsido Linear Dynemic Rango, ND - Not Detected 


\section{Appendix D}

Computer Program of VOC Transport Model for Lab-Scale Simulated Waste Drums 
D-2 
c program calculates the VOC concentration as a function of time

c in a simulated waste drum. The drum contains small poly bags initially

c filled with VOC-containing air. These bags were placed in a large poly c bag inside a 90-mil rigid polyethylene liner, inside a vented metal drum.

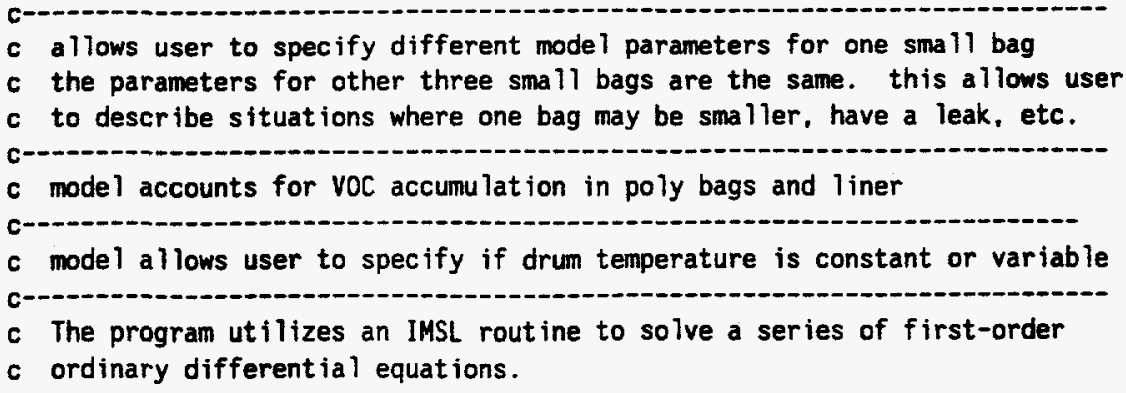

c

character ${ }^{*} 32$ test, if name, of name, vocid(9)

real aa $(1,1), y y(5,5), y z(9), \operatorname{sb} 1(5,21), \operatorname{sb} 2(5,21), 1 b(5,21), \mathrm{dh}(5,21)$

real param(50),p,d,ap(5), ad(5),v(5), xp(5), xd(5), mw

integer ivoc(5)

common/qq/p, d, ap, ad, v, xp, xd, pi, patm, pHg, dfh, c0,mw, tempo,

*vpb, vpc, y0, s0c0,nft, thr1

common/ss/s6,s7,s8,s9

external fon, ivpag. sset

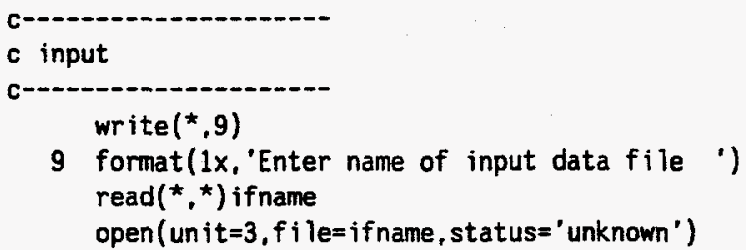

User provided input

nvoc - number of vocs in drum

$y(i, n)$ - $i$-th VOC concentration in $n$-th layer of confinenent, (mol/cm3) $n=1$, sma 11 bag headspace (for 3 identical bags)

$n=2$. small bag headspace (for 4 th small bag)

allows user to specify unique conditions of one of four small bags

$n=3$, large bag headspace

$n=4$, drum liner headspace

$n=5$, drum headspace

ap(n) - permeation surface area around $n$-th layer of confinement (cm2)

$\operatorname{ad}(n)$ - cross-sectional area for diffusion out of $n$-th layer of conf inement ( $\mathrm{cm} 2)$

$x p(n)$ - thickness of permeable surface $(\mathrm{cm})$

$x d(n)$ - length of diffusional path between layers of confinement (cm)

$v(n)$ - void volume in $n$-th layer of conf inement $(\mathrm{cm} 3)$

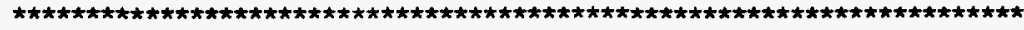

ivoc - VOC ident if ication number

1 - CCl4 2 - cyclohexane 3 - methanol 4 - $\mathrm{CH}_{2} \mathrm{Cl} 2$

5 - toluene 6 - TCA 7 - TCE 8 - Freon-113 9 - p-xylene

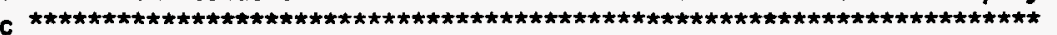

vocid(1)= 'carbon tetrachloride'

voc id (2) = "cyc lohexane"

voc id (3) = "methanol"

vocid (4) = 'methy lene chloride'

vacid(5)= 'to luene"

$\operatorname{voc}$ id $(6)=' 1,1,1-\operatorname{trich}$ loroethane'

vocid(7)= "trich loroethylene"

$\operatorname{vocid}(8)=$ 'Freon $-113^{\prime}$

$\operatorname{vocid}(9)=$ 'p-xy lene' 


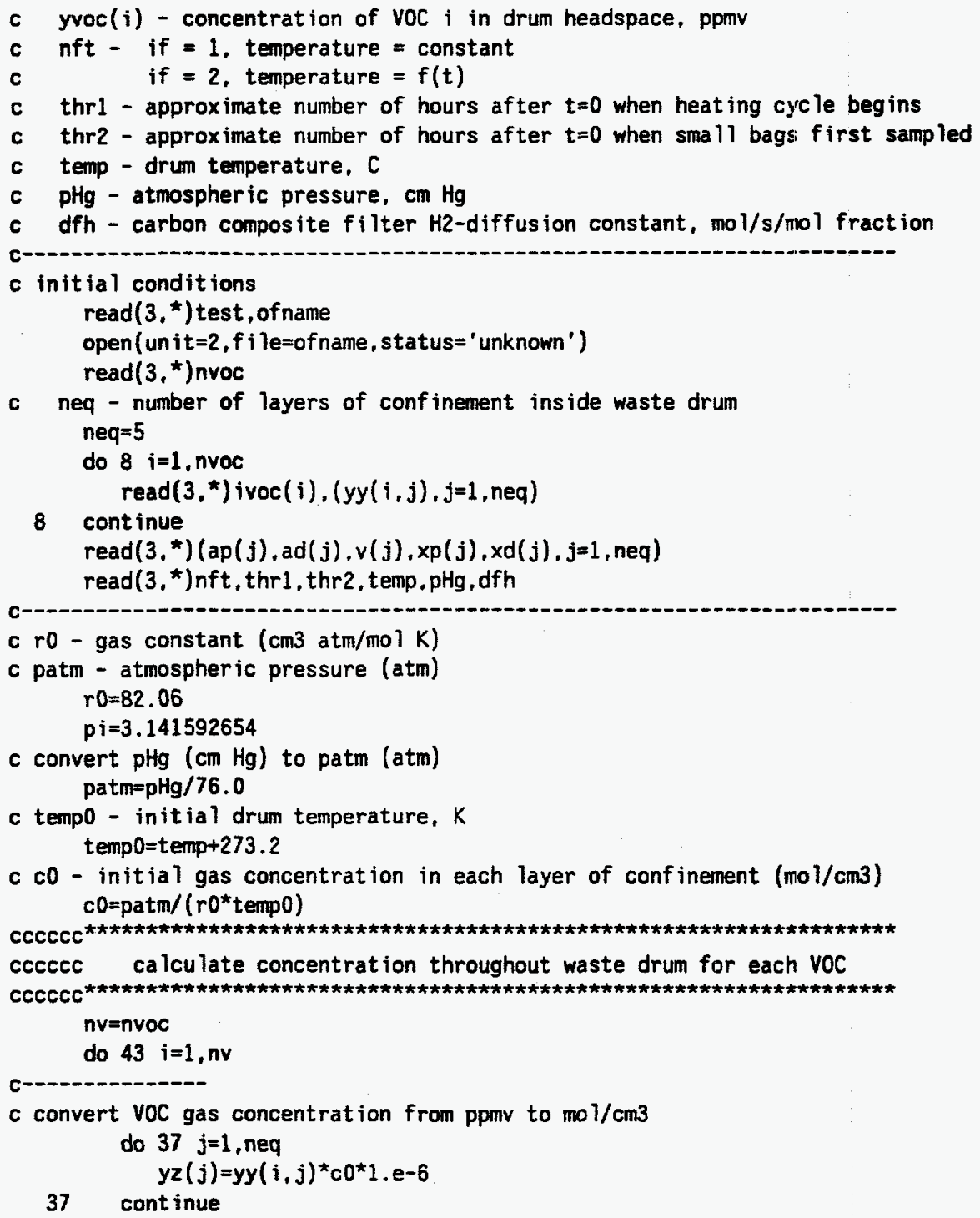


c tol - error tolerance
tol $=1 . e-6$

ido $=1$

c $\mathrm{mw}$ - VOC molecular weight

c p - VOC permeability coefficient across polyethylene $(\mathrm{cm} 3 \mathrm{~cm} / \mathrm{cm} 2 \mathrm{~s} \mathrm{cmHg}$ )

c d-diffusivity $(\mathrm{cm} 2 / \mathrm{s})$ of VOC in air

c sOco - VOC solubility in polymer/VOC gas conc. [cm3/cm3 poly/atm/(mol/cm3)]

call $\operatorname{vprop}(i \operatorname{voc}(i), c 0, m w, p, d, v p b, v p c, s 0 c 0)$

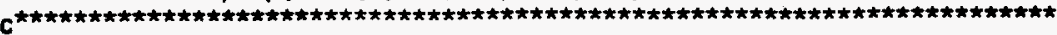

c calculation of VOC concentrations ins ide waste drum over 21 days

c

c nh - counter

$\mathrm{nh}=0$

do 20 is $=1,21$

c subrout ine to calculate time interval, dtend (sec)

24 call dti(yz(1),dtend)

tend $=t+d t e n d$

c calculation of VOC concentration in each volume inside waste drum

CALL IVPAG(ido, nq, fen, fenj, aa, t, tend, tol, param, yz)

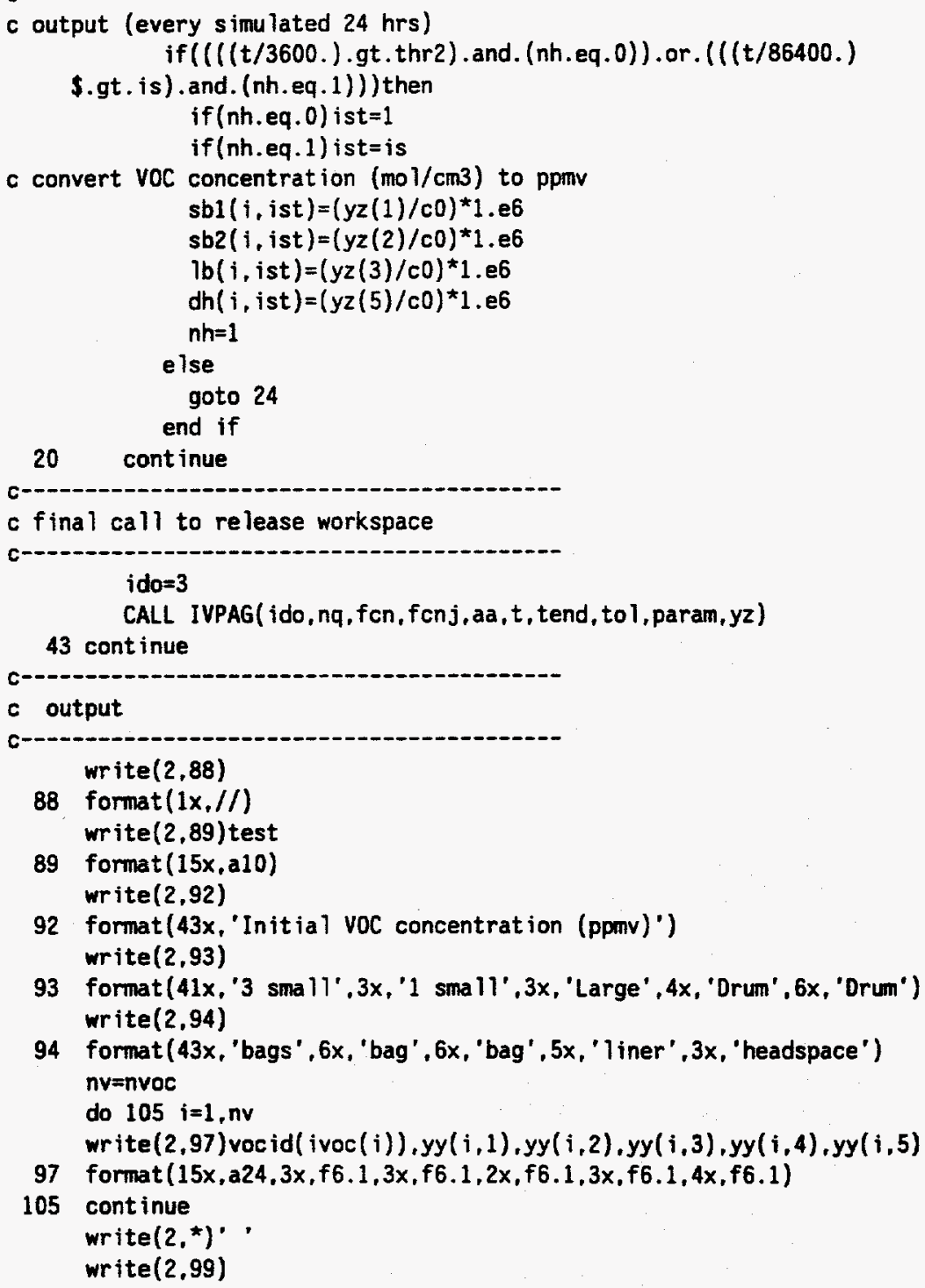

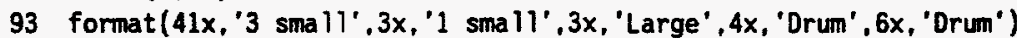
write $(2,94)$

94 format (43x, 'bags',6x, 'bag',6x, 'bag', 5x, '1 iner',3x, 'headspace')

$n v=n v o c$ do $105 i=1, n v$ write (2,97) vocid( $i \operatorname{voc}(i)), y y(i, 1), y y(i, 2), y y(i, 3), y y(i, 4), y y(i, 5)$

97 format $(15 x, a 24,3 x, f 6.1,3 x, f 6.1,2 x, f 6.1,3 x, f 6.1,4 x, f 6.1)$

105 continue write $\left(2,{ }^{\star}\right)$

write $(2,99)$ 
99 format (15x. 'Model parameters: ")

write $(2,101)$

101 format (32x, $A p(\mathrm{~cm} 2)^{\prime}, 2 x_{,}{ }^{\prime} A d(\mathrm{~cm} 2)^{\prime}, 2 x_{,}{ }^{\prime} V(\mathrm{~cm} 3)^{\prime}, 3 x_{,}{ }^{\prime} \operatorname{xp}(\mathrm{cm})^{\prime}$.

$\left.\$ 3 x,{ }^{\prime} x d(\mathrm{~cm})^{\prime}\right)$

write(2,107) ap (1), ad(1),v(1), xp(1),xd(1)

107 format $(15 x, ' 3$ sma 11 bags' $, 5 x, 2(f 6,0,4 x, f 4.2,4 x), f 5.2)$

write $(2,109)$ ap (2), ad(2),v(2), xp (2), xd(2)

109 format (15x,' 1 smal1 bag', $6 x, 2(f 6.0,4 x, f 4.2,4 x), f 5.2)$

write(2,111) ap (3), ad(3),v(3), xp(3), xd(3)

111 format(15x,'Large bag', $8 x, 2(f 6,0,4 x, f 4.2,4 x), f 5.2)$

write $(2,113)$ ap (4), ad(4),v(4), xp(4), xd(4)

113 format(15x, 'Drum liner'.7x,2(f6.0,4x,f4.2,4x),f5.2)

write $(2,117) \mathrm{ap}(5), \mathrm{ad}(5), v(5), \times \mathrm{xp}(5), x d(5)$

117 format (15x.' 'Drum headspace', $3 x, 2(f 6,0,4 x, f 4.2,4 x), f 5.2)$

write $\left(2,{ }^{*}\right)$ " *

write $(2,131)$ temp

131 format(15x,'Initial drum temperature (C): '.2x,f4.1)

if (nft.eq.1) then

write $(2,133)$

133 format (15x, 'Drum temperature during the trial: constant') else

write (2,135)

135 format (15x. 'Drum temperature during the trial: variable') write (2,137)thrl

137 format (15x.' 'Heating cycle began approximately' ,f4.1,

*' hrs after $t=0^{\prime}$ )

end if

write $(2,139)$ thr2

139 format(15x. 'First samples collected from small bags', 1x,

*'approximately ',f $4.1,{ }^{\prime}$ hrs after $t=0$ ') write $(2,141) \mathrm{pHg}$

141 format (15x,'Ambient pressure (cm Hg): ',2x,f4.1) write $(2,143) d f h$

143 format(15x, 'Hydrogen diffusion characteristic across filter',1x,

*' (mol/mol fraction/s): ',2x,e12.5) write $\left(2,{ }^{*}\right)$ '

write $(2,145)$

145 format (15x,'Predicted small bag concentrations (ppmv):') write $(2,147) \operatorname{voc} i d(i \operatorname{voc}(1)), \operatorname{vocid}(i \operatorname{voc}(2)), \operatorname{vocid}(i \operatorname{voc}(3))$.

frocid(ivoc(4)), vocid(ivoc(5))

147 format $(20 x, a 20,5 x, a 14, a 21,3 x, a 22,1 x, a 22)$ write $(2,153)$

153 format (15x,'Day '.1x,2('3 smal1',2x,'1 smal1',5x), '3 small',2x, *'1 sma 11',7x,2('3 small',2x,'1 small',6x)) write $(2,154)$

154 format (22x,2('bags',5x, 'bag',9x), 'bags', 5x, 'bag',11x, \#2('bags', 5x, 'bag', 10x))

do 160 in=1,21

write $(2,155)$ in, $(\operatorname{sbl}(j, i n), \operatorname{sb} 2(j$, in $), j=1, n$ voc)

155 format $(15 x, i 2,4 x, 3(f 5.1,4 x, f 5.1,7 x), 2 x, 2(f 5,1,4 x, f 5,1,7 x))$

160 cont inue write $(2,163)$ test

163 format $\left(1 \times, 11(/), 15 x, a 10,^{\prime}\right.$ (cont inued)') write $\left(2,{ }^{*}\right) \cdot$

write $(2,245)$

245 format (15x, 'Other predicted VOC concentrations (ppmv):') write $(2,247)$ vocid(ivoc(1)), $\operatorname{vocid}(i \operatorname{voc}(2))$, $\operatorname{vocid}(i \operatorname{voc}(3))$, frocid(ivoc(4)), vocid(ivoc(5))

247 format (20x,a20, 5x,a14,a21,3x,a22,1x,a22)

write $(2,253)$ 
c $g 1$ - fraction of moles in $v(1)$ relative to $v(3)$ $g 1=y(1)^{*} v(1) /\left(y(1)^{*} v(1)+y(3)^{*} v(3)\right)$ 
c 92 - fraction of moles in $v(2)$ relative to $v(3)$

$g 2=y(2)^{\star} v(2) /\left(y(2)^{\star} v(2)+y(3)^{\star} v(3)\right)$

$z 2=a p(2)^{\star} x p(2)^{\star} \operatorname{stp}$

$s 9=s 00^{\star} \operatorname{patm}^{\star}(y(2)+y(3))$

else

$g 2=0$.

end if

c rate of change of VOC concentration in one different sma 11 bag $y p(2)=(a+b)^{\star}(y(3)-y(2)) / v(2)-g 2^{\star} y p(9)^{\star} z 2 / v(2)$

c note: rate of VOC leaving one different small bag and entering $v(3)$ $q=q+(a+b)^{\star}(y(3)-y(2))$

c rate of change of VOC concentration in large poly bag

$s 7=0$.

$a=0.5^{\star} \mathrm{ptk}^{\star} \mathrm{ap}(3)^{\star} \mathrm{pHg}^{\star} \mathrm{ptc} / \mathrm{xp}(3)$

$b=d t k^{\star} \operatorname{ad}(3) / x d(3)$

if $(y(3) . g t .1 . e-10)$ then

c $g 3$ - fraction of moles in $v(3)$ relative to $v(4)$

$g 3=y(3)^{\star} v(3) /\left(y(3) * v(3)+y(4)^{*} v(4)\right)$

$z 3=\operatorname{ap}(3)^{\star} x p(3)^{\star} s t p$

$s 7=50 \mathrm{co*} \mathrm{patm}^{*}(y(3)+y(4))$

else

$g 3=0$.

end if

$y p(3)=\left(-q+(a+b) *(y(4)-y(3))-3^{*}(1-g 1)^{*} y p(6)^{*}\right.$

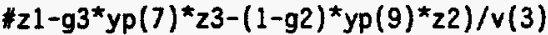

$q=(a+b) *(y(4)-y(3))$

c

c rate of change of VOC concentration in liner headspace

$s 8=0$.

if $(y(4) \cdot g t .1 . e-10)$ then

c 94 - fraction of moles in $v(4)$ relative to $v(5)$ $g 4=y(4)^{\star} v(4) /(y(4) * v(4)+y(5) * v(5))$

$\mathrm{g} 5=1-\mathrm{g} 4$

$z 4=\operatorname{ap}(4)^{\star} \times p(4)^{\star} \operatorname{stp}$

$s 8=s 0 c 0^{*} \operatorname{patm}^{*}(y(4)+y(5))$

else

g4 $=0$.

g5 $=0$.

end if

$a=p t k{ }^{*} a p(4)^{\star} p H g^{\star} p t c / x p(4)$

$b=d t k^{*} a d(4) / x d(4)$

if (dt4.gt.0.) then

$x 4=y(4)^{\star} d t 4 / t k$

else

$x 4=y(5)^{*} d t 4 / t k$

end if

$y p(4)=\left(-q+(a+b)^{\star}(y(5)-y(4))-(1-g 3)^{\star} y p(7)^{\star}\right.$

* $\left.z 3-g 4^{\star} y p(8)^{\star} z 4\right) / v(4)-x 4$

$q=(a+b) *(y(5)-y(4))$

c

c rate of change of VOC concentration in drum headspace

call headspt (nft, thrl, to, $t, t 5, d t 5$ )

$\mathrm{df}=\mathrm{dfh} \mathrm{dtk}^{\mathrm{d}} \mathrm{dh2}$

if $(d t 5 . g t .0$.) then

$x 5=y(5)^{\star} t 5^{\star}\left(d t 4 / t k^{\star \star} 2+d t 5 / t 5^{\star \star} 2\right)$

else

$x 5=0$.

end if

$y p(5)=\left(-q-d f^{\star} y(5) / c 0-g 5^{*} y p(8)^{*} z 4\right) / v(5)+x 4-x 5$

c

c rate of change of VOC content per small bag wall(6) - (three identical bags). 
c large bag( 7$)$, liner(8), sma 11 bag wall (9) - (one different bag)

c VOC-specific values for ak; specify which vOC using vpb

c carbon tetrachloride ( $\mathrm{vpb}=1242.43)$

if (vpb.eq. 1242.43) ak=8.e-6

c methylene chloride ( $\mathrm{vpb}=1325.9)$

if (vpb.eq.1325.9) ak $=1 . e-6$

c TCA (vpb=2136.6)

if (vpb.eq. 2136.6) ak $=4 . e-6$

c TCE $(\mathrm{vpb}=1018.6)$

if $(\mathrm{vpb} . \mathrm{eq} .1018 .6) \mathrm{ak}=4 . e-6$

c Freon-113 ( $v p b=1099.9)$

if ( vpb.eq. 1099.9) ak =8.e-7

c assume solubility is proportional to VOC concentration

$y p(6)=a k^{\star}(s 6-y(6))$

$y p(7)=a k^{*}(s 7-y(7))$

yp $(8)=a k^{*}(s 8-y(8))$

$y p(9)=a k^{*}(s 9-y(9))$

return

end

SUBROUTINE FCNJ(neq, $t, y, d y p d y)$

real y(neq), dypdy $\left({ }^{*}\right)$

return

end

subrout ine vprop $(i, c 0, a m w, p m, d f, b, c, s 0 c 0)$

rea $1 \mathrm{mw}(9), p(9), d(9), v p b(9), v p c(9), s c(9)$

$c \mathrm{mw}(i)$ - molecular weight of compound $i$

c $p(i)-V O C$ i permeability across polyethylene at $25 \mathrm{C}, \mathrm{cm} 3 \mathrm{~cm} / \mathrm{cm} 2 \mathrm{~s} \mathrm{~cm} \mathrm{Hg}$

c $\mathrm{df}(i)$ - diffusion of VOC $i$ in air at $25 \mathrm{C}$ (Reference $=$ ?)

c vpb(i) - Antoine equation coefficient, B, for $i$-th component

c vpc(i) - Antoine equation coefficient, $C(K)$, for $i$-th component

c sc(i) - VOC solubility in polymer/[VOC] gas, (cm3 VOC/cm3 poly) (cm3/mol VOC)

c-con

$\operatorname{mw}(1)=153.82$

$p(1)=161 . e-10$

$d(1)=0.0828$

$\mathrm{vpb}(1)=1242.43$

$\operatorname{vpc}(1)=-43.15$

c assumed value for normalized solubility

$\operatorname{sc}(1)=0.025 /\left(1000 .^{\star} c 0^{\star} 1 . e-6\right)$

c 2 = cyclohexane

$\operatorname{mw}(2)=84.1$

$\mathrm{p}(2)=1860 \cdot \mathrm{e}-10$

$d(2)=0.0750$

$\mathrm{vpb}(2)=1203.526$

$\operatorname{vpc}(2)=-50.287$

$\operatorname{sc}(2)=0$.

c $3=$ methanol

$\mathrm{mw}(3)=32.0$

$p(3)=19 . e-10$

$d(3)=0.152$

$\operatorname{vpb}(3)=1473.11$

$\operatorname{vpc}(3)=-43.15$

$\operatorname{sc}(3)=0$.

c 4 = methy lene chloride

$\operatorname{mw}(4)=84.9$

$p(4)=244 \cdot e^{-10}$

$d(4)=0.104$

$\mathrm{vpb}(4)=1325.9$

$\operatorname{vpc}(4)=-20.55$ 
$\operatorname{sc}(4)=0.023 /\left(1006 .{ }^{\star} \operatorname{co\star } 1 . e-6\right)$

c 5 = toluene

$\operatorname{nm}(5)=92.1$

$p(5)=1100 \cdot e-10$

$d(5)=0.0849$

$\mathrm{vpb}(5)=1343.943$

$\operatorname{vpc}(5)=-53.773$

$\operatorname{sc}(5)=0$.

c 6 = TCA

$\operatorname{mw}(6)=133.4$

$p(6)=138 \cdot e-10$

$d(6)=0.0794$

$\mathrm{vpb}(6)=2136.6$

$\operatorname{vpc}(6)=29.65$

c $7=$ TCE

$\operatorname{sc}(6)=0.017 /\left(994 .{ }^{\star} \mathrm{CO}^{\star} 1 . \mathrm{e}-6\right)$

$m \mathrm{~m}(7)=131.4$

$p(7)=311 . e-10$

$d(7)=0.0875$

$\mathrm{vpb}(7)=1018.6$

$\operatorname{vpc}(7)=-80.45$

$\operatorname{sc}(7)=0.013 /\left(300 .{ }^{*} c 0^{\star} 1 . e-6\right)$

c $8=$ Freon -113

$m_{w}(8)=187.4$

$p(8)=27 . e-10$

$c$ est imated diffusivity (Wi lke-Lee eqn)

$d(8)=0.062$

$\operatorname{vpb}(8)=1099.9$

$\operatorname{vpc}(8)=-45.65$

$\operatorname{sc}(8)=0.016 /\left(1010 .{ }^{*}{ }^{*} 0^{*} 1 . e-6\right)$

c $9=p$-xylene

$m w(9)=106.2$

$p(9)=1000 . e-10$

$d(9)=0.0670$

$\mathrm{vpb}(9)=1453.43$

$\operatorname{vpc}(9)=-57.840$

$\operatorname{sc}(9)=0$.

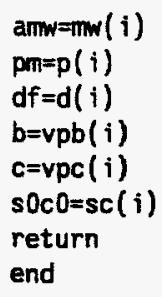

end

subrout ine linert ( $n f t, t h r 1, t 0, t, t k, d t l)$

$x=t / 86400$.

$n=\operatorname{int}(t) / 86400$

$d t=x-n$

$t r=d t \star 86400$.

if (nft.eq. 1) then 


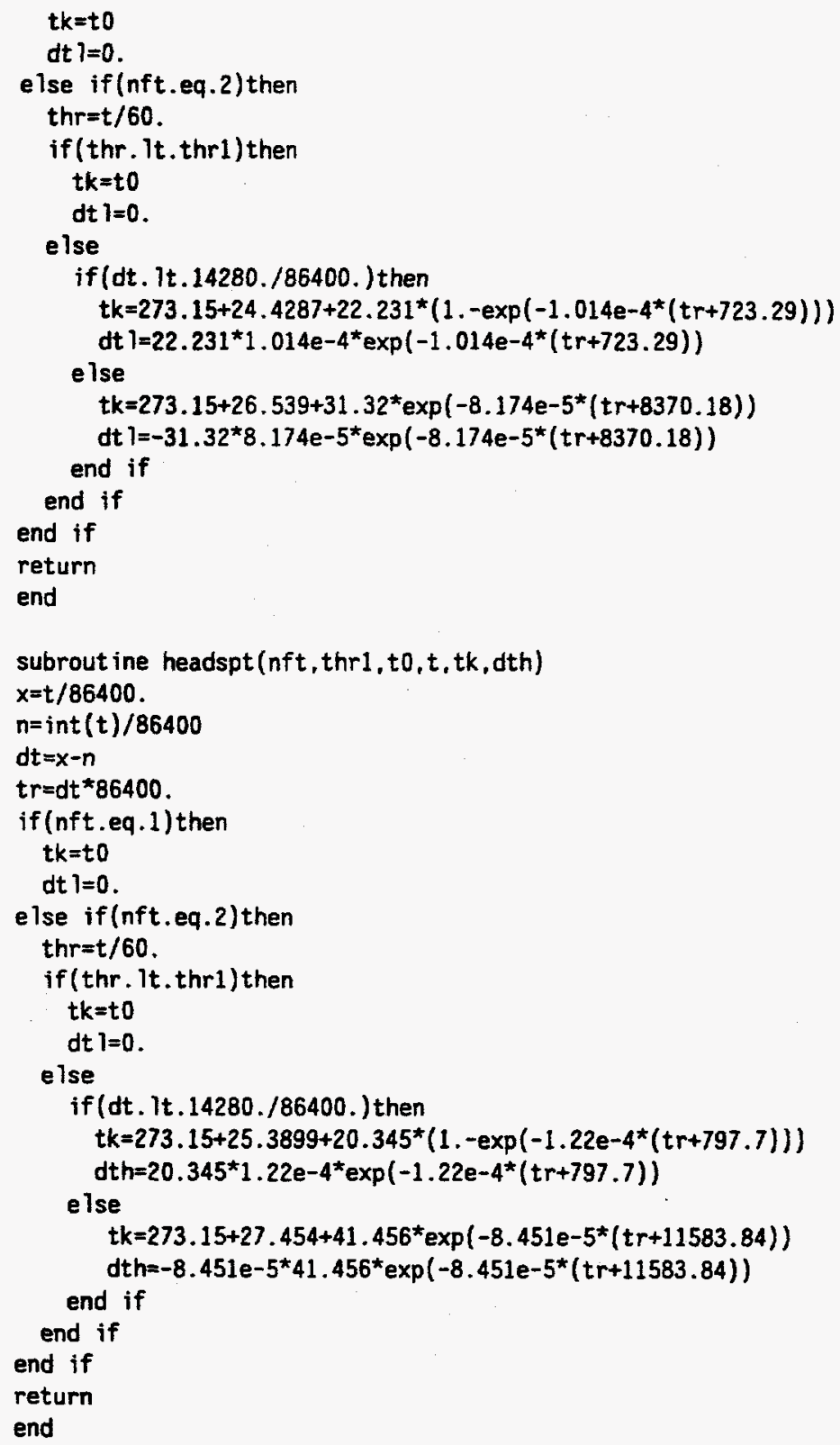




\section{Appendix E}

Computer Program Output for Lab-Scale Simulated Waste Drum VOC Transport Experiments 


\section{E-2}


Trial 1.1

\begin{tabular}{lccccc} 
& \multicolumn{7}{c}{ Initial voc concentration (ppow) } \\
& 3 small & 1 small & Large & Drum & Drum \\
& bags & bag & bag & liner & hesdspace \\
methylene chloride & 1012.0 & 1012.0 & 0.0 & 0.0 & 0.0 \\
Freon-113 & 903.0 & 903.0 & 0.0 & 0.0 & 0.0 \\
$1,1.1-t r i c h l o r o e t h a n e$ & 977.0 & 977.0 & 0.0 & 0.0 & 0.0 \\
carbon tetrachloride & 305.0 & 305.0 & 0.0 & 0.0 & 0.0 \\
trichloroethylene & 310.0 & 310.0 & 0.0 & 0.0 & 0.0
\end{tabular}

Model parameters:

$\begin{array}{lccccc} & A p(\mathrm{~cm} 2) & A d(\mathrm{~cm} 2) & V(\mathrm{~cm} 3) & x p(\mathrm{~cm}) & x d(\mathrm{~cm}) \\ 3 \text { small begs } & 2550 . & 0.01 & 4000 . & 0.01 & 15.00 \\ 1 \text { small bag } & 2550 . & 0.01 & 4000 . & 0.01 & 15.00 \\ \text { Large bag } & 12800 . & 0.01 & 34000 . & 0.01 & 15.00 \\ \text { Drum liner } & 10000 . & 0.71 & 12000 . & 0.23 & 1.18 \\ \text { Drum headspace } & 0 . & 0.00 & 16000 . & 0.00 & 0.00\end{array}$

Initial drum temperature (C): 24.7

Drum temperature during the trial: variable

Heating cycle began approximately 20.0 hrs after $t=0$

First samples collected from small bags approximately 19.0 hrs after $t=0$

Ambient pressure (cm Hg): 64.5

Hydrogen diffusion characteristic across filter (mol/mol fraction/s): $\quad 0.440005-05$

Predicted small bag concentrations (ppomv):

\begin{tabular}{|c|c|c|c|c|c|c|c|c|c|}
\hline \multicolumn{2}{|c|}{ methylene chloride } & \multicolumn{2}{|c|}{ Freon-113 } & \multicolumn{2}{|c|}{ 1,1,1-trichloroethane } & \multicolumn{2}{|c|}{ carbon tetrachloride } & \multicolumn{2}{|c|}{ trichloroethylene } \\
\hline $\begin{array}{c}3 \text { small } \\
\text { bags }\end{array}$ & $\begin{array}{l}1 \text { small } \\
\text { bag }\end{array}$ & $\begin{array}{c}3 \text { small } \\
\text { bags }\end{array}$ & $\begin{array}{c}1 \text { small } \\
\text { beg }\end{array}$ & $\begin{array}{c}3 \text { small } \\
\text { bags }\end{array}$ & $\begin{array}{l}1 \text { small } \\
\text { bag }\end{array}$ & $\begin{array}{c}3 \text { small } \\
\text { bags }\end{array}$ & $\begin{array}{l}1 \text { small } \\
\text { bag }\end{array}$ & $\begin{array}{c}3 \text { sinall } \\
\text { bags }\end{array}$ & $\begin{array}{c}1 \mathrm{smal} / \\
\mathrm{bag}\end{array}$ \\
\hline 229.0 & 229.0 & 515.9 & 515.9 & 239.7 & 239.7 & 63.7 & 63.7 & 53.5 & 53.5 \\
\hline 182.0 & 182.0 & 314.1 & 314.1 & 166.2 & 166.2 & 38.0 & 38.0 & 29.0 & 29.0 \\
\hline 157.1 & 157.1 & 249.7 & 249.7 & 136.8 & 136.8 & 30.8 & 30.8 & 21.8 & 21.8 \\
\hline 138.0 & 138.0 & 216.7 & 216.7 & 118.8 & 118.8 & 27.3 & 27.3 & 18.6 & 18.6 \\
\hline 122.7 & 122.7 & 195.7 & 195.7 & 107.4 & 107.4 & 25.4 & 25.4 & 17.1 & 17.1 \\
\hline 110.3 & 110.3 & 180.2 & 180.2 & 99.9 & 99.9 & 24.1 & 24.1 & 16.3 & 16.3 \\
\hline 100.2 & 100.2 & 167.6 & 167.6 & 94.6 & 94.6 & 23.3 & 23.3 & 15.7 & 15.7 \\
\hline 91.9 & 91.9 & 156.8 & 156.8 & 90.7 & 90.7 & 22.6 & 22.6 & 15.4 & 15.4 \\
\hline 85.2 & 85.2 & 147.4 & 147.4 & 87.8 & 87.8 & 22.1 & 22.1 & 15.1 & 15.1 \\
\hline 79.6 & 79.6 & 139.1 & 139.1 & 85.4 & 85.4 & 21.7 & 21.7 & 14.9 & 14.9 \\
\hline 75.0 & 75.0 & 131.7 & 131.7 & 83.4 & 83.4 & 21.3 & 21.3 & 14.7 & 14.7 \\
\hline 71.1 & 71.1 & 125.0 & 125.0 & 81.7 & 81.7 & 20.9 & 20.9 & 14.5 & 14.5 \\
\hline 67.9 & 67.9 & 119.0 & 119.0 & 80.1 & 80.1 & 20.6 & 20.6 & 14.4 & 14.4 \\
\hline 65.1 & 65.1 & 113.5 & 113.5 & 78.7 & 78.7 & 20.3 & 20.3 & 14.2 & 14.2 \\
\hline 62.8 & 62.8 & 108.6 & 108.6 & 77.4 & $\pi .4$ & 20.1 & 20.1 & 14.1 & 14.1 \\
\hline 60.7 & 60.7 & 104.1 & 104.1 & 76.1 & 76.1 & 19.8 & 19.8 & 13.9 & 13.9 \\
\hline 58.9 & 58.9 & 100.1 & 100.1 & 74.9 & 74.9 & 19.5 & 19.5 & 13.8 & 13.8 \\
\hline 57.4 & 57.4 & 9.4 & 96.4 & 73.7 & 73.7 & 19.3 & 19.3 & 13.7 & 13.7 \\
\hline 56.0 & 56.0 & 93.0 & 93.0 & 72.5 & 72.5 & 19.0 & 19.0 & 13.5 & 13.5 \\
\hline 54.7 & 54.7 & 89.9 & 89.9 & 71.4 & 71.4 & 18.8 & 18.8 & 13.4 & 13.4 \\
\hline 53.6 & 53.6 & 87.0 & 87.0 & 70.3 & 70.3 & 18.6 & 18.6 & 13.3 & 13.3 \\
\hline
\end{tabular}


Trial 1.1 (continued)

\begin{tabular}{|c|c|c|c|c|c|c|c|c|c|c|}
\hline \multirow[b]{2}{*}{ Day } & \multicolumn{2}{|c|}{ methylene chloride } & \multicolumn{2}{|c|}{ Freon- 113} & \multicolumn{2}{|c|}{ 1,1,1-trichloroethane } & \multicolumn{2}{|c|}{ carbon tetrachloride } & \multicolumn{2}{|c|}{ trichloroethylene } \\
\hline & $\begin{array}{c}\text { Large } \\
\text { bag }\end{array}$ & $\begin{array}{c}\text { Drum } \\
\text { headspace }\end{array}$ & $\begin{array}{l}\text { Large } \\
\text { bag }\end{array}$ & $\begin{array}{c}\text { Drum } \\
\text { headspace }\end{array}$ & $\begin{array}{c}\text { Large } \\
\text { bog }\end{array}$ & $\begin{array}{c}\text { Drum } \\
\text { headspace }\end{array}$ & $\begin{array}{l}\text { Large } \\
\text { beg }\end{array}$ & $\begin{array}{c}\text { Drum } \\
\text { headspace }\end{array}$ & $\begin{array}{c}\text { Large } \\
\text { beg }\end{array}$ & $\begin{array}{c}\text { Drunl } \\
\text { headsface }\end{array}$ \\
\hline 1 & 220.6 & 91.0 & 153.5 & 6.1 & 208.9 & 39.6 & 54.4 & 7.6 & 49.3 & 12.5 \\
\hline 2 & 177.8 & 117.6 & 197.8 & 32.1 & 156.4 & 61.2 & 35.6 & 11.8 & 27.7 & 11.9 \\
\hline 3 & 154.1 & 110.1 & 195.6 & 51.3 & 130.9 & 65.4 & 29.7 & 14.6 & 21.2 & 12.3 \\
\hline 4 & 135.6 & 100.1 & 185.4 & 63.2 & 115.2 & 67.13 & 26.8 & 16.5 & 18.4 & 12.9 \\
\hline 5 & 120.7 & 91.3 & 174.0 & 69.2 & 105.1 & 69.7 & 25.0 & 17.6 & 17.0 & 13.3 \\
\hline 6 & 108.7 & 84.0 & 163.2 & 71.6 & 98.3 & 70.9 & 23.9 & 18.3 & 16.2 & 13.5 \\
\hline 7 & 98.9 & 78.0 & 153.4 & 71.9 & 93.5 & 74.6 & 23.1 & 18.7 & 15.7 & 13.6 \\
\hline 8 & 90.9 & 73.1 & 144.5 & 79.2 & 90.0 & 79.18 & 22.5 & 18.8 & 15.4 & 13.6 \\
\hline 9 & 84.4 & 69.0 & 136.6 & 70.0 & 87.2 & 79.7 & 22.0 & 18.9 & 15.1 & 13.6 \\
\hline 10 & 78.9 & 65.6 & 129.5 & 68.5 & 85.0 & 79.3 & 21.6 & 18.8 & 14.9 & 13.5 \\
\hline 11 & 74.4 & 62.8 & 123.0 & 67.0 & 83.1 & 70.7 & 21.2 & 18.6 & 14.7 & 13.5 \\
\hline 12 & 70.7 & 60.4 & 117.2 & 65.5 & 81.4 & 70.1 & 20.9 & 18.5 & 14.5 & 13.4 \\
\hline 13 & 67.5 & 58.4 & 111.9 & 64.1 & 79.9 & 69.3 & 20.6 & 18.3 & 14.4 & 13.3 \\
\hline 14 & 64.8 & 56.6 & 107.2 & 62.7 & 78.5 & 68.4 & 20.3 & 18.1 & 14.2 & 13.2 \\
\hline 15 & 62.5 & 55.0 & 102.8 & 61.5 & 77.1 & 67.5 & 20.0 & 17.9 & 14.1 & 13.1 \\
\hline 16 & 60.5 & 53.6 & 98.9 & 60.4 & 75.9 & 66.6 & 19.8 & 17.7 & 13.9 & 13.0 \\
\hline 17 & 58.8 & 52.4 & 95.3 & 59.3 & 74.7 & 65.7 & 19.5 & 17.5 & 13.8 & 12.9 \\
\hline 18 & 57.2 & 51.3 & 92.0 & 58.3 & 73.5 & 64.8 & 19.3 & 17.3 & 13.7 & 12.8 \\
\hline 19 & 55.8 & 50.2 & 89.0 & 57.2 & 72.4 & 63.8 & 19.0 & 37.1 & 13.5 & 12.7 \\
\hline 20 & 54.6 & 49.3 & 86.2 & 56.3 & 71.3 & 62.9 & 18.8 & 16.9 & 13.4 & 12.6 \\
\hline 21 & 53.5 & 48.4 & 83.7 & 55.4 & 70.2 & 62.0 & 18.5 & 16.6 & 13.3 & 12.4 \\
\hline
\end{tabular}


Trial 1.3

\begin{tabular}{|c|c|c|c|c|c|c|}
\hline & \multicolumn{4}{|c|}{ Initial voc concentration (pponv) } & \multirow[b]{2}{*}{$\begin{array}{c}\text { Drun } \\
\text { headspace }\end{array}$} \\
\hline & & $\begin{array}{c}3 \text { small } \\
\text { bags }\end{array}$ & $\begin{array}{c}1 \text { smail } \\
\text { bag }\end{array}$ & $\begin{array}{c}\text { Large } \\
\text { bag }\end{array}$ & $\begin{array}{l}\text { Drum } \\
\text { liner }\end{array}$ & \\
\hline \multicolumn{2}{|c|}{ methylene chloride } & 1012.0 & 1012.0 & 58.0 & 0.0 & 0.0 \\
\hline \multicolumn{2}{|c|}{ Freon-113 } & 903.0 & 903.0 & 52.0 & 0.0 & 0.0 \\
\hline \multirow{2}{*}{\multicolumn{2}{|c|}{$\begin{array}{l}\text { 1,1,1-trichloroethane } \\
\text { carbon tetrachloride }\end{array}$}} & 977.0 & 977.0 & 53.0 & 0.0 & 0.0 \\
\hline & & 305.0 & 305.0 & 17.0 & 0.0 & 0.0 \\
\hline \multicolumn{2}{|c|}{ trichloroethylene } & 310.0 & 310.0 & 18.0 & 0.0 & 0.0 \\
\hline \multicolumn{7}{|c|}{ Model parameters: } \\
\hline & $A p(\mathrm{~cm} 2)$ & $\operatorname{Ad}(\mathrm{cm} 2)$ & $V(\mathrm{~cm} 3)$ & $x p(\mathrm{~cm})$ & $x d(\mathrm{~cm})$ & \\
\hline 3 small bags & 2550. & 0.00 & 4000 & 0.01 & 0.23 & \\
\hline 1 small beg & 2550. & 0.03 & 2000 & 0.01 & 0.43 & \\
\hline Large beg & 12800. & 0.01 & 35000 & 0.01 & 15.00 & \\
\hline Drum liner & 10000 & 0.71 & 13000 & 0.23 & 1.18 & \\
\hline Drum headspace & 0. & 0.00 & 16000 & 0.00 & 0.00 & \\
\hline
\end{tabular}

Initial drum temperature (C): 24.7
Drum temperature during the trial: constant
First samples collected from small bags approximately $20.0 \mathrm{hrs}$ after $t=0$
Ambient pressure (cm $\mathrm{Hg}): 64.5$
Hydrogen diffusion characteristic across filter (mol/mol fraction/s): $0.44000 \mathrm{E}-05$

\begin{tabular}{|c|c|c|c|c|c|c|c|c|c|c|}
\hline \multirow[b]{2}{*}{ Day } & \multicolumn{2}{|c|}{ methylene chloride } & \multicolumn{2}{|c|}{ Freon-113 } & \multicolumn{2}{|c|}{ 1,1,1-trichloroethane } & \multicolumn{2}{|c|}{ carbon tetrachloride } & \multicolumn{2}{|c|}{ trichloroethylene } \\
\hline & $\begin{array}{c}3 \text { small } \\
\text { bags }\end{array}$ & $\begin{array}{l}1 \text { small } \\
\text { bag }\end{array}$ & $\begin{array}{c}3 \text { small } \\
\text { bags }\end{array}$ & $\begin{array}{l}1 \text { small } \\
\text { bag }\end{array}$ & $\begin{array}{c}3 \text { smalt } \\
\text { bags }\end{array}$ & $\begin{array}{l}1 \text { small } \\
\text { bag }\end{array}$ & $\begin{array}{c}3 \text { small } \\
\text { bags }\end{array}$ & $\begin{array}{l}1 \text { small } \\
\text { beg }\end{array}$ & $\begin{array}{c}3 \text { small } \\
\text { bags }\end{array}$ & $\begin{array}{c}1 \text { smalt } \\
\text { bag }\end{array}$ \\
\hline 1 & 237.9 & 228.8 & 587.8 & 358.9 & 263.3 & 216.1 & 70.2 & 58.9 & 55.5 & 52.6 \\
\hline 2 & 189.4 & 186.6 & 381.7 & 220.4 & 175.0 & 167.5 & 40.9 & 38.9 & 30.8 & 29.9 \\
\hline 3 & 164.8 & 162.8 & 297.3 & 204.0 & 143.9 & 139.7 & 32.8 & 31.9 & 23.1 & 22.7 \\
\hline 4 & 146.2 & 144.7 & 249.9 & 196.5 & 125.1 & 122.4 & 28.9 & 28.4 & 19.6 & 19.4 \\
\hline 5 & 131.4 & 130.2 & 220.4 & 188.1 & 113.1 & 111.4 & 26.7 & 26.4 & 17.9 & 17.8 \\
\hline 6 & 119.4 & 118.4 & 200.2 & 178.8 & 105.2 & 104.1 & 25.3 & 25.1 & 17.0 & 16.9 \\
\hline 7 & 109.7 & 108.8 & 185.0 & 169.6 & 99.8 & 99.0 & 24.3 & 24.2 & 16.4 & 16.4 \\
\hline 8 & 101.7 & 101.0 & 172.9 & 160.9 & 96.0 & 95.4 & 23.7 & 23.6 & 16.1 & 16.0 \\
\hline 9 & 95.1 & 94.5 & 162.8 & 153.0 & 93.2 & 92.8 & 23.1 & 23.1 & 15.8 & 15.8 \\
\hline 10 & 89.7 & 89.2 & 154.1 & 145.7 & 91.0 & 90.7 & 22.7 & 22.7 & 15.6 & 15.6 \\
\hline 11 & 85.2 & 84.8 & 146.5 & 139.2 & 89.3 & 89.1 & 22.4 & 22.4 & 15.5 & 15.4 \\
\hline 12 & 81.4 & 81.1 & 139.7 & 133.3 & 87.9 & 87.7 & 22.2 & 22.1 & 15.3 & 15.3 \\
\hline 13 & 78.3 & 78.0 & 133.7 & 127.9 & 86.8 & 86.6 & 21.9 & 21.9 & 15.2 & 15.2 \\
\hline 14 & 75.6 & 75.4 & 128.3 & 123.1 & 85.7 & 85.6 & 21.7 & 21.7 & 15.1 & 15.1 \\
\hline 15 & 73.4 & 73.2 & 123.4 & 118.7 & 84.8 & 84.7 & 21.6 & 21.5 & 15.0 & 15.0 \\
\hline 16 & 71.5 & 71.3 & 119.0 & 114.8 & 84.0 & 83.8 & 21.4 & 21.4 & 14.9 & 14.9 \\
\hline 17 & 69.8 & 69.7 & 115.0 & 111.1 & 83.2 & 83.1 & 21.2 & 21.2 & 14.8 & 14.8 \\
\hline 18 & 68.4 & 68.2 & 111.3 & 107.9 & 82.4 & 82.3 & 21.1 & 21.1 & 14.7 & 14.7 \\
\hline 19 & 67.1 & 67.0 & 108.0 & 104.9 & 81.7 & 81.6 & 20.9 & 20.9 & 14.7 & 14.7 \\
\hline 20 & 66.0 & 65.9 & 105.0 & 102.1 & 81.0 & 80.9 & 20.8 & 20.8 & 14.6 & 14.6 \\
\hline 21 & 65.0 & 64.9 & 102.3 & 99.6 & 80.4 & 80.3 & 20.7 & 20.6 & 14.5 & 14.5 \\
\hline
\end{tabular}


Trial 1.3 (continued)

Other predicted voc concentrations (pomv):

methylene chloride

Day Large Drum
bag headspace

2

3$$
7
$$$$
8
$$$$
8
$$$$
10
$$$$
\begin{aligned}
& 10 \\
& 11
\end{aligned}
$$$$
12
$$$$
13
$$$$
14
$$$$
15
$$$$
16
$$$$
17
$$$$
18
$$$$
19
$$$$
20
$$

21

$$
\text { Freon-113 }
$$

Freon-113 1,1,1-trichloroethane

bag headspace

$162.0 \quad 5.9$

$197.8 \quad 26.2$

$198.4 \quad 43.0$

70.1

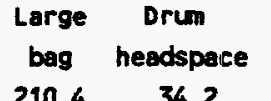

$210.4 \quad 34.2$

$162.3 \quad 56.7$

$136.4 \quad 62.4$

$120.4 \quad 66.1$

190.0

103.1

69.1

$98.4 \quad 73.2$

$94.9 \quad 74.3$

$92.4 \pi .1$

$90.4 \pi .5$

$88.8 \quad 75.6$

$87.5 \quad 75.6$

$86.4 \quad 75.4$

$85.4 \pi 5.1$

$84.5 \quad 74.8$

$83.7 \quad 74.4$

$82.9 \quad 74.0$

82.273 .5

$81.5 \quad 73.0$

$80.8 \quad 72.5$

$80.2 \quad 72.0$
191.3

182.0

172.5

163.5

155.3

147.8

141.1

135.0

129.5

124.5

120.0

115.9

112.2

108.8

105.7

102.9

100.3

98.0

43.0
55.4

63.6

68.5

71.2

72.6

73.0

72.9

72.5

72.0

71.3

70.7

69.4

68.9

68.3

67.8

$65.8 \quad 59.2$

$64.8 \quad 58.5$
67.3

66.8 carbon tetrachloride

Large Drum

bag headspace

55.9

37.6

31.3

28.1

26.2

25.0

24.1

23.5

23.0

22.6

22.3

22.9

21.9

21.7

21.5

21.3

21.2

21.0

20.9

20.8

20.6
6.8

10.7

13.5

15.6

17.1

18.1

18.8

19.2

19.4

19.5

19.6

19.6

19.5

19.5

19.4

19.3

19.2

19.1

19.0

18.9

18.7 trichloroethylene

Large Drum

beg headspece

$50.5 \quad 11.7$

$29.2 \quad 11.6$

$22.4 \quad 12.0$

$19.3 \quad 12.7$

$17.7 \quad 13.2$

$16.9 \quad 13.6$

$16.4 \quad 13.8$

$16.0 \quad 13.5$

$15.8 \quad 14.0$

$15.6 \quad 14.0$

$15.4 \quad 14.0$

$15.3 \quad 14.0$

15.214 .0

$15.1 \quad 14.0$

15.013 .9

$14.9 \quad 13.9$

$14.8 \quad 13.8$

$14.7 \quad 13.8$

$14.6 \quad 13.7$

$14.6 \quad 13.7$

$14.5 \quad 13.6$ 
Trial 2.1

\begin{tabular}{|c|c|c|c|c|c|c|}
\hline & Initial & \multicolumn{3}{|c|}{ I voc concentration (ppmi) } & \multirow[b]{2}{*}{$\begin{array}{c}\text { Drum } \\
\text { headspace }\end{array}$} \\
\hline & & $\begin{array}{c}3 \text { small } \\
\text { bags }\end{array}$ & $\begin{array}{c}1 \text { small } \\
\text { bag }\end{array}$ & $\begin{array}{c}\text { Large } \\
\text { bag }\end{array}$ & $\begin{array}{l}\text { Drum } \\
\text { liner }\end{array}$ & \\
\hline \multicolumn{2}{|c|}{ methylene chloride } & 1012.0 & 1012.0 & 58.0 & 0.0 & 0.0 \\
\hline \multicolumn{2}{|c|}{ Freon-113 } & 903.0 & 903.0 & 52.0 & 0.0 & 0.0 \\
\hline \multicolumn{2}{|c|}{ 1,1,1-trichloroethane } & 977.0 & 977.0 & 53.0 & 0.0 & 0.0 \\
\hline \multicolumn{2}{|c|}{ carbon tetrachloride } & 305.0 & 305.0 & 17.0 & 0.0 & 0.0 \\
\hline \multicolumn{2}{|c|}{ trichloroethylene } & 310.0 & 310.0 & 18.0 & 0.0 & 0.0 \\
\hline \multicolumn{7}{|c|}{ Model parameters: } \\
\hline & $A p(\mathrm{~cm} 2)$ & $\operatorname{Ad}\left(\mathrm{cm}^{2}\right)$ & $V(\mathrm{~cm} 3)$ & $\operatorname{xp}(\mathrm{cm})$ & $x d(\mathrm{~cm})$ & \\
\hline 3 small bags & 2550 . & 0.00 & 4000 & 0.01 & 0.23 & \\
\hline 1 small beg & 2550. & 0.03 & 2000. & 0.01 & 0.43 & \\
\hline Large bag & 12800 . & 0.01 & 35000 . & 0.01 & 15.00 & \\
\hline Drun liner & 10000 . & 0.71 & 13000. & 0.23 & 1.18 & \\
\hline Orun headspace & 0. & 0.00 & 16000 . & 0.00 & 0.00 & \\
\hline
\end{tabular}

Initial drum temperature (C): 24.7

Drum temperature during the trial: variable

Heating cycle began approximately $21.0 \mathrm{hrs}$ after $t=0$

first samples collected from small bags approximately $24.0 \mathrm{hrs}$ after $t=0$ Ambient pressure (cm Hg): 64.5

Hydrogen diffusion characteristic across filter (mol/mol fraction/s):

$0.44000 E-05$

Predicted small beg concentrations (pponv):

methylene chloride

Day 3 small 1 small$$
\text { bags }
$$$$
218.7
$$$$
218.7-214.7
$$

$181.4 \quad 179.2$

$156.4 \quad 154.8$

$137.2 \quad 136.0$

$121.9 \quad 120.9$

109.5108 .7

$99.4 \quad 98.8$

91.290 .7

84.584 .1

$79.0 \quad 78.6$

$74.4 \quad 74.1$

$70.6 \quad 70.3$

67.3

64.6

62.3

60.3

58.5

56.9

55.5

54.3

53.2 freon-113

3 small 1 small

bags bag

$\begin{array}{ll}485.8 & 276.3\end{array}$

$326.9 \quad 211.6$

$256.4 \quad 200.7$

$219.4 \quad 190.5$

$196.4 \quad 179.0$

$179.8 \quad 167.7$

$166.7 \quad 157.2$

$155.6 \quad 147.8$

$146.1 \quad 139.3$

$137.7 \quad 131.7$

$130.2 \quad 124.8$

$123.4 \quad 118.7$

$117.4 \quad 113.1$

$112.0 \quad 108.1$

$107.1 \quad 103.6$

$102.6 \quad 99.4$

98.595 .7

$94.9 \quad 92.2$

91.5

88.4

85.6 $1,1,1$-trichloroethane

3 small 1 small

bags bag

$220.7 \quad 203.4$

$164.2 \quad 158.7$

$134.7 \quad 131.5$

$117.0 \quad 115.0$

$105.7 \quad 104.5$

$98.3 \quad 97.5$

93.292 .7

$89.5 \quad 89.1$

$86.6 \quad 86.3$

$84.3 \quad 84.1$

$82.4 \quad 82.2$

$80.7 \quad 80.5$

$79.1 \quad 79.0$

$7.7 \quad 77.6$

$76.4 \quad 76.3$

$75.1 \quad 75.0$

$73.9 \quad 73.8$

$72.7 \quad 72.6$

$71.6 \quad 71.5$

$70.5 \quad 70.4$

$69.4 \quad 69.3$ carbon tetrachloride

3 small 1 small

bags bag

$56.5 \quad 51.8$

$37.5 \quad 36.1$

$30.3 \quad 29.7$

$27.0 \quad 26.7$

$25.1 \quad 24.9$

$23.9 \quad 23.8$

$23.0 \quad 23.0$

$22.4 \quad 22.4$

$21.9 \quad 21.9$

$21.5 \quad 21.5$

$21.1 \quad 21.1$

$20.8 \quad 20.8$

$20.5 \quad 20.5$

$20.2 \quad 20.2$

$19.9 \quad 19.9$

$19.7 \quad 19.6$

$19.4 \quad 19.4$

19.219 .1

18.9 18.9

$18.7 \quad 18.7$

$18.4 \quad 18.4$ trichloroethylene

3 small 1 small

bags bag

$46.9 \quad 45.0$

$28.7 \quad 28.0$

$21.5 \quad 21.3$

$18.5 \quad 18.3$

$17.0 \quad 16.9$

16.216 .1

$15.7 \quad 15.7$

$15.3 \quad 15.3$

$15.1 \quad 15.1$

$14.9 \quad 14.9$

$14.7 \quad 14.7$

$14.5 \quad 14.5$

$14.3 \quad 14.3$

$14.2 \quad 14.2$

$14.1 \quad 14.0$

$13.9 \quad 13.9$

$13.8 \quad 13.8$

$13.6 \quad 13.6$

$13.5 \quad 13.5$

$13.4 \quad 13.4$

$13.3 \quad 13.3$ 
Trial 2.1 (continued)

\begin{tabular}{|c|c|c|c|c|c|c|c|c|c|c|}
\hline \multirow[b]{2}{*}{ Day } & \multicolumn{2}{|c|}{ methylene chloride } & \multicolumn{2}{|c|}{ Freon-113 } & \multicolumn{2}{|c|}{ 1,1,1-trichloroethane } & \multicolumn{2}{|c|}{ carbon tetrachloride } & \multicolumn{2}{|c|}{ trichloroethylene } \\
\hline & $\begin{array}{l}\text { Large } \\
\text { bag }\end{array}$ & $\begin{array}{c}\text { Drum } \\
\text { headspace }\end{array}$ & $\begin{array}{l}\text { Large } \\
\text { beg }\end{array}$ & $\begin{array}{c}\text { Drum } \\
\text { headspace }\end{array}$ & $\begin{array}{c}\text { Large } \\
\text { bag }\end{array}$ & $\begin{array}{l}\text { Drum } \\
\text { heedspace }\end{array}$ & $\begin{array}{l}\text { Large } \\
\text { bag }\end{array}$ & $\begin{array}{c}\text { Drum } \\
\text { headspace }\end{array}$ & $\begin{array}{c}\text { Large } \\
\text { bag }\end{array}$ & $\begin{array}{c}\text { Orum } \\
\text { headspare }\end{array}$ \\
\hline 1 & 211.5 & 103.4 & 185.0 & 12.5 & 196.8 & 47.6 & 49.1 & 8.8 & 43.5 & 12.9 \\
\hline 2 & 177.2 & 118.6 & 202.0 & 36.2 & 154.3 & 62.5 & 35.0 & 12.2 & 27.4 & 12.2 \\
\hline 3 & 153.4 & 110.7 & 195.8 & 54.7 & 128.9 & 66.1 & 29.3 & 14.8 & 21.0 & 12.5 \\
\hline 4 & 134.8 & 100.5 & 184.6 & 65.5 & 113.4 & 68.2 & 26.4 & 16.6 & 18.2 & 13.0 \\
\hline 5 & 120.0 & 91.5 & 172.8 & 70.8 & 103.5 & 69.7 & 24.8 & 17.7 & 16.9 & 13.3 \\
\hline 6 & 108.0 & 84.0 & 161.9 & 72.7 & 96.9 & 70.7 & 23.7 & 18.4 & 16.1 & 13.5 \\
\hline 7 & 98.2 & 77.9 & 151.9 & 72.8 & 92.2 & 71.3 & 22.9 & 18.7 & 15.6 & 13.6 \\
\hline 8 & 90.2 & 73.0 & 143.0 & 71.8 & 88.8 & 71.3 & 22.3 & 18.8 & 15.3 & 13.6 \\
\hline 9 & 83.7 & 68.8 & 135.1 & 70.4 & 86.1 & 71.1 & 21.8 & 18.8 & 15.1 & 13.6 \\
\hline 10 & 78.3 & 65.4 & 127.9 & 68.8 & 83.9 & 70.7 & 21.4 & 18.7 & 14.9 & 13.5 \\
\hline 11 & 73.9 & 62.5 & 121.4 & 67.2 & 82.0 & 70.0 & 21.1 & 18.5 & 14.7 & 13.5 \\
\hline 12 & 70.1 & 60.1 & 115.6 & 65.6 & 80.4 & 69.3 & 20.7 & 18.4 & 14.5 & 13.4 \\
\hline 13 & 67.0 & 58.0 & 110.4 & 64.1 & 78.9 & 68.5 & 20.4 & 18.2 & 14.3 & 13.3 \\
\hline 14 & 64.3 & 56.2 & 105.6 & 62.7 & 77.5 & 67.6 & 20.2 & 18.0 & 14.2 & 13.2 \\
\hline 15 & 62.0 & 54.6 & 101.3 & 61.3 & 76.2 & 66.7 & 19.9 & 17.8 & 14.0 & 13.1 \\
\hline 16 & 60.1 & 53.3 & 97.4 & 60.1 & 74.9 & 65.7 & 19.6 & 17.6 & 13.9 & 13.0 \\
\hline 17 & 58.3 & 52.0 & 93.8 & 59.0 & 73.7 & 64.8 & 19.4 & 17.3 & 13.8 & 12.9 \\
\hline 18 & 56.8 & 50.9 & 90.5 & 57.9 & 72.6 & 63.9 & 19.1 & 17.1 & 13.6 & 12.7 \\
\hline 19 & 55.4 & 49.9 & 87.5 & 56.9 & 71.4 & 63.0 & 18.9 & 16.9 & 13.5 & 12.6 \\
\hline 20 & 54.2 & 48.9 & 84.8 & 55.9 & 70.3 & 62.0 & 18.6 & 16.7 & 13.4 & 12.5 \\
\hline 21 & 53.1 & 48.0 & 82.3 & 55.0 & 69.2 & 61.1 & 18.4 & 16.5 & 13.3 & 12.4 \\
\hline
\end{tabular}


Trial 2.3

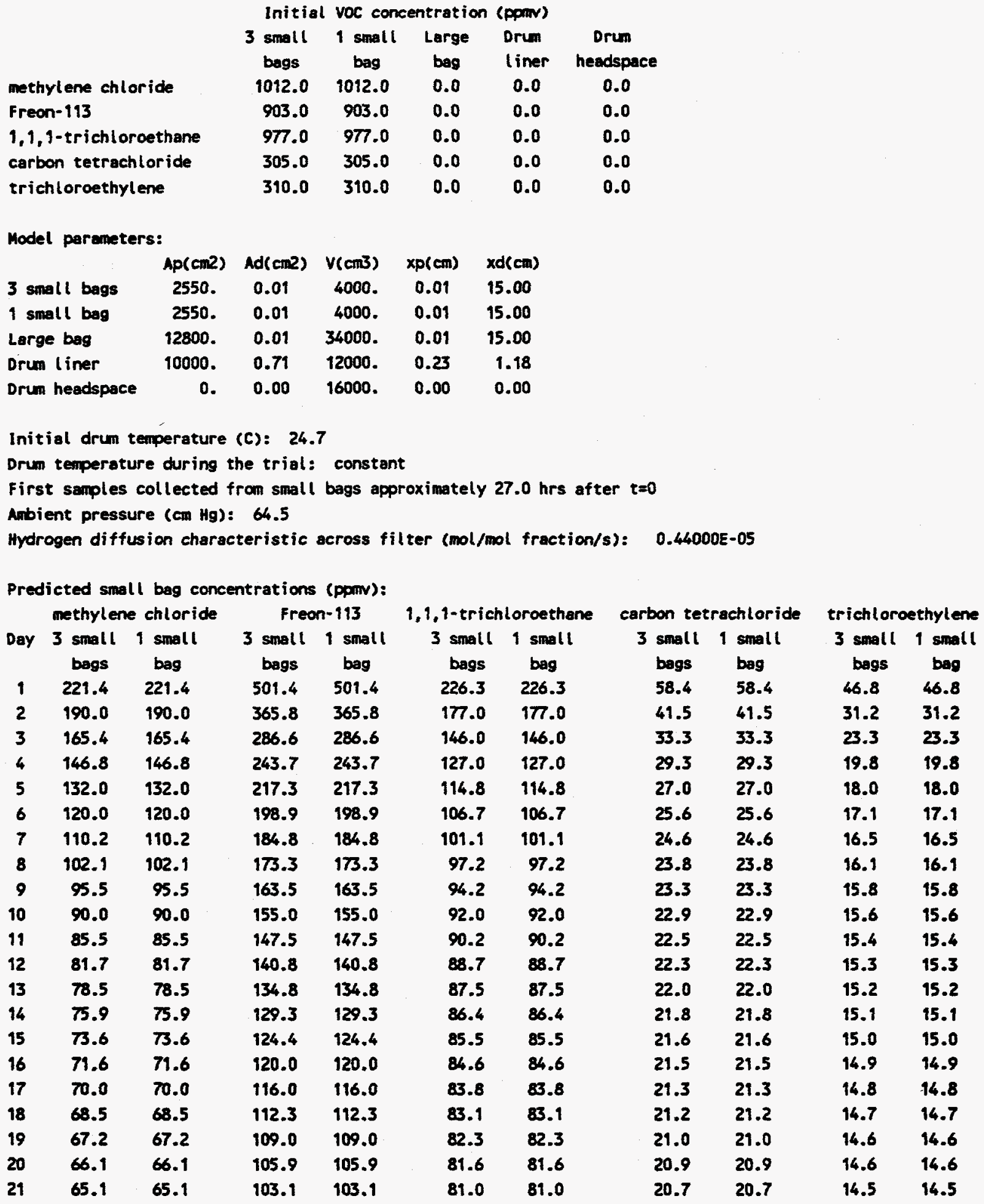


Trial 2.3 (continued)

Other predicted voc concentrations (pprnv):

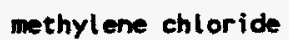

65.3

63.9

62.8

61.8

60.8

60.0

59.3

58.6

$$
\text { Freon-113 }
$$

Large Drun

bag headspace

$157.1 \quad 7.4$

$189.5 \quad 22.0$

$196.2 \quad 39.0$

$191.3 \quad 52.1$

$182.8 \quad 60.9$

173.5

164.6

156.4

148.9

142.2

136.1

130.6

125.6

121.0

116.9

113.2

109.7

106.6

103.8

101.2

98.8

66.5 1,1,1-trichloroethane Large bag headspace $199.5 \quad 41.7$ $164.5 \quad 55.2$ $138.5 \quad 61.3$ $122.2 \quad 65.4$ $111.7 \quad 68.6$ $104.5 \quad 71.2$ $99.6 \quad 73.1$ $96.0 \quad 74.4$ $93.4 \quad 75.3$ $91.3 \quad 75.8$ $89.7 \quad 76.0$ $88.3 \quad 76.0$

$87.1 \quad 7.9$

$86.1 \quad 5.7$

$85.2 \pi 5.3$

$84.3 \quad 74.9$

$83.6 \quad 74.5$

$82.8 \quad 74.1$

$82.1 \quad 73.6$

$81.4 \quad 73.1$

$80.7 \quad 72.6$ carbon tetrachloride trichloroethylene

Large orum

Large beg headspace

$50.2 \quad 7.6$

$38.2 \quad 10.3$

31.8

13.1

15.4

$26.5 \quad 16.9$

$25.2 \quad 18.0$

$24.3 \quad 18.7$

$23.7 \quad 19.1$

$23.2 \quad 19.4$

$22.8 \quad 19.6$

$22.5 \quad 19.6$

$22.2 \quad 19.6$

$22.0 \quad 19.6$

$21.8 \quad 19.6$

$21.6 \quad 19.5$

$21.4 \quad 19.4$

$21.3 \quad 19.3$

$21.1 \quad 19.2$

$21.0 \quad 19.1$

$20.8 \quad 19.0$

20.7

18.8

$43.2 \quad 11.4$

$29.6 \quad 11.2$

$22.6 \quad 11.7$

$19.4 \quad 12.5$

$17.8 \quad 13.1$

$16.9 \quad 13.5$

$16.4 \quad 13.7$

$16.0 \quad 13.9$

$15.8 \quad 13.9$

$15.6 \quad 14.0$

$15.4 \quad 14.0$

$15.3 \quad 14.0$

$15.2 \quad 14.0$

$15.1 \quad M .0$

$15.0 \quad 13.9$

$14.9 \quad 13.9$

14.813 .8

$14.7 \quad 13.8$

$14.6 \quad 13.7$

14.513 .7

14.5

13.6 
Trial 3.1

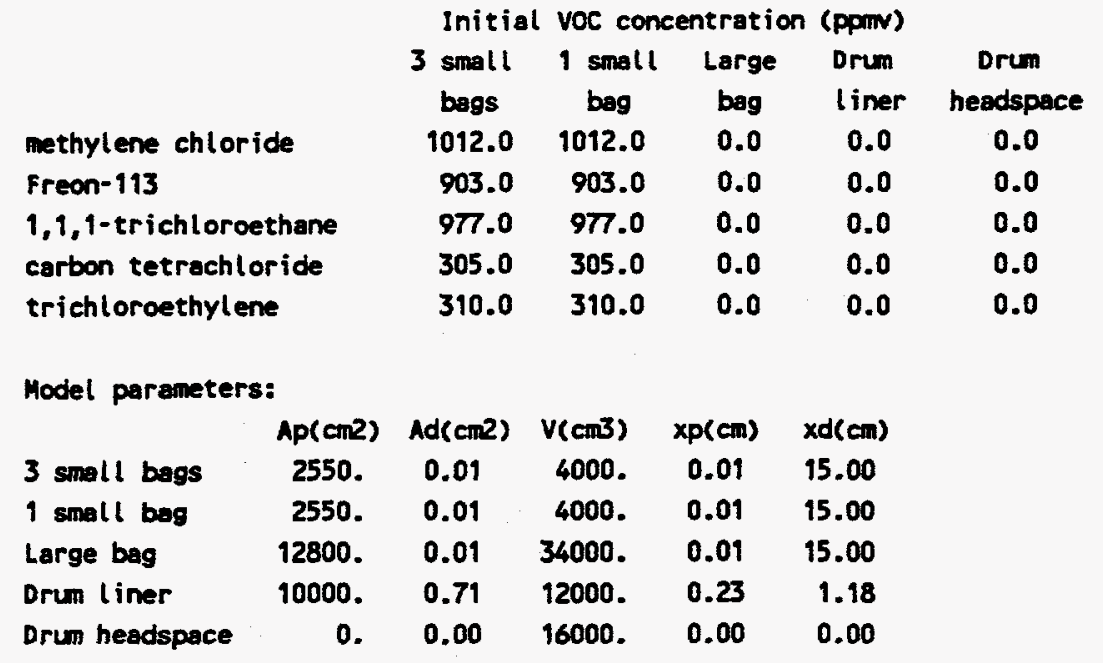

Initial drum temperature (C): 24.7

Drum temperature during the trial: variable

Heating cycle began approximately $22.0 \mathrm{hrs}$ after $t=0$

First samples collected from small bags approximetely 21.0 hrs after $t=0$

Ambient pressure $(\mathrm{cm} \mathrm{Hg}): 64.5$

Hydrogen diffusion characteristic across filter (mol/mol fraction/s): $\quad 0.44000$-05

Predicted small bag concentrations (pomv): methylene chloride Freon-113

Day 3 small 1 small 3 small 1 small.

bags bag bags bag bags bag

$\begin{array}{lllllll}1 & 224.7 & 224.7 & 495.9 & 495.9 & 231.4 & 231.4\end{array}$

$\begin{array}{lllllll}2 & 182.0 & 182.0 & 314.2 & 314.2 & 166.3 & 166.3\end{array}$

$\begin{array}{llllllll}3 & 157.1 & 157.1 & 249.8 & 249.8 & 136.8 & 136.8\end{array}$

$\begin{array}{lllllll}4 & 138.0 & 138.0 & 216.7 & 216.7 & 118.8 & 118.8\end{array}$

$\begin{array}{lllllll}5 & 122.7 & 122.7 & 195.7 & 195.7 & 107.4 & 107.4\end{array}$

$\begin{array}{lllllll}6 & 110.3 & 110.3 & 180.2 & 180.2 & 99.9 & 99.9\end{array}$

$\begin{array}{lllllll}7 & 100.2 & 100.2 & 167.6 & 167.6 & 94.6 & 94.6\end{array}$

$\begin{array}{llll}91.9 & 91.9 & 156.8 & 156.8\end{array}$

$90.7 \quad 90.7$

$\begin{array}{llll}147.4 & 147.4 & 87.8 & 87.8\end{array}$

85.285 .2

$139.1 \quad 139.1$

$79.6 \quad 79.6$

$131.7 \quad 131.7$

$75.0 \quad 75.0$

125.0

125.0

$67.9 \quad 67.9$

$119.0 \quad 119.0$

$\begin{array}{llll}65.1 & 65.1 & 113.5 & 113.5\end{array}$

$62.8 \quad 62.8$

108.6

108.6

$60.7 \quad 60.7$

104.1

104.1

59.0

59.0

100.1

100.1

$57.4 \quad 57.4$

96.4

96.4

56.0

56.0

93.0

93.0

89.9

89.9

54.7
53.6

54.7

87.0

87.0

$85.4 \quad 85.4$

$83.4 \quad 83.4$

$81.7 \quad 81.7$

80.180 .1

$78.7 \quad 78.7$

$7.4 \quad 7.4$

$76.1 \quad 76.1$

$74.8 \quad 74.8$

$73.7 \quad 73.7$

$72.5 \quad 72.5$

$71.4 \quad 71.4$

$70.3 \quad 70.3$

\begin{tabular}{cccc}
\multicolumn{2}{c}{ carbon tetrachloride } & \multicolumn{3}{c}{ trichloroethylene } \\
3 small & 1 small & 3 small & 1 small \\
bags & bag & bags & bag \\
60.6 & 60.6 & 50.8 & 50.8 \\
38.0 & 38.0 & 29.0 & 29.0 \\
30.8 & 30.8 & 21.8 & 21.8 \\
27.3 & 27.3 & 18.6 & 18.6 \\
25.4 & 25.4 & 17.1 & 17.1 \\
24.1 & 24.1 & 16.3 & 16.3 \\
23.3 & 23.3 & 15.7 & 15.7 \\
22.6 & 22.6 & 15.4 & 15.4 \\
22.1 & 22.1 & 15.1 & 15.1 \\
21.7 & 21.7 & 14.9 & 14.9 \\
21.3 & 21.3 & 14.7 & 14.7 \\
20.9 & 20.9 & 14.5 & 14.5 \\
20.6 & 20.6 & 14.4 & 14.4 \\
20.3 & 20.3 & 14.2 & 14.2 \\
20.1 & 20.1 & 14.1 & 14.1 \\
19.8 & 19.8 & 13.9 & 13.9 \\
19.5 & 19.5 & 13.8 & 13.8 \\
19.3 & 19.3 & 13.7 & 13.7 \\
19.0 & 19.0 & 13.5 & 13.5 \\
18.8 & 18.8 & 13.4 & 13.4 \\
18.6 & 18.6 & 13.3 & 13.3 \\
& & &
\end{tabular}


Trial 3.1 (continued)

other predicted voc concentrations (ppmv):

\begin{tabular}{|c|c|c|c|c|c|c|c|c|c|c|}
\hline \multirow[b]{2}{*}{ Day } & \multicolumn{2}{|c|}{ methylene chloride } & \multicolumn{2}{|c|}{ Freon-113 } & \multicolumn{2}{|c|}{ 1,1,1-trichloroethane } & \multicolumn{2}{|c|}{ carbon tetrachloride } & \multicolumn{2}{|c|}{ trichloroethylene } \\
\hline & $\begin{array}{c}\text { Large } \\
\text { bag }\end{array}$ & $\begin{array}{c}\text { Drum } \\
\text { headspace }\end{array}$ & $\begin{array}{l}\text { Large } \\
\text { bag }\end{array}$ & $\begin{array}{c}\text { Drum } \\
\text { headspace }\end{array}$ & $\begin{array}{c}\text { Large } \\
\text { bag }\end{array}$ & $\begin{array}{c}\text { Drum } \\
\text { headspace }\end{array}$ & $\begin{array}{c}\text { Large } \\
\text { bag }\end{array}$ & $\begin{array}{c}\text { Drum } \\
\text { headspace }\end{array}$ & $\begin{array}{c}\text { Large } \\
\text { bag }\end{array}$ & $\begin{array}{c}\text { Drum } \\
\text { headsfrace }\end{array}$ \\
\hline 1 & 216.9 & 95.7 & 159.5 & 7.3 & 204.9 & 42.3 & 52.4 & 7.9 & 47.0 & 12.5 \\
\hline 2 & 177.8 & 117.6 & 197.8 & 32.1 & 156.4 & 61.2 & 35.6 & 11.8 & 27.7 & 11.9 \\
\hline 3 & 154.1 & 110.1 & 195.6 & 51.3 & 130.9 & 65.3 & 29.7 & 14.6 & 21.2 & 12.3 \\
\hline 4 & 135.6 & 100.1 & 185.4 & 63.2 & 115.2 & 67.18 & 26.8 & 16.5 & 18.4 & 12.9 \\
\hline 5 & 120.7 & 91.3 & 174.0 & 69.2 & 105.1 & 69.7 & 25.0 & 17.6 & 17.0 & 13.3 \\
\hline 6 & 108.7 & 84.0 & 163.2 & 71.6 & 98.3 & 70.9 & 23.9 & 18.3 & 16.2 & 13.5 \\
\hline 7 & 98.9 & 78.0 & 153.4 & 71.9 & 93.5 & 71.5 & 23.1 & 18.7 & 15.7 & 13.6 \\
\hline 8 & 90.9 & 73.1 & 144.5 & 71.2 & 90.0 & $71 . B$ & 22.5 & 18.8 & 15.4 & 13.6 \\
\hline 9 & 84.4 & 69.0 & 136.6 & 69.9 & 87.2 & 71.7 & 22.0 & 18.9 & 15.1 & 13.6 \\
\hline 10 & 79.0 & 65.6 & 129.4 & 68.5 & 85.0 & 71.3 & 21.6 & 18.8 & 14.9 & 13.5 \\
\hline 11 & 74.4 & 62.8 & 123.0 & 67.0 & 83.0 & 70.7 & 21.2 & 18.7 & 14.7 & 13.5 \\
\hline 12 & 70.7 & 60.4 & 117.2 & 65.5 & 81.4 & 70.10 & 20.9 & 18.5 & 14.5 & 13.4 \\
\hline 13 & 67.5 & 58.3 & 111.9 & 64.1 & 79.9 & 69.2 & 20.6 & 18.3 & 14.4 & 13.3 \\
\hline 14 & 64.8 & 56.6 & 107.2 & 62.8 & 78.5 & 68.4 & 20.3 & 18.1 & 14.2 & 13.2 \\
\hline 15 & 62.5 & 55.0 & 102.8 & 61.5 & 7.1 & 67.5 & 20.0 & 17.9 & 14.1 & 13.1 \\
\hline 16 & 60.5 & 53.7 & 98.9 & 60.4 & 75.9 & 66.16 & 19.8 & 17.7 & 13.9 & 13.0 \\
\hline 17 & 58.8 & 52.4 & 95.3 & 59.3 & 74.7 & 65.7 & 19.5 & 17.5 & 13.8 & 12.9 \\
\hline 18 & 57.2 & 51.3 & 92.0 & 58.3 & 73.5 & 64.13 & 19.3 & 17.3 & 13.7 & 12.8 \\
\hline 19 & 55.9 & 50.2 & 89.0 & 57.3 & $\mathbf{7} .4$ & 63.13 & 19.0 & 17.1 & 13.5 & 12.7 \\
\hline 20 & 54.6 & 49.3 & 86.2 & 56.3 & 71.3 & 62.9 & 18.8 & 16.9 & 13.4 & 12.6 \\
\hline 21 & 53.5 & 48.4 & 83.7 & 55.4 & 70.2 & 62.10 & 18.5 & 16.6 & 13.3 & 12.4 \\
\hline
\end{tabular}

E-12 
Trial 3.4

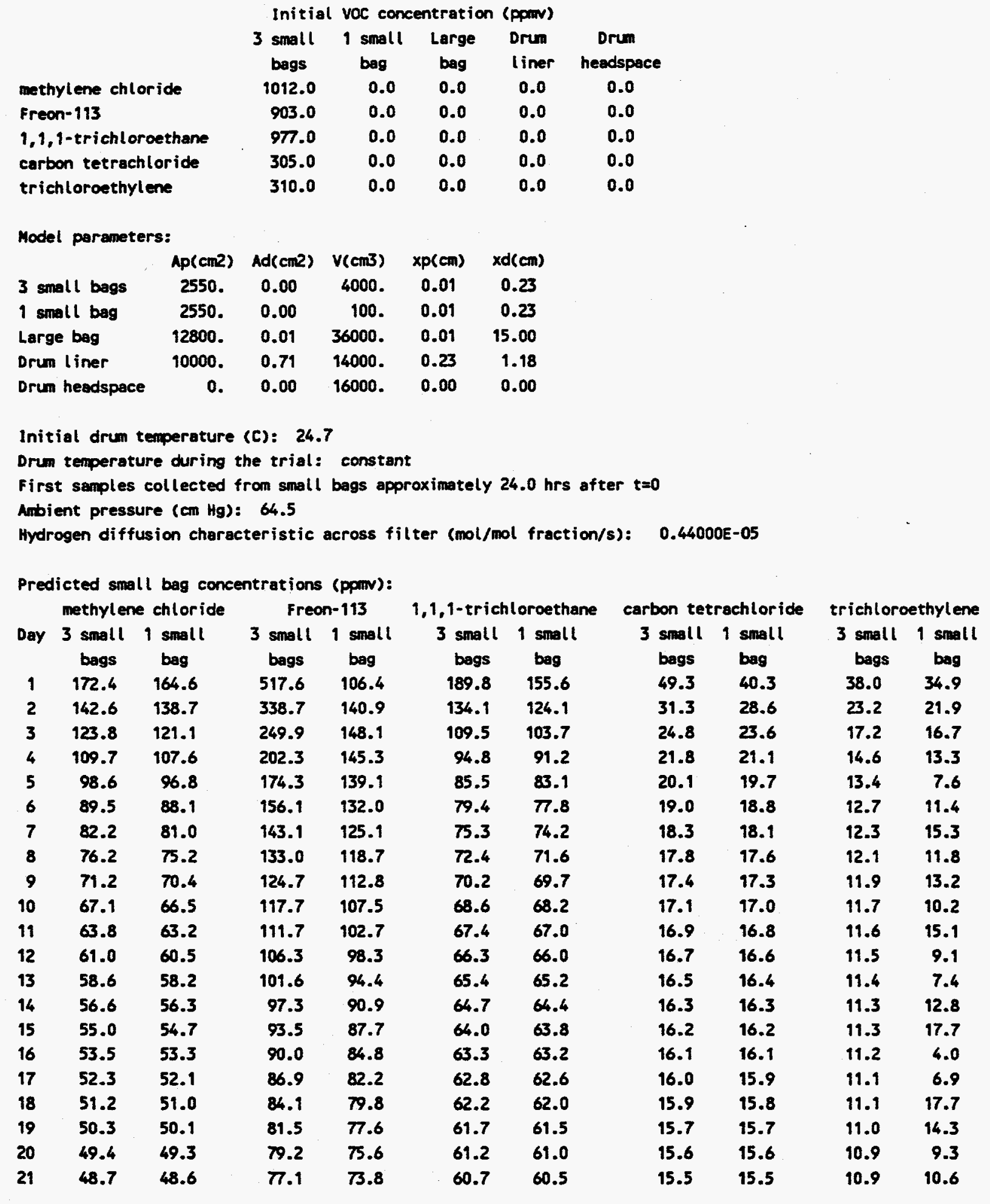


Trial 3.4 (continued)

other predicted voc concentrations (pporv):

methylene chloride Freon-113

Day Large Drum
bag headspace

\section{$164.5 \quad 66.2$}

$138.6 \quad 85.9$

$121.0 \quad 84.3$

$107.5 \quad 78.6$

$96.8 \quad 72.8$

$88.1 \quad 67.8$

$81.0 \quad 63.7$

75.2

60.2

70.4

57.4

$66.5 \quad 55.1$

$63.2 \quad 53.1$

$60.5 \quad 51.5$

$58.2 \quad 50.1$

$56.3 \quad 48.9$

$54.7 \quad 47.9$

$53.3 \quad 47.0$

52.1

46.2

51.0

45.5

$50.1 \quad 44.9$

$49.3 \quad 44.3$

48.6

\begin{abstract}
Freon-113
\end{abstract}
Large Drum
bag headspace

$108.8 \quad 3.7$

$141.6 \quad 15.2$

148.128 .1

$145.1 \quad 38.5$

$138.8 \quad 45.8$

$131.8 \quad 50.4$

$124.8 \quad 53.1$

$118.4 \quad 54.5$

$112.6 \quad 55.1$

$107.3 \quad 55.1$

$102.5 \quad 54.9$

$98.2 \quad 54.5$

$94.3 \quad 54.0$

$90.8 \quad 53.5$

$87.6 \quad 53.0$

$84.7 \quad 52.5$

$82.1 \quad 52.0$

$79.7 \quad 51.5$

$77.5 \quad 51.1$

$75.6 \quad 50.7$

$73.7 \quad 50.3$ 1,1,1-trichloroethane Large Drum bag headspace $155.4 \quad 28.7$ $123.9 \quad 43.1$ $103.6 \quad 47.6$ $91.1 \quad 50.3$

$83.1 \quad 52.5$

$77.8 \quad 54.1$

$74.2 \quad 55.4$

$71.6 \quad 56.2$

$69.6 \quad 56.7$

$68.2 \quad 57.0$

$67.0 \quad 57.1$

$66.0 \quad 57.0$

$65.2 \quad 56.9$

$64.4 \quad 56.7$

$63.8 \quad 56.4$

$63.1 \quad 56.1$

$62.6 \quad 55.8$

$62.0 \quad 55.4$

$69.5 \quad 55.0$

$64.0 \quad 54.7$

$60.5 \quad 54.3$ carbon tetrachloride trichloroethylene

$\begin{array}{cccc}\begin{array}{c}\text { Large } \\ \text { bag }\end{array} & \begin{array}{c}\text { Drum } \\ \text { headspace }\end{array} & \begin{array}{c}\text { Large } \\ \text { bag }\end{array} & \begin{array}{c}\text { Drum } \\ \text { headspace }\end{array} \\ 40.2 & 5.6 & 34.8 & 9.2 \\ 28.6 & 8.1 & 21.9 & 8.9 \\ 23.6 & 10.2 & 16.7 & 9.1 \\ 21.1 & 11.8 & 14.4 & 9.5 \\ 19.7 & 12.9 & 13.3 & 9.9 \\ 18.7 & 13.7 & 12.6 & 10.2 \\ 18.1 & 14.1 & 12.3 & 10.3 \\ 17.6 & 14.4 & 12.0 & 10.4 \\ 17.3 & 14.6 & 11.9 & 10.5 \\ 17.0 & 14.7 & 11.7 & 10.5 \\ 16.8 & 14.7 & 11.6 & 10.5 \\ 16.6 & 14.7 & 11.5 & 10.5 \\ 16.4 & 14.7 & 11.4 & 10.5 \\ 16.3 & 14.6 & 11.3 & 10.5 \\ 16.2 & 14.6 & 11.2 & 10.5 \\ 16.1 & 14.5 & 11.2 & 10.4 \\ 15.9 & 14.4 & 11.1 & 10.4 \\ 15.8 & 14.3 & 11.0 & 10.3 \\ 15.7 & 14.3 & 11.0 & 10.3 \\ 15.6 & 14.2 & 10.9 & 10.2 \\ 15.5 & 14.1 & 10.9 & 10.2\end{array}$


Trial 4.1

\begin{tabular}{|c|c|c|c|c|c|c|}
\hline & \multicolumn{4}{|c|}{ Initial voC concentration (ppom) } & \multirow{3}{*}{$\begin{array}{c}\text { Drum } \\
\text { headspace }\end{array}$} \\
\hline & & 3 small & 1 small & Large & Drum & \\
\hline & & bags & bag & bag & liner & \\
\hline \multicolumn{2}{|c|}{ methylene chloride } & 1010.0 & 1010.0 & 0.0 & 0.0 & 0.0 \\
\hline \multicolumn{2}{|c|}{ Freon-113 } & 1010.0 & 1010.0 & 0.0 & 0.0 & 0.0 \\
\hline \multicolumn{2}{|c|}{ 1,1,1-trichloroethane } & 1020.0 & 1020.0 & 0.0 & 0.0 & 0.0 \\
\hline \multicolumn{2}{|c|}{ carbon tetrachloride } & 301.0 & 301.0 & 0.0 & 0.0 & 0.0 \\
\hline \multicolumn{2}{|c|}{ trichloroethylene } & 297.0 & 297.0 & 0.0 & 0.0 & 0.0 \\
\hline \multicolumn{7}{|c|}{ Model parameters: } \\
\hline & $A p(\mathrm{~cm} 2)$ & $\operatorname{Ad}(\mathrm{cm} 2)$ & $V(\mathrm{~cm} 3)$ & $\operatorname{xp}(\mathrm{cm})$ & $x d(\mathrm{~cm})$ & \\
\hline \multirow{2}{*}{$\begin{array}{l}3 \text { small bags } \\
1 \text { small bag }\end{array}$} & 2550 . & 0.00 & 4000 & 0.01 & 0.23 & \\
\hline & 2550. & 0.00 & 4000 & 0.01 & 0.23 & \\
\hline \multirow{2}{*}{$\begin{array}{l}\text { Large bag } \\
\text { Drum liner }\end{array}$} & 12800 . & 0.01 & 34000 & 0.01 & 15.00 & \\
\hline & 10000. & 0.71 & 12000 & 0.23 & 9.18 & \\
\hline Drum headspace & 0. & 0.00 & 16000 & 0.00 & 0.00 & \\
\hline
\end{tabular}

Initial drum temperature (C): 24.7

Drum tenperature during the trial: variable

Heating cycle began approximately $23.0 \mathrm{hrs}$ after $t=0$

First samples collected from small bags approximately $23.0 \mathrm{hrs}$ after $t=0$ Ambient pressure (cm $\mathrm{Hg}$ ): 64.5

Hydrogen diffusion characteristic across filter (mol/mol fraction/s): $\quad 0.44000 \mathrm{E}-05$

\begin{tabular}{|c|c|c|c|c|c|c|c|c|c|c|}
\hline \multirow[b]{2}{*}{ Day } & \multicolumn{2}{|c|}{ methylene chloride } & \multicolumn{2}{|c|}{ Freon- 113} & \multicolumn{2}{|c|}{ 1,1,1-trichloroethane } & \multicolumn{2}{|c|}{ carbon tetrachloride } & \multicolumn{2}{|c|}{ trichloroethylene } \\
\hline & $\begin{array}{l}3 \text { small } \\
\text { begs }\end{array}$ & $\begin{array}{l}1 \text { small } \\
\text { beg }\end{array}$ & $\begin{array}{l}3 \text { small } \\
\text { bags }\end{array}$ & $\begin{array}{c}1 \text { small } \\
\text { bag }\end{array}$ & $\begin{array}{c}3 \text { small } \\
\text { begs }\end{array}$ & $\begin{array}{l}1 \text { small } \\
\text { bag }\end{array}$ & $\begin{array}{c}3 \text { small } \\
\text { begs }\end{array}$ & $\begin{array}{c}1 \text { small } \\
\text { beg }\end{array}$ & $\begin{array}{c}3 \text { smell } \\
\text { begs }\end{array}$ & $\begin{array}{c}1 \text { small } \\
\text { bag }\end{array}$ \\
\hline 1 & 220.4 & 220.4 & 534.1 & 534.1 & 234.0 & 234.0 & 57.2 & 57.2 & 46.3 & 46.3 \\
\hline 2 & 181.6 & 181.6 & 351.8 & 351.8 & 173.6 & 173.6 & 37.5 & 37.5 & 27.8 & 27.8 \\
\hline 3 & 156.8 & 156.8 & 279.5 & 279.5 & 142.8 & 142.8 & 30.4 & 30.4 & 20.9 & 20.9 \\
\hline 4 & 137.7 & 137.7 & 242.4 & 242.4 & 124.1 & 124.1 & 27.0 & 27.0 & 17.8 & 17.8 \\
\hline 5 & 122.4 & 122.4 & 219.0 & 219.0 & 112.2 & 112.2 & 25.0 & 25.0 & 16.4 & 16.4 \\
\hline 6 & 110.0 & 110.0 & 201.6 & 201.6 & 104.2 & 104.2 & 23.8 & 23.8 & 15.6 & 15.6 \\
\hline 7 & 100.0 & 100.0 & 187.5 & 187.5 & 98.7 & 98.7 & 23.0 & 23.0 & 15.1 & 15.1 \\
\hline 8 & 91.7 & 91.7 & 175.5 & 175.5 & 94.7 & 94.7 & 22.3 & 22.3 & 14.7 & 14.7 \\
\hline 9 & 85.0 & 85.0 & 165.0 & 165.0 & 91.6 & 91.6 & 21.8 & 21.8 & 14.5 & 14.5 \\
\hline 10 & 79.4 & 79.4 & 155.6 & 155.6 & 89.1 & 89.1 & 21.4 & 21.4 & 14.3 & 14.3 \\
\hline 11 & 74.8 & 74.8 & 147.3 & 147.3 & 87.1 & 87.1 & 21.0 & 21.0 & 14.1 & 14.1 \\
\hline 12 & 71.0 & 71.0 & 139.8 & 139.8 & 85.3 & 85.3 & 20.7 & 20.7 & 13.9 & 13.9 \\
\hline 13 & 67.7 & 67.7 & 133.1 & 133.1 & 83.6 & 83.6 & 20.4 & 20.4 & 13.8 & 13.8 \\
\hline 14 & 65.0 & 65.0 & 127.0 & 127.0 & 82.2 & 82.2 & 20.1 & 20.1 & 13.6 & 13.6 \\
\hline 15 & 62.6 & 62.6 & 121.5 & 121.5 & 80.8 & 80.8 & 19.8 & 19.8 & 13.5 & 13.5 \\
\hline 16 & 60.6 & 60.6 & 116.5 & 116.5 & 79.4 & 79.4 & 19.5 & 19.5 & 13.3 & 13.3 \\
\hline 17 & 58.8 & 58.8 & 112.0 & 112.0 & 78.1 & 78.1 & 19.3 & 19.3 & 13.2 & 13.2 \\
\hline 18 & 57.3 & 57.3 & 107.8 & 107.8 & 76.9 & 76.9 & 19.0 & 19.0 & 13.1 & 13.1 \\
\hline 19 & 55.9 & 55.9 & 104.0 & 104.0 & 75.7 & 73.7 & 18.8 & 18.8 & 13.0 & 13.0 \\
\hline 20 & 54.6 & 54.6 & 100.6 & 100.6 & 74.5 & 74.5 & 18.6 & 18.6 & 12.8 & 12.8 \\
\hline 21 & 53.4 & 53.4 & 97.4 & 97.4 & 73.4 & 73.4 & 18.3 & 18.3 & 12.7 & 12.7 \\
\hline
\end{tabular}


Trial 4.1 (continued)

Other predicted voc concentrations (ppmiv): methylene chloride

\begin{tabular}{|c|c|c|}
\hline Day & $\begin{array}{c}\text { Large } \\
\text { beg }\end{array}$ & $\begin{array}{c}\text { Drum } \\
\text { headspace }\end{array}$ \\
\hline
\end{tabular}

$$
213.1 \quad 99.6
$$

$177.5 \quad 117.3$

$153.8 \quad 109.8$

$135.3 \quad 99.9$

$120.5 \quad 91.1$

$108.5 \quad 83.8$

$98.7 \quad 77.8$

$$
90.7 \quad 72.9
$$

$84.2 \quad 68.9$

$78.8 \quad 65.5$

$74.3 \quad 62.6$

$70.5 \quad 60.3$

$67.4 \quad 58.2$

$64.7 \quad 56.4$

$62.4 \quad 54.9$

$60.4 \quad 53.5$

$58.7 \quad 52.3$

$57.1 \quad 51.1$

55.7 . 50.1

$54.5 \quad 49.2$

53.4

48.3 freon-113

Large Drum

bag headspace

$184.3 \quad 9.7$

$221.1 \quad 35.9$

$218.7 \quad 57.4$

$207.4 \quad 70.6$

$194.7 \quad 77.4$

$182.6 \quad 80.0$

$171.6 \quad 80.4$

$161.7 \quad 79.6$

152.878 .2

$144.8 \quad 76.6$

$137.6 \quad 74.9$

$131.1 \quad 73.3$

$125.2 \quad 71.7$

119.970 .2

115.1

110.6

106.6

102.9

99.6

96.5

93.6 1,1,1-trichloroethane

\begin{tabular}{cc}
\hline Large & Drul \\
bag & headspace \\
209.6 & 46.7 \\
163.3 & 63.9 \\
136.7 & 68.2 \\
120.3 & 70.8 \\
109.8 & 72.7 \\
102.6 & 74.0 \\
97.6 & 74.7 \\
93.9 & 75.0 \\
91.0 & 74.8 \\
88.7 & 74.4 \\
86.7 & 73.8 \\
84.9 & 73.1 \\
83.4 & 72.3 \\
81.9 & 71.4 \\
80.5 & 70.5 \\
79.2 & 69.5 \\
77.9 & 68.6 \\
76.7 & 67.6 \\
75.5 & 66.6 \\
74.4 & 65.7 \\
73.2 & 64.7
\end{tabular}

carbon tetrachloride trichloroethylene

$\begin{array}{cccc}\begin{array}{c}\text { Large } \\ \text { bag }\end{array} & \begin{array}{c}\text { Drum } \\ \text { headspace }\end{array} & \begin{array}{c}\text { Large } \\ \text { bag }\end{array} & \begin{array}{c}\text { Drun } \\ \text { headspace }\end{array} \\ 49.9 & 8.1 & 42.9 & 11.9 \\ 35.1 & 11.6 & 26.6 & 11.4 \\ 29.3 & 14.4 & 20.4 & 11.8 \\ 26.4 & 16.3 & 17.6 & 12.3 \\ 24.7 & 17.4 & 16.2 & 12.7 \\ 23.6 & 18.1 & 15.5 & 12.9 \\ 22.8 & 18.4 & 15.0 & 13.0 \\ 22.2 & 18.6 & 14.7 & 13.0 \\ 21.7 & 18.6 & 14.5 & 13.0 \\ 21.3 & 18.5 & 14.3 & 13.0 \\ 20.9 & 18.4 & 14.1 & 12.9 \\ 20.6 & 18.3 & 13.9 & 12.8 \\ 20.3 & 18.1 & 13.8 & 12.7 \\ 20.0 & 17.9 & 13.6 & 12.7 \\ 19.8 & 17.7 & 13.5 & 12.5 \\ 19.5 & 17.5 & 13.3 & 12.4 \\ 19.3 & 17.2 & 13.2 & 12.3 \\ 19.0 & 17.0 & 13.1 & 12.2 \\ 18.8 & 16.8 & 13.0 & 12.1 \\ 18.5 & 16.6 & 12.8 & 12.0 \\ 18.3 & 16.4 & 12.7 & 11.9\end{array}$


Trial 4.3

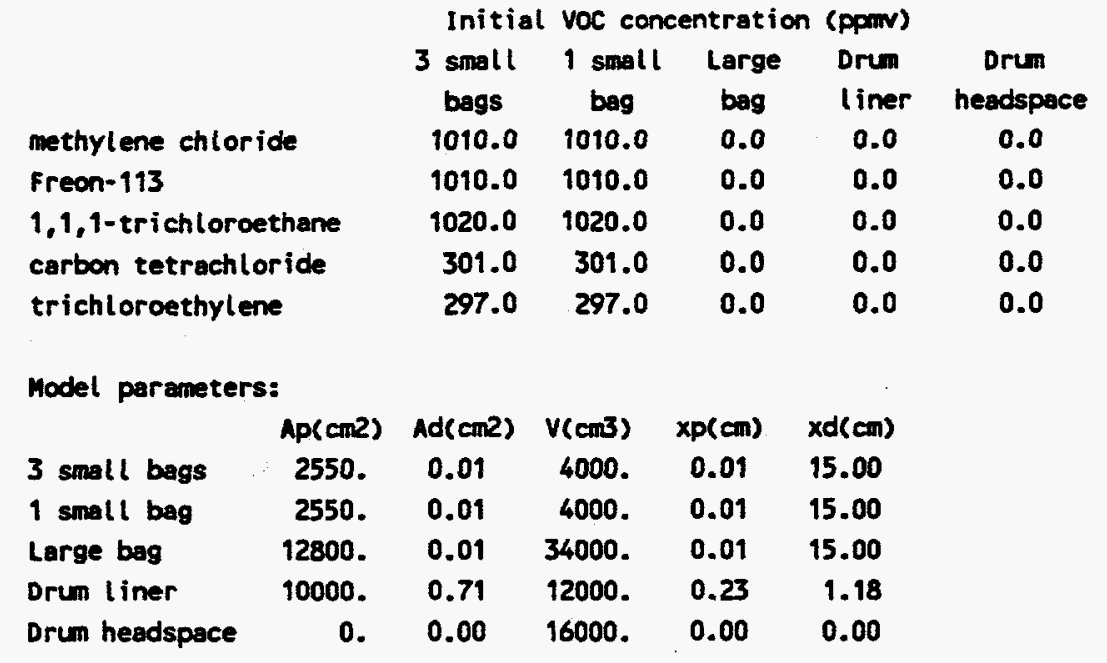

Initial drum temperature (C): 24.7

Drum temperature during the trial: constant

First samples collected from small bags approximately 24.0 hrs after $t=0$

Anbient pressure $(\mathrm{cm} \mathrm{Hg}): 64.5$

Hydrogen diffusion characteristic across filter (mol/mol fraction/s): $\quad 0.44000$ E-05

Predicted small bag concentrations (ppow):

$$
\text { methylene chloride Freon-113 }
$$

\section{Freon-113}

Day 3 small 1 small

227.1227 .1

$189.6 \quad 189.6$

$165.1 \quad 165.1$

$146.5 \quad 146.5$

$131.8 \quad 131.8$

$119.8 \quad 119.8$

$110.0 \quad 110.0$

$101.9 \quad 101.9$

$95.3 \quad 95.3$

89.9

85.3

89.9

85.3

81.5

81.5

78.4

$$
78.4
$$

75.7

$$
75.7
$$

73.4

$$
73.4
$$

$79.5 \quad 79.5$

$69.8 \quad 69.8$

$68.4 \quad 68.4$

67.1

66.0

67.1

64.9
3 small 1 small

bags bag

$592.2 \quad 592.2$

$409.1 \quad 409.1$

$320.6 \quad 320.6$

$272.6 \quad 272.6$

243.0

222.4

206.7

193.8

182.9

173.4

165.0

157.4

150.7

144.7

139.2

134.2

129.7

125.6

121.9

118.5

115.3 1,1,1-trichloroethane

3 smali 1 small

bags bag

$248.6 \quad 248.6$

$184.8 \quad 184.8$

$152.4 \quad 152.4$

$132.6 \quad 132.6$

$119.9 \quad 119.9$

$111.4 \quad 111.4$

$105.6 \quad 105.6$

$101.4 \quad 101.4$

$98.4 \quad 98.4$

96.096 .0

94.294 .2

$92.7 \quad 92.7$

$91.4 \quad 91.4$

$90.3 \quad 90.3$

$89.3 \quad 89.3$

$88.3 \quad 88.3$

$87.5 \quad 87.5$

$86.7 \quad 86.7$

$86.0 \quad 86.0$

$85.2 \quad 85.2$

84.584 .5 carbon tetrachloride

3 small 1 small

bags beg

$61.7 \quad 61.7$

$41.0 \quad 49.0$

$32.8 \quad 32.8$

$28.9 \quad 28.9$

$26.7 \quad 26.7$

$25.2 \quad 25.2$

$24.2 \quad 24.2$

$23.5 \quad 23.5$

$23.0 \quad 23.0$

$22.6 \quad 22.6$

$22.2 \quad 22.2$

$22.0 \quad 22.0$

$21.7 \quad 21.7$

$21.5 \quad 21.5$

$21.4 \quad 21.4$

$21.2 \quad 21.2$

$21.0 \quad 21.0$

$20.9 \quad 20.9$

$20.7 \quad 20.7$

$20.6 \quad 20.6$

$20.5 \quad 20.5$ trichloroethylene

3 small 1 small

bags bag

$48.2 \quad 48.2$

$29.9 \quad 29.9$

$22.4 \quad 22.4$

$19.0 \quad 19.0$

$17.3 \quad 17.3$

$16.3 \quad 16.3$

$15.8 \quad 15.8$

$15.4 \quad 15.4$

$15.2 \quad 15.2$

$15.0 \quad 15.0$

$14.8 \quad 14.8$

$14.7 \quad 14.7$

$14.5 \quad 14.5$

$14.4 \quad 14.4$

$14.3 \quad 14.3$

$14.3 \quad 14.3$

$14.2 \quad 14.2$

$14.1 \quad 14.1$

$14.0 \quad 14.0$

$13.9 \quad 13.9$

$13.9 \quad 13.9$ 


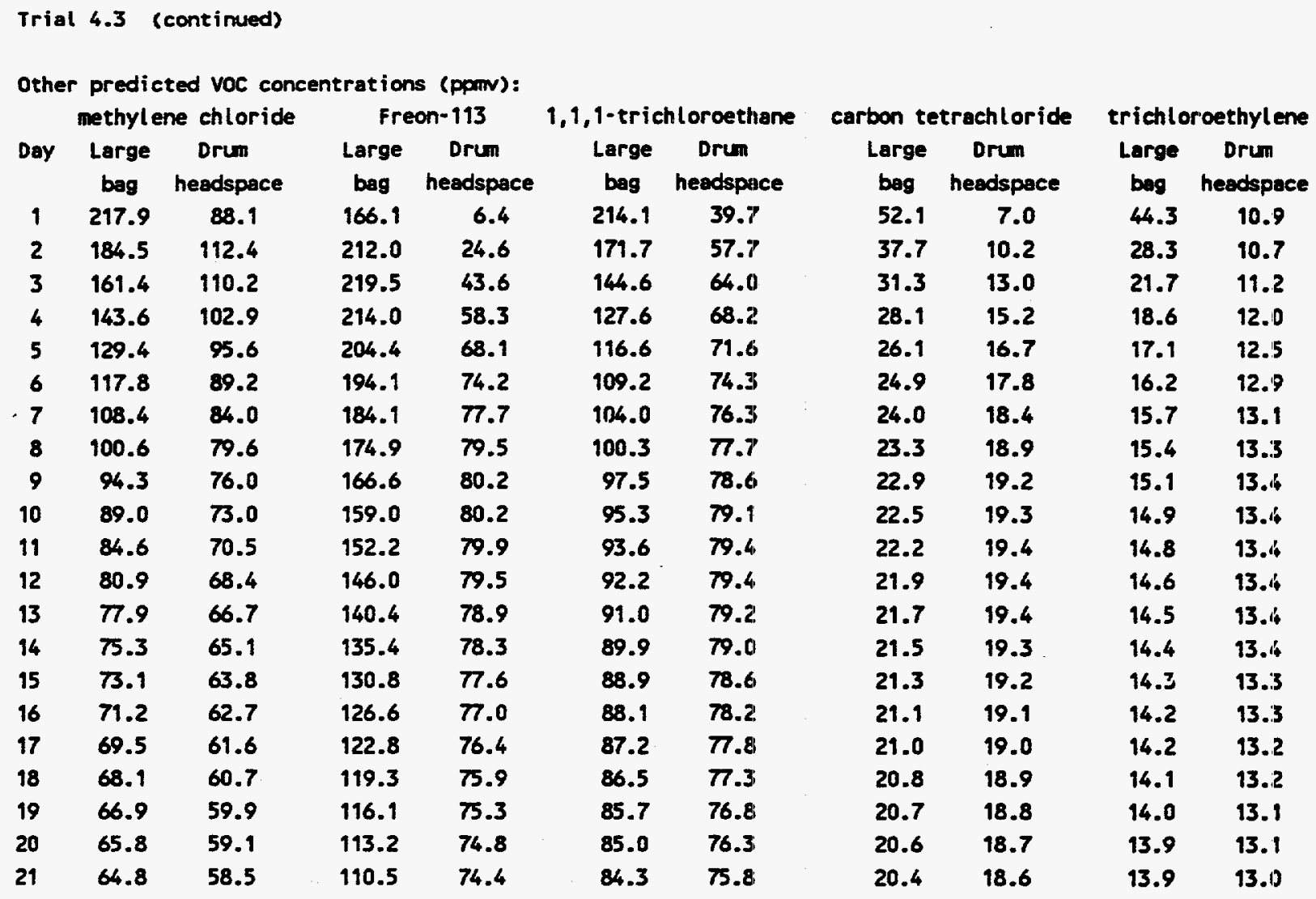

